\title{
Facultad de Informática
}

Tesis de Magister en Tecnología Informática Aplicada en Educación Titulo de la Tesis

La enseñanza de una lengua extranjera utilizando tecnología digital: Estudio descriptivo del tránsito de un material impreso a un entorno virtual de aprendizaje

Nombre y Apellido del tesista: Liliana Esther Simón

Maestría: Tecnología Informática Aplicada en Educación

Directora: Profesora Magister María Alejandra Zangara

Co-director: Licenciado Magister Alejandro González Príncipe 
Quisiera agradecer a todas aquellas personas que siempre estuvieron presentes tanto durante el periodo de asistencia a los postgrados de la maestría como en el desarrollo de mi proyecto de tesis.

A mi papá, Juan, que con sus ya 85 años me ayudó en cuidar y entretener a mis hijos en momentos claves de mis estudios.

A mi marido, Sergio, quien siempre está presente y me alienta en continuar con mis estudios.

A mi hijos, Augusto, Tomás y Tobías, quienes desde una temprana edad aprendieron la palabra 'tesis' con todas sus connotaciones.

A mis directores de tesis, Alejandro y Alejandra por su guía incondicional, y a mis colegas que siempre me guiaron y animaron en continuar con esta tarea.

A mis colegas amigas y mis amigas de la vida que me han alentado y comprendido sobre mi dedicación en mi camino de desarrollo profesional.

$\mathrm{Y}$, sobre todo, quiero agradecer a mis alumnos que sin ellos nunca me hubiera imaginado enseñar en nuevos escenarios como la virtualidad.

$\mathrm{Y}$, por ultimo, miro al cielo y no puedo olvidar de agradecer a mi mamá Esther que siempre, en la tierra y luego desde el cielo, me alentó y acompañó en mis estudios; y a Dios que me dio dos grandes oportunidades después de momentos muy difíciles en relación a mi salud en estos últimos años.

¡Muchas gracias a todos!

Liliana 
Índice

ÍNDICE DE TABLAS 7

ÍNDICE DE FIGURAS $\quad 7$

LISTA DE ABREVIACIONES 9

INTRODUCCIÓN 10

ANTECEDENTES DEL TEMA DE INVESTIGACIÓN

ESTRUCTURA DEL TRABAJO FUNCIONES DESEMPEÑADAS POR LA TESISTA EN

RELACIÓN A LA INVESTIGACIÓN 15

$\begin{array}{lr}\text { CAPÍTULO } 1 & 17\end{array}$

ENFOQUES METODOLÓGICOS Y LA INTEGRACIÓN DE LAS NUEVAS TECNOLOGÍAS EN LA

\begin{tabular}{ll}
\hline ELE & 17
\end{tabular}

$\begin{array}{ll}1.1 \text { INTRODUCCIÓN } & 17\end{array}$

1.2 LOS ENFOQUES PEDAGÓGICOS EN LOS PROCESOS DE ENSEÑANZA APRENDIZAJE DE UNA LENGUA

EXTRANJERA

1.3 CALL . SU DIMENSIÓN EN EL CAMPO DE LA ENSEÑANZA DE LENGUAS

1.4 LA EDUCACIÓN A DISTANCIA

1.5 LA INTERACCIÓN

1.6 CONCLUSIÓN

\begin{tabular}{lr} 
CAPITULO 2 & 43 \\
\hline
\end{tabular}

DEL DACTA AL E-DACTA 43

DE UN SOPORTE PAPEL A UN SOPORTE VIRTUAL $\quad 43$

2.1 INTRODUCCIÓN

2.2 PROYECTO DACTA

2.3 DESCRIPCIÓN DEL LIBRO DACTA

2.4 SECCIONES DEL LIBRO DACTA

2.5 TUTORÍAS DEL DACTA

2.6 PROYECTO E-DACTA

CONCLUSIÓN

\begin{tabular}{lr} 
CAPITULO 3 & 57 \\
\hline
\end{tabular}

DESCRIPCIÓN DEL CURSO E-DACTA

3.1 INTRODUCCIÓN

3.2 EL CURSO E-DACTA

3.3 Planificación del CURSO E-DACTA

3.4 Planificación Del PROYECTO

3.5 TEXto Guía Y CRonograma

3.6 INSCRIPCIÓN AL CURSO E-DACTA

3.7 DISEÑO Y ELABORACIÓN DEL CURSO E-DACTA

3.8 IMPLEMENTACIÓN DEL CURSO EN EL EVEA

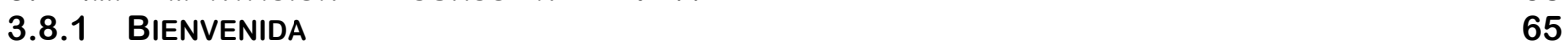

3.8.2 Guías SEMANALES

3.8.3 Diseño de LAS guías de Estudio e-DACTA 70 
3.9 LA COMUNICACIÓN ASINCRÓNICA

3.9.1 LOS FOROS EN EL CURSO E-DACTA

3.10 COMUNICACIÓN SINCRÓNICA

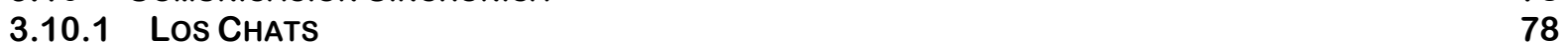

3.11 EVALUACIÓN Y SEGUIMIENTO DE LOS ALUMNOS EN LOS FOROS Y CHATS

3.12 CONCLUSIÓN

CAPÍTULO $4 \quad 83$

PRESENTACION DE RESULTADOS: LAS INTERACCIONES EN UN EVEA

4.1 INTRODUCCIÓN

4.2 LA INTERACCIÓN EN EL E-DACTA

4.3 LA PRESENCIA SOCIAL A TRAVÉS DE LA INTERACCIÓN 85

$\begin{array}{lll}4.4 & \text { CORPUS } & 89\end{array}$

4.5 ANÁLISIS DE LOS CHATS 90

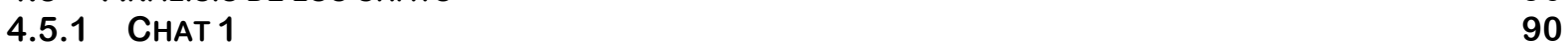

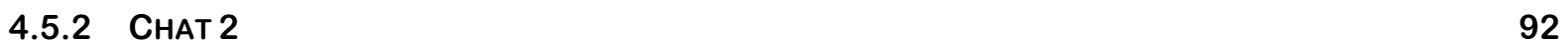

4.5.3 С СAT1YCHAT $2 \quad 93$

4.6 ANÁLISIS DELOSFOROS

$\begin{array}{lr}\text { 4.6.1 FORO } 1 & 99\end{array}$

$\begin{array}{lll}4.6 .2 & \text { FORO } 2 & 100\end{array}$

$\begin{array}{lll}\text { 4.6.3 } & \text { FORO 1Y FORO 2 } & 102\end{array}$

$\begin{array}{lll}4.7 & \text { CONCLUSIÓN } & 107\end{array}$

\begin{tabular}{lr} 
CAPITULO 5 & 109 \\
\hline
\end{tabular}

PRESENTACION DE RESULTADOS: ESTUDIO DE LAS ENCUESTAS DEL CURSO 109

5.1 INTRODUCCIÓN 109

5.2 LAS ENCUESTAS 109

5.3 ENCUESTAS INICIALES

5.3.1 GÉNERO

5.3.2 ESTUDIOS SECUNDARIOS

5.3.3 MOTIVACIÓN POR LA INSCRIPCIÓN AL CURSO

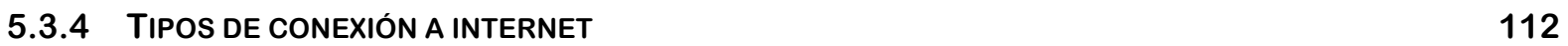

5.3.5 TIEMPO DE DEDICACIÓN PARA EL ESTUDIO DEL CURSO 113

$\begin{array}{ll}\text { 5.3.6 DIFUSIÓN DEL CURSO } & 114\end{array}$

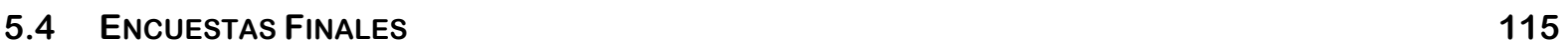

5.5 FACEBOOK DEL CURSO E-DACTA 123

$\begin{array}{lll}5.6 & \text { CONCLUSIÓN } & 127\end{array}$

\begin{tabular}{lr} 
CAPITULO 6 & 129 \\
\hline
\end{tabular}

LA METACOGNICIÓN EN LA DISTANCIA 129

$\begin{array}{lll}6.1 & 129\end{array}$

6.2 EL USO DE E-PORTFOLIOS EN LOS CURSOS A DISTANCIA

$\begin{array}{lll}6.3 & \text { CONCLUSIÓN } & 133\end{array}$

\begin{tabular}{lr} 
CAPITULO 7 & 134 \\
\hline
\end{tabular}

CONCLUSIONES 134

$\begin{array}{ll}7.1 \text { INTRODUCCIÓN } & 134\end{array}$

7.2 APORTES DE LA PRESENTE TESIS

7.3 MARCO TEÓRICO Y ESTADO DEL ARTE

7.4 ESTUDIO COMPARATIVO DE LOS PROYECTOS DACTA \& E-DACTA

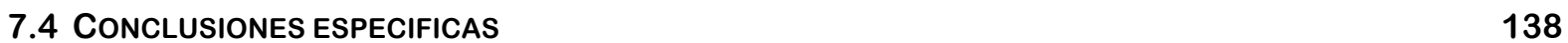

SOBRE EL ESTUDIO DE LAS INTERACCIONES EN EL E-DACTA

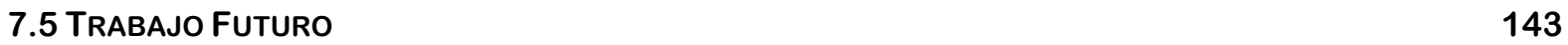


APÉNDICES

APÉNDICE 1

TEXTO GUÍA

APÉNDICE 2

CRONograma: e-DACTA SchedULER

APÉNDICE 3

AFICHE DE DIFUSIÓN

APÉNDICE 4

FICHA DE INSCRIPCIÓN 2010/2015

APÉNDICE 5

RESUMEN DE ENCUESTA INICIAL Y FINAL

APÉNDICE 6

FORMULARIO DE LA ENCUESTA INICIAL ON-LINE (2010/2015)

APÉNDICE 7

FORMULARIO DE LA ENCUESTA FINAL ON-LINE (2010/2015)

APÉNDICE 8

INFORME ENVIADO A LOS TUTORES

APÉNDICE 9

FORUM ETIQUETTE

APÉNDICE 10

MUESTRA DE UNA GUÍA

APÉNDICE 11

CHAT 1

CHAT 2

APÉNDICE 12

CORPUS DE LOS FOROS

FORO 1

FORO 2

APÉNDICE 13

200

EJEMPLO DE UN FORO SOBRE RETROALIMENTACIÓN 


\section{Índice de Tablas}

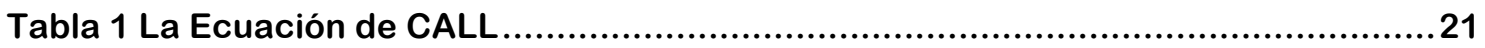

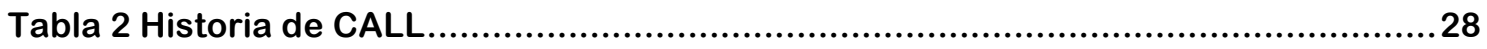

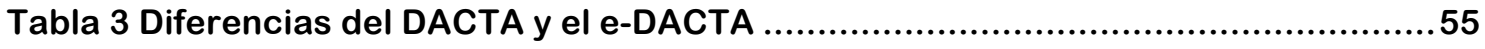

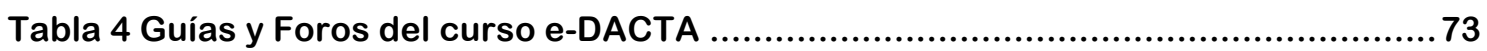

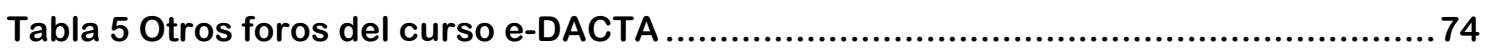

Tabla 6 Cuadro comparativo de los proyectos DACTA y e-DACTA ............................82

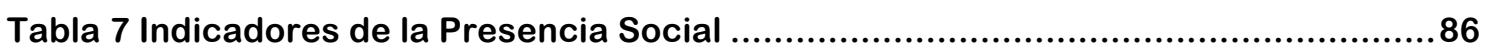

Tabla 8 Otros Elementos y Estrategias de Aprendizaje .......................................... 87

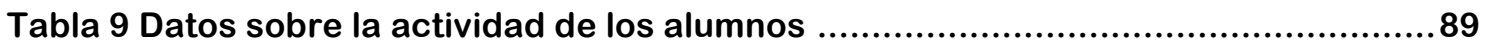

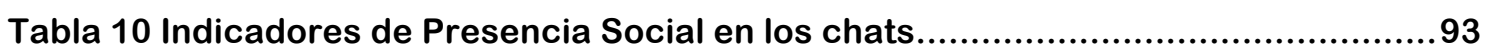

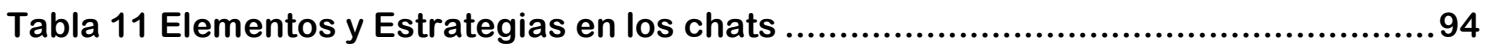

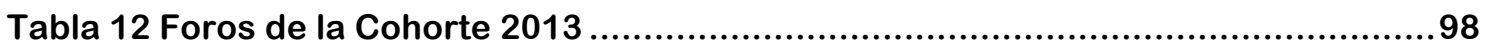

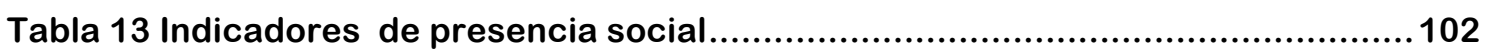

Tabla 14 Indicadores de Otros elementos en los foros .........................................103

\section{Índice de Figuras}

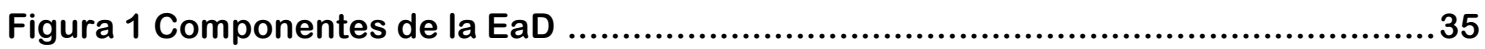

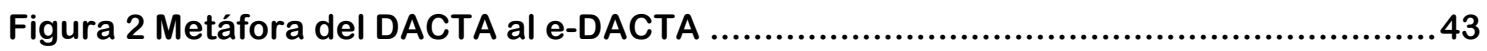

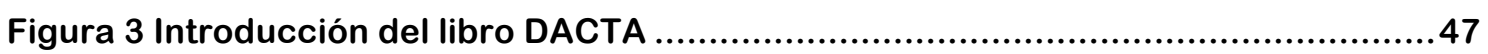

Figura 4 Grado de dificultad de los textos y tareas del DACTA ................................50

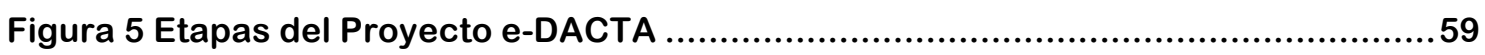

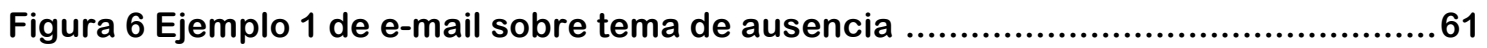

Figura 7 Ejemplo 2 de e-mail sobre tema de ausencia...........................................62

Figura 8 Ejemplo de e-mail de la primera planilla de inscripción ................................63

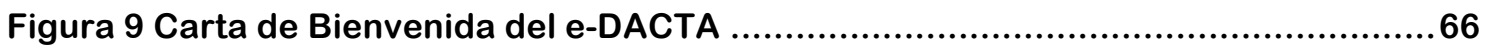

Figura 10 Barra de Navegación del e-DACTA ......................................................67

Figura 11 Ejemplo de una página de inicio una semana del curso ..............................68

Figura 12 Tareas de la primera semana del curso ................................................69

Figura 13 Consigna del primer foro del curso e-DACTA ........................................ 70

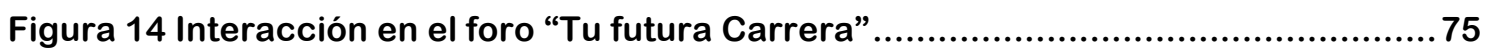

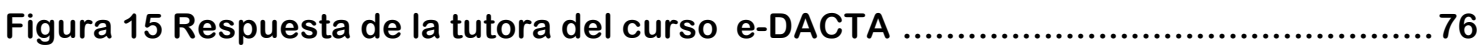

Figura 16 Comentarios de las Encuestas cohorte 2008 .........................................77

Figura 17 Frecuencia de la Presencia Social en los chats......................................96

Figura 18 Uso de otros elementos en los chats ...................................................97 


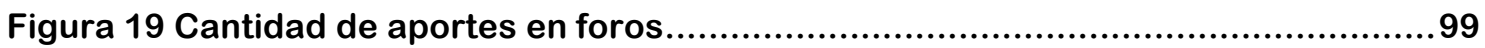

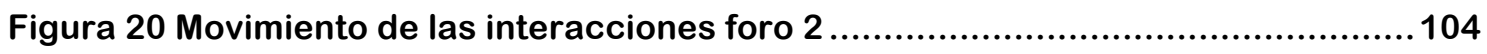

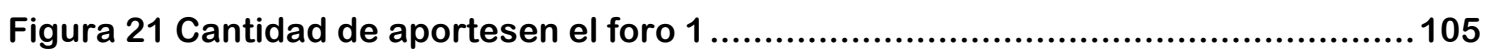

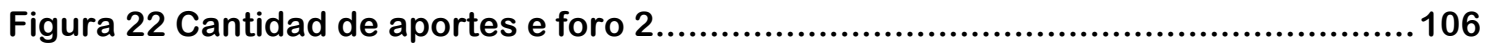

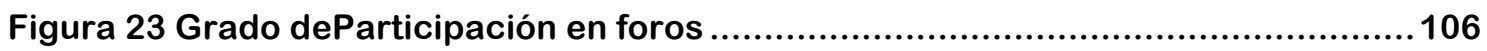

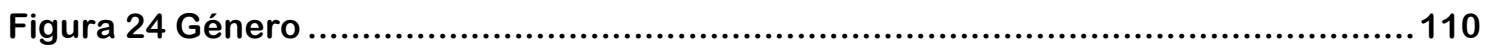

Figura 25 Año de finalización de la escuela secundaria $\quad$........................................111

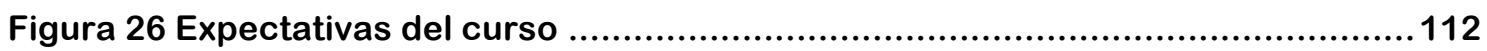

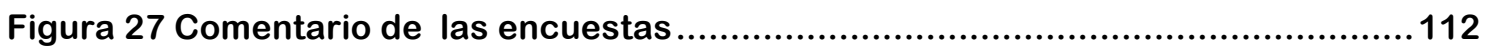

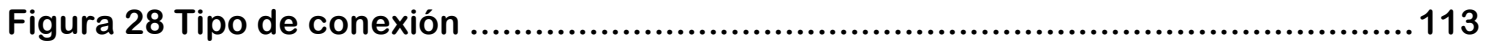

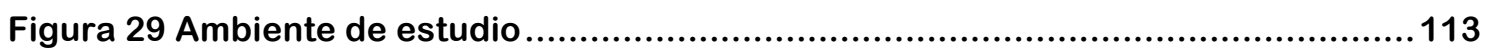

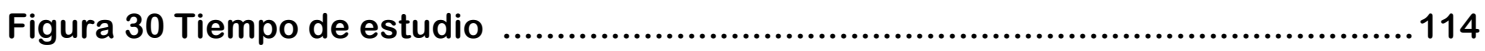

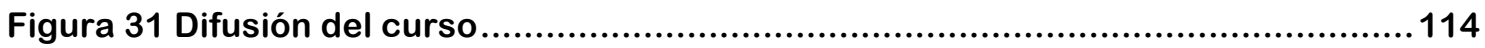

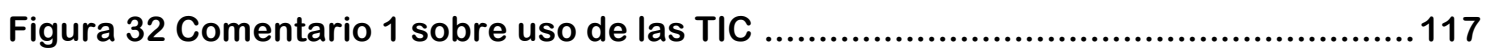

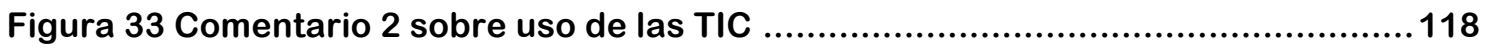

Figura 34 Comentarios sobre Andamiaje y presencia social .................................118

Figura 35 Comentario sobre las habilidades metacognitivas ............................119

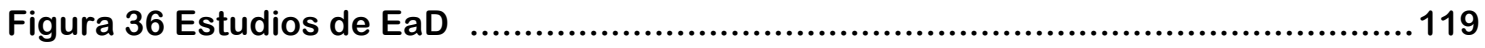

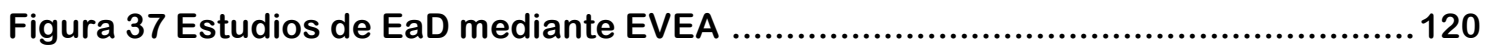

Figura 38 Uso de tecnologías como herramienta de estudio-1..............................120

Figura 39 Uso de tecnologías como herramienta de estudio-2 .............................121

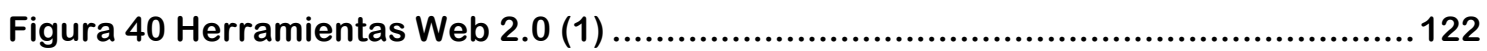

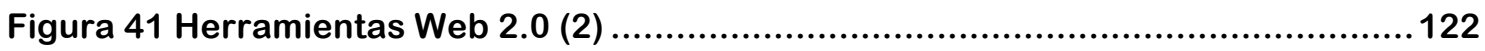

Figura 42 Uso de las redes sociales .................................................................... 123

Figura 43 Ejemplo 1 de posteo en el Facebook del e-dacta .......................................123

Figura 44 Ejemplo 2 de posteo en el Facebook del e-dacta ....................................124

Figura 45 Ejemplo 3 de posteo en el Facebook del e-dacta .....................................125

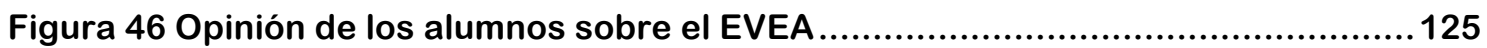

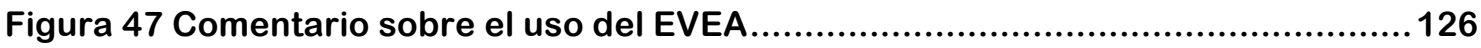

Figura 48 Ejemplo de e-portfolio con formato de Blog .......................................131 


\section{Lista de abreviaciones}

CALL: Computer Assisted Language Learning (en español: Aprendizaje de Lenguas mediado por la computadora)

CEFR: Common European Framework of Reference for Languages: Learning, teaching, assessment. En español: Marco Común Europeo de Referencia para las Lenguas: Aprendizaje, Enseñanza, Evaluación.

CMC: Computer Mediated Communication (en español, Comunicación mediada por la computadora)

CMCL: Computer Mediated Communication Language Learning (en español: Aprendizaje de Lenguas mediado por la computadora)

DACTA: Dispositivo de apoyo académico por tareas auto-administradas

EaD: Educación a Distancia

e-DACTA: Dispositivo electrónico de apoyo académico por Tareas Auto-administradas

EVEA: Entorno/s Virtual/es de Enseñanza y Aprendizaje

ELE: Enseñanza de Lengua Extranjera

FAHCE: Facultad de Humanidades y Ciencias de la Educación

LE: Lengua Extranjera

LM: Lengua Meta

MALL: Mobile Assisted Language Learning (en español, Aprendizaje de Lenguas asistido por tecnología móvil)

RAE: Real Academia Española

TIC: Tecnologías de Información y de Comunicación

UNLP: Universidad Nacional de La Plata

ZDP: Zona de Desarrollo Próximo 


\section{Introducción}

La presente tesis tiene como objetivo principal la realización de un estudio descriptivo de la actualización de una propuesta de enseñanza a distancia soportada inicialmente por un material impreso que con el tiempo se transformó en una renovada propuesta digital que propone un material más interactivo y una presencia más fuerte desde el punto de vista del rol del docente gracias a las nuevas tecnologías que propician mayores posibilidades de interacción entre los participantes.

Todos aquellos que hemos estudiado una carrera universitaria conocemos y comprendemos la etapa inicial que varía dependiendo de la obligatoriedad de los cursos de ingresos y/o de nivelación que ofrecen cada unidad académica. En nuestro caso las carreras de inglés han sido desde su creación particulares en el sentido que los ingresantes deben poseer sólidos conocimientos de la lengua y poseer habilidades y estrategias de aprendizaje específicos que se atribuyen a los procesos de enseñanza y aprendizaje de lenguas extranjeras. El transito entre la escuela media y el nivel universitario presenta diferentes tipos de obstáculos que abarcan áreas que van desde lo cognitivo y lo social hasta lo afectivo. Las políticas de inclusión y de permanencia que proponen nuestras unidades académicas en estas primeras etapas impulsaron la concreción de estos proyectos teniendo en cuenta el desgranamiento en el universo de alumnos de la etapa inicial de las carreras universitarias y en especial la de las carreras de inglés.

La primera propuesta contiene un material de estudio en formato de libro denominado DACTA Inglés 1, "Dispositivo de Apoyo Académico por Tareas AutoAdministradas" (autores: Liliana Simón y Juan Stamboni), acompañado en sus inicios de tutorías presenciales y virtuales (vía teléfono, e-mail y fax) que fueron realizadas por los autores del libro. Este libro se gestó ante la necesidad de aportar un andamiaje para todas aquellas personas que se inscriben en las carreras de inglés de la Facultad de Humanidades y Ciencias de la Educación (FAHCE) de la Universidad Nacional de La Plata (UNLP). La estructura del libro fue desarrollada con un formato especial que fomenta la práctica de una lengua a través de la guía del texto como soporte. La fundamentación de este libro se basó ante la necesidad de proveer al futuro alumno de un conocimiento introductorio sobre la lengua inglesa en relación a las estrategias y habilidades ya adquiridas y necesarias para poder cursar las primeras materias de las carreras. 
La segunda es una propuesta mediada íntegramente por tecnología digital en formato electrónico -un curso de pre-ingreso denominado e-DACTA- con el soporte de un entorno virtual de enseñanza y aprendizaje - EVEA. En esta segunda propuesta se escogió el nombre de la primera propuesta precedido por la letra "e" y seguida de un guión para evidenciar el formato electrónico de la propuesta y "DACTA" para destacar la continuidad de la primera propuesta renovada en sus contenidos y en especial en relación al innovador formato digital. Ambas propuestas se planificaron con la posibilidad de propiciar la interacción entre docentes, alumnos y el material de estudio. Por este motivo, el presente estudio abordará distintos temas que permiten entender los fundamentos de los proyectos haciendo hincapié en la interacción y en la interactividad. Si bien el objetivo principal es la descripción de las propuestas mencionadas, nuestro objetivo de investigación pretende confirmar como una propuesta digital propicia la interacción entre los participantes del curso propuesto.

Nuestra decisión de integrar en el segundo proyecto a las nuevas tecnologías se debe en gran medida a las posibilidades que ellas brindan. Gracias a sus características de perfil democrático que permiten que las tecnologías estén presentes en las escuelas secundarias y/o en los hogares, junto con las mejoras en la comunicaciones en las redes, nuestro curso puede llegar a muchas más personas en cualquier momento y en cualquier lugar gracias a la característica distintiva de ubiquidad presente en las nuevas tecnologías aplicadas a la enseñanza y de aprendizaje de lenguas.

Creemos que el curso virtual de pre-ingreso e-DACTA, que está en vigencia desde el año 2008, ha cumplido con su objetivo principal de mediador y facilitador en el tránsito entre la escuela media y el nivel universitario. Al realizar el estudio descriptivo de nuestros proyectos DACTA y e-DACTA estaremos analizando los diferentes elementos que se involucraron en los mismos: los recursos humanos (alumnos, docentes, coordinadores), los materiales (guías de estudios), las actividades propuestas en los chats, foros, etc., el diseño instruccional del curso y las emociones que surgieron y que adquirieron un papel importante en el desarrollo de la propuesta virtual. 
Los objetivos de la presente tesis son los siguientes:

- Describir los proyectos DACTA y e-DACTA desde su creación, desarrollo e implementación.

- Estudiar el impacto de la propuesta que contiene un diseño instruccional desarrollado especialmente para el contexto de enseñanza de lenguas en el nivel pre-inicial de la carreras.

- Analizar la interacción a partir de un estudio de la presencia social que se evidencia en las huellas que dejan los actores en su participación activa de las propuestas.

- Presentar y desarrollar la importancia de las estrategias y conocimiento metacognitivo en el curso e-DACTA.

- Presentar un análisis de los datos que arrojan las encuestas iniciales y finales realizadas por los participantes en relación a su acercamiento a las nuevas tecnologías desde diferentes puntos de vista: cognitivo, social y afectivo.

- Conocer y comprender mejor el perfil del alumno a partir de las emociones que se involucran en la etapa inicial de la carrera.

- Describir la integración de la red social Facebook como apoyatura en la comunicación del curso.

- Encontrar las fortalezas y debilidades en relación al impacto que provoca la ejecución del curso e-DACTA.

La concreción del presente trabajo pretende ser una contribución a la reflexión y a la práctica de los procesos de enseñanza y aprendizaje de una lengua extranjera mediados por la utilización de las TIC. También, al escribir este material pretendemos compartir nuestra experiencia sobre el uso de tecnologías en la enseñanza de la lengua inglesa con todos los profesores de inglés que sientan la necesidad de integrar las TIC en sus propuestas pedagógicas.

A partir de la valiosa información que arrojan los datos extraídos de los foros, los chats, las encuestas y los e-portfolios realizados por nuestros alumnos podemos asumir que las instancias de interacción del e-DACTA mediadas por un andamiaje (Bruner, 1988) provisto por los tutores que facilitan una exposición de la lengua extranjera en un contexto adecuado, favorecen el progreso de los alumnos en sus zonas de desarrollo próximo, ZDP, (Vigotsky, 1988) y propician el desarrollo de estrategias metacognitivas en los procesos de enseñanza- aprendizaje de la LE (lengua extranjera). 


\section{Antecedentes del tema de investigación}

\section{Libro}

Simón, Liliana y Stamboni, Juan. (1999) DACTA, Dispositivo de Apoyo Académico por Tareas Auto administradas, Inglés 1.Páginas: 92) Facultad de Humanidades y Ciencias de la Educación, UNLP. ISSN 1514-9366

\section{Presentaciones en Jornadas y Congresos}

- "Pre-ingreso Virtual: Proyecto e-DACTA" presentado en el V Encuentro de Profesores del Departamento Lenguas y Literaturas Modernas, UNLP, Buenos Aires, Argentina. (2008) - "e-DACTA, curso de pre-ingreso para las carreras de inglés en la Facultad de Humanidades y Ciencias de la Educación en la UNLP". Primeras Jornadas de Ingreso a Distancia organizado por La Dirección de Educación a Distancia de la Secretaria de Asuntos Académicos, UNLP. (2011)

- "Proyecto e-DACTA: curso de pre-ingreso virtual de las carreras de inglés de la UNLP", presentado en las Terceras Jornadas Internacionales de Nuevas Tecnologías aplicada a la enseñanza de Lenguas, Córdoba, provincia de Córdoba, Argentina. (2011)

\section{Publicaciones online}

Curso de pre-ingreso virtual de las carreras de inglés de la UNLP. Proyecto de articulación entre la Escuela Media y la Universidad.

Publicado en SEDICI, repositorio institucional de la UNLP, <consulta realizada el 19/03/2016: http://sedici.unlp.edu.ar/handle/10915/18325 >

\section{Actas en Congresos}

Simón, Liliana, "Proyecto e-DACTA. Curso de pre-ingreso para las carreras de lengua inglesa", en las actas de Terceras Jornadas Internacionales de Nuevas Tecnologías aplicada a la enseñanza de Lenguas. Córdoba, Provincia de Córdoba, Argentina. ISBN No. 978-950-33-0596-6 (2007) 


\section{Premio}

(2013) “ICT IN ACTION", premio otorgado a los 10 mejores proyectos de tecnología aplicada a la educación en la Argentina otorgado por el British Council y Editorial Macmillan por el diseño y desarrollo del proyecto de pre-ingreso virtual e-dacta de las carreras de inglés de la Facultad de Humanidades y Ciencias de la Educación de la Universidad Nacional de La Plata. Weblink: http://issuu.com/macmillanar/docs/m13british_projects-6marzo

\section{Funciones desempeñadas por la tesista en relación a la investigación}

\section{Desde 2007}

Elaboración, coordinación y ejecución del proyecto e-DACTA: un curso totalmente a distancia de pre-ingreso para alumnos aspirantes a las carreras del profesorado y traductorado de inglés.

\section{$1999 / 2000$}

Elaboración del libro DACTA y ejecución de tutorías presenciales y no presenciales (vía email y telefónica).

http://sedici.unlp.edu.ar/bitstream/handle/10915/56492/Documento completo.pdf?sequence=3

\section{5}

Participación de 3 Workshops sobre la validación de descriptores del dominio de la lengua inglesas relacionados con actividades de mediación y de estrategias del CEFR (Common European Framework of Reference for Languages) del Consejo Europeo.

\section{Becas}

2009, Open University Santander Abbey Fellowship (3 meses), Reino Unido.

2014, Beca PROFITE, 2014, otorgada por el Ministerio de Educación de la Nación de la Republica Argentina, Programa de Finalización de Tesis. 


\section{Estructura del Trabajo Funciones desempeñadas por la tesista en relación a la investigación}

El presente estudio de tesis se estructura en seis capítulos que abordaran distintos temas que configuran los ejes explicativos de la investigación junto con la descripción del curso e-DACTA, el análisis de las interacciones y las conclusiones finales. Ellos son:

El capítulo 1 presenta los enfoques teóricos que nos acompañaron en el desarrollo de los proyectos y que se utilizaron como base para la confección del curso. Además, presenta una revisión el estado de arte y la evolución en la integración de las TIC y la ELE (Enseñanza de la Lengua Extranjera) desde su inicio hasta nuestros días.

En el capítulo 2 presentamos los dos proyectos, el DACTA y el e-DACTA y describiremos cómo la primera propuesta impulsó la creación de un nuevo proyecto digital.

El capítulo 3 aborda la descripción del curso e-DACTA en detalle desde la planificación del mismo, su fundamentación en relación a su modalidad a distancia, su diseño instruccional y las herramientas utilizadas para propiciar la interacción de la ELE en los foros y chats.

El capítulo 4 profundiza el concepto de interacción y analiza el corpus de nuestra investigación. Este capitulo nos ayuda a comprender la importancia de las interacciones en las propuestas didácticas en la ELE.

El capítulo 5 presenta los resultados y datos obtenidos mediante las encuestas iniciales y finales realizadas por los alumnos junto con la presencia de las redes sociales que acompañan el curso e-DACTA.

El capítulo 6 abordamos el tema de la meta-cognición en relación al uso de eportfolios cuyo trabajo sistemático provoca en el alumno reflexiones meta-cognitivas de su propio aprendizaje. 
En el capítulo 7 presentaremos los aportes de la presente tesis, las conclusiones generales y las conclusiones específicas de los temas estudiados junto con nuestras aspiraciones de trabajos futuros.

El anexo consta de datos, tablas y gráficos que completan e ilustran la descripción del aula virtual junto con el corpus que utilizamos para el análisis de las interacciones. 


\section{Capítulo 1}

\section{Enfoques metodológicos y la integración de las nuevas tecnologías en la ELE}

\subsection{Introducción}

En la primera parte de este capítulo vamos a presentar distintos enfoques teóricos que se aplican en los procesos de enseñanza y aprendizaje de la lengua inglesa y que tomamos como marco teórico en el desarrollo de las prácticas educativas virtuales. Presentaremos de las teorías cognitivas, socioculturales, interaccionistas y de la pedagogía del post-método los aportes que las mismas nos brindan para poder así comprender mejor como se aprende una lengua extranjera (LE) haciendo hincapié tanto en el análisis de los enfoques que perduran en el tiempo como en los que presentan nuevas tendencias metodológicas.

En la segunda parte daremos un detalle desde la perspectiva histórica de CALL Computer Assisted Language Learning (Aprendizaje de Lenguas Asistido por Computadora) que se focaliza en la integración de las tecnologías en la enseñanza de una LE; y también ahondaremos sobre la importancia de los conceptos de autoregulación y metacognición y la presencia de las emociones en los cursos virtuales.

En la tercera parte presentaremos el tema de las interacciones en un curso a distancia tomando como dato interesante en la descripción de la transición del proyecto DACTA al curso online e-DACTA que este último propició las interacciones entre los participantes del curso. Gass, Mackey y Pica (1998) en Lamy y Hampell (2007: 21) han destacado que la adquisición de una LE es más efectiva cuando la exposición de la lengua a aprender (Lengua Meta) es parte de la interacción entre los participantes, mucho más que la interactividad con los textos y que la interacción propicia una negociación del conocimiento por parte de los aprendientes. También explicaremos porque en nuestra descripción de las interacciones hacemos una diferencia entre los conceptos de interacción e interactividad. 


\subsection{Los enfoques pedagógicos en los procesos de enseñanza aprendizaje de una Lengua Extranjera}

Presentaremos en esta investigación diferentes enfoques pedagógicos pertinentes a la enseñanza de lenguas enfocados hacia el análisis de la participación de los alumnos en nuestro curso quienes al comunicarse en una LE dentro de un entorno virtual realizan interacciones con otros pares y expertos. Comenzaremos con los aportes de las teorías cognitivas y las teorías socioculturales con sus raíces en los estudios de L.S. Vygotsky.

Para Vygotsky la adquisición de la lengua materna o extranjera es "un proceso socio-cognitivo anclado en el empleo instrumental de la lengua". (Mondada, 2001:112) "Los actores de una interacción conforman un núcleo cuya estructura optimiza el desarrollo cognitivo y en consecuencia el desarrollo lingüístico del aprendiente de una lengua. En los encuentros sociales, estas consecuencias lingüísticas se van modificando hasta llegar a formar construcciones de secuencias aceptadas de la lengua meta, esto se da "a través del dinamismo de la interacción, de la inter-comprensión, de la negociación del sentido y del estatus de los participantes“. (Chiappa; Lira; Sara \& Simón, 2005).

Según Vygotsky (1978:57) cada función mental en el desarrollo cultural del niño aparece dos veces: primero en el nivel social y luego en el nivel individual; el primero entre personas (inter-psicológico) y el segundo dentro del niño (intra-psicológico). Y, agrega que este desarrollo sucede como una forma de aprendizaje: la interacción con los maestros o pares permiten que el aprendiente avance a través de la zona de desarrollo próximo (ZDP). LA ZDP implica la distancia entre el nivel real de desarrollo determinado por la resolución de problemas independientes y el nivel de desarrollo potencial, determinado a través de la resolución de problemas bajo la guía de un adulto o en colaboración con compañeros más capaces." (Vygotsky, 1978: 86). Tanto Bruner como Vygotsky hacen hincapié en el entorno social en el que los adultos juegan un rol activo asistiendo al niño en su aprendizaje. El término "andamiaje" (en inglés, scaffolding) es utilizado por Wood, Bruner y Ross (Wood et al., 1976) al describir como la interacción de tutores con preescolares ayudaron un problema de reconstrucción de bloques; esta ayuda proporcionado por el adulto al niño ayuda a desarrollar habilidades mediante un proceso de andamiaje. Bruner (1978: 19) se refiere al andamiaje como los pasos que se toman para reducir los grados de libertad al llevar adelante alguna tarea; de esta manera, el niño se puede concentrar en la dificultad de la habilidad que está en proceso de adquirir. 
Las teorías cognitivas (Lamy and Hampel, 2007:19) estudian el proceso de aprendizaje como manifestaciones internas que suceden dentro de la estructura cognitiva de un individuo. Por otro lado, los investigadores de las teorías socioculturales abordan el estudio del aprendizaje de una lengua como procesos interpersonales situados en un contexto social y cultural. Ambas teorías han sido desarrolladas y enfocadas en el contexto de enseñanza y aprendizaje de lenguas bajo la modalidad presencial pero tienen mucha aplicabilidad en el estudio de la enseñanza y aprendizaje de lenguas bajo la modalidad en línea. Según Levy (1998:93) en Lamy \& Hampel (2007:19) las teorías cognitivas y socioculturales poseen el potencial de brindar información para la investigación y las prácticas educativas mediadas por las nuevas tecnologías.

Las teorías cognitivas tratan a la adquisición de una lengua como un producto de entrada (INPUT, en inglés), también traducido en español como un caudal lingüístico y otro de salida (OUTPUT, en inglés). La exposición a la lengua (Ellis, 2000: 194 en Lamy \& Hampel, 2007: 20) sería la entrada y la producción del aprendiente sería la salida. El tercer concepto central es la interacción, el cual desarrollaremos más adelante.

La hipótesis de Krashen $(1981,1985)$ resaltó la importancia de una entrada comprensible (Comprehensible INPUT, en inglés), es decir, la exposición del aprendiente a la lengua meta llevada a cabo por un experto (hablante nativo/profesor/otro alumno) en contextos orales y/o escritos que poseen una forma un poco más difícil de la competencia lingüística del aprendiente pero que es aún comprensible para él. La apropiación del conocimiento (INTAKE, en inglés) se realiza cuando el aprendiente lo comprende y usa este conocimiento como parte de su producción (OUTPUT) oral o escrita bajo las convenciones del uso apropiado de la lengua. Para Krashen (1981:101 en Lamy \& Hampel (2007: 21)) la función principal de una clase de LE es proveer una apropiación del conocimiento para lograr una adquisición mediante actividades significativas y comunicativas.

Si bien este trabajo se basa en las teorías arriba mencionadas, no podemos dejar de mencionar el concepto de B. Kumaravadivelu (2001) sobre la noción de la pedagogía del post-método que ha tomado importancia en estos últimos años dentro del ámbito de los profesionales e investigadores de la lengua inglesa a nivel mundial y que aporta un punto de vista compartido en la ejecución del proyecto e-DACTA.

B. Kumaravadivelu (2001) se refiere a la pedagogía del post-método (Postmethod Pedagogy, en inglés) en un sentido amplio que incluye no solo las estrategias áulicas, 
materiales de enseñanza, objetivos curriculares y métodos de evaluación sino también un amplio rango de experiencias históricas, políticas y socioculturales que directa o indirectamente influyen en la prácticas educativas de una LE. Dentro de esta definición, B. Kumaravadivelu (2001) visualiza un sistema tridimensional que consiste en parámetros pedagógicos: particularidad, practicabilidad y posibilidad. Kumaravadivelu (2001) propone un nuevo marco para elaborar una pedagogía basada en un número de macro estrategias:

(a) maximizar las oportunidades de aprendizaje,

(b) facilitar una interacción negociada,

(c) minimizar los desajustes perceptuales,

(d) activar heurísticos intuitivos,

(e) propiciar una conciencia lingüística,

(f) contextualizar entradas lingüísticas,

(g) integrar habilidades idiomáticas,

(h) promover la autonomía del alumno,

(i) incentivar la conciencia cultural y

(j) garantizar la pertinencia social.

Kumaravadivelu hace hincapié en la práctica reflexiva y la investigación en el aula como eje fundamental en la aplicación del método. $\mathrm{Y}$, cómo consecuencia, esto involucra una mayor dedicación al desarrollo profesional que muchas veces es dejado de lado por diversas causas.

\subsection{CALL . Su dimensión en el campo de la enseñanza de lenguas}

La didáctica de enseñanza de lenguas cuenta con una vasta literatura en metodologías de enseñanza que permiten transferir los avances de los estudios de didáctica presencial al ámbito virtual de acuerdo a su aplicabilidad. Si bien, dadas las características particulares de los EVEA no se puede hacer una mera extrapolación; los enfoques de enseñanza nos brindan un punto de partida amplio sobre las bases fundamentales para la comprensión del aprendizaje de lenguas extranjeras y de los procesos puestos en juego. Las didácticas de las lenguas deben siempre considerar el vertiginoso avance y cambios de las TIC que con frecuencia dificultan las posibilidades de que los docentes conozcan y se apropien de las mismas para luego aplicar y optimizar sus prácticas educativas. 
Con respecto a la literatura que podemos encontrar en la actualidad sobre la enseñanza de lenguas mediadas por el uso de las TIC, se destacan los trabajos que se han realizado desde la década de los 60 (1960-70) sobre CALL Research (Investigación sobre CALL). ${ }^{1}$ CALL Research desarrolla sus estudios sobre el aprendizaje de lenguas en cualquier contexto que implique el uso de una computadora (Egbert \& Petrie, 2005:4) CALL Research se focaliza en el aprendizaje de lenguas en cualquier contexto donde el proceso de enseñanza y aprendizaje sucede, pero no sólo en la clase tradicional sino en otros ámbitos, como hogares, bibliotecas, cibercafés y en diferentes tiempos (sincrónicos y asincrónicos). Además, las investigaciones realizadas sobre CALL abarcan otras tecnologías y no sólo el uso de las computadoras de escritorio (Egbert \& Petrie, 2005:4), incluye cualquier forma de tecnología manejada como celulares inteligentes, laptops, tabletas y otros.

Egbert \& Petrie (2005:5) afirman que CALL no es una metodología de enseñanza y agrega que es un proceso que implica ciertas variables y lo analiza en la siguiente tabla (1) denominada "La Ecuación de CALL" 2 :

Estudiantes (con sus pensamientos, comportamientos, motivaciones, experiencias y comprensión)

+ Lengua/ldioma (incluye su estatus y estructura)

+ Contexto (entornos físicos y temporales y las influencias sociales, económicas, culturales y lingüísticas)

+ Una o más herramientas (y las posibilidades que la herramienta ofrece)

+ Tareas lactividades (contenido, estructura y organización)

+ Los compañeros y docentes (u otras personas que forman parte del proceso)

\section{$=$ CALL}

Tabla 1

La Ecuación de CALL

Debido a los rápidos cambios en la enseñanza y las innovaciones tecnológicas, CALL se encuentra en una revisión constante. (Keun Huh \& Wen-chi Hu en Egbert \& Petrie

\footnotetext{
${ }^{1}$ CALL es un acrónimo que en inglés significa "Computer Assisted Language Learning" (Enseñanza de lenguas asistida por computadoras)

2 "Mi traducción. A menos que se indique lo contrario, las traducciones me pertenecen."
} 
(2005:9)). Esto implica un desafío para los investigadores de CALL que deben incorporar los cambios y las nuevas tecnologías a sus estudios.

Keun Huh \& et al. en Egbert \& Petrie (2005:10-11) hablan de tres debilidades que se pueden encontrar en las investigaciones realizadas sobre CALL (“CALL Research"). Una de ellas es la vacancia de marco teórico que sustente estos estudios. La segunda debilidad que mencionan Keun Huh \& et al. (2005:13) son las limitaciones que existen en "CALL Research": muchas veces los investigadores no consideran los resultados negativos de sus estudios como valiosos descubrimientos. Estos investigadores ponen énfasis en los aspectos positivos y por consecuencia las conclusiones se han enfocado en los beneficios de la tecnología computacional para la enseñanza de idiomas sin considerar aquellos efectos que son poco o nada beneficiosos en el uso de las nuevas tecnologías. Finalmente, la tercera debilidad que marcan Keun Huh \& et al (2005) es el tecno-centrismo en la investigación de CALL; es decir, esto sucede cuando los estudios se focalizan en las tecnologías solamente.

Si bien CALL no es la única sigla que hace referencia a la enseñanza de idiomas mediada por computadoras, es la sigla que se ha utilizado con mayor frecuencia entre investigadores y docentes a nivel mundial. Otras siglas reconocidas, no sólo por el entorno de enseñanza de idiomas, es la sigla inglesa CMC (Computer Mediated Communication), en español: Comunicación Mediada por Computadoras. CMC puede responder, según Lamy \& Hampel (2007:7), a dos necesidades en el campo de la enseñanza de idiomas: la comunicación mediada por computadora como un medio en donde el proceso de enseñanza y aprendizaje sucede o como un fin en sí mismo. Los alumnos pueden involucrase en el aspecto comunicativo de sus estudios intercambiando la lengua meta mediante el uso de las computadoras y la conexión a internet en vez de las conversaciones que han venido llevándose a cabo en las clases tradicionales.

A mediados de la década de los 90 comienza a utilizarse la sigla CMCL, Computermediated communication Language Learning, (en español: Comunicación mediada por computadoras en la enseñanza de lenguas) fortaleciendo la orientación hacia el aprendizaje de lenguas (Lamy \& Hampel, 2007:7). CMCL surge con las nuevas oportunidades de aprendizaje que son ofrecidas a alumnos de lenguas. Estas primeras oportunidades son actividades asincrónicas que permiten la comunicación vía internet entre personas de forma no simultánea; más adelante se incorporan las actividades sincrónicas que viabilizan el intercambio de información por Internet en tiempo real. 


\section{La enseñanza de una lengua extranjera utilizando tecnología dígital}

Lamy \& Hampel (2007:9) resumen la historia de CALL tomando los tres periodos que Warschauer y Healey (1998) describieron y los cuales fueron delimitados por los avances tecnológicos. Al primer periodo lo denominaron CALL Conductista (Behaviouristic CALL, en inglés). Según Warschauer (1996) la primera fase de CALL fue concebida en la década del 60 e implementada en las décadas del 60 y 70 . En esta primera fase sólo las macro-habilidades de lectura y escritura estaban presentes. Las actividades que se desarrollaban de repetición y práctica (llamados en inglés Drill and Practice) se basaban en el modelo de la computadora como tutor, es decir, la computadora funcionaba como un vehículo de distribución de materiales educativos para los alumnos. Estos ejercicios de repetición no gozaban de buena reputación, ya que fueron llamados en forma peyorativa Drill and Kill (en español: ejercitar y matar); pero Warschauer (1996) sostiene que poseen ventajas en el aprendizaje de una LE y enumera las siguientes:

- La exposición repetitiva sobre los mismos materiales es beneficioso y hasta esencial en el aprendizaje.

- La computadora es ideal para realizar ejercicios de repetición, ya que la máquina no se aburre presentando el mismo material y puede proveer una feedback (retroalimentación) inmediata y objetiva.

- La computadora permite presentar el material en forma individual, autoregulando los tiempos y dejando tiempo libre en la clase para otras actividades.

A fines de la década del 70 e inicios de la década del 80, la fase de CALL Conductista comienza a debilitarse debido a dos factores principales: el rechazo a los enfoques de enseñanza conductistas y a la introducción de la computadora personal que comienza a ofrecer nuevas posibilidades en la enseñanza de idiomas.

Warschauer $(1996,2000)$ denomina al segundo período CALL Comunicativo (en inglés: Communicative $C A L L$ ) y esta denominación se debe al surgimiento del enfoque comunicativo en la década de los 80 hasta la década de los 90 . Este nuevo enfoque deja de lado aquellas actividades que no proponían tareas que involucraran 'comunicación auténtica' ${ }^{3}$. Si bien la computadora mantiene su superioridad como el poseedor de la respuesta correcta y la interacción entre computadora y alumno, es más frecuente el contacto entre alumnos mediado por las computadoras. Las nuevas tecnologías comienzan

\footnotetext{
${ }^{3}$ En la enseñanza de L.E. se denomina "comunicación auténtica" a las instancias en que la L.M. es utilizada con fines de comunicaciones reales que se comparan con el uso de un idioma en la vida cotidiana, en contraposición a situaciones "creadas" dentro del contexto del aprendizaje de una lengua.
} 
a ser más permeables propiciando una mayor flexibilidad que se orienta hacia la posibilidad de que el alumno tenga un poco más de control y elección en los procesos de enseñanza y aprendizaje mediados por la computadora. Las macro-habilidades de escucha y de habla comienzan a incorporarse en este periodo.

John Underwood (1984:52) citado por Warschauer (1996) propuso una serie de premisas para distinguir el período llamado CALL Comunicativo. Según Underwood, CALL Comunicativo se distingue de los otros períodos por las siguientes características:

- Se focaliza en el uso de las formas lingüísticas.

- Enseña la gramática de forma implícita en vez de explícita.

- Permite y alienta en los estudiantes la producción de formas lingüísticas originales en lugar de manipular lengua prefabricada.

- No juzga, ni evalúa todas las participaciones de los alumnos, ni los recompensa con mensajes de felicitaciones, luces o sonidos de campanas.

- Evita decirles a los alumnos que se equivocaron y es más flexible a la variedad de respuestas que el alumno proporciona.

- Utiliza la lengua meta en forma exclusiva y crea un entorno en el que el uso de la lengua meta se siente natural tanto en la pantalla de la computadora como fuera de ella.

- Nunca intenta hacer nada que un libro ya pueda hacer.

En este período el modelo de la computadora como tutor continúa presente en actividades de ejercicios de repetición aunque estas actividades se diferencian de las del primer período porque en esta nueva etapa el alumno se encuentra con una mayor posibilidad de elección, control e interacción. Se suma a este período el modelo de la computadora como estímulo. El propósito de las actividades de CALL mediante este modelo, según Taylor \& Perez 1989:63 en Warschauer (1996) es estimular al alumno a participar en discusiones, impulsar la escritura y formar un pensamiento crítico.

En referencia al período comunicativo, Brierley \& Kemble (1991) y Taylor (1980) en Warschauer (1996) ven a la computadora como una herramienta. El acento en este modelo está en darle impulso al alumno para que use la lengua meta de una manera comprensiva. 


\section{La enseñanza de una lengua extranjera utilizando tecnología dígital}

Algunos ejemplos de este modelo son los procesadores de texto, herramientas de revisiones gramaticales y de ortografía, programas de publicación y concordancers ${ }^{4}$.

El tercer período se lo denomina CALL Integrado (Integrative CALL, en inglés); esta fase comienza a fines de la década de los 90 . Su nombre hace referencia a la convergencia de las nuevas tecnologías. La democratización en el uso de internet, la variedad y la accesibilidad de productos multimedia permitieron que los medios textuales visuales, gráficos se integraran con las posibilidades de la inclusión de sonidos, animaciones y videos abriendo un abanico de múltiples posibilidades en la enseñanza de lenguas como la creación de contenidos ricos y variados. Asimismo, en este período el trabajo colaborativo y el enfoque socio-cognitivo comienza a tomar más fuerza gracias a las nuevas propuestas que los nuevos entornos propician con respecto al trabajo en grupo respaldados por enfoques de enseñanza basado en tareas o proyectos.

Este periodo de CALL se divide en dos etapas: CALL integrado basado en la multimedia, etapa que se relacionan con el uso de computadoras complementadas por CDROM de uso educativo y la segunda etapa denominada CALL integrado basado en internet que en los últimos años se orientó hacia la enseñanza mediada por aplicaciones que se alojan "en la nube" (comúnmente conocido en inglés como cloud computing) y que permiten el procesamiento y almacenamiento masivo de datos en servidores que albergan la información del usuario gracias al desarrollo de la WWW ${ }^{5}$. Esta nueva estructura llamada "hipermedia" permite a los nuevos programas una navegación más fluida donde se entrelaza lo textual con imágenes, animaciones y/o sonidos y como consecuencia propician la adquisición de una LE (Warschauer,1996) proporcionando un ambiente más auténtico. Estos recursos pueden facilitar la integración de las cuatro macro-habilidades ${ }^{6}$ en una sola tarea. Además, los alumnos tienen un mayor control sobre su aprendizaje ya que pueden estudiar a su ritmo, volver o adelantarse en las diferentes partes de un programa.

En referencia a la primera etapa de este período, CALL integrado basado en la multimedia, Warschauer (1996) señala el fracaso de gran impacto en la enseñanza de idiomas en el uso del software multimedia. Los factores que él menciona son varios; entre

\footnotetext{
4 "Concordancer" es un software que se puede instalar en la computadora o se puede acceder al mismo desde una página en internet, y se utiliza para la búsqueda y análisis de la lengua desde un corpus. Es muy útil para explorar las relaciones entre palabras y nos proporciona una información bastante aproximada a uso de la lengua en contextos auténticos. (Texto adaptado el 5-3-2016 en: http://www.teachingenglish.org.uk/think/articles/concordancers-elt )

${ }^{5}$ World Wide Web: conjunto de protocolos que entrelazan los archivos de hipertexto.

${ }^{6}$ Las macro-habilidades son un conjunto de cuatro capacidades complejas que le permiten a una persona comunicarse de manera eficiente; cada una de ellas se las denominan macro-habilidades de escucha, habla, lectura y escritura.
} 
ellos señala la falta de disponibilidad de programas de calidad y las desventajas que surgen en el armado de estos programas sumado a que los docentes a veces no cuentan con el tiempo y/o el conocimiento tecnológico suficiente para desarrollarlos sin tener en cuenta aquellos programas más complejos y sofisticados. De ahí que muchos de los softwares comerciales frecuentemente fallan en basar sus programas en los principios pedagógicos pensados y diseñados para un contexto específico. Pero más allá de todas estas cuestiones, Warschauer (1996) señala un problema fundamental: los programas de computadora todavía no son lo suficientemente inteligentes para ser realmente interactivos. Un programa multimedia no pude distinguir entre lo que es correcto y lo que es apropiado y con respecto a los sistemas de reconocimiento de voces (Speech Recognition, en inglés) aún los mismos no logran diagnosticar problemas de pronunciación o entonación. Si bien ya existe la Inteligencia Artificial (IA) que podría solucionar estos problemas, es limitado los que se ha desarrollado en investigación en la enseñanza de idiomas. Underwood (1989) citado por Warschauer (1996) anticipó que el próximo período de CALL se llame Intelligent CALL, iCALL, (CALL Inteligente, en español) y tal vez será dentro de este período cuando podremos ver estos avances tecnológicos. Según Holland, Sams \& Kaplan, 2013) iCALL ya se encuentra presente en la construcción de escenarios animados o micro mundos virtuales en la que los aprendientes de lenguas interactúan mediante el uso de la lengua meta (por ejemplo, Second Life). El problema que percibe Holland \& et al. (2010) en su libro Intelligent Language Tutors, es que las investigaciones de estos entornos quedan por lo general inconclusos debido a políticas presupuestarias.

CALL no ha sido la única forma con que los expertos en la integración de las tecnologías en la enseñanza de lenguas. El uso de internet propició la computación mediada por las comunicaciones, CMC (en inglés, Computer Mediated Communication); una sigla que comenzó a utilizarse en la década de los '60, aunque según Warschauer (1996) la misma se popularizó a partir de la década de los '90 y en los últimos años ha provocado un impacto en la enseñanza de idiomas. A partir de las nuevas formas de comunicación, los alumnos de lenguas pueden comunicarse de manera asincrónica; por ejemplo, mediante mensajes electrónicos (e-mails) en la lengua meta en cualquier momento el día y desde casi cualquier lugar donde se encuentren con conexión a internet. $Y$, también de manera sincrónica el alumno de LE puede comunicarse en tiempo real con uno o con varios de sus pares, con sus profesores o cualquier otra persona en el mundo que comparta su lengua materna mediante programas de chats o de video conferencias. 
Si bien los textos han predominado en la comunicación en esta primera década del siglo XXI, los medios audiovisuales se han incorporado a la enseñanza de lenguas de tal manera que la combinación de los modos de comunicación y las posibilidades que los nuevos softwares brindan han propiciado el nacimiento de un nuevo concepto comúnmente conocido con la sigla WWW (World Wide Web). Este concepto se lo han denominado de varias formas, entre ellas: la Web 2.0, la red social y la red interactiva. Los nuevos desarrollos de software han provocado un cambio muy importante en los usuarios de Internet. Hemos pasado de ser simples espectadores de una Web estática (Web 1.0) a ser partícipes como usuarios más activos de una web más colaborativa (Web 2.0) que nos brinda las posibilidades de crear contenidos de una manera más flexible, ágil, y amigable. En esta etapa han nacido y crecido notablemente los blogs educativos, las wikis educativas, los mundos virtuales, los EVEA, etc. En la actualidad los trabajos en línea de los alumnos son cada vez con más frecuencia compartidos por los docentes y alumnos de lengua en la "nube" mediante un blog de aula, una wiki, un espacio en un EVEA, grupos en Facebook, Twitter, entre otras y muchas más aplicaciones; todas estas herramientas de la Web 2.0 permiten que las clases de lenguas dejen de tener un horario fijo y un lugar único para poder desde estar en contacto con sus alumnos y participar en tareas virtuales relacionadas con los contenidos de sus cursos o programas de enseñanza de lenguas.

Para Warschauer (1996) Internet es un medio de comunicación global y una fuente ilimitada de material auténtico; aunque el éxito no reside en el medio sino cómo se pone en uso el mismo. Es decir, aunque hoy en día se utilicen los blogs, wikis, grupos de redes sociales, etc., como espacios de mediación entre profesores y alumnos, todavía faltan los lineamientos necesarios o enfoques metodológicos apropiados que acompañen estas nuevas líneas de comunicación.

En el siguiente cuadro resumimos las fases en que Warschauer (2000) dividió a CALL en tres épocas: 


\begin{tabular}{|c|c|c|c|c|}
\hline $\begin{array}{c}\text { PERÍODO } \\
\text { DE CALL }\end{array}$ & Época & $\begin{array}{c}\text { Metodología de } \\
\text { enseñanza }\end{array}$ & $\begin{array}{c}\text { Macro- } \\
\text { Habilidades }\end{array}$ & Tareas \\
\hline Conductista & $1970-1980$ & Estructuralista & Lectura y escritura & Individualista \\
\hline Comunicativo & $1980-1990$ & Comunicativo & $\begin{array}{c}\text { Lectura, Escritura, } \\
\text { Escucha y Habla }\end{array}$ & $\begin{array}{c}\text { Mayores } \\
\text { posibilidades de } \\
\text { Interacción }\end{array}$ \\
\hline Integral & Siglo XXI & Socio-cognitivo & $\begin{array}{c}\text { Escucha y Habla } \\
\text { (en nuevas plataformas } \\
\text { tecnológicas) }\end{array}$ & Colaborativo \\
\hline
\end{tabular}

Tabla 2

Historia de CALL

(Elaboración propia del autor de la presente tesis)

Esta tabla refleja cómo la metodología de la época de cada década se impone en las actividades mediadas por las posibilidades de las TIC de esos momentos.

Bax (2003) disiente en varios aspectos y considera ambiguo las fases históricas en las que Warschauer (1996) había dividido la historia de CALL. Además, observa unas inconsistencias entre los artículos presentados por Warschauer en 1996 y en 2000. En la tabla 2 podemos observar que Warschauer (1998) divide las fases en décadas que luego en Warschauer (2000) va a modificar desplazándolas a cada una, una década más tarde; además, resalta el cambio de nombres de la primera fase: CALL Conductista la cambia por CALL Estructuralista.

La división en fases que Warschauer (1996) es una clara muestra de una clasificación de las diferentes épocas en que CALL se fueron desarrollando encasillando a cada una de ellas en relación a los enfoques de enseñanza que se utilizan por la mayoría de los profesionales de la enseñanza de las lenguas. De esta manera etiquetó a cada período de acuerdo al enfoque del momento junto con las posibilidades que brindan las tecnologías en esa instancia de la historia. Pero como sucede en todo intento de clasificación, es difícil poder poner los límites en relación al tiempo y los enfoques de enseñanza utilizados sin que se superpongan los cambios que se producen en la línea del 


\section{La enseñanza de una lengua extranjera utilizando tecnología dígital}

tiempo en diferentes lugares de acuerdo a los contextos sociales, políticos y educativos en donde se desarrollen actividades propias de CALL.

Bax (2003) prefiere clasificar los momentos de CALL en tres enfoques enmarcados en los avances y las nuevas posibilidades tecnológicas de los momentos en la historia de CALL y de esta manera evitan la relación con las metodologías de enseñanza de los diferentes momentos. Los enfoques que menciona Bax (2003) son tres:

- CALL Restringido (en inglés, Restricted CALL): su denominación se debe por los tipos de actividades, el rol del profesor y la respuesta inmediata proporcionada (feedback) que se podía ofrecer con el software existente de la época. A este período lo sitúa entre 1969 y 1980 , pero considera que el uso del software y el modo en que se aplica a la enseñanza mediada por computadoras es el que determina el enfoque y no tanto la época en que sucede; por ejemplo: hoy en día las actividades de este enfoque se siguen utilizando.

- CALL Abierto (en inglés, Open CALL): este enfoque se inicia en la década de 1980 y continúa hasta nuestros días. CALL es abierto en todas las dimensiones, dice Bax (2003), desde la respuesta del software hasta el rol del profesor. Agrega que aunque no es completamente abierto en el sentido amplio de la palabra, pero sí lo es en referencia al enfoque anterior: CALL Restringido.

- CALL Integrado (en español, Integrated CALL): este último enfoque lo diferencia de la tercera fase de Warschauer (1996), aclarando que no es integral sino integrado y además agrega que este enfoque no se había aún desarrollado, y por lo tanto, sería el enfoque en el que debemos focalizarnos en nuestro futuro.

Bax (2003) escribe sobre la visión futura de CALL y presenta el concepto de la "normalización". Bax anticipa que va a llegar el día en que CALL desaparezca y esto sucederá cuando llegue el momento de su normalización. Bax (2003) dice que existe un momento en que toda tecnológica se hace invisible; cuando la misma se transforma en una actividad rutinaria hasta el punto en que no se la reconoce como un tecnología y cita como ejemplos: un reloj de pulsera o un lápiz. Complementa su visión diciendo que la integración exitosa de CALL en la enseñanza de lenguas sucederá cuando deje de ser un concepto y un campo de discusión separado de las metodologías de enseñanza. Y, esto sucederá el día en que las computadoras que se encuentren disponibles sean más sofisticadas y probablemente diferentes a las actuales en medidas y formatos, y que sean usadas por alumnos y profesores de lenguas todos los días como parte integral de una clase al igual 
que hoy en día usamos una lapicera o un libro sin miedos y/o inhibiciones dejando de ser el centro de atracción y pasando a ser parte del todo. La posición física de la computadora en la fase normalizada será cuando la misma se encuentre en "todas las clases, en todos los escritorios y en todos los bolsos"(Bax 2003:21).

Bax (2010) retoma y amplía su concepto sobre la normalización de la tecnología en la enseñanza de lenguas que lo inició en su artículo anterior (Bax, 2003), en la que hacía referencia a la invisibilidad de una tecnología pedagógica que logra la misma al pasar por varias etapas hasta tomar un rol específico y normal en las prácticas educativas. Bax (2010) agrega a su concepto de normalización un marco teórico neo-Vygotskiana de la teoría sociocultural y además comenta su preocupación por muchos escritores e investigadores de CALL que han citado este concepto con referencia a tecnologías emergentes como las pizarras interactivas. Su preocupación radica en que esta tecnología no ha llegado al estado de normalización. Se ha llegado a decir que las mismas podrían reemplazar al docente. A Bax (2010) le preocupa tanto la fascinación de parte de algunos educadores sobre las tecnologías como el rechazo en el uso de las nuevas tecnologías en la enseñanza. Desde la perspectiva neo-Vygotskiana que Bax formula en su marco teórico ampliado (Bax, 2010) considera importante para llegar a la normalización de una tecnología el siguiente concepto de aprendizaje: el aprendizaje sucede como un proceso social en un contexto cultural y comunicativo en el cual la ayuda de un experto u otro par desarrollando estrategias de aprendizaje para lograr una solución de problema/s mediante una asistencia adecuada.

La evolución de la Web 2.0 cuya denominación implica una progreso en el desarrollo de la web, se caracteriza por el surgimiento de muchas herramientas webs que gracias a las nuevas posibilidades que ofrece la web (una web más dinámica, más colaborativa y más democrática) han provocado cambios muy significativos en el uso de herramientas webs que hoy en día podemos usar de una manera más accesible e interactiva propiciados por la mayor accesibilidad a internet y a la mayor posibilidad de conexiones entre usuarios.

Todavía no hay estudios contundentes que avalen un cambio en la educación gracias a estas tecnologías, pero si podemos decir que se ha producido un gran cambio en la manera en que nos comunicamos y mediamos los conocimientos. Debido al constante cambio en el mundo de las tecnologías parece que estuviéramos viviendo en un "estado de beta perpetuo" con respecto a estas tecnologías emergentes. (Pegrum, 2009: 24). Levy (1997) ya había escrito sobre cómo la rapidez y la continua aparición de nuevas herramientas tecnológicas dejan atrás, como en una carrera, a los educadores y usuarios 
en poder evaluarlas de una manera apropiada y eficaz para su uso educativo adecuado. Lamy \& Hampel (2007) ya nombraban a ciertas herramientas web como tecnologías emergentes: blogs, wikis, redes sociales y dispositivos móviles. Si bien los blogs educativos de clase, de la escuela o del alumno y las wikis se continúan utilizando como sitios donde se exponen los trabajos de los alumnos ya sean publicados por los docentes, alumnos o encargados de las TIC en una institución escolar, podríamos decir que hoy en día hay un estallido en los usos de las aplicaciones móviles con sus ventajas y desventajas y con los obstáculos del uso permitido de los móviles en las instituciones educativas tanto en nivel primario como en el nivel secundario.

Kukulska-Hulme \& et al (2015) describen un proyecto llevado a cabo por la universidad británica, Open University en conjunto con el British Council sobre el aprendizaje móvil (en inglés, m-learning) y a la que ellos llaman pedagogía móvil (Mobile Pedagogy, en inglés). Esta nueva tendencia en la integración de las nuevas tecnologías en la enseñanza de inglés se la denomina comúnmente con el acrónimo MALL (Mobile Assisted Language Learning; en español, Aprendizaje Asistido por Móviles). Con el avance de la tecnología móvil y la accesibilidad de los teléfonos inteligentes y otros dispositivos como las tabletas, vocablo derivado del inglés tablets, han propiciado el uso de aplicaciones (apps, en inglés) para estos aparatos electrónicos. Los dispositivos móviles han posibilitado un aprendizaje ubicuo gracias a la combinación de los dispositivos y del mayor y mejor alcance de la conexión inalámbrica a internet; por lo tanto, en la actualidad el aprendizaje puede ocurrir en cualquier momento y en cualquier lugar.

Nos podríamos preguntar si hoy en día el acrónimo CALL es todavía apropiado con el surgimiento de las nuevas tecnologías móviles. Jarvis y Krashen (2014) dicen que CALL ha quedado obsoleto debido a que se centra en la enseñanza de la lengua limitado al uso de la computadora y que se focaliza en el aprendizaje consciente. Tampoco creen que MALL y TELL (Technology Enhanced Language Learning, en español se traduce como Aprendizaje potenciado /enriquecido por la tecnología) sean más apropiados aunque Jarvis y Krashen (2014) aducen que aunque estas siglas incorporan los cambios en las tecnologías aplicadas, insisten en que el foco de las mismas recae otra vez sobre un aprendizaje consciente. Ellos prefieren usar MALU (Mobile Assisted Language Use, en español: El uso de la lengua asistido por móviles) definido así por Jarvis \& Krashen (2014) ya que este acrónimo incluye el uso las computadoras de escritorio y las móviles en los procesos de enseñanza y aprendizaje de una lengua. 
MALL es una sub-área de CALL y de m-Learning, (Kukulska-Hulme, 2006). MALL es la evolución de CALL que agrega, al uso de las computadoras de escritorio, aquel dispositivo que permite una fácil portabilidad y que propicia una aprendizaje ubicuo con el cual el alumno se comunica con sus profesores en cualquier momento y en cualquier lugar.

El acrónimo que más se utiliza en la actualidad por los profesores de inglés en los últimos congresos nacionales e internacionales sigue siendo CALL, no tanto así, aunque MALL a comenzado a tomar fuerza en su uso.

\title{
1.4 La Educación a Distancia
}

\begin{abstract}
"El estudiante asiste a la escuela virtual desde su casa. El sistema educativo para una sociedad de la información será independiente con respecto a la distancia (...) también respecto de cualquier país en particular. El estudiante no se agrupa simplemente porque vive en la misma área (...) Esta visión tiene como premisa la base del desarrollo de las tecnologías de la información que permiten la realidad virtual".
\end{abstract}

(Tiffin \& Rajasingham,1995)

En esta tercera parte del primer capítulo tomaremos el concepto de educación a distancia debido a que los proyectos que describiremos fueron realizados mediante esta modalidad de educación. También presentaremos elementos que consideramos claves en nuestro estudio sobre la educación a distancia: la autorregulación, la metacognición, las emociones y las interacciones.

La EaD (educación a distancia) (Ferrante, 2004) "es un sistema basado en el proceso de interacción educativa mediado y estrictamente planificado en el cual, si bien en algunas instancias la relación docente-alumno está diferida (preparación de materiales, creación de espacios virtuales de comunicación, etc.)". El tutor en su rol de guía y facilitador posibilita la comunicación sincrónica y asincrónica mediante el abanico de posibilidades que las herramientas virtuales de hoy en día ofrecen en los EVEA. El docente, además, en su rol de tutor provee a sus alumnos de un andamiaje que fortalece el aprendizaje autónomo que no deja de ser personal y afectivo.

Litwin (2000: 12) caracteriza a la EaD como una modalidad flexible en relación a las propuestas de enseñanzas que deben ser claras y definidas y además hace hincapié en que las nuevas tecnologías en las cuales se apoyan los cursos de EaD "favorecen las interacciones entre docentes y alumnos acortando las distancias en la modalidad". En el 
capítulo 4 profundizaremos el tema de las interacciones en los EVEA considerando que esta aseveración de Litwin es el objeto de estudio de nuestro trabajo.

Litwin (2000) también señala la importancia de la aplicación de enfoques novedosos y de la actualización de contenidos sin dejar de lado la presencia docente adecuada y efectiva en la que los docentes no solo evalúan y guían a los alumnos sino que los estimulan a ir un poco más allá de la propuesta ayudándolos a ser alumnos reflexivos y críticos. En relación a los materiales elaborados para estas propuestas pedagógicas, Litwin (2000:23) propone elaborar materiales que "generen desafíos cognitivos a los estudiantes". Las propuestas didácticas que se elaboran para trabajar en la presencialidad no siempre son viables en la virtualidad. Se debe pensar en "orientar y reorientar los procesos de comprensión y de transferencia" (Litwin, 2000:27), es decir, lograr una transposición didáctica desafiante de nuestros materiales y nuevos roles como docentes en los nuevos espacios virtuales. $Y$, por ultimo, no podemos dejar de nombrar la característica distintiva de la EaD como propuestas "democratizadoras". Los espacios educativos se democratizan proponiendo un mayor acceso en relación a cantidad de alumnos, distancias y costos.

La educación a distancia $(\mathrm{EaD})$ se originó producto de los grandes cambios económicos y sociales que ocurrieron en la segunda mitad del siglo XIX. A medida que las formas de comunicación evolucionaban en el tiempo, la educación a distancia también marcaba su recorrido en los cambios que las nuevas tecnologías le proporcionaron: pasamos de una enseñanza por correspondencia, a una enseñanza multimedia, y luego a una enseñanza telemática hasta llegar a la enseñanza colaborativa propiciada por servidores que permiten alojar cursos virtuales en la WWW. Gracias al arribo de las nuevas $\mathrm{TIC}$, la EaD ha cobrado un gran impulso en el desarrollo de cursos en línea especialmente en los niveles superiores de enseñanza impartidos por universidades de reconocidas trayectorias y otras que ya se dedicaban a la educación a distancia como por ejemplo, la OU (Open University) en el Reino Unido, la UOC ( Universidad Abierta de Cataluña), y la UNED (Universidad Nacional de Educación a Distancia) en España. La matrícula de estas instituciones se han incrementado gracias a las TIC que propician una educación global y continua.

El término educación a distancia se originó en Alemania en la universidad de Tübingen cuyos investigadores en la década de los 60 escribieron sobre el estudio a la distancia para describir ciertos principios industriales como la división entre el trabajo y el uso de la tecnología podría ser aplicado al arte de enseñar (Moore, 2012:68). 
La principal característica de la enseñanza a distancia es la separación física llamada distancia transaccional entre los integrantes del proceso de enseñanza y aprendizaje: los tutores y alumnos no se encuentran en un mismo espacio físico, sus encuentros pueden ser sincrónicos y/o asincrónicos; y, por lo general, son totalmente a la distancia. En la actualidad la comunicación es mediatizada por dispositivos tecnológicos que cuentan con internet como computadoras (de escritorio, notebooks, netbooks) y/o dispositivos móviles (teléfonos inteligentes, tabletas, y otros complementos inteligentes llamados wearables ${ }^{7}$ en inglés.) que facilitan en líneas generales la comunicación y la distribución de materiales. En términos generales los cursos a distancia respetan los tiempos de estudio y favorecen el estudio independiente autorregulado por el alumno.

Cuando desarrollamos un curso con la modalidad totalmente a distancia debemos tener en cuenta al desarrollar el diseño instruccional varios aspectos fundamentales, entre ellos:

- Las ventajas y desventajas de la separación física entre alumnos y tutores

- La heterogeneidad de los participantes del curso

- La multiculturalidad

- La metodología de enseñanza a emplear

- El tipo de comunicación como mediación en los proceso de enseñanza y aprendizaje

- El diseño del entorno

- El tipo de tutorías

- La evaluación de los alumnos

- La evaluación del curso

El armado de un curso virtual implica la organización de cuatro componentes que se crean con el objetivo de favorecer la distribución de tareas y el trabajo en equipo.

Los componentes son:

- La administración

- Las tutorías: atención a los estudiantes

- La producción y diseño de materiales y del entorno

- La evaluación de los aprendizaje y del sistema

\footnotetext{
${ }^{7}$ Ejemplos de complementos inteligentes: relojes inteligentes, pulseras de actividad, gafas inteligentes, ropa inteligente, etc.
} 
Estos componentes (figura 1) interactúan entre sí mediante una coordinación que ya ha llevado a cabo la planificación previa del curso.

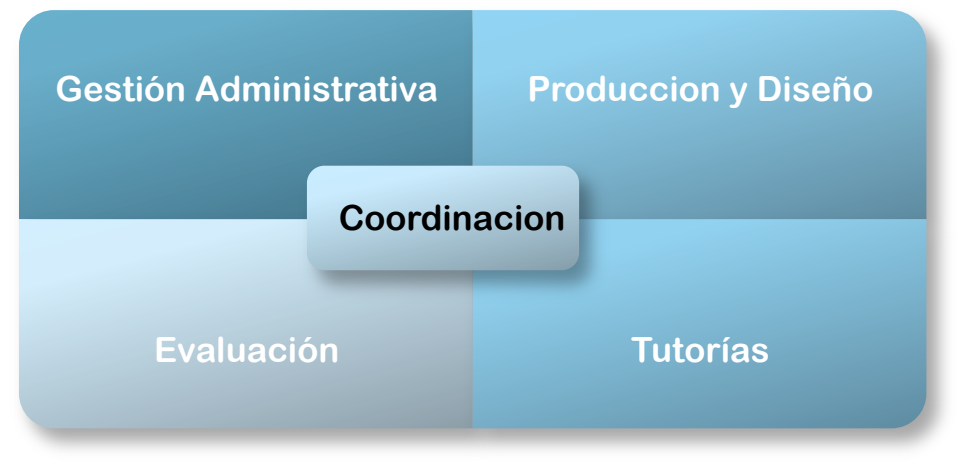

Figura 1

Componentes de la EaD

La interacción entre los componentes (figura 1) se facilita mediante pautas acordadas por la coordinación en la planificación del curso sobre los materiales de enseñanza, el tipo de tutorías, las evaluaciones y los soportes tecnológicos mediados por una comunicación fluida de los recursos humanos involucrados en el proyecto para satisfacer las necesidades y demandas del proyecto y lograr las metas prefijadas dentro del marco institucional. En el capítulo 3 vamos a profundizar la descripción de los componentes de la EaD de nuestro curso e-DACTA en relación al desarrollo del proyecto.

\subsection{La interacción}

La interacción es el eje central de nuestro estudio en el curso de e-DACTA. El camino del DACTA hacia el e-DACTA propició un flujo de interacciones mayor gracias al uso de las nuevas tecnologías. En esta introducción al tema comenzaremos por describir la importancia de las interacciones y luego en el capitulo 4 describiremos la presencia de las mismas en el corpus seleccionado profundizando en las interacciones del e-DACTA.

La interacción (Bange, 1992) implica una actividad social en la que los participantes de una propuesta pedagógica (como por ejemplo, una propuesta de enseñanza) se comunican utilizando una segunda lengua en un entorno de reciprocidad conociendo tanto aspectos lingüísticos como no lingüísticos. "La interacción se entiende como una negociación que está orientada hacia la acción, en ella se co-construyen los discursos y se 
lleva a cabo la intercomprensión ${ }^{8}$ (en nuestro contexto, sería más apropiado hablar de 'comprensión') por parte de los participantes”. (Pujol Berché, 2001:10 en Chiappa; Lira; Sara \& Simón, 2005). "Estas negociaciones en el marco de la clase, designadas con el nombre de contrato didáctico son, por un lado, las relaciones entre el docente y el alumno que obedecen a reglas casi siempre intangibles; por otro lado, producen una especie de juego cuyas reglas provisoriamente estables, permiten a los protagonistas y sobre todo al alumno tomar decisiones. Esto se produce en un marco seguro, tranquilizador; lo que asegura independencia en los procesos de apropiación de la lengua extranjera." (Chiappa; Lira; Sara \& Simón, 2005).

Ellis (1999:3) se refiere a la interacción como una actividad interpersonal que sucede en una comunicación cara a cara aunque también se puede referir a una actividad intrapersonal que involucra un proceso mental. La interacción interpersonal en CALL sucede en contextos virtuales (Chapelle: 2005:54) y además, la interacción en CALL se da también entre el alumno y la computadora que podría distinguirse del vocablo interacción, denominando este proceso como interactividad.

El beneficio lingüístico que se obtiene a través de la interacción entre los estudiantes (Chapelle, 2005:55) resulta de la negociación de significado entre ellos. La idea de un ajuste que permita a los estudiantes hacer conexiones esenciales entre forma y significado, se pude extender a la interacción entre alumno y computadora (Chapelle, 2005:55). Chapelle lo ejemplifica con actividades de lectura o de escucha: si el alumno se detiene en el proceso de adquisición para pedir ayuda (por ej.: en la forma de ayuda sobre vocabulario, parafrasear o transcripciones de textos) se esperaran resultados beneficiosos similares.

Chapelle resume en tres los tipos de interacciones básicas en el contexto de CALL:

1. Suceden entre personas y los beneficios que aportan las mismas se derivan de la negociación de significado (interacciones interpersonales)

2. Ocurren entre una persona y una computadora y sus beneficios se relacionan con la optimización o modificación del aprendizaje. (Este tipo de interacción según Chapelle (2005) no se clasifican como intrapersonales ni interpersonales; nosotros las denominaremos como un proceso de 'interactividad'.)

\footnotetext{
8 "Intercomprensión" (vocablo que se utiliza en lingüística para representar el "fenómeno que tiene lugar cuando dos personas se comunican entre sí con éxito hablando cada una en su propia lengua". (Consulta realizada 26/03/16: http://www.eurom5.com/p/chisiamo-es/intercomprensione)
} 
3. Suceden dentro de la mente humana focalizando la atención en la forma lingüística en el proceso de aprendizaje. (interacciones intrapersonales)

Según Zangara, A. y Sanz, C. "hay interactividad potencialmente en la estructura (diseño del curso y los materiales), hay interacción (entre personas) e interactividad (entre personas con la tecnología mediadora) en el diálogo y hay condiciones favorecedoras de interactividad en la autonomía del estudiante."

Fainholc (1999: 61) diferencia conceptualmente la interacción de la interactividad afirmando que la interacción acentúa lo social y cultural, mientras que la interactividad se asocia con lo pedagógico.

Chapelle $(2005: 54,55)$ sugiere que estos términos son distintos pero aun así están relacionados. Las interacciones pueden ser lingüísticas y no lingüísticas que se llevan a cabo por personas que intentan comunicarse. Pero cuando hablamos de interacciones mediadas por las computadoras, ya no son interacciones interpersonales o intrapersonales sino interacciones entre la persona y la tecnología. Chapelle concluye su artículo diciendo "Si la interactividad es la interacción que se produce entre el alumno y la computadora, esto es de hecho una concepto importante para el estudio de CALL."

En la educación a distancia se utilizan tecnologías que hacen de puente entre tutores, alumnos y las instituciones educativas (Shearer, 2012). La elección de las tecnologías y de las actividades propician la interacción en estos nuevos entornos. En el presente estudio consideramos la importancia de la fluidez en las interacciones que se producen en el entorno virtual ya que en los procesos de la adquisición de una LE la interacción juega un papel central en la construcción de conocimientos y la apropiación lingüística. Desde la perspectiva socio-cognitiva (Vigotsky, 1988 y Bruner, 1988) podemos decir que el ser humano es un ser social que pertenece a un grupo y se identifica con la cultura del mismo que propicia las interacciones lingüísticas propias de lenguaje humano. Las interacciones de los alumnos en un contexto de enseñanza de lenguas ofrecen oportunidades que mediante actividades propuestas motivantes propician la adquisición de competencias lingüísticas necesarias para comunicarse con fluidez.

Boy (en Moore, 2012: 68) prefiere utilizar el término diálogo en vez de el de interacción debido a que el vocablo interacción incluye relaciones que son manipulativas y negativas, en cambio el diálogo implica una ayuda, construcción e intercambio positivo. El 
término distancia transaccional aparece por primera vez en Boy \& Apps 1980 (en Moore, 2012:68); ellos definen a la 'distancia transaccional' como la interacción entre el entorno, los individuos y los parámetros de comportamiento de una situación.

Más adelante Moore redefine el concepto y desarrolla la teoría transaccional como la separación que existe entre alumno y el profesor. La distancia transaccional (Moore, 2012: 22) es el espacio psicológico y comunicativo que se debe cruzar para lograr los objetivos pedagógicos. Moore propuso, después de haber examinado un gran número de cursos a distancia, un sistema de enlaces entre el diálogo, la estructura y la autonomía del participante del curso.

El diálogo (Shearer, 2012) es la interacción en la comunicación entre participantes de un entorno, la estructura se refiere a la libertad que la propuesta pedagógica provee en relación al ritmo de estudio, objetivos y secuencias de aprendizaje, productos finales y evaluaciones y la autonomía del participante se refiere a la dependencia que el individuo necesita con respecto a la institución o entorno virtual para cumplir con los objetivos y así su aprendizaje es logrado. La teoría de la distancia transaccional es el resultado de la interacción de estas tres variables. Según Shearer (2012) cuanto más diálogo exista entre los participantes del curso, menor va a ser la distancia transaccional.

Shearer (2012) distingue tres factores claves a tener en cuenta al diseñar cursos virtuales dentro del modelo de la comunidad de indagación (Community of Inquiry, en inglés) que fue desarrollado por Garrison, Anderson \& Archer (2005): la presencia social, la presencia cognitiva y la presencia didáctica ${ }^{9}$. Esta clasificación define a la presencia social como la habilidad de los participantes de un entorno en donde se proyectan social y emocionalmente como personas reales a través de las interacciones; la presencia didáctica se da con las acciones que requiere toda experiencia educativa: diseñar, dirigir, facilitar, diagnosticar y evaluar los procesos cognitivos y sociales con el objeto de guiar a los alumnos para cumplir con los objetivos propuestos. $\mathrm{Y}$, la presencia cognitiva que se relaciona con la construcción del conocimiento por parte de los alumnos propiciados por la reflexión continua en la comunidad de indagación.

Las tres presencias son imprescindibles ya que se entrelazan entre sí logrando una experiencia de aprendizaje colaborativo en la virtualidad. Pero es sin duda la presencia

\footnotetext{
${ }^{9}$ Muchos han traducido la presencia didáctica como la presencia docente. Preferimos utilizar didáctica porque en un termino más completo ya que incluye al docente y al material didáctico.
} 
social la que arma el clima de grupo, la que manifiesta las bases sociales de confianza, calidez, satisfacción, empatía, compromiso, emociones que son necesarias para interactuar y propiciar el diálogo.

Esta propuesta de enseñanza y aprendizaje virtual será estudiada, como lo anticipamos anteriormente, no sólo bajo el punto de vista de los enfoques socioconstructivistas, cognitivos e interaccionistas ya mencionados, sino que también se tomarán en cuenta otro elemento que es comúnmente conocido como la cara oculta de los entornos virtuales: el aspecto afectivo; uno de los elementos más difíciles de evidenciar, y mucho más difícil se hace en las prácticas educativas virtuales por la "oscuridad" que existe en los cursos de educación a distancia.

La tecnología tiene la habilidad de confundir, intimidar y de hasta frustrar a los estudiantes usuarios. Aprender a usar el conocimiento y las habilidades informáticas necesarias es un proceso complicado (K.P. King, 2002: 264); y, se suma a esta cuestión el factor afectivo que incide de una manera importante dentro de los entornos de aprendizaje virtuales ya que no contamos con la presencia física del individuo; aunque muchas veces esta ausencia de presencia física es un obstáculo para algunos estudiantes, para otros es una ventaja. En este estudio nos interesa conocer qué emociones afloraron en las distintas interacciones - en términos de motivación, autoestima, ansiedad y otras variables personales - y cuales incidieron en la toma de decisiones de parte de los alumnos en llevar adelante o no, un curso en línea a diferencia de las modalidades presenciales, las cuales están más acostumbrados durante sus estudios primarios y secundarios en general.

Krashen (1982) al destacar la importancia del rol del aprendizaje comprensivo en la adquisición de segundas lenguas (comprehensive input, en inglés) reconoce que el aprendizaje puede ser bloqueado por lo que él denomina 'filtro afectivo' que reduce la habilidad del aprendiente en la apropiación del aprendizaje. Al describir la hipótesis del filtro afectivo, Krashen (1982) menciona la importancia de crear por un lado un ambiente con bajo nivel de ansiedad, además ofrecer un material motivante y mostrar desde el rol del tutor en línea una actitud positiva hacia el aprendiente para que el mismo sienta una autoconfianza en los procesos de aprendizaje.

Según Shearer (2012) las interacciones que se deben examinar son las interacciones entre estudiante-estudiante y entre estudiante-tutor; no sólo como ocurren, sino la frecuencia en su ocurrencia, la oportunidad de las mismas, la intención y la forma de 
intención: petición, debate, instrucción, conversación. Shearer (2012) también considera importante examinar la observación pasiva y la influencia cultural en las interacciones.

Esta observación pasiva a la que hace referencia Shearer (2012) son las interacciones que decidimos denominar interacciones "invisibles"; (la interactividad muchas veces es invisible dependiendo de la tecnología que utilizamos; por ejemplo, los entornos virtuales nos brindan información solo si los alumnos visitaron las guías pero no sabemos fehacientemente si las leyeron o si le dedicaron suficiente tiempo a la lectura, por ejemplo. En contraposición a las interacciones "visibles", por ejemplo, interacciones entre pares y/o docente/s de las cuales tenemos evidencia a través de los aportes en los foros específicos o al participar en diferentes actividades demuestran mediante su participación de interacción haber leído al menos el material de estudio. Por estos motivos, es importante que el diseño instruccional contenga en su propuesta actividades que hagan visible el trabajo de los alumnos.

Sutton ((2000) en Friesen (2013)) habla de otra forma de interacción a la que él denomina Vicarious interaction (en español, interacción indirecta) haciendo referencia a toda aquella interacción que sucede tanto en la presencialidad como en la virtualidad y que sucede en el momento en que no todos los alumnos interactúan directamente con sus pares y docente; es decir, el alumno puede "interactuar" también escuchando o leyendo; estas actividades a veces se interpretan como pasivas y en la virtualidad podríamos decir que estas actividades son invisibles salvo por las herramientas tecnológicas que detectan la presencia de los alumnos que dejan sus huellas digitales en los EVEA.

Si bien los motivos de la falta de participación no es nuestro eje central de estudio tenemos presente que los proyectos de los cursos a distancia contemplan en el diseño instruccional la metodología de promover la independencia y el desarrollo de estrategias de autorregulación en relación al trabajo con los contenidos del curso y los tiempos de estudio de cada alumno; creemos que si bien el docente como tutor puede tener un rol omnipresente, su rol más adecuado es el de acompañar, guiar y de descubrir la ausencia del alumno para ayudarlo y no para observarlo.

Panadero y Tapia (2014) toman el modelo de Zimmerman (2000; 2003) y Zimmerman y Moylan (2009) quienes definen a la autorregulación como "el control que el sujeto realiza sobre sus pensamientos, acciones, emociones y motivación a través de estrategias personales para alcanzar los objetivos que ha establecido". El componente 
cognitivo de la autorregulación es denominado comúnmente metacognición que se basa en el control estratégico de los procesos cognitivos.

El desarrollo de habilidades metacognitivas es de gran importancia en el ámbito de aprendizaje autónomo y autorregulado y requerido para los estudios superiores y en especial para el aprendizaje virtual. Flavell (1979) en Hauck (2007) definen el conocimiento metacognitivo como el conocimiento relacionado con nuestros procesos y productos cognitivos y a las estrategias metacognitivas como el monitoreo activo y su consecuente regulación y orquestación de estos productos.

El alumno autorregula la conducta, la motivación, el afecto y la cognición. La conducta involucra al lugar y ambiente de trabajo, al tiempo de dedicación al estudio y a la realización de las tareas y a la interacción entre pares y expertos. La motivación y el afecto se refieren al control de las emociones que ayudan a optimizar el aprendizaje; y la cognición está relacionada con el control de las diversas estrategias cognitivas que propician un rendimiento óptimo para la adquisición de conocimientos. Además, el alumno debe aprender a autorregular sus tiempos en los contextos de EaD aunque muchas veces los alumnos no logran cumplir con las tareas porque no saben cómo manejar los tiempos. Por este motivo, es muy importante que los alumnos y tutores se encuentren e interactúen virtualmente mediante diferentes formas de interacción para poder lograr cumplir los objetivos del curso. Es esencial la presencia y guía del tutor en todo curso a distancia.

Propiciar un ambiente de autorregulación e impulsar el desarrollo de las estrategias metacognitivas son elementos fundamentales que se deben contemplar en el diseño instruccional de todo curso; seguramente muchos de los alumnos que recibimos en nuestro curso e-DACTA ya se han apropiado, de forma explícita o implícita, de estas habilidades y estrategias durante sus estudios en la escuela secundaria; de todas maneras estos espacios que propician el desarrollo de los mismos están contemplados en el diseño instruccional de los cursos. Por ejemplo, el proyecto e-DACTA contempló la necesidad de la presencia de estos elementos ofreciendo foros especiales como un espacio de autoreflexión denominados comúnmente e-portfolio. Este espacio los ayuda mediante sus aportes a reflexionar sobre su participación y sobre la realización de diversas actividades durante el curso. Ellos deben reflexionar sobre las lecturas y los ejercicios relacionados, sobre los foros y actividades propuestas, sobre los obstáculos con que se encontraron o no. Siempre están guiados por un texto guía que los ayudara a completar un cuestionario reflexivo y además se los invita a evaluar el material utilizado tomando un rol crítico sobre el 
material con respecto a errores posibles detectados, ambigüedades en las tareas y grados de dificultad en el material de estudio.

Como ya dijimos anteriormente el objetivo de la presente tesis es describir la evolución de un proyecto impreso a uno virtual y cómo la interacción propicia la comunicación en un entorno virtual. Describiremos también las interacciones que se originaron en el área de comunicación especialmente en los foros y el chat. En el capítulo 4 retomaremos este tema y trataremos de aportar datos que revelen la presencia social en los mismos, analizando las interacciones y tomando como indicadores del análisis la presencia social que Garrison y Anderson (2005) describieron y dividieron en tres grupos: el afectivo, la comunicación social y la cohesión.

\subsection{Conclusión}

Pudimos observar que desde los inicios de CALL, el uso de las tecnologías en la enseñanza de la lengua ha sido relevante en el campo de la enseñanza de lenguas ya que se fue integrando a las metodologías de enseñanza de una LE de acuerdo a la medida en que las tecnologías fueron avanzando junto con las herramientas que las mismas ofrecen a los docentes de lenguas. Algunas tecnologías junto con las metodologías de enseñanza pasaron a ser obsoletas en relación a los avances tecnológicos y han dejado de utilizarse; por otro lado, otras tecnologías dejaron de ser emergentes y se convirtieron en más estables.

Nuestro trabajo se centrará en CMCL (comunicación mediada por la computadora focalizado en el uso de la lengua) ya que nos interesa observar la comunicación mediada por las tecnologías como las computadoras o dispositivos móviles que nos propician una comunicación fluida y ubicua, considerando que la observación de las interacciones en el entorno virtual de aprendizaje es nuestro tema principal. La CMCL propicia (Ruberg et al:1996) la experimentación, la posibilidad de compartir ideas, una participación mayor y mejor distribuida, y pensamientos colaborativos, pero enfatizan que para que la discusión virtual sea exitosa, se requiere de un ambiente social construido sobre un andamiaje sólido (Vigotsky,1988 \& Bruner,1988) que favorezca la interacción entre pares facilitada por el apoyo del tutor. 


\section{Capitulo 2}

\section{Del DACTA al e-DACTA}

\section{De un soporte papel a un soporte virtual}

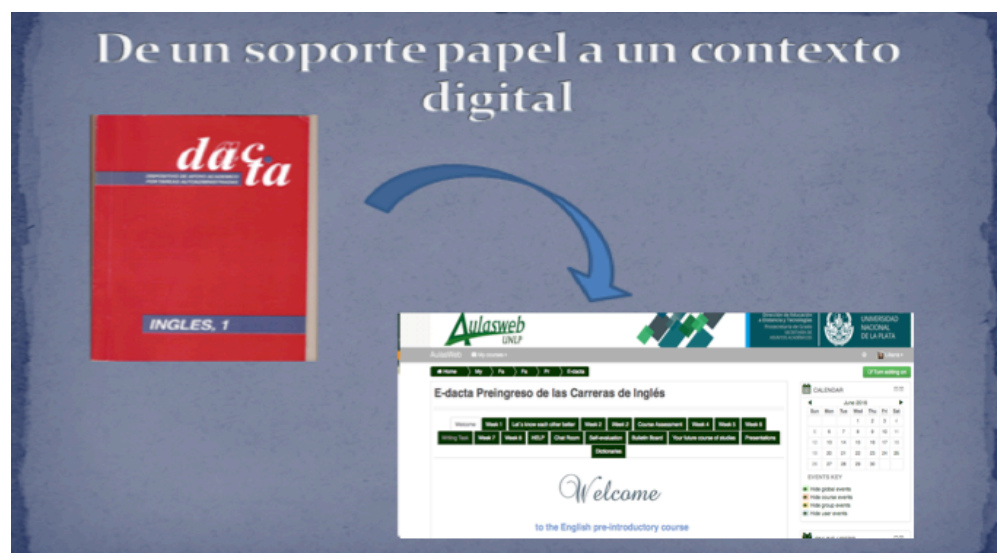

Figura 2

Metáfora del DACTA al e-DACTA

\subsection{Introducción}

En este capítulo se describirán los inicios y la fundamentación de los proyectos denominados DACTA y e-DACTA que se han realizado para los pre-ingresos de las carreras del profesorado, traductorado y licenciaturas de inglés de la Facultad de Humanidades y Ciencias de la Educación (FAHCE) de la Universidad Nacional de La Plata (UNLP).

Si bien el foco de esta tesis es la descripción del curso desarrollado en el entorno virtual, es necesario presentar al primer proyecto, DACTA, para comprender la evolución del material impreso al entorno virtual, e-DACTA (figura 2). El proyecto virtual e-DACTA se inició en el año 2008 y cuenta con su antecesor el libro DACTA que se gestó en el año 1999. La descripción de estas experiencias se centrará en la evolución del proyecto de preingreso que recorre el camino de un texto a un entorno virtual y en los datos que arrojan la descripción de las experiencias realizadas. 


\subsection{Proyecto DACTA}

EI DACTA (Dispositivo Académico por Tareas Auto-administradas) Soporte papel (ISSN 1514-9366) publicado en La Plata 1999 por la Facultad de Humanidades y Ciencias de la Educación de la Universidad Nacional de La Plata y cuyos autores son la profesora Liliana Simón y el profesor Juan Stamboni, es un libro guía que fue especialmente creado y diseñado para los aspirantes a ingresar a las carreras de inglés de la FAHCE- UNLP:

- Licenciatura en Inglés (Orientación Lingüística)

- Licenciatura en Inglés (Orientación Literaria)

- Profesorado en Inglés

- Traductorado en Inglés

Fue concebido como un proyecto inicial de pre-ingreso en el área de Ingreso de la FAHCE-UNLP y en conjunto con el Departamento de Lenguas y Literaturas Modernas de la FAHCE-UNLP en 1999 y fue puesto en marcha en el año 2000. La planificación del proyecto implicó reuniones (iniciales, de seguimiento y finales) con los profesores autores del libro, la directora del Departamento de Lenguas y Literaturas Modernas y la coordinadora del área de ingreso de la FAHCE, UNLP durante un periodo de escritura del libro por tres meses. Posteriormente, se continuó con el diseño del libro y su publicación. Y, finalmente con la planificación de las tutorías que fueron facilitadas por los mismos escritores del libro en el periodo de inscripción a los cursos de ingreso.

En el prefacio del libro se presenta al libro DACTA como el inicio de publicaciones de una serie de libros "en el marco de un conjunto de estrategias de mejoramiento de la calidad educativa y desarrollo de proyectos innovadores". El objetivo principal del libro DACTA, Inglés 1 es poder guiar y hacer reflexionar al futuro alumno de las carreras ya mencionadas con respecto al nivel requerido para poder orientarse durante la etapa del ingreso a las carreras de inglés mediante la presentación de temas teóricos y prácticos con actividades guiadas y ejercicios de auto-corrección (el libro cuenta con las respuestas a las actividades propuestas al final del mismo). Además del soporte del libro este proyecto contó con tutorías presenciales y a distancia brindadas por los autores del libro DACTA.

El perfil del alumno esperado para el ingreso a las carreras de grado de inglés de la FAHCE-UNLP comprende la posesión de ciertos recursos lingüísticos que involucran una larga lista que comprende varios ítems que van desde el conocimiento lingüístico, el 
fonológico, el gramatical, el funcional, los registros de formalidad, la coherencia y la cohesión hasta la fluidez y la exactitud en el uso de una LE en sus formas orales y escritas.

EI CEFR, (sigla inglesa, Common European Framework of Reference for Languages: Learning, Teaching, Assessment), en español Marco Común Europeo de Referencia para las Lenguas: Aprendizaje, Enseñanza, Evaluación ${ }^{10}$, ha enmarcado los diferentes niveles de referencia de habilidades y conocimientos que una persona posee de una LE. Este marco de referencia internacional describe las habilidades de la lengua en una escala de niveles que se inician en el nivel $A 1$, alumnos que inician sus estudios de lengua, a C2 aquellos que han logrado el nivel de dominio de la lengua más alto. Fue diseñado para proveer transparencia, coherencia y una base comprensiva para facilitar la elaboración de programas y diseños curriculares, diseños de material y evaluaciones del nivel de una lengua extranjera.

Para ingresar a las carreras de inglés es requisito fundamental que el alumno posea un nivel del idioma B2 según el CEFR o como se lo denomina con anterioridad por docentes de inglés y en libros de enseñanza como un nivel intermedio alto. Los descriptores de los niveles de competencias lingüísticas se pueden encontrar detallados en el banco de sitio web de CEFR ${ }^{11}$

Con respecto al nivel general de los alumnos ingresantes, los profesores que dictan clases en los cursos introductorios de las carreras arriba mencionadas han detectado que un porcentaje alto de alumnos manifiestan en sus clases un nivel insuficiente y a veces muy bajo en el uso de la LE y en el caso de ingresar a las carreras con un nivel no esperado, se encontrarían con dificultades al comenzar a cursar las cátedras del primer nivel de las carreras: Lengua Inglesa 1, Fonética y Fonología Inglesa 1 y Gramática Inglesa 1 (todas estas materias se dictan en el idioma inglés y son materias comunes para todas las carreras de inglés).

Muchos alumnos descubren al iniciar las carreras de inglés de la FAHCE-UNLP que no están acostumbrados a realizar ejercicios de lectura y de escucha con material

\footnotetext{
${ }^{10}$ Common European Framework of Reference for Languages: Learning, teaching, assessment (CEFR). En español: Marco Común Europeo de Referencia para las Lenguas: Aprendizaje, Enseñanza, Evaluación. Este marco común europeo también es utilizado en otros paises para medir el nivel e comprensión y expresión oral y escrita de una lengua

11 http://www.coe.int/t/dg4/education/elp/elp-reg/Source/Key_reference/EAQUALSBank_levels_EN.pdf). (Consulta realizada en la página web del "Council of Europe" el 07/01/2016)
} 


\section{La enseñanza de una lengua extranjera utílizando tecnología dígital}

auténtico $^{12}$, y que su vocabulario y recursos sintácticos son limitados tanto en las áreas del uso de inglés informal como en el uso de lengua académica o técnica. Otro dato interesante que se ha detectado mediante evaluaciones formales e informales realizadas en los cursos de ingreso es que los alumnos que han logrado aprobar evaluaciones del nivel B2 equivalente a reconocidos exámenes internacionales ${ }^{13}$, también manifiestan dificultades en el manejo de la LE y muchos no alcanzan los objetivos mínimos de las materias del primer año.

Tomando en cuenta los números que arrojaban en las inscripciones (de un promedio de 300 alumnos, ingresan un promedio de 150 alumnos) y sumando las manifestaciones de preocupación por parte de los docentes y autoridades de nuestra carreras en particular, la coordinadora de los cursos de ingreso de FAHCE-UNLP, Profesora Coordinadora Susana Sautel observó además en su momento (1990/2000) otros obstáculos que provocan una deserción generalmente simbolizado con las palabras "desgranamiento estudiantil". Socolovsky (2014) y hace referencia al mismo como un "problema del desgranamiento estudiantil -que se produce especialmente en los primeros años de las carreras y que afecta de manera selectiva a los estudiantes que proceden de hogares socioeconómicamente más desaventajados-“ <y que> no puede ser desatendido.” En nuestro caso, nuestra preocupación se inicia durante el periodo de ingreso de las carreras de inglés. Por estos motivos, se decidió en conjunto con las autoridades de la Facultad, FAHCEUNLP, formar un grupo de trabajo con profesores de los cursos de ingreso de 1998 y 1999 de las carreras de inglés y francés y diseñadores de la facultad para desarrollar el proyecto que consistía en la escritura de los libros DACTA de inglés y francés para todos los futuros alumnos que realizaran la inscripción a las carreras en noviembre de cada año y quienes luego de efectivizar la inscripción debían cursar el curso de ingreso de nivelación en el mes de febrero del siguiente año. Durante los meses de noviembre, diciembre y enero, los alumnos del curso de ingreso de las carreras mencionadas trabajarían en forma autónoma con estos libros.

\footnotetext{
${ }^{12}$ Material autentico es todo material textual, de audio, video, etc. que se encuentra en la vida cotidiana y que se puede utilizar como material de enseñanza de lenguas. Su valor agregado es que este material es comúnmente utilizado por el hablante nativo de la LM y representa un mayor grado de dificultad que los textos adaptados para la enseñanza. Por ejemplo, periódicos, libros, series de televisión, películas, etc. que están presentes en la cotidianidad de los hablantes nativos de las lenguas.

${ }^{13}$ FCE: El "First Certificate English" Test pertenece a "Cambridge Interntational Examinations" y es parte de la Universidad de Cambridge del Reino Unido; es el examen internacional más reconocido y estandarizado en la Argentina.
} 


\subsection{Descripción del libro DACTA}

En la figura 3 podemos visualizar la introducción del libro en la página 7 (página introductoria del libro DACTA); en ella se pueden observar las pautas, los requisitos y las debilidades idiomáticas con las que los aspirantes al ingreso se encuentran al momento del ingreso a las carreras de inglés de la FAHCE-UNLP que se han manifestado históricamente y a través de la experiencia docente y en referencia a las preocupaciones que también ya hemos mencionamos en los párrafos anteriores.

La habilidades lingüísticas de la lengua meta que los futuros estudiantes necesitan para ingresar a la universidad se detallan en la figura 3 seguida de un resumen del contenido de esta página. Estas habilidades lingüísticas son los requisitos mínimos para el ingreso a las carreras de inglés y hacen referencia como una introducción a la guía de "Lectura y Comprensión y Uso de la Lengua" del libro DACTA.

En su introducción se explica los requerimientos básicos necesarios para la admisión en los cursos de grado. El aspirante debe demostrar que su educación previa de la lengua inglesa ha alcanzado un nivel superior al nivel intermedio y que el mismo lo califique para lograr hablar, escribir y entender en forma adecuada para cursar las materias en inglés.

\section{Language Skills for Students Entering University Courses in English \\ A Reading Comprehension and Use of Language Guide}

\section{Introduction}

Admission to our degree courses in English involve certain entrance requirements. The student must show that his/her earlier education in the English language has reached, at least, an upper intermediate level and has qualified him/her to speak, write and understand English sufficiently well as to attend university courses in this language.

However, even those students who already fulfill the abovementioned requirements, may feel that their command of the English language is imited and sometimes insufficient. Many students may find that:

- They are often not used to reading or listening to authentic language.

- Their vocabulary and syntactic resources are often limited, particularly in the areas

of informal colloquial English and academic/technical language.

- Their writing is often inaccurate and disorganised.

- They need to revise much of the grammatical ground that they covered at earlier

stages of their training.

- They do not perceive that they are making progress.

- They are often not independent as learners. 
Podemos observar que en el segundo párrafo se manifiesta la preocupación de los docentes por aquellos aspirantes que aún teniendo el nivel requerido pueden sentir que su dominio de la lengua meta es limitado y a veces insuficiente (énfasis nuestro). Y, luego detallan en forma de lista lo que muchos alumnos pueden descubrir al iniciar sus estudios:

- No poseen hábitos de lectura y/o escucha de material auténtico.

- El vocabulario y los recursos sintácticos son limitados, especialmente en las áreas del uso de la LE en sus registros informales y coloquiales y en uso del lenguaje académico y técnico. ( Es decir, muchas veces los alumnos no saben diferenciar y aplicar el registro apropiado en el contexto que se requiera según las actividades).

- Sus producciones escritas son frecuentemente desorganizadas y/o inapropiadas

- Necesitan revisar la gramática de los temas ya estudiados en los inicios de sus estudios de la LE.

- No perciben si están progresando en su nivel de lengua.

- No se comportan mayormente con independencia.

En referencia a los registros formales e informales, podemos aclarar que los alumnos muchas veces no poseen los recursos lingüísticos suficientes para poder diferenciar los registros de formalidad e informalidad. Estos recursos varían en la elección del vocabulario y estructuras en general y de otros recursos. Al escribir un e-mail a un amigo utilizamos un registro informal que implica el uso de un vocabulario coloquial, estructuras simples y hasta incompletas debido al grado de conocimientos entre el emisor y receptor del e-mail y de un uso de emoticones muy frecuente hoy en día. En cambio si cambiamos el contexto del e-mail escribiendo a una persona que no conocemos elegiremos un registro más formal y distante entre el emisor y el receptor.

\subsection{Secciones del libro DACTA}

El libro DACTA consta de cuatro partes denominadas módulos. Se eligió este término ya que el mismo denota un "conjunto unitario de piezas que se repiten en una construcción de cualquier tipo, para hacerla más fácil, regular y económica" y también significa "unidad educativa que forma parte de un programa de enseñanza". (Definiciones extraídas del diccionario RAE) 
La estructura del libro ofrece una flexibilidad tal que ayuda al alumno autorregular su aprendizaje. No es necesario realizar una lectura de estudio líneal del libro, es decir, el alumno puede decidir por cual módulo comenzar o continuar por el módulo que prefiera, el que sienta es más motivante o necesario para él. De todas maneras, se sugiere la lectura lineal desde el inicio al final de cada módulo debido al incremento de complejidad en ciertas tareas. Esto se explica en el inicio de cada módulo.

\section{Módulo 1}

Este primer módulo consiste en una serie de textos seguidos por ejercicios de lectura y comprensión los cuales están graduados desde un nivel de complejidad menor a mayor. Cada uno de los textos está seguido por ejercicios de selección múltiple, ejercicios de respuestas de tipo "Verdadero o Falso" y ejercicios de actividades de respuesta de textos, descripciones de personajes o resúmenes breves. Todas estas actividades cuentan con las respuestas para las actividades cerradas (opciones provistas) o con un ejemplo guía para respuestas de la actividades abiertas (texto libre sin opciones).

Además este módulo contiene una introducción de las actividades que se desprenden de la lectura de varios textos. Se guía a los alumnos dándoles una serie de consejos desde cuáles son los mejores hábitos de lectura y de comprensión hasta cómo desarrollar estrategias para realizar una lectura exitosa, y así poder consolidar lo ya aprendido y beneficiarse con la adquisición de nuevo vocabulario. También esta introducción informa a sus lectores que en los módulos 2 y 4 se encontrarán con ejercicios y explicaciones gramaticales que han sido especialmente diseñados para comprender, usar ciertas estructuras gramaticales y vocabulario de una manera apropiada.

Los seis textos elegidos para trabajar las estrategias de lectura y comprensión son textos que se diferencian por su contenido que van desde informes de temas sociales, científicos y tecnológicos que se pueden encontrar en una revista o periódico y extractos de narraciones de cuentos.

Además de la importancia de la selección del material en relación al vocabulario y estructuras gramaticales, los textos acompañados de los ejercicios de comprensión se dispusieron de acuerdo a su complejidad que va de más fácil a más difícil. 
Cada texto está acompañado de indicadores de grado de dificultad y que se puede visualizar fácilmente para los lectores con los siguientes símbolos:

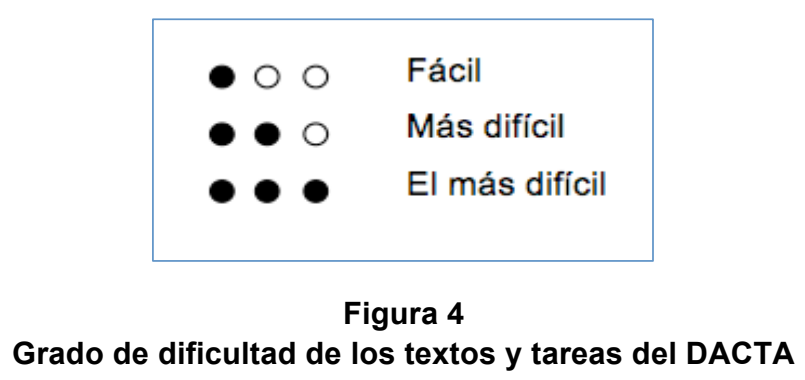

\section{Módulo 2}

Esta unidad se denomina Práctica del Lenguaje (en inglés, Language Practice). En la introducción a este módulo se detalla el tipo de ejercicios con los que ese trabajan en este espacio y se hace hincapié en la necesidad de trabajar con tareas que implican el razonamiento sobre el control que el futuro alumno debe tener sobre la lengua tanto en las formas gramaticales aceptadas y en el vocabulario del nivel requerido para el ingreso a las carreras y que en general presentan dificultades de la apropiación del conocimiento de los mismos en relación a los alumnos que se sitúan en el nivel B2 en la adquisición de la lengua inglesa.

Los ejercicios que presenta este módulo son de construcción gramatical a nivel oracional y de vocabulario. Los tipos de ejercicios son: ejercicios cerrados de elección múltiple (textos para completar con 4 opciones), ejercicios de formación de las palabras (textos para completar con la forma gramatical correcta de una palabra dadas junto con el texto), ejercicios cerrados (textos para completar con palabra cuyo énfasis está en el nivel gramatical sin pistas), ejercicios de transformación con una palabra clave (este tipo de ejercicio implica escribir a partir de una oración completa, una nueva oración sin cambiar el significado de la primera y agregando una palabra clave nueva provista por el ejercicio y con el límite de poder utilizar entre 2 a 5 palabras incluyendo la dada).

El objetivo de este módulo es intensificar la práctica del uso de léxicos equivalentes, construcciones directas e indirectas, expresiones idiomáticas, verbos compuestos, etc. que seguramente el futuro alumno de las carreras ya mencionadas ya posee como conocimiento de la lengua pero que tal vez no ha llegado a apropiarse del mismo, es decir, no maneja o conoce bien las estructuras del nivel esperado (B2). 
En la sección vocabulario se agrega una leyenda de ayuda (en inglés, "tip") que aconseja al alumno intentar desarrollar estrategias de comprensión con respecto al nuevo vocabulario que encuentran durante las lecturas. No siempre en todas las circunstancias el alumno puede tener un diccionario a su alcance. Muchas veces (por ejemplos, una situación de examen), el alumno debe de alguna manera deducir el significado de algún termino de acuerdo al contexto de los textos.

Al igual que el Modulo 1, los ejercicios en este módulo presentan un grado de dificultad que va de más fácil a más difícil y se visualiza fácilmente con los mismos símbolos utilizados en el Módulo 1 (figura 4).

\section{Módulo 3}

En este módulo se presentan guías para trabajar con diferentes géneros literarios: cuentos cortos y novelas.

En la primera parte del módulo los lectores leen un cuento corto y luego realizan un análisis de textos narrativos y literarios (punto de vista, localización, argumento, conflicto, personajes y temas) y responden preguntas de comprensión acompañadas por sus respuestas al final del módulo. Este módulo fue pensado para brindar un andamiaje a los futuros alumnos debido a que otra de las debilidades con las que los profesores de los primeros años de las carreras nos encontramos es que los alumnos no cuentan con las estrategias discursivas para poder producir un análisis literario de los cuentos cortos, novelas y otras narraciones que deberán estar leyendo en un futuro inmediato.

En la introducción de este módulo se facilitan pautas para que el alumno cuente con herramientas en su discurso lingüístico para un análisis completo de un cuento corto. Los párrafos iniciales del módulo explican los diferentes elementos que se pueden analizar al hablar de un texto literario de ficción: el punto de vista del narrador, el tiempo y el espacio donde transcurren los eventos, el argumento junto con el conflicto el clímax y desenlace, los personajes y el tema. Luego, en base a las pautas dadas, se sugiere la lectura de dos cuentos cortos "Puppet on a String" de Patrick Gordon y del cuento corto "A Stitch in Time", de John Wyndham seguida de dos guías con ejercicios de comprensión relacionados con los elementos de análisis ya provistos en la introducción y con las posibles respuestas al final del módulo. 
En la segunda parte de este módulo se presentan los elementos literarios que permiten un análisis de la lectura de novelas en general: el tiempo y el espacio donde transcurren los eventos, el argumento, los personajes, el tema, el estilo y la estructura y la reacción del lector como respuesta a la lectura de la novela.

\section{Módulo 4}

Este módulo es complementario de los primeros módulos ya que presenta las referencias gramaticales con descripciones de estructuras y de sus usos con ejemplos en cada sección. Este módulo es de referencia para los primeros módulos del DACTA ya que funciona como un andamiaje que provee al alumno de explicaciones gramaticales y del uso apropiado de la lengua. Las selecciones de estos temas gramaticales se realizaron teniendo en cuenta las dificultades gramaticales que plasman las evaluaciones en esta primera etapa de las carreras de inglés. Los temas son: las formas de los condicionales, estilos directo e indirecto, preposiciones, concesiones, expresiones que connotan hábitos, y frases verbales.

\subsection{Tutorías del DACTA}

Durante los dos primeros años de vigencia del libro DACTA (2000 y 2001) los alumnos contaron con diferentes tipos de tutorías: virtuales, comunicación telefónica, fax, emails y presenciales en el Departamento de Lenguas y Literaturas Modernas, FAHCEUNLP. Las tutorías presenciales estuvieron a cargo de los autores del libro DACTA: Profesor Juan Stamboni y Profesora Liliana Simón. La cantidad de consultas en las tutorías realizadas sobre el material de estudio durante el primer y segundo año fueron escasas y debido a este motivo, se dejaron de realizar a partir del tercer año. En el año 2000, la cantidad estimada de consultas realizadas telefónicamente fueron diez: cuatro e-mails recibidos, tres llamadas telefónicas, ninguna comunicación por fax y tres personas se acercaron a las consultas personalmente. En el año 2001 las cantidades fueron aún menores, cuatro en total, y es por este motivo que se decidió no continuar con las tutorías; de todas maneras, el libro continuó en vigencia por muchos años más y en forma paralela desde el 2008 con el curso virtual e-DACTA hasta estos días como material de referencia para el ingreso. Lamentablemente no contamos con los registros escritos de las tutorías del DACTA. Los tutores nos informaron que las consultas se trataron sobre la carrera pero ninguna en referencia a dudas que podrían provocar al material del libro DACTA. 
Si bien el material del libro DACTA acompañó a los aspirantes de las carreras de inglés durante varios años, la preocupación por el desgranamiento estudiantil continuaba siendo una temática relevante en los siguientes años. Con el advenimiento de las nuevas formas de integración de las tecnologías en las clases y junto con las nuevas propuestas de inclusión y democratización de la enseñanza en el nivel superior en relación a la enseñanza de lenguas, se comenzaron a gestar nuevas formas de elaboración de nuevas propuestas didácticas digitalizadas para proveer el andamiaje deseado a los futuros alumnos. En principio se pensó en realizar una serie de CD-ROM pero pronto se comenzaron a fortalecer los EVEA (Entornos Virtuales de Enseñanza y Aprendizaje) y a partir de la proliferación en el uso de estos nuevos espacios surgió la idea de poder diseñar un curso de pre-ingreso virtual que propiciaría una comunicación más fluida y contenedora en un solo espacio. De esta manera se dejó de lado la idea de armar una serie de CD-ROM y se comenzó a gestar el e-DACTA, un curso de pre-ingreso virtual con el objetivo de poder fortalecer la debilidad que había tenido el DACTA: las tutorías, y por ende la escasez en las interacciones entre alumnos y docentes.

\subsection{Proyecto e-DACTA}

El presente proyecto fue presentado en el año 2007 ante la Secretaría Académica de la Facultad de Humanidades y Ciencias de la Educación de la Universidad Nacional de La Plata y avalado por la Profesora Susana Sautel, Coordinadora del Área de ingreso, por la Decana de la FAHCE-UNLP, Profesora Ana Barletta y por la directora del Departamento de Lenguas y Literaturas Modernas de la FHCE-UNLP, Magister Leticia Moccero; y ha sido ideado, diseñado, desarrollado y puesto en marcha por la Profesora Coordinadora del proyecto Liliana Simón.

El curso de pre-ingreso e-DACTA se encuentra en vigencia desde el año 2008 y forma parte de un programa amplio para el uso en otros espacios y campos disciplinares pertenecientes a la Dirección de Educación a Distancia de la UNLP, el EVEA denominado WebUnlp y luego a partir del año 2015 el curso virtual se alojó en el nuevo EVEA de Moodle también perteneciente a la presidencia de la UNLP, Aulasweb.

El inicio del proyecto e-DACTA (Dispositivo Académico por Tareas Autoadministradas electrónico) implicó no solo re-significar los objetivos propuestos en el libro DACTA, sino crear nuevos contenidos y tareas, diseñar una nueva propuesta didáctica y 
adaptarlos a la nueva la interfaz sin perder el eje fundamental del primer proyecto de orientar y acompañar a los futuros ingresantes en su primer acercamiento a las carreras de inglés y en la mayoría de los casos al ámbito universitario.

Los objetivos pedagógicos pretenden ampliar las prácticas de disponibilidades y habilidades en lengua inglesa a efectos de favorecer la articulación entre saberes adquiridos en el nivel medio y el trayecto de esos mismos saberes en la institución universitaria. Es decir, los objetivos continúan siendo los mismos, el cambio se observa en el soporte en el cual se ofrecen los objetivos y contenidos y las posibilidades de realizar otras tareas que impliquen una mejor interacción y optimización en los recursos que propicien esta deseada interacción en la comunicación entre los entre los participantes del curso.

Tanto el libro DACTA como el curso virtual e-DACTA fueron creados para todas aquellas personas que desean estudiar las carreras del profesorado, traductorado y licenciaturas en inglés que ofrece la Facultad de Humanidades y Ciencias de la Educación, UNLP.

Para diferenciar el tipo de destinatarios en los dos proyectos, podríamos utilizar dos vocablos diferentes: alumnos ingresantes y alumnos aspirantes. Esto se debe a la distancia en que se encuentra el futuro alumno universitario de su ingreso a la universidad en estas carreras arriba mencionadas. Los ingresantes son alumnos del curso de ingreso que se realiza en forma totalmente presencial en los meses de febrero y marzo; $y$, los alumnos del curso virtual e- DACTA, son aspirantes debido a que el curso se realiza en un período previo a las inscripciones en la Facultad. No han realizado las inscripciones a las carreras aún.

Resumimos en la siguiente tabla 3 los datos que aportan las características fundamentales y diferencias entre los dos proyectos: 


\begin{tabular}{|l|c|c|}
\hline & DACTA & E-DACTA \\
\hline Inicio & 1999 & 2008 \\
\hline Destinatarios & Alumnos ingresantes & Alumnos aspirantes \\
\hline Formato & Textual & Virtual/Multimodal \\
\hline Tutorías & 2000 y 2001 & Desde 2008 \\
\hline Modalidad & Virtual y presencial & Virtual \\
\hline
\end{tabular}

Tabla 3

Diferencias del DACTA y el e-DACTA

Como ya expresamos anteriormente que si bien el libro DACTA se acompaño con tutorías virtuales y presenciales, las mismas fueron pocas y la que se realizaron fueron hechas en referencia a las inscripciones y a las carreras, no al material de estudio del DACTA. Además, debemos aclarar que las mismas se realizaron en una época en que los e-mails aún no estaban incorporados como herramienta de estudio y/o de comunicación entre alumnos y docentes de nivel secundario.

El libro DACTA se ofrece en el momento de inscripción (en los meses de noviembre y diciembre) mientras que el curso e- DACTA se pone en marcha en un período previo al de la inscripción (entre los meses de septiembre/noviembre). La decisión de esta fecha de ejecución del curso se debe principalmente en primer lugar a un motivo pedagógico. El alumno que se inicia en las carreras del profesorado y traductorado y licenciaturas en inglés de la Facultad de Humanidades y Ciencias de la Educación, UNLP, requiere de la posesión de conocimientos previos del idioma inglés para cumplir con los objetivos mínimos de las primeras materias de las carreras, el nivel B2 enmarcado en el CEFR (ya mencionado con anterioridad en este capítulo). Este nivel se reconoce por la demostración de los conocimientos de estructuras, vocabulario, fluidez oral y escrita del nivel mencionado, pero muchas veces el futuro alumno universitario desconoce su propio nivel del idioma inglés y necesita de una guía como un curso de nivelación que lo ayude a determinar si sus conocimientos del idioma son suficientes para comenzar una carrera universitaria que demanda el uso de una lengua extranjera en sus formas escritas y orales apropiadas al 
contexto académico que a su vez se encuentra enmarcado en el contexto de las asignaturas del primer año de las carreras de inglés de la FAHCE-UNLP. Y, en segundo lugar, esta decisión sobre el periodo de realización del curso virtual es adecuada para el aspirante ya que todavía no es alumno del curso de ingreso; el curso e-DACTA lo guiará en sus futuros estudios autorregulando su aprendizaje de una LE y también funcionará como una ayuda en la toma de decisión de la elección de su futura carrera universitaria.

Esta decisión fue pensada en principio para aquellos futuros alumnos que viven lejos de la ciudad de La Plata y que desean iniciar sus estudios universitarios al año siguiente. Gracias al curso virtual cada aspirante tiene de esta manera un acercamiento previo a la universidad y a la carrera en la virtualidad. Además, la época en que se imparte es justo cuando la mayoría de los futuros alumnos están finalizando sus estudios secundarios y aún residen en sus ciudades lejos de la ciudad de La Plata donde se encuentra la Facultad. Observamos también un beneficio desde el punto de vista económico, en particular de las familias del futuro alumno ya que el alumno no se muda aún y está realizando un curso que es proporcionado gratuitamente sobre la carrera a estudiar en un futuro muy cercano.

\section{Conclusión}

En este capítulo hemos presentado una descripción de los dos proyectos, DACTA y eDACTA, que acompañan a los futuros estudiantes de las carreras de inglés de la FAHCEUNLP desde el año 1999 y continúa hoy en la actualidad.

El libro DACTA ha estado vigente por más de una década y quedará como material de repositorio en SEDICI ${ }^{14}$ Repositorio Institucional de la UNLP. La transición del libro a un curso virtual propició la presencia social que estaba casi ausente en el libro DACTA. Esta cuasi ausencia de interacciones impulsó la creación del curso e-DACTA en un EVEA cuyo entorno propició el desarrollo de las interacciones.

\footnotetext{
${ }^{14}$ http://sedici.unlp.edu.ar/bitstream/handle/10915/56492/Documento completo.pdf?sequence=3
} 


\section{Capitulo 3}

\section{Descripción del curso e-DACTA}

\subsection{Introducción}

En este capítulo vamos a describir el desarrollo del curso e-DACTA en el EVEA Aulasweb de la UNLP donde se aloja nuestro curso, la presencia de los subsistemas de la EaD en el curso, los pasos del diseño instruccional, el diseño de las guías de estudio y los diferentes tipos de líneas de comunicación que se utilizaron. También se presentará en este capítulo una introducción a la importancia de la comunicación asincrónica en los foros y chats de nuestro curso. Tomaremos ejemplos con capturas de pantallas del curso para ejemplificar la descripción de la cohorte 2013.

\subsection{El curso e-DACTA}

La disponibilidad y accesibilidad de las redes de información y comunicación han posibilitado el desarrollo del presente curso dentro de un entorno virtual de enseñanza y aprendizaje. El entorno virtual sobre el que se diseñó el curso se denomina Webunlp, EVEA perteneciente a la Universidad Nacional de La Plata dentro la Dirección de Educación a Distancia de la UNLP que se utilizó hasta el año 2013, y a partir del año 2014 se trasladó al nuevo EVEA denominado Aulasweb que también pertenece a la misma Dirección de Educación a Distancia de la UNLP.

El curso e- DACTA de pre-ingreso ha sido uno de los primeros cuatro cursos de ingreso que se han creado en las diferentes unidades académicas de la UNLP y que se desarrollan con la modalidad a distancia; modalidad que democratiza la enseñanza permitiendo el acceso a muchas más personas, principalmente aquellas personas que por vivir a una distancia lejana a nuestra institución no podrían realizar el curso.

El curso e-DACTA hereda del libro DACTA Inglés 1 las tareas auto-administradas que implican un cambio en los roles habituales de los alumnos y profesores en los procesos 
de enseñanza y aprendizaje. Este tipo de tareas implica una mayor responsabilidad por parte de los alumnos del curso ya que ellos deben decidir en qué momentos realizar las mismas aunque se aconseja siempre realizarlas dentro de un tiempo estipulado durante el curso para poder cumplir con los requisitos mínimos del mismo y para propiciar las tareas de interacción entre los integrantes del curso. Asimismo, los alumnos cuentan con guías y cronogramas que ayudan al alumno organizarse dentro del esquema del curso. Los alumnos, entonces, autorregulan sus estudios en los diferentes estadios del curso. Esta forma de estudio en la virtualidad muchas veces es nueva para los alumnos que provienen del nivel secundario, pero gracias a estos entornos nuevos de enseñanza y aprendizaje, los alumnos aprenden, como dice Marta Mena (2004) en una entrevista para el portal educ.ar: "Un alumno presencial cuando toma una o dos asignaturas a distancia aprende a administrar mejor su tiempo y sus espacios de estudio; aprende a resolver problemas en forma autónoma mucho más rápidamente; aprende a gestionar la información y a generar sus propias experiencias de aprendizaje. Desarrolla actitudes de autonomía e independencia que son fundamentales para su futura vida profesional". Es por esto que el alumno de un curso a distancia debe desarrollar entre otras estrategias, las estrategias de autorregulación para poder lograr el aprendizaje deseado.

\subsection{Planificación del curso e-DACTA}

El curso de pre-ingreso e-DACTA se diferencia principalmente de los cursos tradicionales de ingreso en que éste es el primer curso a distancia en la historia de todos los cursos y cátedras del Departamento de Lenguas y Literaturas Modernas de la FAHCE de la UNLP; siendo su objetivo principal el de afianzar y desarrollar competencias lingüísticas escritas en idioma inglés para iniciación en los estudios universitarios.

El proyecto se desarrolló en varias etapas que se inician con la planificación del proyecto, continuó con la elaboración de las guías de trabajo y del material de estudio, el diseño del EVEA, la puesta en marcha del curso y terminó con la evaluación del curso. Estas etapas las reunimos en la figura 5 que simboliza el inicio en la base y termina en la punta. 


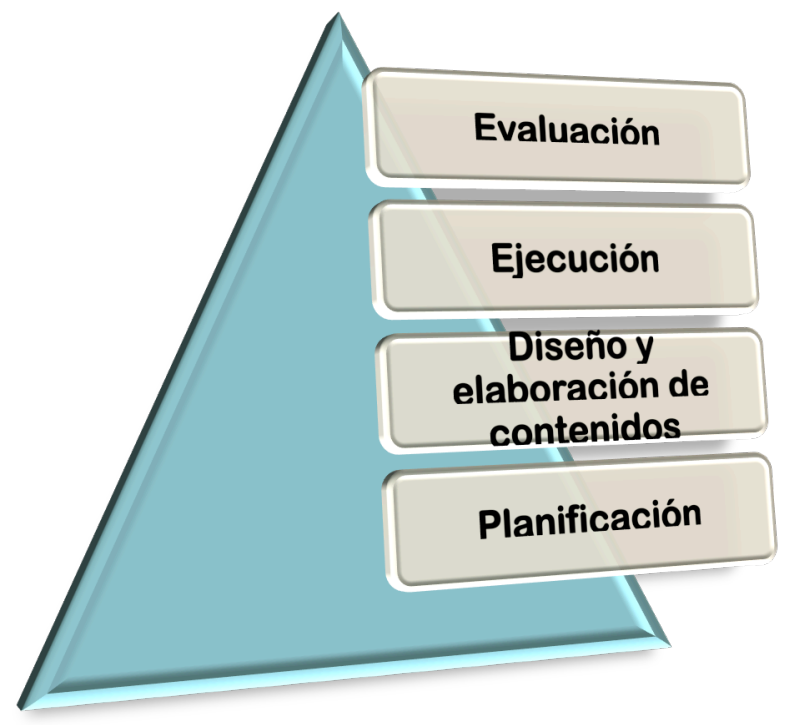

Figura 5

Etapas del Proyecto e-DACTA

\subsection{Planificación del proyecto}

En esta primera etapa se llevaron a cabo reuniones en el Departamento de Lenguas y Literaturas Modernas de la FAHCE-UNLP para el desarrollo del proyecta e-dacta. Se presentó el proyecto que se diseñó con el apoyo del área de Educación a Distancia del Rectorado de la Universidad Nacional de La Plata a las autoridades académicas de la Facultad de Humanidades y Ciencias de la Educación de la Universidad Nacional de La Plata. Una vez aprobado el proyecto, se inició con las tareas de coordinación de tareas del mismo. El coordinador comenzó con la planificación propiamente dicha del curso e-DACTA. Las tareas realizadas desde la coordinación del curso fueron varias y se llevaron a cabo siguiendo un plan de guía para el desarrollo sistemático de las tareas para poder optimizar la puesta en marcha el curso. Las mismas fueron:

- Elaboración del texto guía del curso

- Elaboración de un cronograma del curso

- Elaboración de formularios de inscripción

- Inscripción del curso: pautas, requisitos y tiempos

- Elaboración, diseño y análisis de las encuestas iniciales y finales

- Planificación de materiales y las tareas del curso

- Elaboración de la guía para confeccionar e-portfolios 
- Elaboración y diseño de las auto-evaluaciones del curso

- Elaboración de encuesta a tutores

- Evaluación final del curso

\subsection{Texto Guía y Cronograma}

La elaboración del "Texto guía" (Apéndice 1) se basó en el proyecto ya aprobado. Se tomaron los objetivos y metas del mismo y se trabajó sobre la jerarquización y secuencia de los contenidos del curso para poder escribir un texto guía del curso para los alumnos. El texto guía es una carta de presentación del curso que describe la metodología de trabajo, el acompañamiento y seguimiento de los tutores, los requisitos técnicos necesario y el cronograma inicial del curso.

La presencia de este texto es fundamental para guiar al alumno del curso. Su entrega se realiza después de que el alumno haya realizado la inscripción al curso y de haber cumplido con los requisitos mínimos para registrarse en el mismo; el alumno recibe en su casilla de correo personal un e-mail en formato de carta de bienvenida al curso con dos archivos adjuntos el Texto Guía (Apéndice 1) en formato PDF y un tutorial en formato PPT armado como Presentación del EVEA; de esta manera, el alumno obtiene información sobre el curso en sí y sobre el nuevo espacio virtual y así logra dar los primeros pasos al registrarse en el entorno.

Tanto el texto guía como el cronograma (Apéndice 2) marcan los pasos a seguir para realizar el curso con éxito. Se recomienda a los alumnos imprimir los mismos para poder concretar un seguimiento efectivo del curso. El cronograma los ayuda a seguir el curso al mismo tiempo que el resto de los participantes del curso y así poder lograr estar al día con todas las tareas, sobre todo las tareas que requieren interacción entre los integrantes (principalmente en los foros) y las tareas que requieren la entrega de las mismas a sus tutores y también destacamos la importancia de respetar los tiempos de corrección y continuidad del programa.

La duración del curso de la cohorte del primer año, 2008, fue de 3 meses, a partir del mes de septiembre hasta noviembre, es decir, durante 12 semanas. A partir del 2009 se modificó el tiempo de ejecución del curso debido al análisis de los resultados de las encuestas finales. Las mismas brindaron datos que impulsó la modificación del tiempo a 
dos meses, o sea, ocho semanas. Estos datos los presentaremos más adelante en el capítulo 5.

Una de las características de los cursos a distancia es el manejo de un tiempo más flexible. Si bien existe esta flexibilidad en el curso e-DACTA dado a que sabemos que los alumnos del último año de las escuelas secundarias de Argentina realizan sus viajes de fin de curso en los últimos meses del año y los mismos pueden coincidir con este curso. También han presentado otros motivos por ausencia como tareas propias o externas a la escuela secundaria. Para evitar estos inconvenientes, el coordinador envía esta información en los primeros e-mails solicitando se contacten por motivos de ausencia en el curso y para poder así organizar en conjunto los tiempos de los alumnos.

Todos los e-mails se redactan en la lengua meta: lengua inglesa; únicamente recurrimos a la lengua materna, español, cuando percibimos que tal vez el alumno no posea los recursos lingüísticos suficientes para expresarse en la LE o se sienta cohibido al escribir en otra lengua.

Estos son dos ejemplos de e-mails en los que los alumnos escriben por los motivos de sus ausencias:

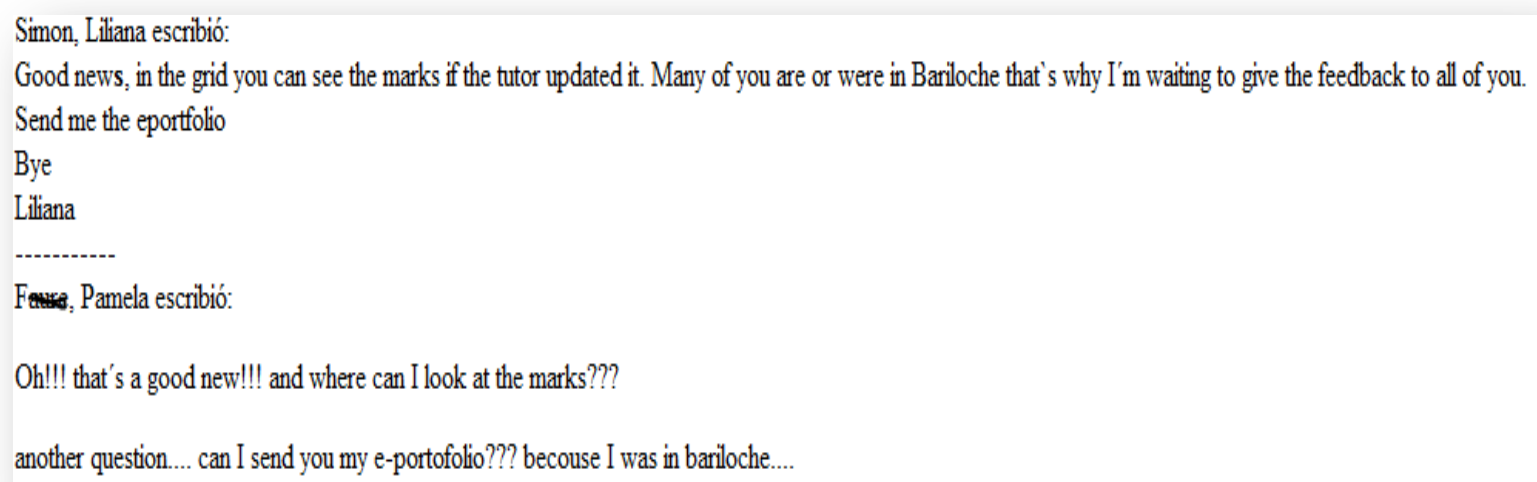

Ejemplo 1 de e-mail sobre tema de ausencia

En el e-mail de la figura 6 el coordinador le informa a los alumnos que en la planilla (de seguimiento) pueden ver sus notas y que además está esperando para enviar los comentarios de los trabajos debido a que otros alumnos también han estado ausentes por 
el mismo motivo Una alumna le responde e informa que estuvo de viaje de fin de curso (en la ciudad de Bariloche). La alumna responde demostrando una emoción probablemente de interés por la noticia la cual se percibe por el uso repetitivo de los símbolos de admiración y exclamación pidiendo ayuda para encontrar las notas en la plataforma; además demuestra interés en cumplir con las tareas al preguntar si todavía puede enviar su portafolio debido a que estaba de viaje.

En el siguiente e-mail (figura 7) podemos observar un e-mail general que la coordinadora envía y un e-mail de respuesta de un alumno. El e-mail que redactó la coordinadora es un e-mail formal escrito con un vocabulario neutral pero afectivo demostrando preocupación por la ausencia de los alumnos en el entorno; además, observamos que se recurrió a la lengua materna para lograr una cercanía mayor. Aclaramos que este e-mail se envió después de otros previamente enviados por el tutor y de los cuales no se habían tenido respuestas. En la respuesta a este e-mail podemos observar que el alumno responde pidiendo disculpas por su ausencia y cuidando los registros de formalidad en la estructura, el vocabulario, la puntuación y estilo del e-mail. Este tipo de líneas de comunicación provocan una presencia social esencial para mantener a los alumnos activos en el curso. En el próximo capítulo desarrollaremos con más detalles la importancia de la presencia social en este tipo de cursos.

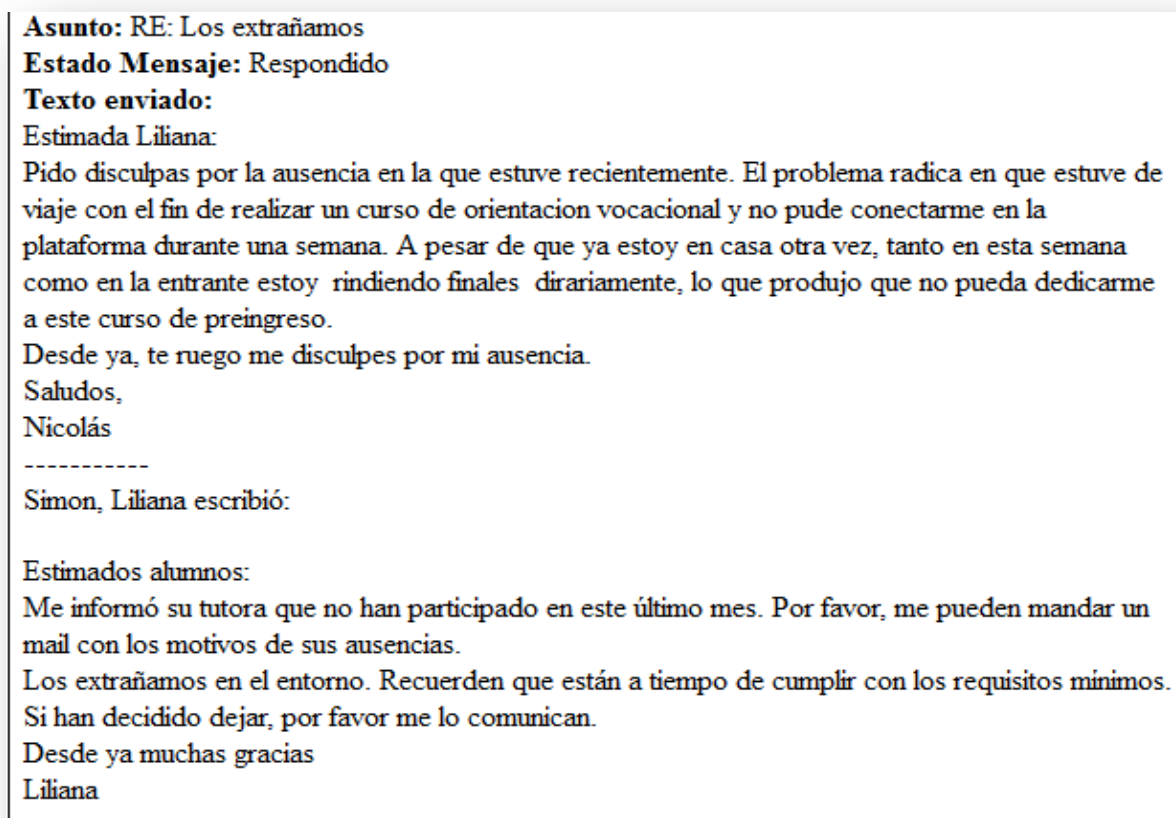




\subsection{Inscripción al curso e-DACTA}

La inscripción durante los primeros años se realizó personalmente y por vía e-mail. Los alumnos llenaban un formulario (Apéndice 4) con sus datos personales y respondían unas preguntas sobre el tipo de conexión de internet que usaría el alumno para realizar el curso (Dial-up/ banda ancha), lugar desde donde se conectaría (hogar/ciber café /escuela/amigo/trabajo, etc.), medio por el cual se informó sobre este curso (diario, radio/ folletos/página web de la FAHCE, escuela, charla, amigo/familia, etc.) y la motivación principal por la cual se inscribe en el curso.

En la siguiente figura 8 se puede apreciar la primera ficha utilizada confeccionada con procesador de texto Word:

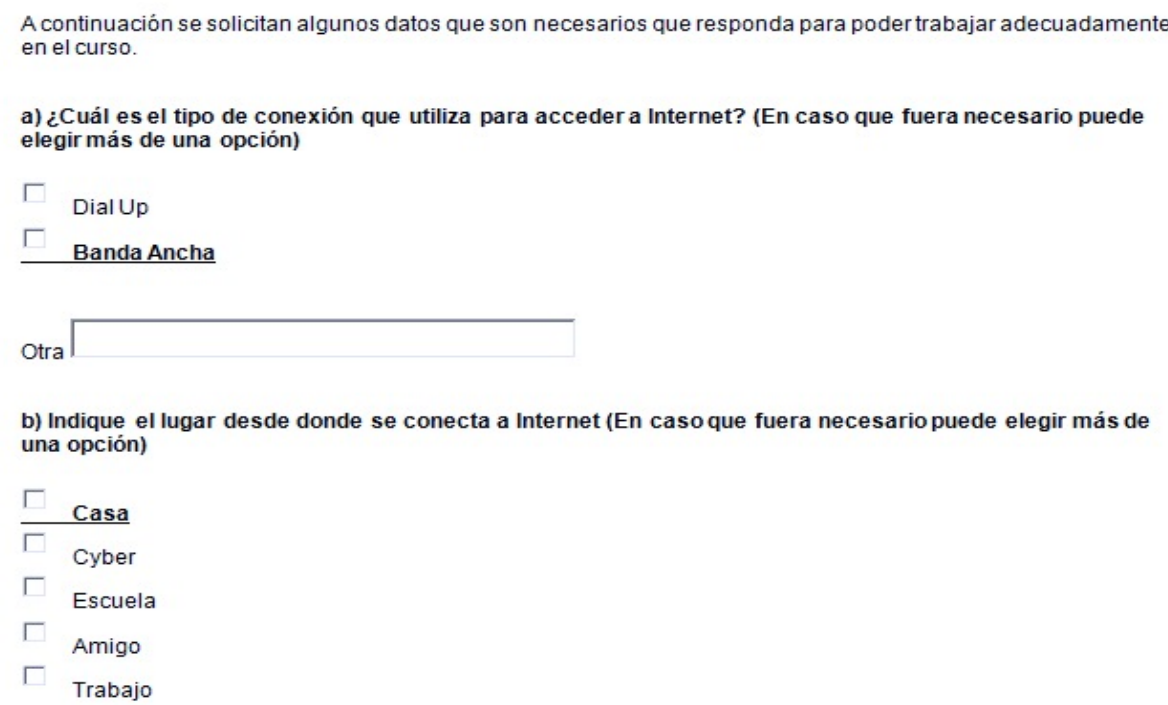

Figura 8

Ejemplo de e-mail de la primera planilla de inscripción

Los datos personales como nombre, apellido, DNI y dirección de e-mail son necesarios para inscribir a los alumnos del curso de pre-ingreso. Una vez finalizado el periodo de inscripción, el coordinador agregaba en una hoja de las planillas del programa Excel estos datos y se los entregaba a la secretaria de la Dirección de Educación a 
Distancia de la UNLP quienes finalizaban la inscripción agregando a los alumnos inscriptos en la nueva aula virtual.

El resto de los datos que arrojaban las respuestas a las preguntas formuladas en la planilla de inscripción recolectaron una información muy substancial, ya que gracias a estos datos comenzábamos a conocer mejor la forma en que los alumnos se conectaban y las posibles variables con las que contábamos en referencia a las conexiones de internet que tenían a su alcance, los lugares donde se conectaban y su motivación por realizar el curso.

A partir del año 2010 las inscripciones comenzaron a hacerse solamente online mediante una herramienta de Google, en ese momento llamada GoogleDocs (ahora Google Drive). Gracias a esta herramienta de Google se creó una planilla online (Apéndices 5 y 6 ) la cual agilizó y optimizó el tiempo del coordinador y mejoró eficazmente la creación de los formularios de inscripción ya el formulario online vuelca los datos en una planilla de hoja de cálculos, muy útil para poder realizar las otras planillas para evaluación. Asimismo, se agregaron más preguntas a las planillas para conocer mejor el perfil del alumno.

\subsection{Diseño y elaboración del curso e-DACTA}

Siguiendo la figura 5 sobre el desarrollo del proyecto, describiremos en los siguientes párrafos el progreso del segundo nivel de la misma: Diseño y elaboración de contenidos.

Una vez seleccionados los docentes para colaborar en el curso con las funciones de expertos en contenidos y de tutores, los mismos iniciaron sus actividades con la búsqueda de un material de lectura atractivo y acorde con el nivel de los futuros participantes; la búsqueda de material partió de una encuesta realizada en las clases prácticas de Lengua Inglesa 1 (una de las primeras materias de las carreras de inglés de la UNLP) para poder saber que temas les atañe a los alumnos con intereses comunes de una misma generación. Se seleccionaron los siguientes tópicos de una lista larga de temas: la familia, la tecnología, la música, los idiomas y los animales. Con los temas seleccionados se inició la búsqueda del material para confeccionar guías de trabajo.

Una vez recopilado los textos de lectura y de escucha, se diseñaron actividades de pre y post lectura en un formato sencillo y accesible mediante el uso del procesador de texto Word. Las tareas de los tutores continuaron en la segunda etapa con las tutorías de 
un grupo de alumnos del curso y en la tercera etapa con la evaluación personalizada de los alumnos de sus grupos.

Las primeras actividades del coordinador en este nivel fue guiar y supervisar la confección del material realizado por los tutores (ver Informe enviado a los tutores sobre tareas a realizar durante la elaboración de materiales: Apéndice 8), luego adaptar todo el material utilizando un software apropiado para el contexto y que fuera amigable con el nuevo entorno.

Los contenidos se plasmaron en una secuencia didáctica con tareas que respondían a un tema como eje principal y unificador; una vez armados con formato de documentos de procesador de textos, la coordinadora se encargó desde el punto de vista pedagógico de revisar y editar y luego digitalizar el material mediante un programa que permitió que el alumno interactúe con el material hipertextual que ofrece una respuesta inmediata (feedback, en inglés) a sus respuestas.

\subsection{Implementación del curso en el Entorno virtual de Enseñanza y}

\section{Aprendizaje}

Los EVEA son espacios mediante sistemas telemáticos que permiten el desarrollo de cursos virtuales con accesos restringidos o no, y que son diseñados para que las personas que accedan a él puedan desarrollar espacios que propicien los procesos de enseñanza y aprendizaje.

En nuestra universidad, UNLP, contamos con plataformas diseñadas por la Facultad de Informática y a las cuales podemos acceder mediante la Dirección de Educación a Distancia que nos ofrecieron una de sus plataformas para desarrollar nuestro proyecto: WebUNLp, https://webunlp.ead.unlp.edu.ar/, en los inicios del proyecto y Aulasweb, https://aulasweb.ead.unlp.edu.ar/, en la actualidad.

\subsubsection{Bienvenida}

La página de inicio del curso es un espacio de Bienvenida y se muestra en ella una carta de bienvenida escrita especialmente para los destinatarios del curso. (Ver figura 9). 


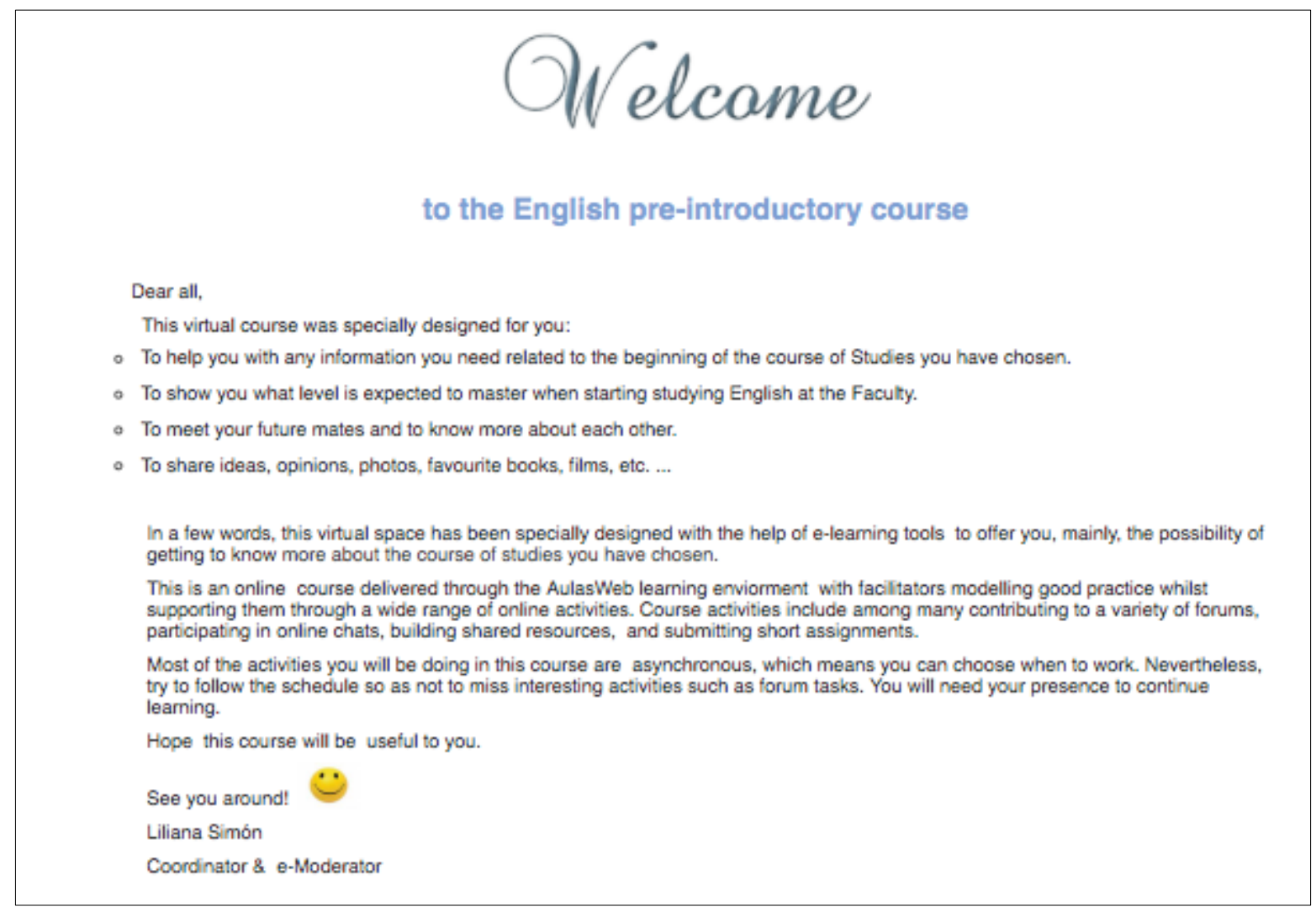

Figura 9

Carta de Bienvenida del e-DACTA

El formato de carta en la presentación del curso logra un acercamiento inicial cordial hacia los alumnos del curso. Se inicia y finaliza con un saludo, se describe en términos generales el curso que van a realizar destacando que fue diseñado especialmente para brindarles información sobre las carreras que han elegido, el nivel requerido para estudiar inglés en las carreras de la FAHCE propiciando la socialización con los futuros compañeros y comenzar a conocerse, para compartir ideas, fotos, libros y películas favoritas, etc. Este curso virtual a través del EVEA Aulasweb permite optimizar las prácticas educativas mediante una variedad de actividades a desarrollarse en línea. Estas actividades implican la contribución en foros, la participación en chats, la entrega de actividades, etc. Aunque la mayoría de estas actividades se realizan de manera asincrónica, se sugiere seguir el calendario para estar al día con todas las actividades pero especialmente las que requieren la presencia coordinada para el trabajo colaborativo.

$\mathrm{Ni}$ bien termina la carta en la página de inicio, los alumnos se encuentran con los primeros pasos a seguir: la primera tarea que consiste en leer un documento que explica detalladamente el curso junto con el cronograma del curso y se los invita a comenzar el curso por la Semana 1 (Week 1, en inglés). El objetivo de esta primera semana es que el 
alumno comience a familiarizarse con el entorno realizando tareas simples de reconocimiento del espacio.

En la misma página de inicio del curso (figura 10) podemos visualizar la barra de navegación que permite cambiar de espacios (llamados temas en los EVEA de Moodle). Cada semana denominadas "Week "se irán visualizando al inicio de la misma hasta llegar a la semana 8.

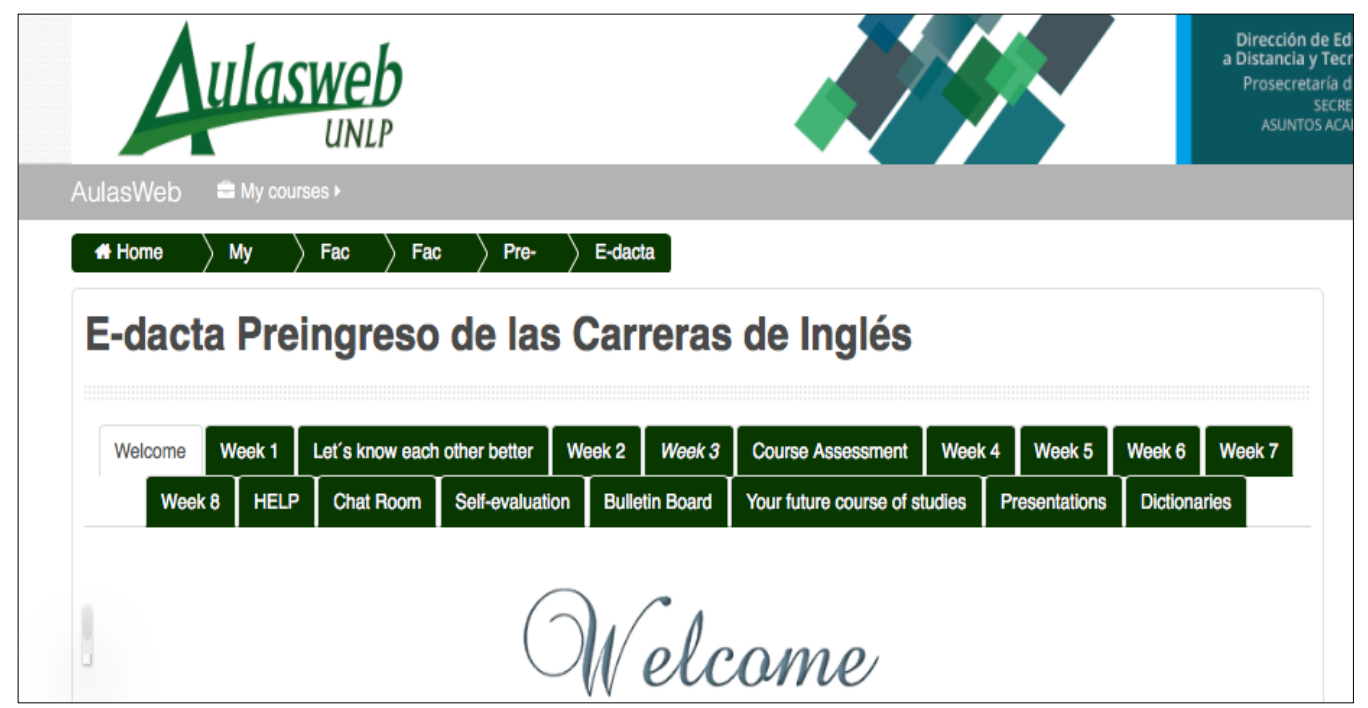

Figura 10

Barra de Navegación del e-DACTA

Cada semana el alumno es guiado en relación a las actividades que debe realizar. Además de los espacios semanales llamados Week (Week 1, Week 2, etc.) existen otros espacios. Ellos son:

- Presentaciones de los alumnos realizados en un PPT de Google Drive

- Informes de tareas realizadas

- Ayuda

- Sala de Chat

- Auto-evaluación del curso

- Boletín de Información General

- Información sobre las carreras

- Diccionarios online 


\subsubsection{Guías Semanales}

EI EVEA Aulasweb permite organizar los contenidos por temas. En vez de armarlo con números como Unidad 1, unidad 2, etc., se decidió organizar el curso por semana junto con la fecha de inicio para poder ubicarlos en los tiempos estipulados y así guiar a los alumnos eficazmente. En la figura 11 podemos ver una captura de pantalla que tomamos como ejemplo para describir una semana del curso. Se presenta la guía de trabajo 1 detallando los tiempos de trabajo en que se inicia la semana y sobre que va a tratar la guía de trabajo, en este caso trata sobre las Familias Modernas. También se les indica en que momento iniciaran el trabajo en los foros. Una vez que hayan trabajado con la guía y foro se les pide a los alumnos que dejen sus comentarios y opiniones sobre el trabajo realizado en la semana en otro foro. Por ejemplo, se les pregunta qué les gustó más del trabajo con las guías, qué aprendieron, etc. Las respuestas dadas por los alumnos hacen que los alumnos reflexionen tomando una postura crítica de sus aprendizajes y a la vez las mismas nos nutren con información muy valiosa para futuros cambios en los contenidos del curso. Al finalizar la página de esta semana se detalla en una lista recordatorios en referencia al tiempo de trabajo de la semana, de contactarse con el tutor ante cualquier duda y del inicio de trabajo en los foros a partir del día jueves de esa semana.

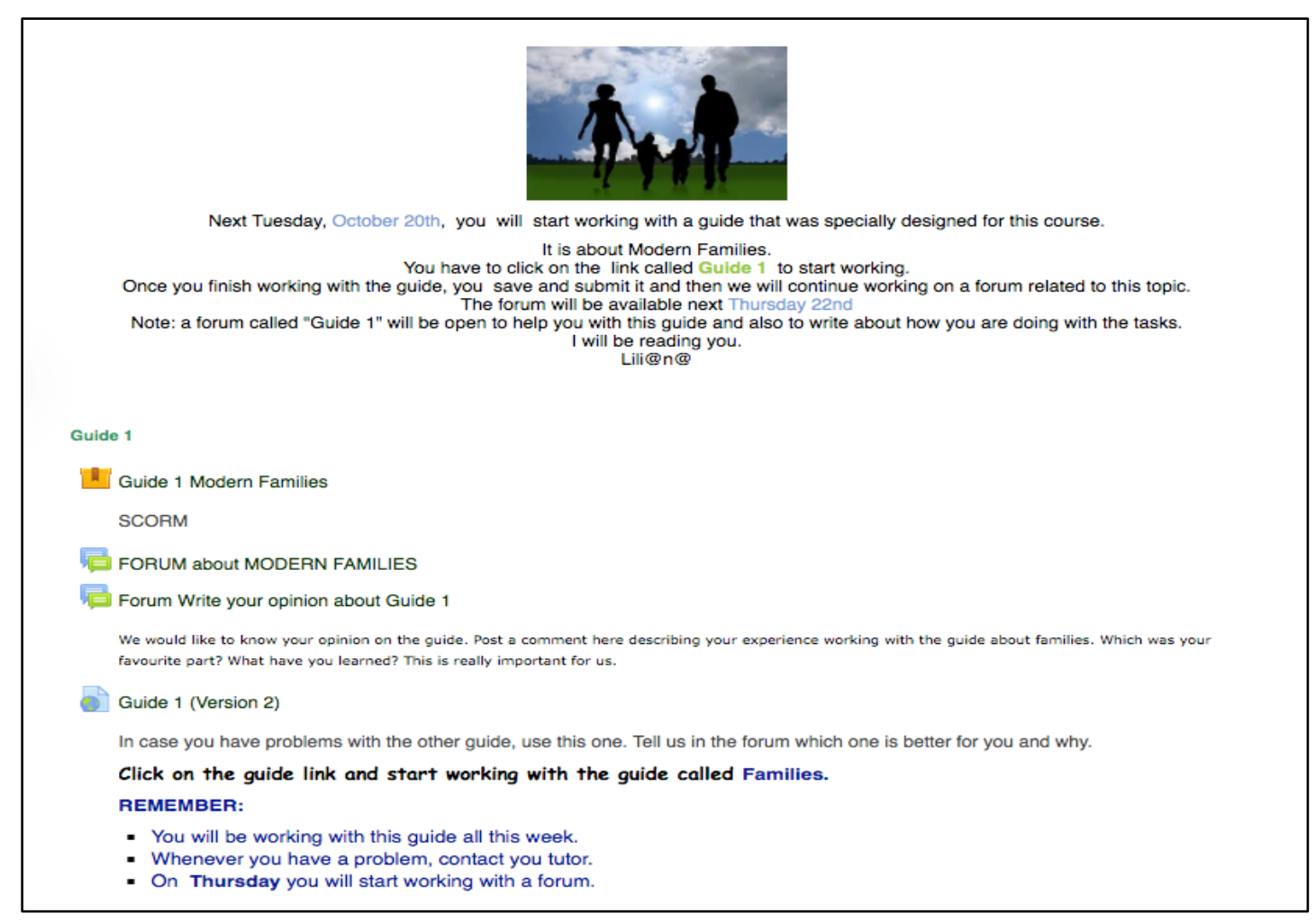

Figura 11

Ejemplo de una página de inicio de una semana en el curso e-DACTA 
La propuesta didáctica de cada guía es acompañar después del trabajo con las mismas con tareas relacionadas de los temas dados en cada foro.

Podemos notar en la figura 12 como se explica en la primera semana del curso una tarea de lectura sobre la participación en los foros (Apéndice 9) relacionadas con las convenciones a seguir al trabajar en los foros llamado en inglés Forum Etiquette y además se proporciona un enlace para realizar la primera encuesta sobre conocimientos tecnologicos del alumno.

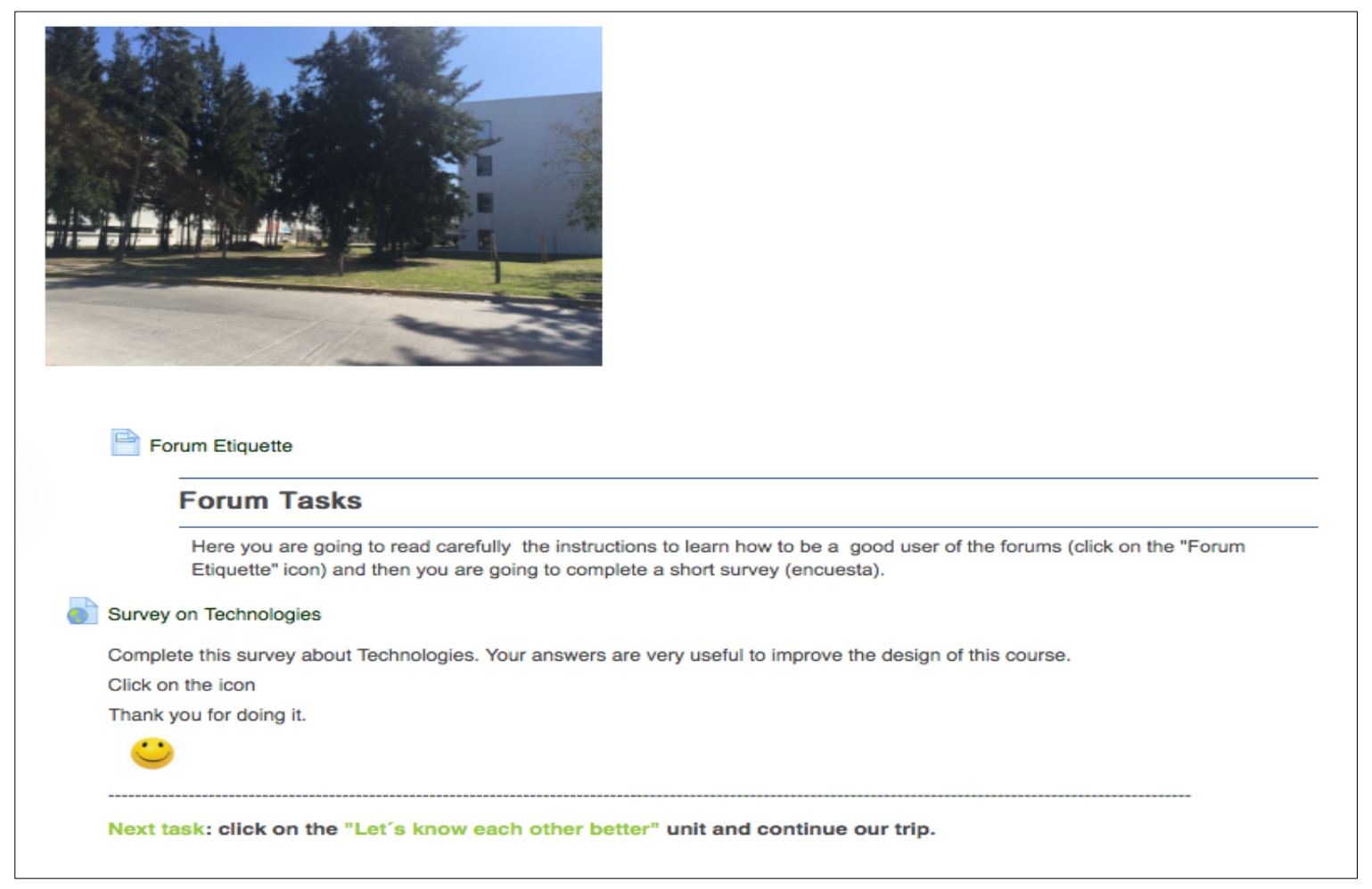

Figura 12

Tareas de la primera semana del curso e-DACTA

Consideramos que es necesario que el alumno comprenda y aprenda a participar de una manera apropiada y respetuosa con sus pares y tutores en la redacción de los e-mails y foros; también destacamos la importancia de seguir las convenciones y consignas en sus aportes en los foros indicándoles a los alumnos que deben respetar el límite de palabras y que las formas lingüísticas y gramaticales utilizadas deben ser adecuadas y apropiadas al contexto académico. El límite de palabras es importante para propiciar un ambiente participativo y ecuánime. 
Las instrucciones del primer foro Welcome to the Course (figura 13) muestran lo expresado en el párrafo anterior. Las instrucciones hacen referencia a realizar una lectura previa de texto sobre las convenciones para trabajar en foros, qué información debe incluir el párrafo junto con el límite de palabras y sugerencias sobre cómo lograr un texto después de editarlo en detalle.

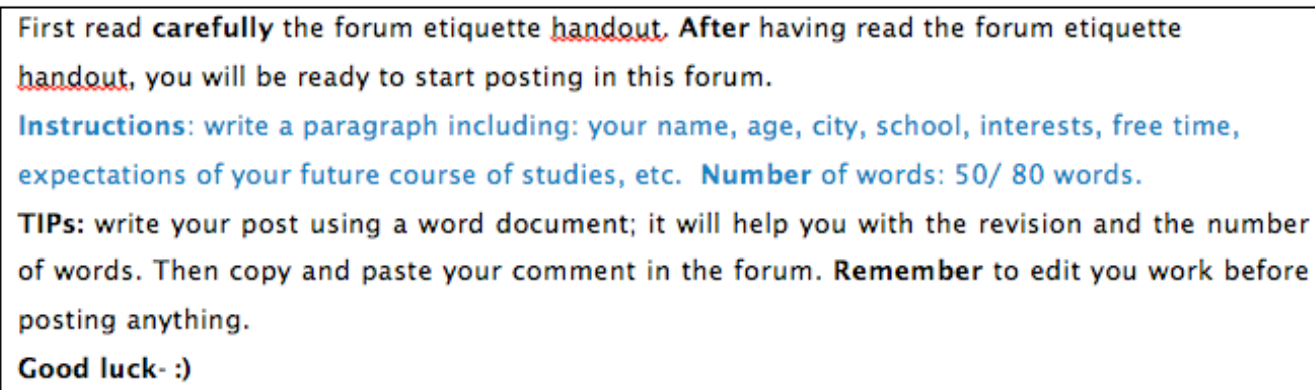

Figura 13

Consigna del primer foro del curso e-DACTA

Los aportes de los alumnos en este foro de 'Bienvenida al Curso' (Apéndice 12) son el primer contacto que los alumnos tienen entre sí, comienzan a conocerse: escriben una corta presentación en la LM. En los ejemplos del apéndice 12 podemos advertir inmediatamente el interés y las expectativas por hacer el curso, para determinar el nivel del inglés, para saber si eligieron bien la carrera, y para contar sobre sus gustos y en qué localidad se encuentran al hacer este curso.

\subsubsection{Diseño de las guías de estudio e-DACTA}

Se digitalizaron 5 guías de estudio intensivo con el software eXeLearning ${ }^{15}$, herramienta de código abierto (en inglés, "open source") que nos permite crear contenidos educativos sin ser experto en HTML o XML. Las guías realizadas con este software propician una interactividad entre el alumno y los contenidos.

Cada guía fue diseñada con un eje temático que provoca una sensación de contextualización en la realización de las variadas actividades. Otra característica de las guías es que el nivel de los textos y las tareas de las mismas están realizados siguiendo

\footnotetext{
15 Sitio web de eXeLearning: http://exelearning.net/
} 


\section{La enseñanza de una lengua extranjera utílizando tecnología dígital}

una secuencia que va ordenada desde ítems gramaticales y vocabulario más sencillo a más complejos.

Como expresamos anteriormente, los temas fueron seleccionados a partir de una encuesta que realizamos con alumnos de las carreras de inglés. Los alumnos de un promedio de 20 años votaron de una lista extensa por los temas que más les interesaban (ver Lista en el Apéndice 8 en el Informe Enviado a los Tutores) quedando seleccionados los siguientes temas:

- Familia

- Tecnología

- Música

- Idiomas

Todas las actividades de cada guía del curso e-DACTA se desplegaron a partir de estos temas. Las guías confeccionadas proporcionan diferentes actividades. Ellas son:

- Lectura de textos o escucha de audios.

- Actividades de pre y post lectura con soporte de audio y/o de video.

- Actividades de completamiento (Fill in the blanks, en inglés).

- Actividades de adquisición de vocabulario.

- Ejercicios gramaticales.

- Revisión de estructuras y vocabulario.

Los alumnos disponen de una semana de práctica en las que pueden autorregular sus propios tiempos para trabajar con cada guía. Aunque el curso favorece la autonomía del alumno creemos que es posible que no todos los alumnos de nivel secundario han desarrollado las habilidades de autorregulación; es por este motivo, que les sugerimos a los alumnos trabajar los primeros días de la semana solamente con las guías para luego dedicar las segunda parte de la semana con las otras actividades. De todas maneras, las guías continúan visibles y a disposición de los alumnos hasta finalizar el curso en caso de necesitar revisar o desear volver a hacer los ejercicios.

Los temas desarrollados en las guías funcionan como un disparador de ideas y opiniones que los alumnos van formando para así luego participar de manera activa y con recursos lingüísticos y gramaticales necesarios para una mejor participación de las 


\section{La enseñanza de una lengua extranjera utilizando tecnología dígital}

siguientes actividades como por ejemplo: participación en foros de discusión, trabajar en actividades que involucran un juego y en la redacción de una anécdota o carta.

Tomaremos como ejemplo la guía de la semana 3. En el Apéndice 10 se pueden ver ejemplos de capturas de pantallas de esta guía. La guía "Música" es la segunda de las guías del curso e-DACTA. ${ }^{16}$

La página comienza con una explicación seguida de un ejercicio de comprensión con respuesta inmediata: la lectura de un texto sobre la historia de Abba (un grupo musical) seguido de un ejercicio de post-lectura de verdadero/falso. Las respuestas al ejercicio son inmediatas, es decir, se obtienen ni bien se hace clic en una respuesta. La siguiente sección está preparada para que los alumnos trabajen con vocabulario extraído de la lectura y consta de tres ejercicios; en la siguiente página hay dos enlaces realizados con dos diccionarios online que seguramente necesitaran para realizar las actividades. En la primera tarea buscan vocabulario y frases que involucran la connotación de la palabra "amor" en el texto de Abba; la segunda tarea consiste en completar con algunas de esas frases o palabras y otras sugeridas y en la tercera tarea trabajan con vocabulario relacionado con la vestimenta que los músicos, bailarines y cantantes usan a partir de una frase dicha por una cantante resaltando la importancia del vestuario para los músicos. En la siguiente sección se trabaja con un texto sobre el cantante Elvis Presley a los que se les ocultaron los tiempos verbales; la actividad consta de completar con el verbo dado la forma correcta de las conjugaciones y tiempos verbales con ayudas para cada uno de los blancos a completar. En la próxima sección de la guía los alumnos trabajan con un video del grupo musical U2; mientras escuchan la canción, ven el video y van completando oraciones con opciones múltiples, de las cuales deben elegir la opción que completa la oración correctamente al comprender la letra de la canción. En la última sección de la guía se trabaja con un formato de escritura que los alumnos necesitan manejar para poder expresar opiniones.

Como ya se mencionó anteriormente, se le sugiere al alumno trabajar con la guía durante la primera mitad de la semana y así poder disponer de los últimos días para participar en el foro o actividad que complementa cada guía semanal. De esta manera se guía al alumno para optimizar sus tiempos y lograr los objetivos semanales.

\footnotetext{
${ }^{16}$ Esta guía se puede visualizar online: http://www.cavila.unlp.edu.ar/fahce/G2/
} 


\subsection{La Comunicación Asincrónica}

\subsubsection{Los Foros en el curso e-DACTA}

Se abren un promedio de 10 foros en cada cohorte. El primer foro en abrirse es el de "Bienvenida al Curso" seguidos en el orden de apertura por el foro de "Ayuda", el foro sobre "Información Perteneciente a las Carreras" y el de "Despedida al curso". Todos estos foros permanecen abiertos durante toda la duración del curso. En cambio, los foros de las guías permanecen ocultas hasta que cada contenido de la semana se hace visible cuando comienza la nueva semana. Cada guía comprende la apertura y el uso de dos foros por cada una, excepto en el caso de la última guía en la que la actividad que la acompaña es una composición de práctica.

Los foros que se complementan con las actividades de las guías son:

\begin{tabular}{|c|c|c|c|}
\hline GUÍAS & $\begin{array}{c}\text { Temas Desarrollados en } \\
\text { los Foros sobre los } \\
\text { Contenidos }\end{array}$ & $\begin{array}{l}\text { Tipo de } \\
\text { Foro }\end{array}$ & Foros de Reflexión \\
\hline $\begin{array}{l}\text { Modern Families } \\
\text { (Familias } \\
\text { Modernas) }\end{array}$ & $\begin{array}{c}\text { Families and Technology } \\
\text { (Las familias y las tecnologías) }\end{array}$ & Opinión & Guía 1 \\
\hline $\begin{array}{l}\text { Music } \\
\text { (Música) }\end{array}$ & $\begin{array}{c}\text { Music Ingredient } \\
\text { (El ingrediente musical) }\end{array}$ & Opinión & Guía 2 \\
\hline $\begin{array}{l}\text { Technology } \\
\text { (Tecnología) }\end{array}$ & $\begin{array}{c}\text { Describing a technological } \\
\text { device } \\
\text { (Descripción de un dispositivo } \\
\text { tecnológico) }\end{array}$ & $\begin{array}{c}\text { Tarea de } \\
\text { Descripción }\end{array}$ & Guía 3 \\
\hline $\begin{array}{l}\text { Languages } \\
\text { (Idiomas) }\end{array}$ & $\begin{array}{l}\text { (no se usa la herramienta de } \\
\text { foros) }\end{array}$ & -- & Guía 4 \\
\hline
\end{tabular}

Tabla 4

Guías y Foros del curso e-DACTA 
La tabla 4 representa la metodología de trabajo del curso que propicia una interactividad entre el material y los alumnos autorregulada por cada alumno durante la primera parte de cada semana, una interacción propuesta por las consignas de cada foro que acompaña la temática de cada guía y por último los foros de reflexión sobre las guías los cuales propician el desarrollo de las habilidades metacognitivas. En la siguiente sección desarrollaremos en más detalle el tema sobre el uso de los e-portfolios del curso e-DACTA y su evolución en el uso de los mismos en este curso en particular, en relación a su formato y dinámica. Los foros que visualizamos en la tabla 5 tienen diferentes funciones.

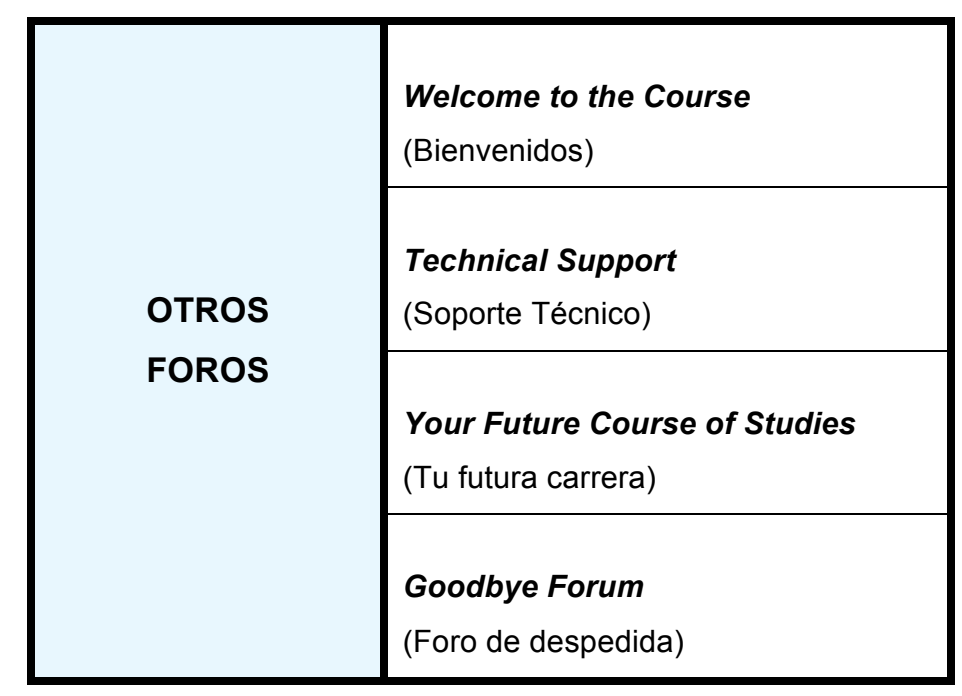

Tabla 5

Otros foros del curso e-DACTA

Welcome to the Course (en español: Bienvenidos al curso) es el foro que les da la bienvenida a todos los alumnos y les pide a los alumnos presentarse ante el resto de sus compañeros del curso. Su existencia es esencial para dar inicio al curso y comenzar a romper el hielo y a interactuar con el entorno y con los compañeros. Lo mismo sucede con el último foro, Goodbye Forum (en español: Foro del Despedida) que se utiliza para cerrar el curso y dar la despedida del mismo.

El foro Technical Support (en español: Soporte Técnico) es también un foro necesario para evacuar dudas sobre el uso del entorno y para poder solucionar problemas con los que se pueden encontrar los alumnos al realizar las tareas durante el curso; este foro se sitúa en el espacio denominado Help (en español, Ayuda). 


\section{La enseñanza de una lengua extranjera utilizando tecnología dígital}

Y, por último, el foro 'Your Future Course of Studies '(en español: Tu futura carrera) es un foro muy interesante desde el punto de vista social ya que en él, los alumnos comparten temas que van desde el interés por la carrera, los libros, el idioma, la nueva institución dónde comenzaran sus estudios al siguiente año, hasta buscar y dar información sobre la ciudad, las distancias entre el centro y la facultad, etc.; notamos que lo encuentran especialmente útil para aquellos que también buscan alojamiento y nuevas amistades.

En la figura 14 el alumno Christian escribe en el foro un aporte sobre su preocupación al no poder encontrar alojamiento en los alrededores de la ciudad de La Plata; titula su aporte con puntos suspensivos seguido de la palabra tristeza, el texto lo inicia con un emoticón que expresa tristeza, dos puntos suspensivos y escribe que no puede encontrar una habitación confortable. En el segundo aporte vuelve a escribir un nuevo pedido sobre el mismo tema. Aunque el texto contiene algunos errores gramaticales, logra comunicarse y vuelve a pedir que le recomienden un lugar para alquilar que sea tranquilo, cómodo y accesible económicamente por los alrededores de la ciudad de La Plata. Además solicita se le informe sobre lugares que no son adecuados para los estudiantes; pide por favor y finaliza diciendo que se siente desesperado.

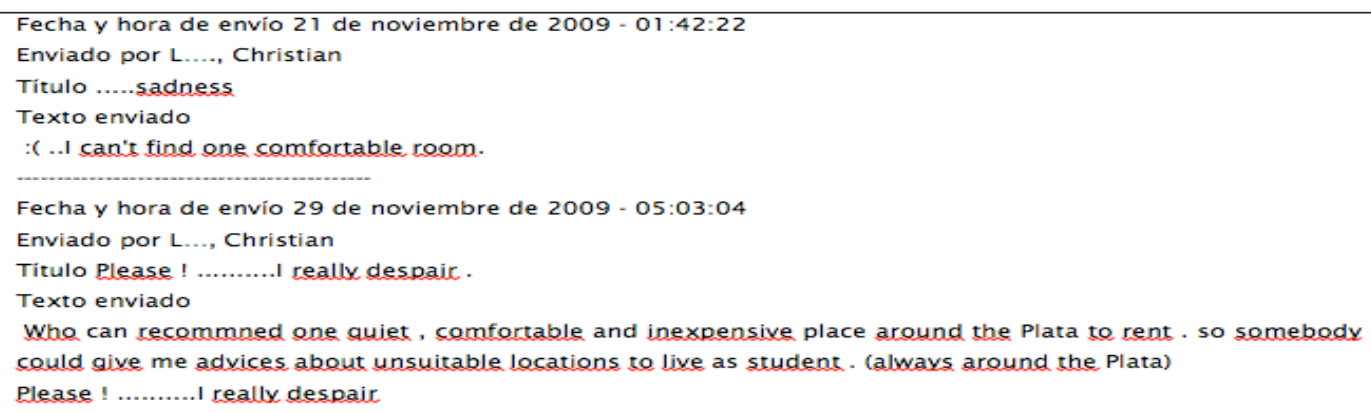

Figura 14

Interacción en el foro "Tu futura Carrera"

En la figura 15 podemos ver como la interacción entre la estudiante avanzada de inglés ${ }^{17}$ y un alumno surge a partir de la motivación del alumno por la necesidad de saber más sobre su futura carrera creando de esta manera un contexto con un objetivo auténtico que impulsa el uso de la lengua meta para obtener información que el alumno requiere.

\footnotetext{
${ }^{17}$ En varias de las cohortes del e-DACTA hemos tenido el privilegio de la asistencia de un alumno avanzado como tutora de el foro "Tu futura carrera" para guiar a los futuros alumnos en temas como en este ejemplo en la figura 15.
} 


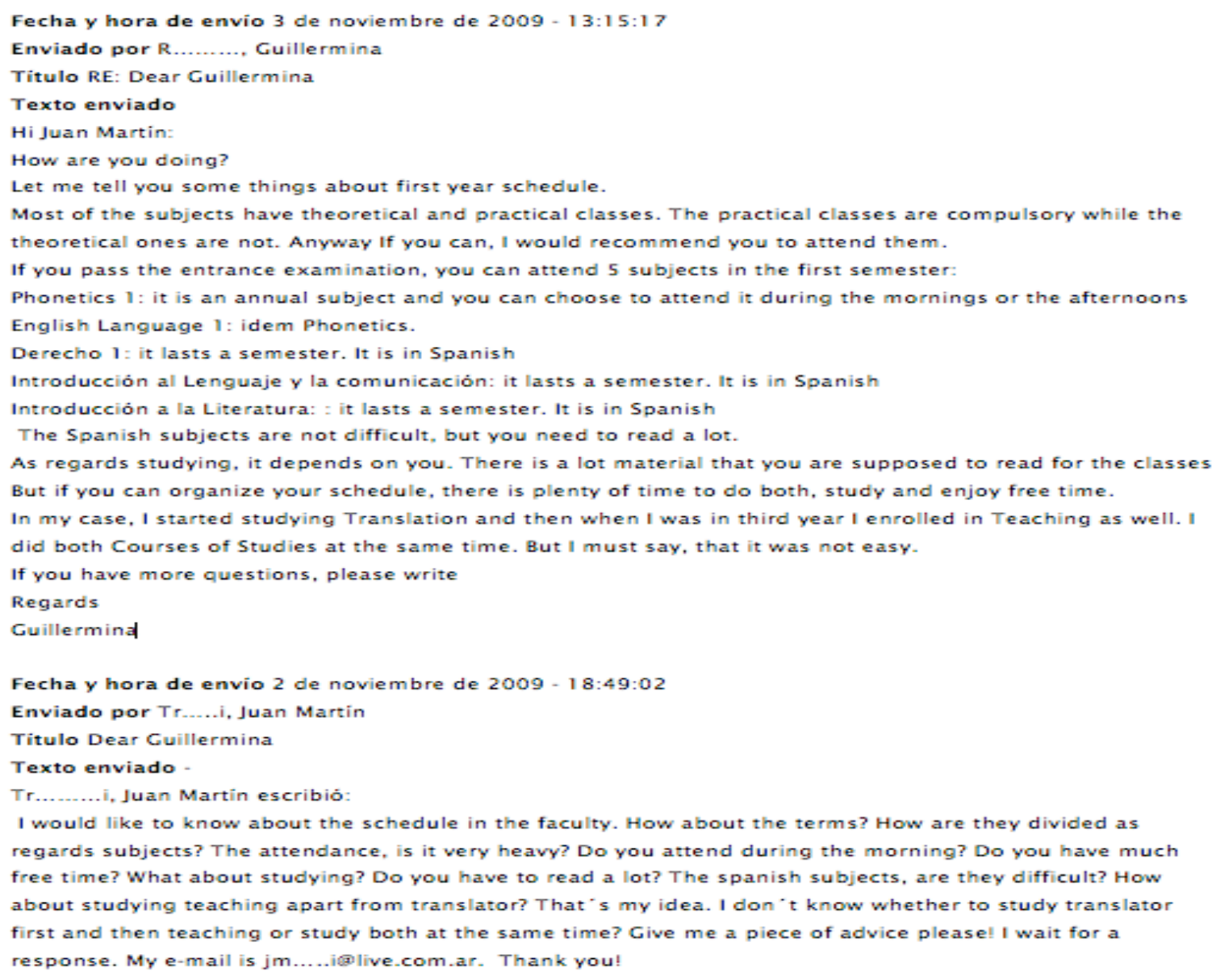

Figura 15

Respuesta de la tutora del curso e-DACTA

Los foros son vehículos de interacción entre los tutores y alumnos. El alumno Juan Martín quiere saber sobre los calendarios, los semestres, la asistencia (si <la carga horaria> es muy pesada), si asisten a clase durante la mañana, si tienen mucho tiempo libre, que hay sobre el estudio, si tienen que leer mucho, si las materias en español son difíciles, y que hay sobre estudiar profesorado además de traductorado, $<$ ya que $>$ esta es su idea. No sabe si estudiar traductorado primero y luego profesorado o estudiar ambas al mismo tiempo, solicita ayuda y queda en espera de respuesta, deja su e-mail y agradece.

La tutora alumna le responde siguiendo las formalidades utilizando un registro neutral que se inicia y finaliza con saludos y que en referencia al contenido, responde a cada una de las preguntas realizadas por Juan Martín de manera clara y amable. 
Al leer los aportes realizados por los alumnos en los foros (ver selección de aportes de un foro en Apéndice 12) distinguimos en ellos las posibles lecturas que se pueden hacer de cada uno dependiendo del lector de los mismos. El aporte en un foro propicia un encuentro entre el escritor y los lectores. Desde el punto de vista social, el lector, que forma parte de una pequeña comunidad que propicia el entorno, provoca en los alumnos una necesidad de responder y colaborar en un juego de interacciones que se va formando en los diferentes hilos de comunicación en cada foro. La perspectiva del lector con rol de tutor va más allá de la simple lectura; no solo se detiene en el contenido de los aportes que un simple lector detecta en la lectura sino en las formas lingüísticas y gramaticales apropiadas, el tutor va más allá porque al mismo tiempo que lee el contenido del aporte va pensando en el andamiaje que va a proveer próximamente al detectar inestabilidades en las formas lingüísticas no apropiadas del lenguaje usado por los alumnos.

En las clases presenciales la interacción entre pares y docente se da tanto en formas escritas como orales y el andamiaje proporcionado también se canaliza mediante las mismas formas escritas $u$ orales, y en general, suceden en el mismo momento en que se producen. En cambio en la virtualidad, y como los alumnos del e-DACTA lo han manifestado en las encuestas finales, después de experimentar con la modalidad a distancia, expresaron que si bien no tuvieron problemas en sus aprendizajes, notaban una desventaja en referencia a la ausencia del contacto físico y/o el contacto visual (en inglés, eye contact) que la modalidad a distancia se evidencia. (Ver comentarios de alumnos en la figura 16)

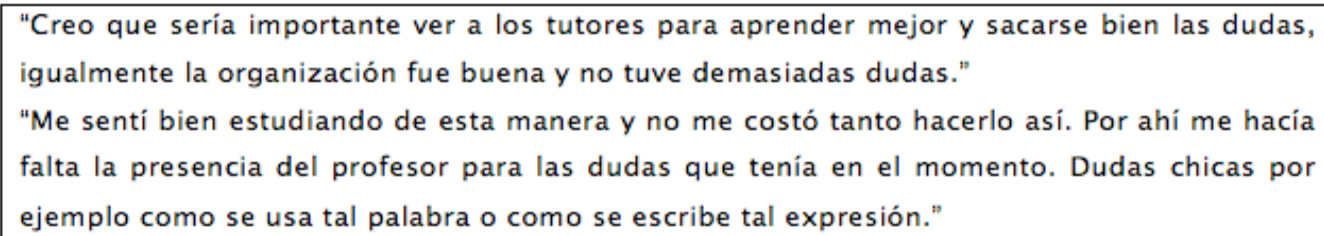

Figura 16

Comentarios extraídos de las Encuestas de la cohorte 2008 del e-DACTA

Podemos deducir al leer los comentarios que la ausencia de contacto físico es más una costumbre que provocan las clases presenciales y/o un sentimiento de extrañamiento que un obstáculo en el proceso de enseñanza y aprendizaje. 


\section{La enseñanza de una lengua extranjera utilizando tecnología dígital}

Resumiendo, podemos decir entonces que los aportes en los foros se caracterizan por su aspecto social que se entrelazan con sus formas lingüísticas y sus contenidos de expresión provocando, en el caso del e-DACTA, un contacto, exposición y supuesto aprendizaje de la lengua meta que es propiciado por la característica del perfil del alumno del curso e-DACTA que tiende a ser autónomo y que autorregula su aprendizaje. Aclaramos que expresamos un "supuesto aprendizaje" porque es difícil comprobar si el alumno de curso e-DACTA está aprendiendo algo nuevo, afianzando conocimientos ya adquiridos o simplemente aplicando conocimiento ya apropiado.

La presencia del tutor en los foros tiene como función principal estimular y provocar en los alumnos el impulso a participar mediante un seguimiento de apoyo ya sea vía mensajería, es decir, mediante e-mails en el caso de una ausencia larga o en el hilo de la conversación de los foros provocando una mayor participación en los mismos y asistiendo y propiciando el buen desarrollo de estas activadas. De esta manera, el alumno orientado y motivado va desarrollando su propio proceso de aprendizaje. Si bien los alumnos reciben emails con anuncios generales en forma regular, también reciben e-mails personales en casos en que necesiten solucionar algún problema tecnológico, de comprensión de contenido o para comunicar algún problema personal que les impide trabajar o continuar con las tareas del curso. Asimismo, debemos destacar que es el tutor quien garantiza la presencia institucional frente a los alumnos en el entorno de enseñanza y aprendizaje; es mediante las tutorías donde el enlace entre docentes y alumnos se plasma. $\mathrm{Y}$, es mediante el espacio de las tutorías donde el proceso de retroalimentación se origina. De ahí la importancia de la actividad continua en estos espacios para que cada alumno llegue hasta el final el curso. El rol del tutor es fundamental proveyendo un andamiaje continuo al participar con una presencia fuerte en el inicio del curso, y luego durante, al contactarse diariamente y cada vez que se lo requiere o considere oportuno aportar en la discusión ya sea para que el hilo de la discusión no se corte como también al iniciar y finalizar cada uno de los foros con conclusiones o resúmenes del mismo.

\subsection{Comunicación Sincrónica}

\subsubsection{Los Chats}

La palabra Chat proviene de la palabra inglesa "conversación": en inglés; sin embargo, un chat no es igual que una conversación cara a cara. En una conversación 
presencial los participantes están físicamente presentes visualizando a sus participantes y observando sus movimientos y gestos que completan el significado de las conversaciones. En un chat los participantes generalmente pueden acceder libremente y a veces hasta una cantidad irrestricta de participantes se involucran en una conversación. Las características sobresalientes del chat sincrónico serían el tiempo real, la velocidad, los intercambios breves, los turnos, el uso de abreviaciones y emoticones, entre otros. La velocidad en un chat provoca muchas veces que los participantes pierdan el hilo por la cantidad de mensajes que se suceden al mismo tiempo en la comunicación entre varios participantes y esto hace que la conversación a veces se torne caótica por momentos. Otra característica sobre los participantes de un chat es que algunos son más activos que otros; también hay participantes que ingresan a la sala de chat y solo leen los aportes o aportan poco a la conversación merodeando o espiando en la conversación (en inglés distinguen a esta actividad con el vocablo lurking). Los intercambios con frecuencia son breves, la longitud promedio va de una a cuatro líneas y casi siempre están compuestos por oraciones incompletas o por pocas palabras o una solo frase y con muchas abreviaturas, emoticones y símbolos. Los turnos se deben respetar para poder tener una conversación coherente pero a veces la demora en la conectividad puede provocar que un participante saltee el suyo.

Muchos investigadores de la ELE como Blake (2000), Lee (2001) y Smith (2003) en Levy \& Stockwell $(2006,89)$ han observado que el chat sincrónico presenta muchas de la características propias de la conversación cara a cara y detalla las siguientes: verificación de comprensión, clarificación de pedidos, revisión de confirmación, uso de la lengua materna, auto-correcciones, creación de palabras, pedidos, uso de aproximaciones y estrategias compensatorias. En nuestro análisis del chat del curso se pueden observar la presencia de la mayoría de estas características.

\subsubsection{El Chat en el curso e-DACTA}

El uso de la herramienta Chat se incorporó en el curso como un recurso de socialización y acercamiento entre pares y docentes. La idea central del uso del lengua a aprender, en nuestro caso inglés, prevalece y hemos propiciado con el uso de esta herramienta tecnológica una mayor exposición en el uso de la lengua extranjera con tareas flexibles y motivantes. 
El tutor propone horarios a partir de la primera semana del curso y una vez seleccionados los horarios, se invitan a los alumnos a asistir a las sesiones de chat en los diferentes horarios programados. Los primeros encuentros intentan romper el hielo y hablar sobre inquietudes que los alumnos tienen de las carreras. También se entremezclan curiosidades por saber de la otra persona, de dónde es, a que escuela va o fue, si trabaja o solo estudia, etc. Los encuentros siguientes se centran en reflexiones sobre lo que han trabajado en la semana, y en charlar sobre algún tema que propone el tutor.

No todos asisten a las sesiones de chat; a veces, no pueden por sus actividades otras veces se olvidan o llegan tarde. De todas maneras, si no pueden asistir a algunas o todas, los chats quedan disponibles para leerlos más tarde o releerlos.

\subsection{Evaluación y seguimiento de los alumnos en los foros y chats}

En referencia a la evaluación y seguimiento de los alumnos del e-DACTA tomamos en cuenta el objetivo general del e- DACTA de guiar y acompañar a los alumnos en los momentos de la toma de decisión de sus futuras carreras y además tenemos presente que se trabaja mayormente con conocimientos ya adquiridos; son entonces estos motivos suficientes para focalizarnos como tutores evaluadores en el concepto de "retroalimentación" de los aportes realizados por los alumnos, más que en la "evaluación del error" como tratamiento final del mismo en las producciones de los alumnos. Es decir, aclaramos que tenemos en todo momento presente los lineamientos del curso e- DACTA que es guiar y no evaluar para adquirir un certificado o pasar de nivel.

Los foros son espacios donde se pondera el contenido del aporte, no corregimos cada error de puntuación, de ortografía, de estilos o gramaticales. Una vez finalizada la semana, en la que los alumnos y tutores interactúan en los foros, los tutores trabajan en el análisis de los foros desde el punto de vista de las producciones lingüísticas que deben seguir las convenciones aceptadas de la lengua para una óptima comunicación teniendo en cuenta que los futuros alumnos serán futuros profesionales de la lengua inglesa. Los tutores escriben un reporte general (Apéndice13) para todos los alumnos en dónde dan explicaciones y ejemplos para trabajar con los errores comunes y recurrentes en sus aportes. En la Cartelera de novedades (en inglés "Bulletin Board") los alumnos pueden descargar el documento (Apéndice 13) que funciona como un andamiaje provisto por los 
tutores y así los alumnos pueden darse cuenta de sus propios errores o de sus compañeros e ir reflexionando sobre el uso de la lengua.

Durante la primera cohorte del curso, 2009, se abrió un foro llamado Language Corner para trabajar sobre los errores que los alumnos cometen en los diferentes foros. El tutor al leer los aportes de los diferentes foros, recolectaba palabras y frases que desde el punto de vista lingüístico y gramatical son inapropiadas y con ellos armaban consignas para que los alumnos en el foro Language Corner reflexionaran sobre los errores en forma conjunta, es decir, los alumnos realizaban tareas de reflexión sobre los errores detectados. Una vez que los temas de corrección habían sido suficientemente discutidos según el criterio de los tutores, se realizaba un resumen para sistematizar los ítems lingüísticos y gramaticales tratados y luego se subía una guía de estudio de estos temas en formato PDF en el área de Trabajo Colaborativo.

En las siguientes cohortes se decidió no usar más el foro Language Corner debido a que algunos alumnos manifestaron que ante la primera respuesta de un alumno ya no tenía sentido repetir el mismo aporte y consideramos que leer repetidas veces las formas no aceptadas podrían confundirlos más. Por lo tanto, se siguió con el tratamiento del error sin utilizar el foro Language Corner y se abrió el un nuevo espacio en el área de Recursos Educativos donde se personalizó una herramienta denominada "Use of English and Vocabulary". De esta manera los alumnos cuentan con un sitio dentro del entorno para poder estudiar temas sobre el uso de la lengua y sus reglas gramaticales.

Además del trabajo en foros y chats, las tareas realizadas por los alumnos son las siguientes:

- Trabajo autónomo con las guías de estudio

- Trabajo colaborativo y de interacción en foros de opinión y tareas de juegos

- Confección de composiciones cortas: anécdotas

- Autoevaluaciones: textos y audios de lectura y de escucha para la comprensión de los mismos

- Tareas de meta-cognición plasmadas en e- portfolios

Aclaramos que no vamos a explayarnos en las tareas relacionadas con las composiciones y con las autoevaluaciones realizadas, debido a que el estudio principal de 
este presente trabajo de tesis son las interacciones del curso e-DACTA que desarrollaremos en detalle en el próximo capítulo.

\subsection{Conclusión}

En este capítulo nos hemos focalizamos en la descripción el curso e-DACTA propiamente dicho que abarca desde la creación, el diseño, la planificación, la ejecución hasta la evaluación. También hemos destacamos la importancia de la presencia social de las comunicaciones sincrónicas y asincrónicas en las interacciones virtuales de manera introductoria para poder desarrollar con mayor profundidad en el próximo capítulo el tema de investigación de nuestra tesis en relación con el curso virtual e-DACTA.

En el siguiente cuadro (tabla 6) podemos representar como la evolución de los proyectos de apoyo al ingreso de las carreras de inglés mejoran en la creación de un espacio de mayor interacción facilitado por las TIC.

\begin{tabular}{|c|c|c|}
\hline PROYECTO & DACTA & E-DACTA \\
\hline Difusión e inscripción & $\begin{array}{l}\text { No posee inscripción. } \\
\text { Los alumnos adquieren el ejemplar } \\
\text { al inscribirse. }\end{array}$ & $\begin{array}{l}\text { Difusión e inscripción que se inició } \\
\text { principalmente vía e-mail y luego online: } \\
\text { páginas web, redes sociales, etc. }\end{array}$ \\
\hline Materiales de estudio & $\begin{array}{l}\text { Soporte textual con formato de libro } \\
\text { de autoevaluación (respuestas } \\
\text { incluidas) }\end{array}$ & $\begin{array}{l}\text { Curso con soporte virtual con guías de } \\
\text { estudios digitalizadas y tareas mediadas } \\
\text { por herramientas tecnológicas: foros, } \\
\text { procesador de textos, chats, etc. }\end{array}$ \\
\hline Tutorías & $\begin{array}{l}\text { Virtuales (teléfono, fax, e-mails) y } \\
\text { presenciales con poca asistencia y } \\
\text { participación de los alumnos. }\end{array}$ & $\begin{array}{l}\text { Solamente virtuales; las mismas } \\
\text { propiciaron una mayor presencia e } \\
\text { interacción comunicativa social y } \\
\text { pedagógica. }\end{array}$ \\
\hline Evaluación & Autoevaluación & $\begin{array}{l}\text { Autoevaluación, evaluación grupal y } \\
\text { personalizada }\end{array}$ \\
\hline Interacción & $\begin{array}{l}\text { Solo entre docentes y alumnos que } \\
\text { asistieron a las consultas de } \\
\text { tutorías. Poca interacción. }\end{array}$ & $\begin{array}{l}\text { Entre docentes y alumnos y entre } \\
\text { alumnos. Incremento notable de } \\
\text { interacción. }\end{array}$ \\
\hline
\end{tabular}

Tabla 6

Cuadro comparativo de los proyectos DACTA y e-DACTA 


\section{Capítulo 4}

\section{Presentacion de resultados: Las interacciones en un EVEA}

\subsection{Introducción}

En este capítulo retomamos nuestro tema de investigación, las interacciones en un EVEA, que ya presentamos de manera introductoria en el capítulo 1, Sección 1.5. En el presente capitulo analizaremos las mismas desde la importancia de la presencia social en las interacciones tomando como punto de partida la clasificación que realizaron Garrison y Anderson (2005) al observar las interacciones en contextos similares a los nuestros. Analizaremos muestras del corpus de chats y foros de la cohorte 2013 del e-DACTA con los indicadores de la presencia social observados por Garrison y Anderson. Además, agregaremos a nuestro análisis otros elementos que se evidencian en la interacción que tanto Levy \& Stockwell $(2006,89)$ como otros autores, entre ellos Tarone (1981), han estudiado y clasificado como elementos que se encuentran presentes en las interacciones.

\subsection{La Interacción en el e-DACTA}

"Es a través de la comunicación que la gente envía y recibe

El alumno se vuelve visible en la interacción y es justamente en la visibilidad donde podemos analizar las interacciones. Nos podríamos preguntar porque el alumno de nuestro curso se comunica. $\mathrm{Y}$, podríamos responder desde nuestra experiencia que se comunica porque necesita interactuar con sus pares y tutores por diferentes razones: para poder resolver una tarea, para aclarar dudas, para aprender una lengua, para saber más sobre su futura carrera, para conocer a su/s compañero/s o tutor/es, o simplemente para socializar.

\footnotetext{
18 "It is through communication that people send and receive messages effectively and negotiate meaning." (Rubin \& Thompson, 1994: 30).
} 
La interacción entre el contenido de las guías del e-DACTA y los alumnos funciona como andamiaje en la conversación didáctica creada con el estilo del autor que la elaboró para acercarse al alumno que se encuentra en su soledad leyendo el material provisto. La interacción entre alumno y contenido, llamada interactividad, va más allá de lo concerniente a lo navegación y direccional; implica una conversación didáctica guiada (Holmberg, 1983 en Shearer, 2012).

En el caso del curso e-DACTA las guías fueron escritas y desarrolladas por profesores de lengua inglesa que a su vez son profesores universitarios del curso de ingreso y de los primeros años de los cursos de inglés de la FAHCE-UNLP; este dato es importante destacar debido a que los docentes conocen no sólo nivel de conocimientos esperado por los futuros alumnos y el material necesario para este nivel sino el perfil del alumno de los primeros años de las carreras de inglés en el contexto de las prácticas educativas propiciadas en la Facultad de Humanidades y Ciencias de la Educación de la Universidad Nacional de la Plata.

Otro dato interesante en relación a la importancia de este diálogo didáctico es el observado por Saba (en Shearer, 2012) quien dice que la distancia transaccional se reduce al incrementar el diálogo. De ahí, la importancia en este estudio de facilitar diferentes formas de interacción en los EVEA para reducir esa separación entre el alumno y el tutor. Cuando el alumno lee y realiza las tareas provistas por las guías del curso, las tareas propuestas provocan una interacción entre el texto, las actividades y el alumno. Esta interactividad no es visible. Al igual que el trabajo en las clases presenciales, existe un momento de estudio en que el alumno trabaja con el material y que no sabemos si está aprendiendo hasta que tengamos alguna evidencia en sus producciones.

En el curso e-DACTA los alumnos son invitados a realizar tareas semanales en un tiempo específico para continuar con otras tareas que implican un compromiso en la lectura y el trabajo de las guías para luego realizar las tareas que se desprenden de ellas, es decir, es necesario que el alumno realice las tareas de las guías para así poder entrar en tema, recordar y/o incorporar y luego aplicar el vocabulario ejercitado, expresiones idiomáticas, ítems gramaticales, etc. Es así que la invisibilidad del trabajo con las guías se vuelven más permeable al pedirles a los alumnos una activa participación en los diferentes foros y chats. Pero esto no solo se da en los foros que se desprenden de las guías de trabajo, lo podemos evidenciar también en los foros donde los alumnos dejan sus reflexiones metacognitivas, en las tareas de autoevaluación sobre las actividades realizadas y en los foros donde 
comparten otros temas como preguntas sobre la nueva carrera o la nueva ciudad para aquellos alumnos que se mudarán pronto a nuestra ciudad (La Plata, Provincia de Buenos Aires, Argentina) en donde comenzarán en un futuro cercano la carrera universitaria de inglés.

\subsection{La presencia social a través de la interacción}

Garrison y Anderson (2005) observaron la presencia social y la clasificaron en tres grupos:

- Afectivo: expresión de emociones, recurrir al humor y expresarse abiertamente.

- Comunicación Abierta: seguir el hilo, citar los mensajes de otros, referirse explícitamente a los mensajes de otros, hacer preguntas, expresar aprecio, y expresar acuerdos.

- Cohesión: Vocativos, dirigirse a referirse al grupo usando pronombres inclusivos, elementos fáticos, saludos.

Blake (2000), Lee (2001) y Smith (2003) en Levy \& Stockwell $(2006,89)$ han observado que el chat sincrónico presenta muchas de la características propias de la conversación cara a cara y detalla las siguientes: verificación de comprensión, clarificación de pedidos, revisión de confirmación, uso de la lengua materna, auto-correcciones, creación de palabras, pedidos, uso de aproximaciones y estrategias compensatorias.

Decidimos tomar no solo los indicadores de presencia social que Garrison y Anderson distinguen, sino también incorporar a nuestro estudio otros elementos y estrategias de aprendizaje que encontraremos en el análisis de las interacciones adaptando los elementos estudiados por Levy \& Stockwell (2006) y Tarone (1981) en Armendariz y Ruiz (2005) y motivados por la posibilidad que tendremos de comprender mejor el uso de una LE en las interacciones producidas en el contexto propiciado por el EVEA. Esta decisión propone complementar el estudio de la presencia social junto con las estrategias de aprendizaje que surgen en los procesos de enseñanza y de aprendizaje de una LE. 
Las tabla 7 y 8 presentan los diferentes indicadores de presencia social y otros elementos y estrategias de aprendizaje junto con sus definiciones:

\begin{tabular}{|c|c|c|}
\hline \multicolumn{2}{|c|}{$\begin{array}{l}\text { INDICADORES PRESENCIA } \\
\text { SOCIAL } \\
\text { GARRISON \& ANDERSON (2005) }\end{array}$} & DEFINICIÓN \\
\hline \multirow{3}{*}{ Afecto } & Expresar emociones & $\begin{array}{l}\text { Expresiones convencionales o no convencionales que } \\
\text { manifiestan una emoción. (Ej.: Puntuación repetitiva, } \\
\text { proliferación de mayúsculas, emoticones) }\end{array}$ \\
\hline & Recurrir al humor & Bromas, ironías, medias palabras, sarcasmo \\
\hline & Expresarse abiertamente & $\begin{array}{l}\text { Presenta detalles de la vida fuera de la clase o expresa } \\
\text { vulnerabilidad. }\end{array}$ \\
\hline \multirow{6}{*}{$\begin{array}{l}\text { Comunicación } \\
\text { Abierta }\end{array}$} & Seguir el hilo & $\begin{array}{l}\text { Emplear el signo de respuesta en vez de iniciar nuevo hilo } \\
\text { de comunicación. }\end{array}$ \\
\hline & Citar mensajes de otro & $\begin{array}{l}\text { Emplear los recursos del software para citar los mensajes } \\
\text { completos de otros o cortar y pegar fragmentos de otros } \\
\text { mensajes. }\end{array}$ \\
\hline & $\begin{array}{l}\text { Referirse explícitamente a } \\
\text { los mensajes de otros }\end{array}$ & Hacer referencia a los contenidos de otros mensajes. \\
\hline & Hacer preguntas & $\begin{array}{l}\text { Los estudiantes hacen preguntas de otros estudiantes o del } \\
\text { moderador. }\end{array}$ \\
\hline & Expresar aprecio & $\begin{array}{l}\text { Felicitar a los demás (hacer cumplidos) por el contenido de } \\
\text { sus mensajes. }\end{array}$ \\
\hline & Expresar acuerdos & $\begin{array}{l}\text { Expresar acuerdo con otros o con el contenido de sus } \\
\text { mensajes. }\end{array}$ \\
\hline \multirow{3}{*}{ Cohesión } & Usar vocativos & Dirigirse por referirse a los participantes por sus nombres. \\
\hline & $\begin{array}{l}\text { Dirigirse o referirse al grupo } \\
\text { usando pronombres } \\
\text { inclusivos }\end{array}$ & Dirigirse hay grupo como "nosotros", "nuestro grupo" \\
\hline & Saludar & $\begin{array}{l}\text { Comunicación que desempeña meramente una función } \\
\text { social; saludos, despedidas. }\end{array}$ \\
\hline
\end{tabular}




\begin{tabular}{|c|c|c|}
\hline \multicolumn{2}{|c|}{$\begin{array}{l}\text { OTROS ELEMENTOS PRESENTES } \\
\text { EN LAS INTERACCIONES }\end{array}$} & DEFINICIÓN \\
\hline \multicolumn{2}{|c|}{$\begin{array}{l}\text { Verificación / Confirmación de } \\
\text { comprensión }\end{array}$} & El alumno verifica/confirma la comprensión. \\
\hline \multicolumn{2}{|c|}{$\begin{array}{l}\text { Búsqueda de ayuda para realizar una } \\
\text { tarea }\end{array}$} & $\begin{array}{l}\text { El alumno pide ayuda para realizar una tarea o para pedir un } \\
\text { término correcto. }\end{array}$ \\
\hline \multicolumn{2}{|c|}{$\begin{array}{l}\text { Uso de la lengua materna } \\
\text { (Cambio de Código) }\end{array}$} & $\begin{array}{l}\text { El alumno cambia de lengua. Por lo general pasa de la lengua } \\
\text { meta a la materna. }\end{array}$ \\
\hline \multicolumn{2}{|c|}{ Auto-correcciones } & El alumno se autocorrige ante un error. \\
\hline \multicolumn{2}{|c|}{ Estrategias compensatorias } & $\begin{array}{l}\text { El alumno realiza simplificaciones o reducciones en su } \\
\text { producción lingüísticas debido a la falta de recursos } \\
\text { lingüísticos. }\end{array}$ \\
\hline \multicolumn{2}{|c|}{ Uso de emoticones } & $\begin{array}{l}\text { Curso de caritas emotivas que ofrece la herramienta } \\
\text { tecnológica o caritas realizadas con símbolos. }\end{array}$ \\
\hline \multicolumn{2}{|c|}{ Uso de abreviaciones } & Abreviaciones típicas que se utilizan comúnmente en un chat. \\
\hline \multicolumn{2}{|c|}{ Pedidos de aclaraciones } & Si el alumno no comprende, pide una aclaración. \\
\hline \multirow{3}{*}{ Paráfrasis } & $\begin{array}{l}\text { Creación de } \\
\text { palabras }\end{array}$ & $\begin{array}{l}\text { El alumno utiliza conscientemente estructuras lexicales } \\
\text { incorrectas que poseen rasgos semánticos compartidos de las } \\
\text { dos lenguas. }\end{array}$ \\
\hline & Circunlocución & $\begin{array}{l}\text { El alumno recurre a la descripción de las características de los } \\
\text { elementos del objeto o de la acción al desconocer o no } \\
\text { recordar la palabra. }\end{array}$ \\
\hline & $\begin{array}{l}\text { Uso de } \\
\text { aproximaciones }\end{array}$ & El alumno inventa palabras. \\
\hline
\end{tabular}

Tabla 8

Otros Elementos y Estrategias de Aprendizaje (Adaptación de Levy \& Stockwell (2006) y Tarone (1981) en Armendariz y Ruiz (2005) 
Los indicadores de presencia social descriptos por Garrison \& Anderson (2005) se enfocan en las interacciones producidas en los foros virtuales por lo tanto debemos aclarar que los tres primeros indicadores ( 'seguir el hilo', 'citar mensajes anteriores' y 'referirse explícitamente a los mensajes de otros') en el grupo de indicadores de la comunicación abierta, no los tendremos en cuenta para observar las interacciones del chat pero si los dispondremos para analizar los foros. Con respecto al indicador 'seguir el hilo', podemos observar que en los chats todo el tiempo los alumnos siguen el hilo de la conversación y aun cuando se agregan alumnos al chat retoman el hilo sin inconvenientes. Es por esta razón que consideramos que no es necesario contabilizar este elemento en las interacciones del chat.

Los instrumentos de recogida de información que vamos a analizar en este capítulo son los siguientes:

\section{- Comunicaciones sincrónicas}

Se seleccionaron dos chats (Apéndice 11) generados dentro del curso de e-DACTA. Estos chats se realizaron con la herramienta Chat del EVEA WebUNLP de la cohorte eDACTA 2013. El chat 1 se generó de manera espontánea entre los alumnos debido a un inconveniente tecnológico que se originó en un momento en la herramienta de chat. Se tomó la muestra de este chat debido a la riqueza de las interacciones y además porque que se extendió en el tiempo por casi un día entero, con una sola interrupción de nueve horas entre alumnos del curso que desarrollaron una diálogo que se extiende a lo largo de todo el chat con un objetivo que propusieron los mismos alumnos al encontrarse con un problema tecnológico en la comunicación que estaban utilizando. Si bien hablan de varios temas es interesante observar que siempre vuelven al hilo de la conversación con el afán de cumplir con el objetivo principal propuesto por ellos mismos. El segundo chat seleccionado (Chat 2) se realiza con el coordinador con rol de tutor y los objetivos del encuentro eran varios: sociabilizar con los integrantes del curso, hacerlos sentir parte de un grupo, introducir a los alumnos en temas relacionados con el ámbito universitario que es desconocido para la mayoría y sin dejar de lado uno de los objetivos más importantes que es propiciar el uso de la lengua meta. 


\section{- Comunicaciones asincrónicas}

El entorno EVEA propició las comunicaciones asincrónicas gracias a diferentes herramientas que ofrece el entorno virtual: mensajería, foros y pizarra de comunicaciones. Tomaremos los aportes en los foros para evaluar la presencia social en los mismos. Los foros han sido una de las herramientas que más se han utilizado desde su aparición y que continúan siendo aún vigentes propiciando una comunicación (CMCL) que provee las condiciones necesarias como andamiaje de un aprendizaje cuyo objetivo es la adquisición de la lengua meta.(Lamy \& Hampel (2006:107)). Otra ventaja que Lamy \& Hampel (2006: 111) destacan es la naturaleza asincrónica de este medio que intensifica las estrategias de aprendizaje de aquellos alumnos más reservados ya que este medio les permite trabajar con más tiempo y posibilidades de edición antes de enviar el aporte.

\subsection{Corpus}

El análisis de nuestro corpus fue extraído de dos chats y dos foros de la cohorte 2013. Estos números que recogimos en la siguiente tabla (tabla 9) son importantes para determinar la interacción en el curso.

\begin{tabular}{|c|c|}
\hline \multicolumn{1}{|c|}{$\begin{array}{c}\text { Alumnos de la Cohorte } \\
\text { e-DACTA 2013 }\end{array}$} & $\begin{array}{c}\text { Cantidad } \\
\text { Alumnos }\end{array}$ \\
\hline Inscriptos ante la solicitud de inscripción al curso & 84 \\
\hline Ingresaron al EVEA al solicitar inscripción al EVEA & 65 \\
\hline Nunca ingresaron después de solicitar inscripción al EVEA & 5 \\
\hline Alumnos activos desde inicio al final & 36 \\
\hline Cumplieron con las expectativas mínimas de logro & \\
\hline
\end{tabular}

Tabla 9

Datos sobre la actividad de los alumnos 
Otro dato interesante de esta cohorte fue que del total de 36 alumnos, 5 alumnos fueron los que más participaron en la mayoría de las actividades y los que más cantidad de acceso al EVEA realizaron (entre 100 a 324 accesos en total). También pudimos evidenciar que estos 5 alumnos con alto porcentaje de actividad y cumplimiento de tareas son los que realizaron el curso con éxito. Podríamos entonces deducir a partir de estos datos que el compromiso y la dedicación de estos alumnos hicieron que lograran alcanzar los objetivos del curso con éxito.

\subsection{Análisis de los chats}

\subsubsection{Chat 1}

La característica distintiva de este chat (Apéndice 11) es que se desarrolló de una manera espontanea, es decir, no había sido programado por ninguno de los participantes y se llevó a cabo sin la presencia de tutores. Los alumnos entraban y salían del salón del chat tal vez por curiosidad y/o para poder chatear con un compañero. Todo el chat ronda en una tarea principal auto-impuesta por los mismos alumnos y otras conversaciones de sociabilización que detallaremos más adelante. La tarea surgió ante un inconveniente técnico con la herramienta del chat del EVEA con el que se encontraron los alumnos al querer hacer uso del mismo; por lo tanto, los alumnos decidieron abrir un grupo en la red social Facebook para poder comunicarse con más fluidez y de una manera más privada que el chat del entorno, ya que los tutores no estarían presenciando sus comunicaciones.

Es muy interesante observar y resaltar que, aún sin la presencia de los tutores, toda la conversación se realizó en la lengua meta, inglés. Solamente recurrieron a la lengua materna al no poder encontrar la palabra apropiada en la lengua meta, y luego continuaron con la conversación retomando la lengua meta con naturalidad.

Hay varios momentos en que se expresaron abiertamente: ante la necesidad de armar un grupo de Facebook, al preguntarse de dónde eran, al interrumpir un alumno en la conversación para aclarar que su nivel era básico, al preguntarse que habían hecho la noche anterior, al describir el proceso de armado de grupo en Facebook y la ultima parte del chat con el encuentro de un nuevo alumno que se presentó y lo invitaron a unirse al grupo de Facebook.

De los de 13 alumnos que se unen al chat 1 podemos decir que, según el nivel de 
participación, cinco alumnos participaron activamente, seis se unieron al chat pero no participaron y dos ingresaron y abandonaron. La presencia afectiva es muy importante en este chat. Se visualizan 59 presencias de afecto, 51 presencias con expresiones de emociones: mayúsculas, repetición de letras y emoticones; y se observa también la presencia del humor en tres oportunidades. Es apreciable observar cómo los alumnos siguen el hilo de la conversación a lo largo de todo el extenso chat que se inició el 23/09/13 a las 23:50 y finalizó el 24/09/13 a las 22:37. (Ver Apéndice 11)

Hubo un lapso sin actividad por 9 horas aproximadamente durante la noche y la mañana, aun así el hilo de la conversación se retomó con los mismos temas en forma coherente y continua. Es interesante observar un momento del chat donde la tarea es interrumpida por un alumno que pide disculpas por su nivel de inglés y como sus pares reaccionan de forma afectiva, un alumno decide integrar al compañero en la conversación haciéndole preguntas sencillas, el otro compañero continúa con el hilo de la primera conversación, pero al darse cuenta del nuevo aporte del nuevo compañero, demuestra afecto y le dice que no se preocupe porque todos están aprendiendo. Mientras suceden estos intercambios, continúan solicitando amistad en el grupo de Facebook. Es interesante ver como siempre vuelven a su tarea auto-impuesta (armado del grupo de Facebook) aunque se agreguen nuevos integrantes y hablen de otros temas en forma simultánea.

Los temas que rondan alrededor de la tarea de armado del grupo de Facebook se relacionan con preguntas sobre su primer nombre (ya que el apodo del alumno en el chat solo aporta el apellido del alumno), de dónde son, qué orientación van a estudiar, el nivel de inglés que creen tener, qué están haciendo en ese momento, qué hicieron la noche anterior, se comparan las edades, hablan de un embarazo de una alumna, y se emocionan, la felicitan y se preguntan si será varón o mujer, también manifiestan al encontrarse en Facebook que descubrieron tener amigos en común y se preguntan por estas amistades.

Se realizaron 18 preguntas, dos de las cuales son incorrectas gramaticalmente pero aún así logran la comunicación. Todas las preguntas finalizan con signos de interrogación excepto las dos mal formada, el resto de los aportes carecen de signo de finalización de la oración. Los errores gramaticales más comunes son de puntuación, de ortografía, tiempos verbales incorrectos, falta de vocabulario y estructuras mal formadas. Las oraciones nunca tienen punto final y el uso de minúsculas es constante. Estas dos últimas formas de puntuación serian consideradas inapropiadas en un contexto formal; sin embargo, este uso informal de la lengua es una de las características que distinguen al chat 
de otros géneros, y por lo tanto forman parte de las convenciones aceptadas y distintivas de las conversaciones de chat; también se incluyen en esta clasificación de convenciones propias del chat, las abreviaciones y los emoticones. Los usos de emoticones agregan información afectiva, ya que forman parte del contexto del mensaje y también indican informalidad en las producciones (Gunawardena,1997). La autocorrección en el chat 1 se da una vez en el momento en que un alumno se da cuenta que se equivocó; le faltaba una palabra en su enunciado y se corrige escribiendo un asterisco y luego la palabra que le faltaba.

\subsubsection{Chat 2}

Este chat (Apéndice 11) había sido programado por la coordinadora (con el rol de tutora en este chat) con el primer objetivo de propiciar la socialización entre todos los participantes del curso y así crear un ambiente de pertinencia en el grupo y el segundo objetivo era informativo, es decir, llevar adelante una conversación con los alumnos para que pudieran realizar preguntas sobre el curso y las carreras. En este chat participaron tres alumnos y la tutora. Podemos observar un porcentaje alto de expresiones de emociones como en el chat 1. Los alumnos demuestran un verdadero interés por conocer temas relacionados con el ingreso y la futura carrera: los materiales de estudio, los exámenes, los prácticos, los teóricos, y otros temas.

Pudimos observar que los alumnos manejan correctamente las convenciones de saludo; un alumno utiliza el humor indicando que la tutora llegó tarde a la sesión de chat. Es interesante observar como la emoción del miedo a no tener el nivel aparece en este segundo chat otra vez y se agrega a éste, el miedo a los exámenes.

Los vocativos que se presentan son utilizados por los alumnos cuando se dirigen a la tutora y ellos son "Liliana" , "Lil” y "teacher" ("maestra/profesora" en inglés) siendo estos vocativos que aparecen de igual manera en las clases presenciales. Los saludos de inicio y finalización del chat son todos apropiados al contexto en su forma de registro informal y acompañados de un signo de admiración que indica una emoción del encuentro.

En este chat los alumnos no realizan autocorrecciones; en cambio, si aparece una reflexión sobre un error. En un momento del chat la tutora percibe un error y ayuda al alumno a reflexionar sobre el mismo repitiendo la parte incorrecta que escribió el alumno 
con un signo de pregunta. El alumno se ríe ya que el error provocaba risa, entiende que se equivocó y pide disculpas argumentando que todavía está aprendiendo.

\subsubsection{Chat 1 y Chat 2}

En las siguientes tablas (tablas 10 y 11) podemos percibir en números la ocurrencia de los indicadores sociales y otros elementos presentes en los chats siguiéndolas tablas de Garrison \& Anderson (2005) y Tarone (1981) en Armendariz y Ruiz (2005).

\begin{tabular}{|c|c|c|c|c|}
\hline \multicolumn{2}{|c|}{$\begin{array}{l}\text { INDICADORES PRESENCIA SOCIAL } \\
\text { GARRISON \& ANDERSON (2005) }\end{array}$} & Chat 1 & \multicolumn{2}{|c|}{ Chat 2} \\
\hline \multicolumn{2}{|c|}{ Tipo de Participantes } & Solo alumnos & Tutor & Alumnos \\
\hline \multicolumn{2}{|c|}{ Número de Participantes } & 13 & 1 & 3 \\
\hline \multirow{3}{*}{ Afecto } & Expresión de emociones & 59 & 5 & 32 \\
\hline & Recurrir al humor & 3 & 1 & 5 \\
\hline & Expresarse abiertamente & 5 & 2 & 3 \\
\hline \multirow{6}{*}{$\begin{array}{c}\text { Comunicación } \\
\text { Abierta }\end{array}$} & Seguir el hilo & $\mathrm{n} / \mathrm{a}$ & $\mathrm{n} / \mathrm{a}$ & $\mathrm{n} / \mathrm{a}$ \\
\hline & Citar mensajes de otro & $\mathrm{n} / \mathrm{a}$ & $\mathrm{n} / \mathrm{a}$ & $\mathrm{n} / \mathrm{a}$ \\
\hline & $\begin{array}{l}\text { Referirse explícitamente a los } \\
\text { mensajes de otros }\end{array}$ & $\mathrm{n} / \mathrm{a}$ & $\mathrm{n} / \mathrm{a}$ & $\mathrm{n} / \mathrm{a}$ \\
\hline & Hacer preguntas & 18 & 4 & 14 \\
\hline & Expresar aprecio & 2 & 0 & 4 \\
\hline & Expresar acuerdos & 3 & 0 & 0 \\
\hline \multirow{3}{*}{ Cohesión } & Vocativos & 12 & 0 & 7 \\
\hline & $\begin{array}{l}\text { Dirigirse o referirse al grupo } \\
\text { usando pronombres inclusivos }\end{array}$ & 1 & 0 & 2 \\
\hline & Elementos fáticos, saludos & 22 & 4 & 8 \\
\hline
\end{tabular}

Tabla 10

Indicadores de Presencia Social en los chats

Cohorte 2013 e-DACTA 


\begin{tabular}{|c|c|c|c|c|}
\hline \multicolumn{2}{|c|}{$\begin{array}{c}\text { OTROS ELEMENTOS PRESENTES EN LAS } \\
\text { INTERACCIONES }\end{array}$} & Chat 1 & \multicolumn{2}{|c|}{ Chat 2} \\
\hline \multicolumn{2}{|c|}{ Tipo de Participantes } & Solo alumnos & Tutor & Alumnos \\
\hline \multicolumn{2}{|c|}{ Número de Participantes } & 13 & 1 & 3 \\
\hline \multicolumn{2}{|c|}{ Verificación/ Confirmación de comprensión } & 2 & 0 & 0 \\
\hline \multicolumn{2}{|c|}{ Búsqueda de ayuda para realizar una tarea } & 0 & 0 & 0 \\
\hline \multicolumn{2}{|c|}{ Uso de la lengua materna } & 2 & 4 & 6 \\
\hline \multicolumn{2}{|c|}{ Auto-correcciones } & 1 & 0 & 1 \\
\hline \multicolumn{2}{|c|}{ Uso de emoticones } & 11 & 1 & 4 \\
\hline \multicolumn{2}{|c|}{ Uso de abreviaciones } & 5 & 4 & 4 \\
\hline \multicolumn{2}{|c|}{ Pedidos de aclaraciones } & 1 & 1 & 1 \\
\hline \multirow{3}{*}{ Paráfrasis } & Creación de palabras & 0 & 0 & 0 \\
\hline & Circunlocución & 0 & 0 & 0 \\
\hline & Uso de aproximaciones & 2 & 0 & 1 \\
\hline \multirow{3}{*}{$\begin{array}{c}\text { Grado de } \\
\text { Participación }\end{array}$} & Presencia activa & 5 & 1 & 3 \\
\hline & Presente pero no participa & 6 & 0 & 0 \\
\hline & Abandono & 2 & 0 & 0 \\
\hline
\end{tabular}

Tabla 11

Elementos y Estrategias en los chats

Cohorte 2013 e-DACTA

Tomando los datos que aportan las interacciones de los dos chats analizados podemos concluir lo siguiente:

Desde la perspectiva de los indicadores de presencia social presentados por Garrison \& Anderson (2015) notamos que dentro del grupo denominado 'afecto', reconocemos una importante cantidad de expresiones que connotan emociones realizadas por los alumnos y expresados con los caracteres y signos de puntuación elegidos (signos de admiración, repetición de letras, emoticones, etc.) muchas más que en las interacciones del tutor. Esto demuestra un interés por parte de los alumnos en las actividades a desarrollar en el espacio virtual. Las emociones se fusionan con el deseo de conocer a los 
demás integrantes del curso, con la necesidad de saber más sobre su futura carrera y con la curiosidad que implica el uso de las tecnologías con un grupo afín en relación a las edades y al curso de estudio elegido y a su vez, no debemos dejar de mencionar que el contenido de los diálogos es mediado en una lengua que no es la materna; es una lengua extranjera (inglés) que a la vez es objeto de estudio y de practica para todos los alumnos del curso. Asimismo, se agrega a todos estos elementos presentes en el chat, un componente psicológico de la inhibición que pueden regular psicológicamente la interacción y hasta frenar las emociones plasmándose muchas veces en miedos a equivocarse o a no tener el nivel requerido para ingresar a las carreras de inglés. El humor está presente más veces en las interacciones de los alumnos más que en las del tutor. Se percibió como una tendencia en un alumno en particular en el uso del humor que seguramente puede estar relacionado con atributos de la personalidad del individuo al recurrir al humor reiteradamente. Se expresaron abiertamente en los dos chats al hablar sobre sus vidas fuera de la clase tanto los alumnos como el tutor. Por ejemplo, hablaron sobre temas de los hijos y de la vida social tanto los alumnos como el tutor.

Con respecto a la 'comunicación abierta' podemos decir qué en ambos chats los alumnos hacen varias preguntas para poder construir el diálogo mientras que el tutor realiza pocas. Esto sucede debido a que los alumnos demuestran curiosidad por saber sobre las formalidades de estudio propias de las carreras de las cuales demuestran interés y por lo tanto, realizan más preguntas que el tutor. Los alumnos también expresan pocas expresiones de aprecio. Estas mismas aparecen cuando necesitan reanimar a un compañero cuando demuestra algún miedo o inseguridad sobre su nivel de inglés o de no llegar a aprobar los futuros exámenes. Solo en el chat 1 se expresan acuerdos y seguramente se debe a la necesidad de organizarse con su tarea. El chat 2 no requería de acuerdos para realizar en el dialogo; deducimos que por este motivo no hay evidencia de los mismos.

Con respecto a la 'cohesión', observamos que los alumnos hacen uso de los vocativos con una frecuencia alta y que al dirigirse al grupo utilizan pronombres inclusivos pero de una manera escasa. Es interesante resaltar que los alumnos utilizan las convenciones de los saludos tanto al comenzar la conversación como al finalizarla. 
Podemos observar en la figura 17 la cantidad de aportes que evidencian la presencia de los tres grupos de indicadores que Garrison \& Anderson (2015) clasifican en sus estudios de la presencia Social. El afecto sucede más de 100 veces entre los dos chats por sobre la comunicación abierta y la cohesión.

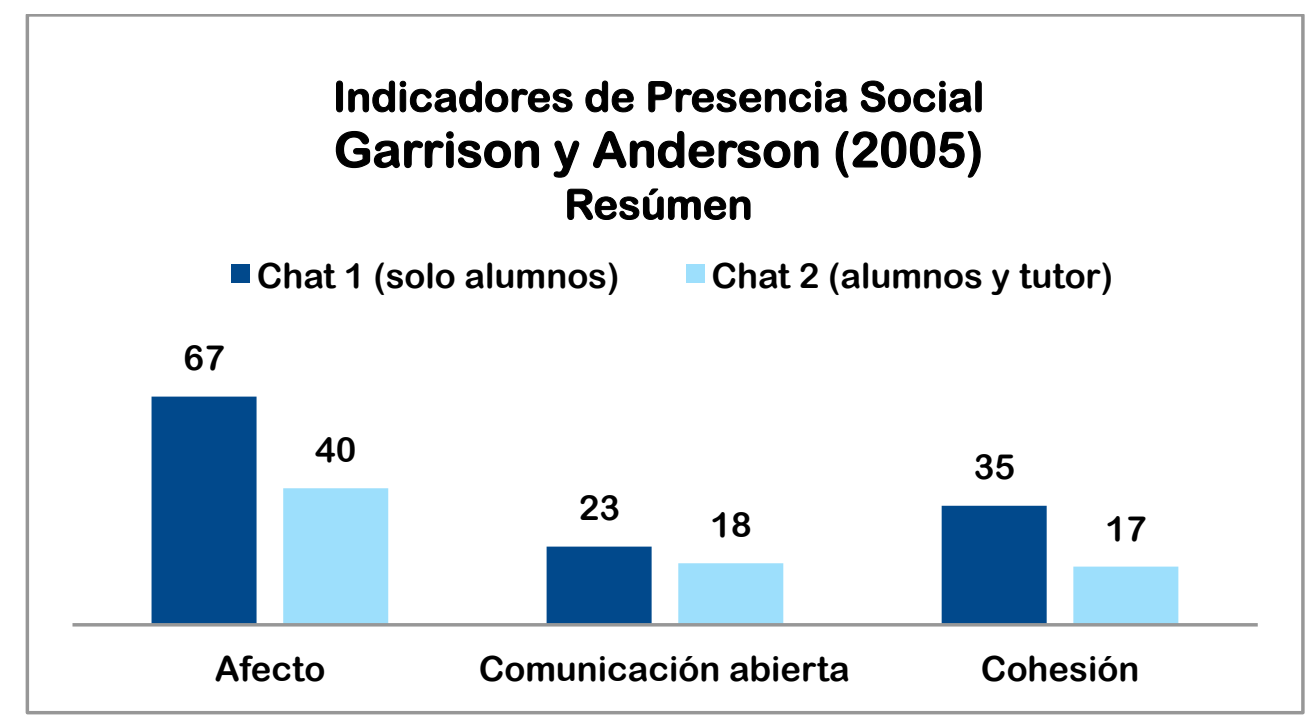

Figura 17

Frecuencia de la Presencia Social en los chats

Desde la perspectiva de los elementos presentes en las interacciones realizadas de un adaptación de los presentados por Levy \& Stockwell (2006), y Tarone (1981) en Armendariz y Ruiz (2005) observamos la presencia de emoticones, la cual es mayor en las interacciones de los alumnos que en la de tutores, aunque presentes en ambos y también de abreviaciones tanto en las interacciones de los alumnos como en la de tutores. Estos dos elementos son muy característicos de las interacciones propiciadas por las herramientas de chat.

En referencia a los otros elementos presentes observamos en la figura 18 que se recurre a la lengua materna en diferentes ocasiones para aclarar la comprensión de vocablos específicos en el caso de los tutores y en el caso de los alumnos cuando desconocen la palabra en la lengua meta. 


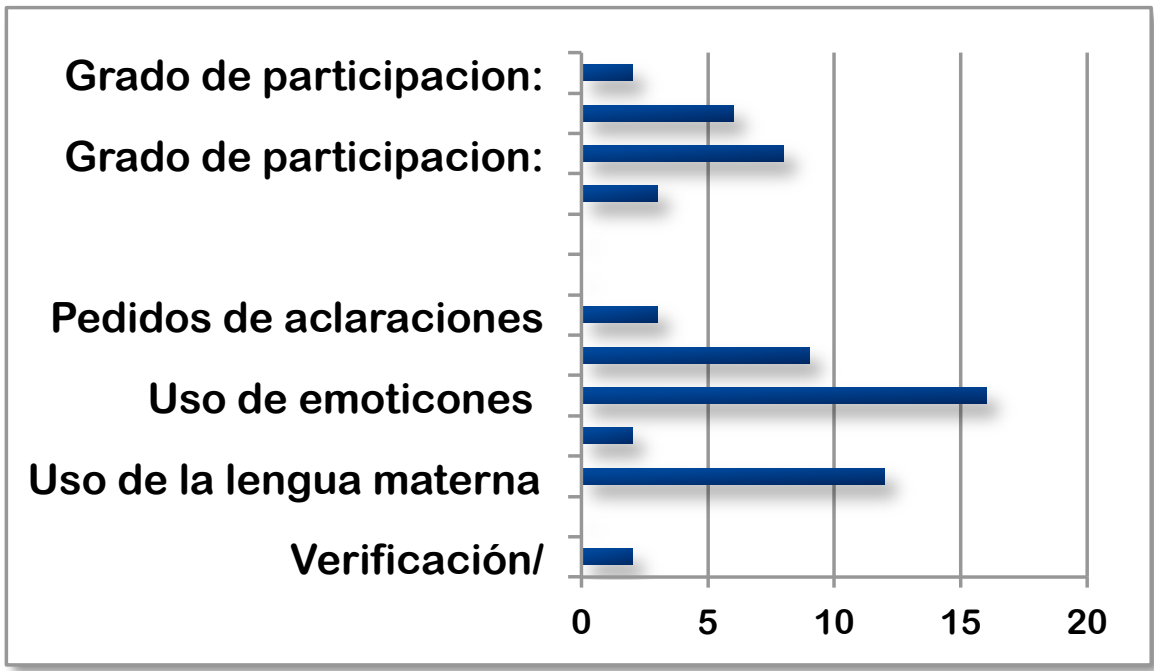

Figura 18

Uso de otros elementos en los chats

Solo los alumnos realizan autocorrecciones: en una ocasión en cada chat cuando se dan cuenta de haber cometió un error. No hay presencia de autocorrecciones en las interacciones del tutor. Solo en el chat 1 pudimos observar que dos veces los alumnos piden verificación o confirmación de comprensión y un pedido de aclaración por falta de comprensión. En ningún momento de los dos chats hay alguna búsqueda de ayuda para realizar una tarea. Creemos que podría haber habido en el Chat 1 , ya que el contenido del chat consistía en la realización de una tarea.

Con respecto al recurso de paráfrasis, no surgieron ejemplos de creación de palabras, ni circunlocución aunque si hubo tres ejemplos de uso de aproximaciones, o sea, palabras similares a la apropiada pero no las usadas por hablantes nativos que pueden provocar una error en la comunicación.

En la figura 18 podemos observar cómo el recurso del uso de los emoticones es el más frecuentes de todos, seguido del uso de la lengua materna y de las abreviaciones. En referencia al grado de participación es tan interesante el dato de la baja cantidad de abandono del chat como el de presencia no activa. Estar presentes e inactivos puede deberse a varias razones: pueden estar conectados y haciendo otra actividad o pueden estar leyendo las interacciones de los chats pero no agregan nada a la conversación. A este tipo de interacción Sutton $(1999,2001)$ la llama interacción indirecta (Vicarious interaction, en inglés). Sutton señala que algunos alumnos al no sentirse cómodos como participantes activos en una conversación o discusión, ya sea por la presencia del tutor u otros alumnos, 
el alumno decide no participar aunque está presente durante el transcurso del chat o de las otras actividades como los foros los cuales leen pero no escriben aportes en los hilos de discusión. Aún así, sin participar directamente, estos alumnos logran aprender mediante la lectura de los aportes de sus compañeros y tutores; es decir, tiene una participación indirecta con un rol de observador.

\subsection{Análisis de los foros}

Durante la cohorte 2013 se abrieron 11 foros en total. Los foros, al igual que los chats, fueron elegidos al azar con la idea de poder encontrar fortalezas y debilidades en los mismos y poder reflexionar sobre los datos que arrojan su análisis. Tomamos para este análisis dos foros del corpus de la cohorte 2013 del e-DACTA: "Bienvenidos al curso" y "Nuevas Tecnologías" (Ver corpus en el Apéndice 12).

En la siguiente tabla 12 presentamos los diferentes foros que se abrieron durante el curso con las cantidades de aportes realizados por los alumnos:

\begin{tabular}{|l|c|}
\hline \multicolumn{1}{|c|}{ FOROS } & Cantidad de aportes \\
\hline Bienvenida & 41 \\
\hline Familia y Tecnología & 36 \\
\hline Nuevas Tecnologías & 26 \\
\hline Música & 30 \\
\hline Guía 1 (reflexiones) & 26 \\
\hline Guía 2 (reflexiones) & 19 \\
\hline Guía 3 (reflexiones) & 13 \\
\hline Guía 4 (reflexiones) & 16 \\
\hline Despedida & 18 \\
\hline Soporte Técnico & 6 \\
\hline Tu Futura Carrera & 9 \\
\hline
\end{tabular}

Tabla 12

Foros de la Cohorte 2013 e-DACTA 
En la tabla 12 podemos observar en la tabla una mayor participación en los foros que acompañan las guías como tareas de integración del trabajo semanal y una menor participación en los foros llamados soporte técnico y en los foros de reflexiones sobre las guías trabajadas. Tampoco hicieron muchos aportes en el foro llamado "Tu Futura Carrera", seguramente se debe a que es un tema que también se trata en los chats. En la siguiente figura 19 podemos visualizar gráficamente los foros con mayor y menor participación.

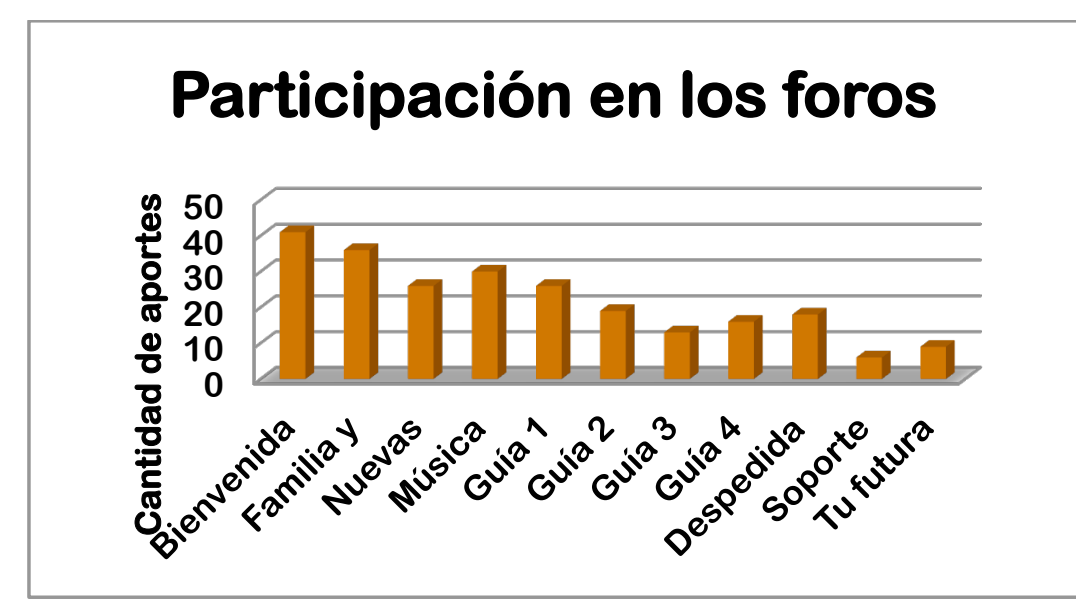

Figura 19

Cantidad de aportes

en los foros de la Cohorte 2013 e-DACTA

\subsubsection{Foro 1}

El foro 1 que analizamos es el primer foro del curso llamado "Bienvenidos al curso" (Apéndice12). Este foro contó con 41 aportes y trabajaron en él 35 alumnos, un coordinador y un tutor. El primer aporte se realizó el 18 de septiembre y el último el 17 de octubre. Participaron en el mismo 35 alumnos: un tutor y el coordinador. El objetivo de la tarea de este foro es presentarse en el curso ante sus compañeros y tutores.

El foro es iniciado por el coordinador quien les escribe nuevamente la consigna y además los aconseja sobre cómo escribir su primer aporte en un foro y de que puntos importantes no deben olvidarse; finaliza el mismo deseándoles suerte junto a un emoticón. Los alumnos escriben sus aportes guiados por las instrucciones dadas: se presentan dando sus nombres, sus edades, el lugar donde viven, sus escuelas, sus hobbies, sus expectativas sobre sus futuras carreras. La mayoría de los alumnos inician el texto saludando a todos los participantes del curso aunque dos alumnos utilizan el vocativo en referencia a la coordinadora que fue quien abrió el foro. Se percibe un entusiasmo en los 
aportes que se refleja en la cantidad de expresiones de emociones, 57 en total, y el cual que demuestra un interés de parte de los alumnos al contar sobre sus vidas y sus expectativas. Debido al tipo de la consigna del foro, ya mencionada anteriormente, la misma provoca que todos los alumnos se expresen abiertamente expresando detalles de su vida.

De los 36 aportes, 12 de ellos siguen el hilo al responder a un asunto ya utilizado en el primer aporte el coordinador $u$ otros ya usados por otros alumnos y se pudo observar que en la mayoría eran expresiones de saludos. En el cuerpo del texto del foro también vuelven a utilizar palabras o frases que indican saludos y algunos saludos enfatizan el hecho y deseo que se verán pronto. Si bien el coordinador finalizó su aporte inicial con un emoticón, solo dos alumnos finalizaron sus aportes con un emoticón.

En ningún momento se recurrió a la lengua materna. Tampoco hubo ninguna presencia de auto correcciones o de uso de paráfrasis; tampoco se utilizaron abreviaciones. En todos los aportes los alumnos lograron comunicarse efectivamente, aun así existieron faltas ortográficas, errores gramaticales y de registro que no impidieron la comunicación.

Si bien éste fue un foro de presentación individual de los participantes, podemos notar la escasa presencia el tutor quien realiza su presentación en un solo foro, su aporte aparece después de que 12 alumnos dejaran los suyos, luego el tutor no reaparece en este foro ni le da un cierre final o incentiva o invita a los que faltaban dejar sus contribuciones al mismo.

\subsubsection{Foro 2}

La consigna de este segundo foro (Apéndice 12) es describir un objeto tecnológico sin decir cuál es y luego sus compañeros deberán adivinar que es. La idea es practicar la escritura de párrafos descriptivos con un formato lúdico. Se proporciona un ejemplo en la consigna del foro.

El coordinador escribe el aporte inicial del foro que comienza el 7 de octubre y que finaliza con un último aporte el 3 de noviembre. Trece alumnos participan en este foro. Sólo dos alumnos escriben un aporte con descripciones detalladas pero nunca más vuelven a participar. 


\section{La enseñanza de una lengua extranjera utilizando tecnología dígital}

Otros dos alumnos no escriben un aporte con la descripción solicitada, aun así participan del juego de adivinar. El resto de los alumnos participan activamente escribiendo sus aportes, respondiendo a las adivinanzas y confirmando cuando la respuesta es correcta o no.

Un alumno escribe dos aportes. El primer aporte lo escribe con pocas pistas y con algunas expresiones incomprensibles. Diez días después vuelve a reescribir el primer aporte en uno segundo agregando más información. Si bien este segundo aporte era más completo, debido a que agregó más información, tampoco era muy comprensible.

El coordinador, como ya dijimos anteriormente, realiza el aporte inicial del foro en el cual repite la consigna y da consejos sobre la importancia de completar primero la guía de estudio sobre tecnología, ya que la misma les va a proveer de vocabulario, estructuras gramaticales y otros recursos lingüísticos necesarios para poder redactar textos descriptivos coherentes, cohesivos y apropiados al contexto.

El primer aporte del tutor en este foro manifiesta su presencia docente expresada en un nuevo asunto que el mismo denomina 'Preguntar y Responder'. En el cuerpo del mensaje vuelve a aclarar la consigna del foro haciendo hincapié en que deben responder adivinando la respuesta y luego esperar la confirmación.

En su segundo aporte el tutor alienta, informa, expresa aprecio, guía y les recuerda parte de las instrucciones. En su tercer aporte el tutor expresa aprecio ante una respuesta correcta de un alumno sobre el ejemplo dado en la consigna utilizando un vocativo (nombre del alumno).

Suponemos que el tutor se confió en el buen flujo de aportes de parte de los alumnos ya qué sólo intervienen solo cuatro veces y después de su último aporte se realizan 14 aportes nuevos de los alumnos. 


\subsubsection{Foro 1 y Foro 2}

En la tabla 13 podemos observar la cantidad de presencia social en los corpus de los foros analizados según la clasificación de Garrison \& Anderson (2005).

\begin{tabular}{|c|c|c|c|c|c|}
\hline \multicolumn{2}{|c|}{$\begin{array}{c}\text { INDICADORES PRESENCIA SOCIAL } \\
\text { Garrison \& Anderson (2005) }\end{array}$} & \multicolumn{2}{|c|}{ Foro 1} & \multicolumn{2}{|c|}{ Foro 2} \\
\hline \multicolumn{2}{|c|}{ Tipo de Participantes } & Tutor & Alumnos & Tutor & Alumnos \\
\hline \multicolumn{2}{|c|}{ Número de Participantes } & 1 & 36 & 1 & 12 \\
\hline \multirow{3}{*}{ Afecto } & Expresión de emociones & 1 & 57 & 0 & 27 \\
\hline & Recurrir al humor & 0 & 0 & 0 & 0 \\
\hline & Expresarse abiertamente & 1 & 36 & $\mathrm{n} / \mathrm{a}$ & $\mathrm{n} / \mathrm{a}$ \\
\hline \multirow{6}{*}{$\begin{array}{c}\text { Comunicación } \\
\text { Abierta }\end{array}$} & Seguir el hilo & 0 & 12 & 0 & 8 \\
\hline & Citar mensajes de otro & 0 & 0 & $\mathrm{n} / \mathrm{a}$ & $\mathrm{n} / \mathrm{a}$ \\
\hline & $\begin{array}{l}\text { Referirse explícitamente a los } \\
\text { mensajes de otros }\end{array}$ & 0 & 0 & 1 & 14 \\
\hline & Hacer preguntas & 0 & 0 & 0 & 6 \\
\hline & Expresar aprecio & 2 & 1 & 5 & 2 \\
\hline & Expresar acuerdos & 0 & 0 & $\mathrm{n} / \mathrm{a}$ & $\mathrm{n} / \mathrm{a}$ \\
\hline \multirow{3}{*}{ Cohesión } & Vocativos & 0 & 2 & 2 & 11 \\
\hline & $\begin{array}{l}\text { Dirigirse o referirse al grupo } \\
\text { usando pronombres inclusivos }\end{array}$ & 0 & 0 & 0 & 2 \\
\hline & Elementos fáticos, saludos & 2 & 53 & 0 & 6 \\
\hline
\end{tabular}

Tabla 13

Indicadores de presencia social

Garrison \& Anderson (2005) en los foros del e-DACTA

En la siguiente tabla 14, podemos observar la presencia de los otros elementos que ocurren en las interacciones de los foros. 


\begin{tabular}{|c|c|c|c|c|c|}
\hline \multicolumn{2}{|c|}{$\begin{array}{l}\text { Otros elementos presentes en las } \\
\text { interacciones }\end{array}$} & \multicolumn{2}{|c|}{ Foro 1} & \multicolumn{2}{|c|}{ Foro 2} \\
\hline \multicolumn{2}{|c|}{ Tipo de Participantes } & Tutor & Alumnos & Tutor & Alumnos \\
\hline \multicolumn{2}{|c|}{ Número de Participantes } & 2 & 35 & 1 & 13 \\
\hline \multicolumn{2}{|c|}{ Verificación/ Confirmación de comprensión } & 0 & 0 & 0 & 0 \\
\hline \multicolumn{2}{|c|}{ Búsqueda de ayuda para realizar una tarea } & 0 & 0 & 0 & 2 \\
\hline \multicolumn{2}{|c|}{ Uso de la lengua materna } & 0 & 0 & 0 & 0 \\
\hline \multicolumn{2}{|c|}{ Auto-correcciones } & 0 & 1 & 0 & 0 \\
\hline \multicolumn{2}{|c|}{ Uso de emoticones } & 1 & 1 & 0 & 1 \\
\hline \multicolumn{2}{|c|}{ Uso de abreviaciones } & 0 & 0 & 0 & 0 \\
\hline \multicolumn{2}{|c|}{ Pedidos de aclaraciones } & 0 & 0 & 0 & 0 \\
\hline \multirow{3}{*}{ Paráfrasis } & Creación de palabras & 0 & 0 & 0 & 0 \\
\hline & Circunlocución & 0 & 0 & 0 & 0 \\
\hline & Uso de aproximaciones & 0 & 0 & 0 & 0 \\
\hline \multirow{3}{*}{$\begin{array}{c}\text { Grado de } \\
\text { Participación }\end{array}$} & Presencia activa & 1 & 35 & 1 & 10 \\
\hline & $\begin{array}{l}\text { Presente pero } \\
\text { no participa }\end{array}$ & 1 & $\mathrm{n} / \mathrm{a}$ & $\mathrm{n} / \mathrm{a}$ & $\mathrm{n} / \mathrm{a}$ \\
\hline & Abandono & $\mathrm{n} / \mathrm{a}$ & $\mathrm{n} / \mathrm{a}$ & (1) & 2 \\
\hline
\end{tabular}

Tabla 14

Indicadores de Otros elementos en los foros Cohorte 2013 e-DACTA

Del análisis de estos dos foros se desprenden la fortaleza y debilidades en la interacción de estos espacios. Podríamos deducir a partir de los datos que obtuvimos que los alumnos tanto en el foro 1 como en el foro 2 se expresaron de manera positiva, comprometida y motivados por las propuestas de las consignas. En el foro 1 observamos el 
deseo de formar parte de un grupo al presentarse con entusiasmo y manifestando el deseo de verse en un futuro inmediato. Todo esto se refleja en el alto número de expresiones emociones y en la elección de las palabras que expresan estas emociones.

En la figura 20 podemos visualizar el flujo de la interacción en el foro 2 propiciada por la tarea propuesta en la consigna del foro. Todos los alumnos responden a la consigna dada, algunos alumnos piden a su tutor que los guíen e interactúan entre sus pares para cumplir con el segundo paso de la consigna que es adivinar el dispositivo tecnológico descripto por cada alumno.

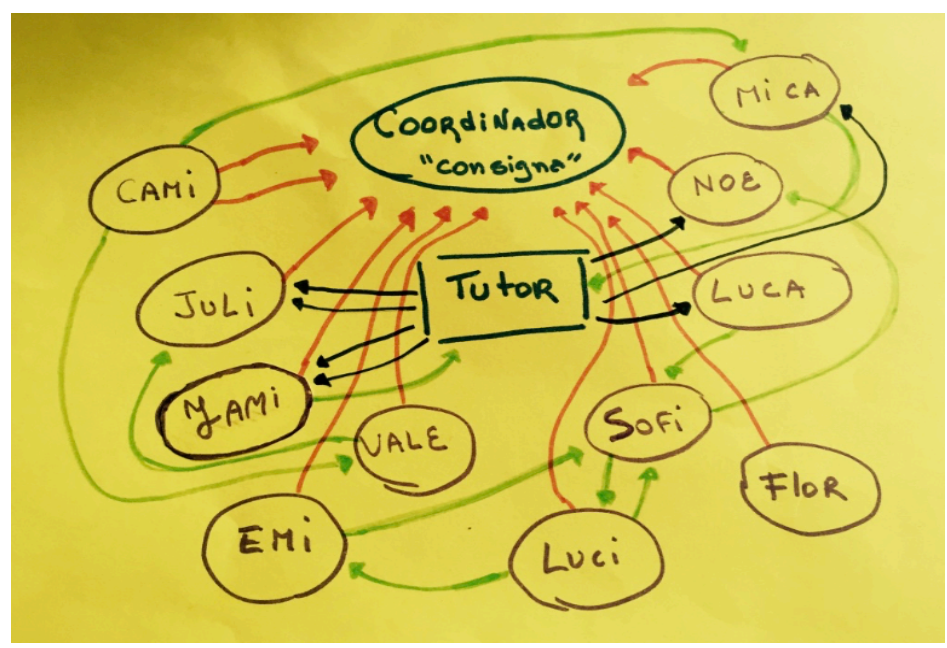

Figura 20

Movimiento de las interacciones

en el foro 2 del e-DACTA

Lamentablemente podemos evidenciar una escasa presencia del docente. Se podría haber propiciado una mayor participación y también se podría haber brindado ayuda a aquellos alumnos que necesitaban para mejorar sus textos o a aquellos que estuvieron ausentes en este foro y necesitaban de un incentivo para escribir. A partir de este análisis se les recomendó a los tutores no olvidarse en las siguientes cohortes del curso e-DACTA a efectuar un seguimiento más minucioso de los alumnos especialmente en relación a su participación en los foros y a realizar un resumen que indique el cierre del foro a modo de formalidad aún cuando los alumnos continúen escribiendo sus aportes; a su vez, dependiendo del tipo de foro, se recomendaron utilizar diferentes herramientas de aplicaciones en web 2.0 para realizar resúmenes como mapas conceptuales, tablas, videos y/o gráficos y así plasmarlos de una manera más clara y fácil de compartir. 
En la siguiente figura 21 podemos ver que el indicador del grupo afecto, la "expresión de emociones", es el que más fluye en las interacciones seguido de la cohesión con los "elementos fáticos y de saludos", el "expresarse abiertamente" y por último los indicadores de "seguir el hilo". Si bien los alumnos están realizando una presentación de su persona en sus aportes no dejan de incluir su alegría y expectativas por realizar el curso y manifestar sus deseos de conocer a sus futuros compañeros y docentes.

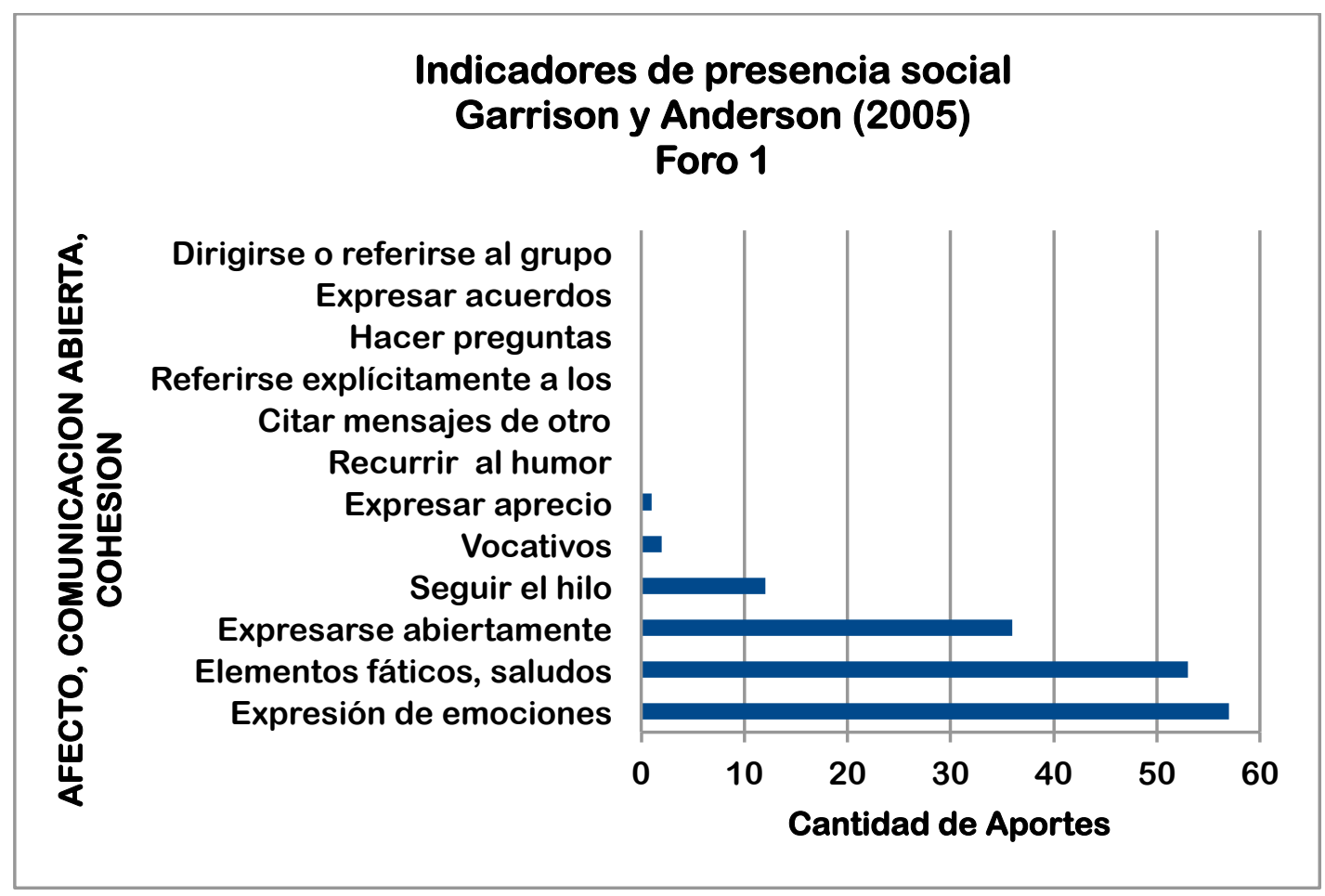

Figura 21

Cantidad de aportes

en el foro 1 de la Cohorte 2013 e-DACTA

En las siguiente figura 22 observamos al compararla con la figura 21 que si bien las expresiones que revelan emociones continúan siendo el primer indicador en cantidad de apariciones, se evidencia la presencia de otros indicadores. Esto se debe al tipo de tarea que los alumnos deben llevar a cabo en el foro 2 que exige una mayor interacción entre los participantes y es así entonces que aparecen otros indicadores ante la necesidad de hacer preguntas, referirse a otros mensajes, usar vocativos, expresar aprecio. 


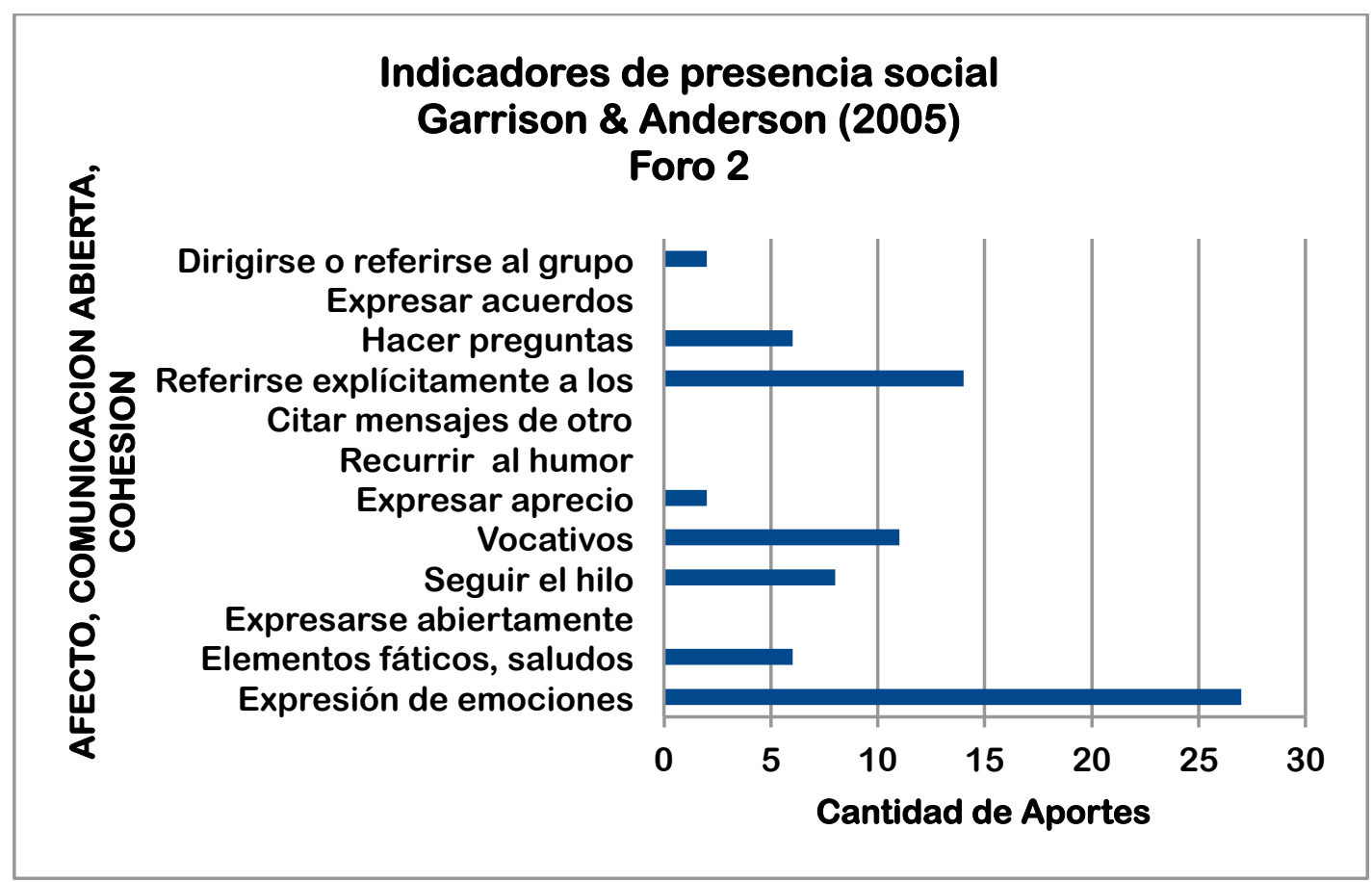

Figura 22

Cantidad de aportes

en el foro 2 de la Cohorte 2013 e-DACTA

En referencia a los otros elementos presentes en los foros notamos que si bien el número de alumnos que participan es menor en el foro 2, ambos foros tienen un alto grado de participación y muy baja deserción (Figura 23).

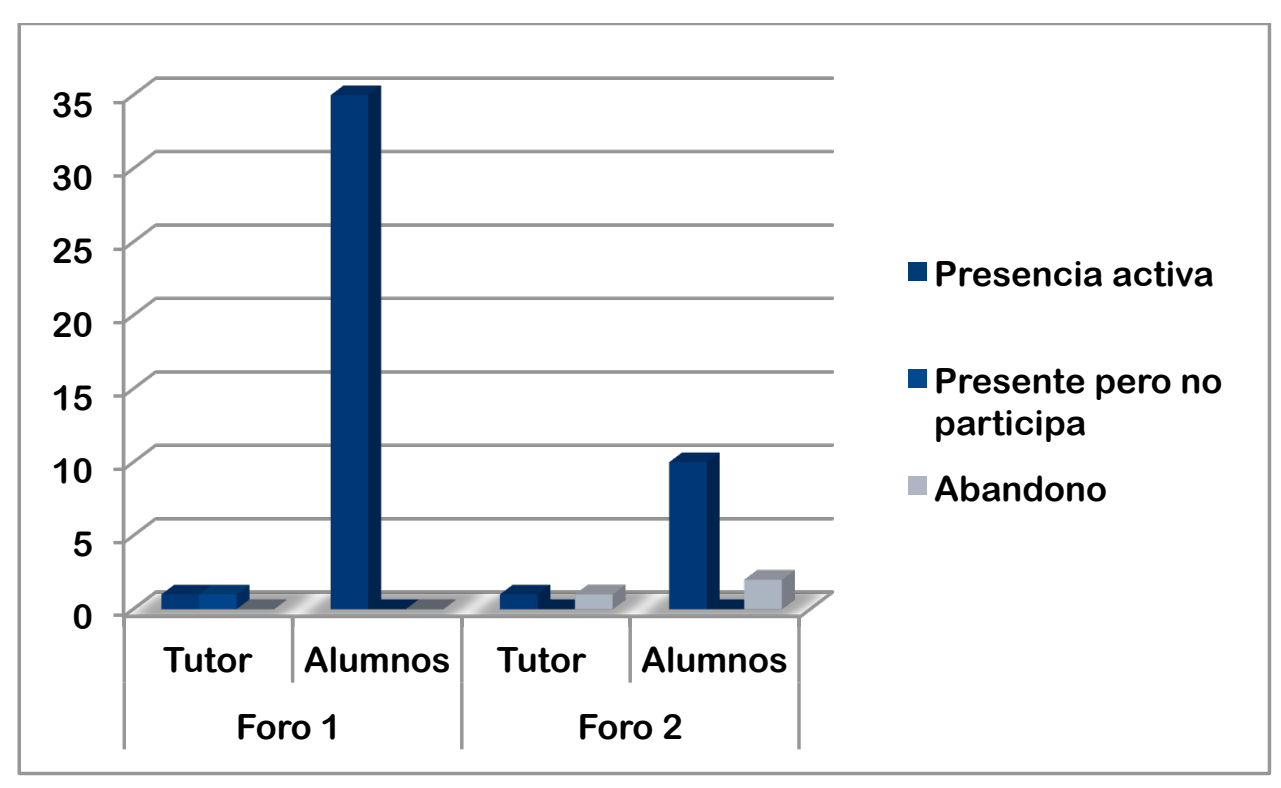

Figura 23

Grado de Participación

en los foros 1 y 2 de la Cohorte 2013 e-DACTA 


\subsection{Conclusión}

En nuestro corpus pudimos evidenciar que, tanto en las producciones de los chats como en la de los foros, los alumnos interactúan de una manera espontánea y entusiasmada; estos sentimientos son plasmados con el alto porcentaje de emociones expresadas. Además, en relación a la cohesión, se visualiza en los indicadores de elementos fáticos y de saludos con los cuales los alumnos manifestaban sus deseos y expectativas de 'verse' pronto en la universidad. Se conjugan de esta manera emociones de felicidad, alegría y expectativas ante la nueva etapa a iniciar.

La presencia social propiciada por los chats y foros es fundamental en los EVEA. La necesidad de pertenecer a un grupo se hace factible con las tecnologías que funcionan como un puente que une las distancias entre alumnos, docentes e instituciones. Woods y Smith (2005) en Levy, M \& Stockwell, Glenn $(2006,100)$ se refieren a la presencia social como el grado en que nosotros percibimos a otros como personas reales (resaltado por el autor) en una interacción la cual varía mucho dependiendo del medio y del contexto.

Pudimos evidenciar que en las sesiones de chats se formaron interacciones cortas y rápidas con abundancia en abreviaciones y emoticones y los temas propuestos se podían perder al mezclarse con otros temas, por problemas de comprensión, conexión, etc. En cambio los foros facilitan una interacción más relajada que propicia la negociación del significado el cual contribuye de manera significativa en la adquisición de una lengua. Según Skehan $(1998)$ citado por Levy $(2006,103)$ la interacción es un mecanismo ideal a través del cual los aprendientes logran identificar los límites y necesidades de mejora de su interlengua ${ }^{19}$.

Podríamos concluir diciendo que en los foros notamos que los alumnos tienden a cuidar más las formas gramaticales y el uso adecuado del vocabulario junto con el registro apropiado que en los chats. Aún así, podemos encontrarnos con producciones realizadas por los alumnos que necesitan trabajar más sobre las formas lingüísticas apropiadas pero

\footnotetext{
19 "Se entiende por 'interlengua', el sistema lingüístico del estudiante de una segunda lengua o lengua extranjera en cada uno de los estadios sucesivos de adquisición por los que pasa en su proceso de aprendizaje." http://cvc.cervantes.es/ensenanza/biblioteca_ele/diccio_ele/diccionario/ (Consulta:12/01/16)
} 
debemos destacar que la comunicación en las producciones fue lograda en todo momento salvo en una producción del foro 2 mencionada en este capítulo.

La presencia social clasificada en tres grupos por Garrison y Anderson (2005) estuvo presente tanto desde lo afectivo como en la comunicación abierta y la cohesión. Desde lo efectivo con las expresiones emociones y humor presente, desde la comunicación abierta siguiendo el hilo, expresando acuerdos y aprecio y desde la cohesión al dirigirse al grupo en el uso de vocativos y en los saludos. $Y$, en referencia a los otros elementos y estrategia de aprendizaje presentes tomando la adaptación de estos elementos de Levy Adaptación de Levy \& Stockwell (2006), y Tarone (1981) en Armendariz y Ruiz (2005) pudimos observar una presencia alta en el uso de emoticones y abreviaciones en los chats, no así en los foros. También notamos un muy bajo uso de la lengua materna como así también de recursos como paráfrasis y otros elementos. El hecho de no recurrir a la lengua materna es un hallazgo importante ya que demuestra que los alumnos poseen recursos lingüístico necesarios para expresarse en una lengua extranjera. 


\section{Capitulo 5}

\section{Presentacion de resultados: Estudio de las encuestas del curso}

\subsection{Introducción}

En este capítulo estudiaremos otro instrumento de recogida de información que son las encuestas realizadas cada año desde el 2008 en las todas las cohortes del e-DACTA. Se diseñaron las mismas con el fin de recoger información necesaria para conocer mejor el perfil de los estudiantes mediante las encuestas iniciales, y con el aporte de las encuestas finales recabamos información sobre el EVEA, las guías de estudio, las actividades propuestas y también reflexiones sobre el trabajo en el curso, las expectativas, las emociones y el trabajo con los tutores. Estas encuestas han arrojado a través de los años información sustanciosa que nos ha ayudado a acomodar el diseño instruccional del curso a medida que íbamos observando la necesidad de cambios y mejoras en el curso e-DACTA. También, detallaremos como la incorporación de las redes sociales, en este caso de Facebook, se utilizó como una vía de comunicación complementaria.

\subsection{Las Encuestas}

En la primera semana del curso se les solicita a los alumnos completar una encuesta inicial para conocer el perfil de los alumnos, saber que conocimientos de tecnología poseen, el tipo de acceso a internet que está al alcance del alumno, las expectativas del curso, etc., y en la última semana del curso se les pide completar la encuesta final del curso (ver Apéndice 7) en donde el alumno se explaya contando su experiencia en forma crítica desde su perspectiva como alumno.

Con los datos que arrojan estas encuestas describiremos en este capítulo el grado de satisfacción del curso, sin dejar de lado otros datos muy interesantes sobre las críticas constructivas que nos han permitido realizar mejoras en el curso. 
En los primeros años del e-DACTA se realizaron encuestas vía e-mail y luego se volcaron los datos en una planilla de datos (Apéndice 5). Desde el 2010 las encuestas al igual que las inscripciones se realizaron vía Google Docs (cuya denominación en la actualidad cambió a Google Drive). (Apéndice 6)

Si bien las fichas de inscripción son el primer medio en aportar datos sobre los alumnos del curso e-DACTA, es a través de las encuestas iniciales, que se realizan en la primera semana del curso, con las que comenzamos a conocer el perfil tecnológico de los alumnos quienes suponemos han adquirido un conocimiento tecnológico durante sus estudios secundarios o a partir de un aprendizaje autodidacta.

\subsection{Encuestas Iniciales}

En las siguientes figuras podemos ver claramente gracias a las herramientas de Google Drive los datos que arrojan las encuestas realizadas y contestadas por 333 alumnos.

\subsubsection{Género}

El 75\% del alumnado es de sexo femenino. Esta información (figura 24) corrobora el dato que el mayor ingreso de personas es de sexo femenino el cual es históricamente mayor al de sexo masculino. Pero en nuestro estudio no es un dato que aporte algo nuevo nuestra descripción.

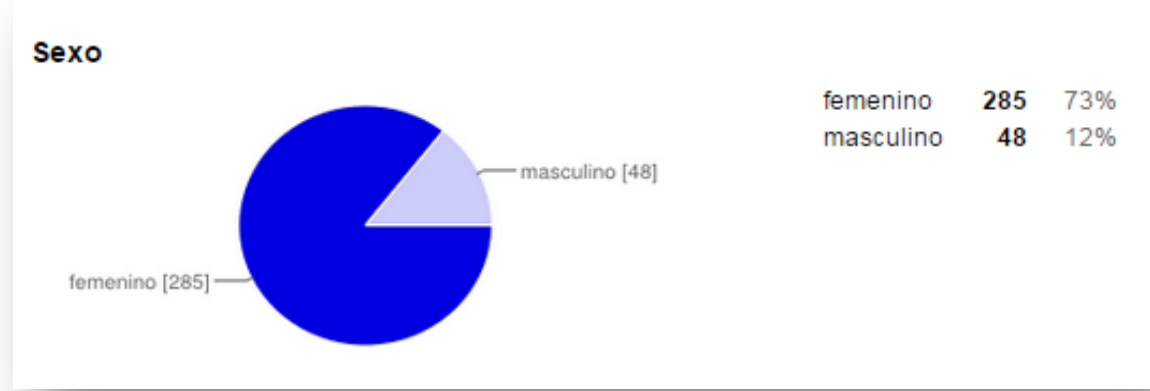

Figura 24

Género 


\subsubsection{Estudios Secundarios}

Durante la primera y segunda cohorte del curso e-DACTA fue requisito para la inscripción que el alumno estuviera cursando el último año de la escuela secundaria porque se pretendía tener un universo de alumnos limitado al ser una experiencia piloto en los primeros años; luego dejó de existir como restricción pero la información quedó como proveedor de un dato de interés. En los últimos años, a diferencia de años anteriores, notamos que los graduados de las escuelas secundarias no siempre ingresaban a una carrera universitaria al año siguiente de haber finalizado sus estudios secundarios. Muchas veces ingresan a una carrera, luego abandonan los estudios y deciden iniciar otra carrera o a veces dejan los estudios por la necesidad de trabajar. Podemos apreciar con los números que arrojan estos datos (figura 25) que son casi parejos los números de alumnos que inician una carrera ni bien terminan la secundaria (39\%) y aquellos que comienzan las carreras de inglés después de unos años de haber finalizado la escuela media (41\%).

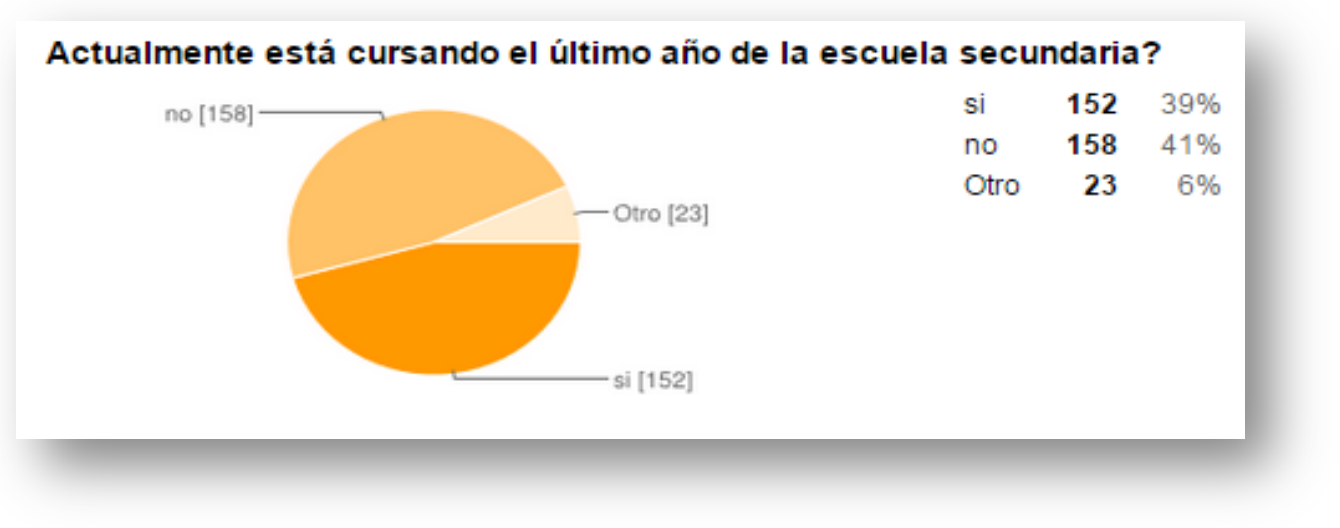

Figura 25

Año de finalización de la escuela secundaria

\subsubsection{Motivación por la inscripción al curso}

Los porcentajes que arrojan esta pregunta (figura 26) sobre las expectativas del curso son también parejas: la mayoría, un $55 \%$, quiere conocer más sobre la carrera aunque vemos que un $46 \%$ desea hacer el curso para aprender más sobre la lengua inglesa. $Y$ en menor proporción, 33\%, conocer más sobre el ámbito universitario. De estos datos podemos observar que el perfil del alumno en su mayoría se focaliza en la carrera elegida y en su preocupación por mejorar sus conocimientos. 


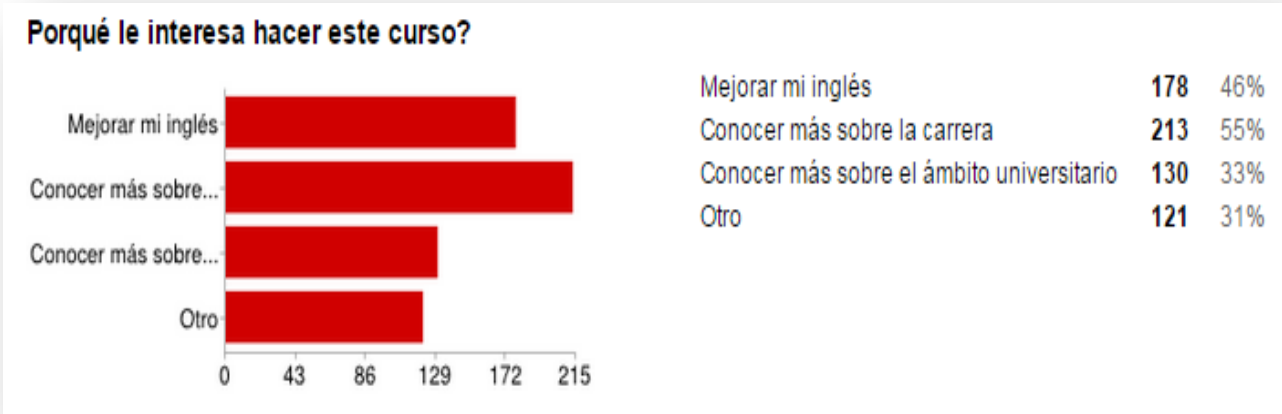

Figura 26

Expectativas del curso

Esta motivación se refleja en un comentario sobre la participación del foro "Tu Futura Carrera "que trata sobre los cursos de inglés en la UNLP y que es, generalmente, moderado por una alumna avanzada en las carreras de inglés de la FAHCE). El comentario en la figura 27 expresa este interés.

\begin{tabular}{l}
\hline "Me ayudó a sacar dudas. la sección de poder preguntar a una \\
chica que está estudiando la carrera me fue muy útil."
\end{tabular}

\section{Figura 27}

Comentario de las encuestas

\subsubsection{Tipos de conexión a internet}

Las figuras 28 y 29 nos informan sobre el tipo de conexión y se puede observar que la conexión Wifi es la que más se utiliza actualmente y que el hogar de los alumnos es desde donde mayormente se conectan. 


\section{Su conexión a internet es:}

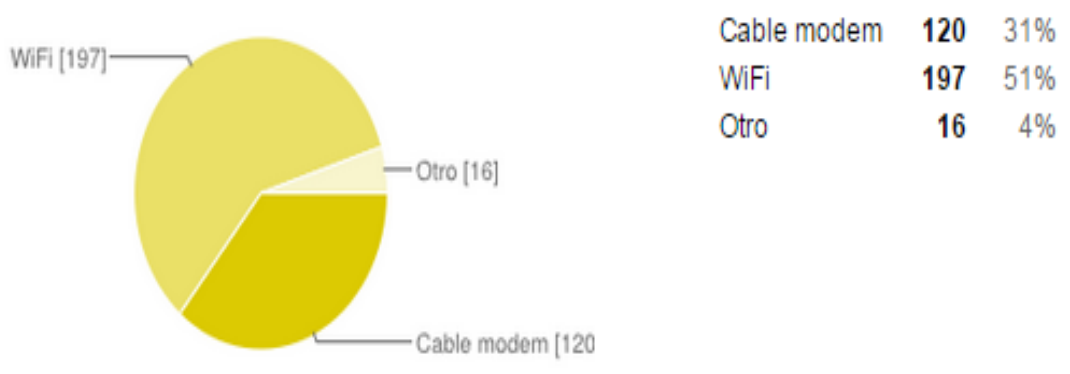

Figura 28

Tipo de conexión

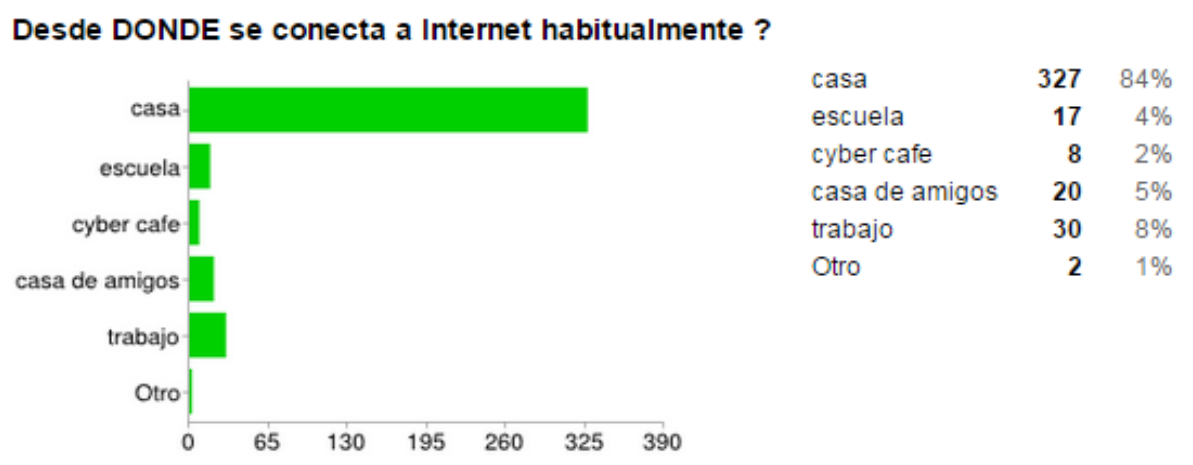

Figura 29

Ambiente de estudio

\subsubsection{Tiempo de dedicación para el estudio del curso}

Otros datos que tomamos para conocer mejor el perfil de alumno del curso fue saber de cuantas horas disponía el alumno para dedicarse a este curso. $Y$ así, con estos datos, pudimos poder hacer ajustes en las siguientes cohortes. La mayoría, el 52\% de los alumnos cuenta con 3 horas semanales disponibles para trabajar en el curso (figura 30), los cuales son suficientes para poder llevar a delante este curso. 


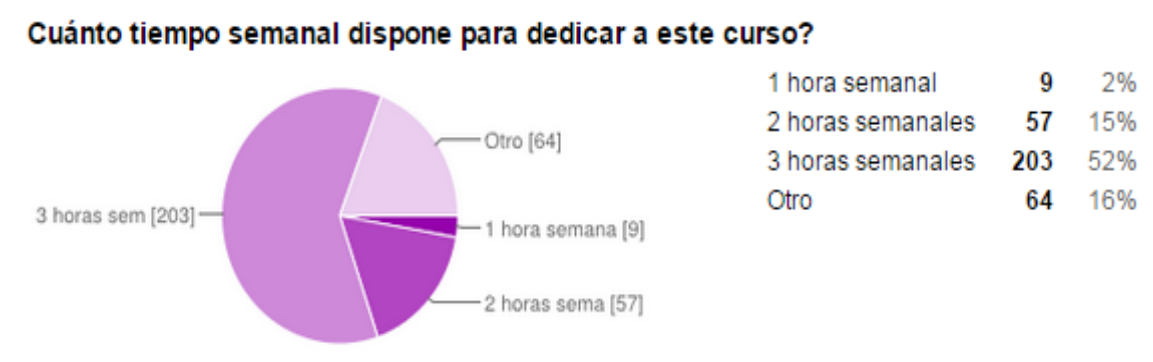

Figura 30

Tiempo de estudio

\subsubsection{Difusión del curso}

Desde el inicio del proyecto el aporte de estos datos fueron fundamentales para poder guiarnos sobre los medios a elegir en las próximas cohortes y para poder optimizar la difusión del curso. La difusión del curso se hizo principalmente desde el Departamento de Lenguas y Literaturas Modernas de la FAHCE, UNLP y desde el área de Educación a Distancia del Rectorado de la UNLP. Se armaron afiches (Apéndice 3) y se enviaron e-mails a las direcciones de escuelas de los ministerios provinciales para difundir en las escuelas secundarias.

El dato interesante que nos aporta esta pregunta (figura 31) es que evidenciamos un incremento en las últimas cohortes en las visitas a la página web de la FAHCE: el $52 \%$ de los alumnos toman conocimiento del curso a través la página web de la facultad, seguido por las recomendaciones de amigos $(24 \%)$ o el comúnmente denominado, de boca en boca.

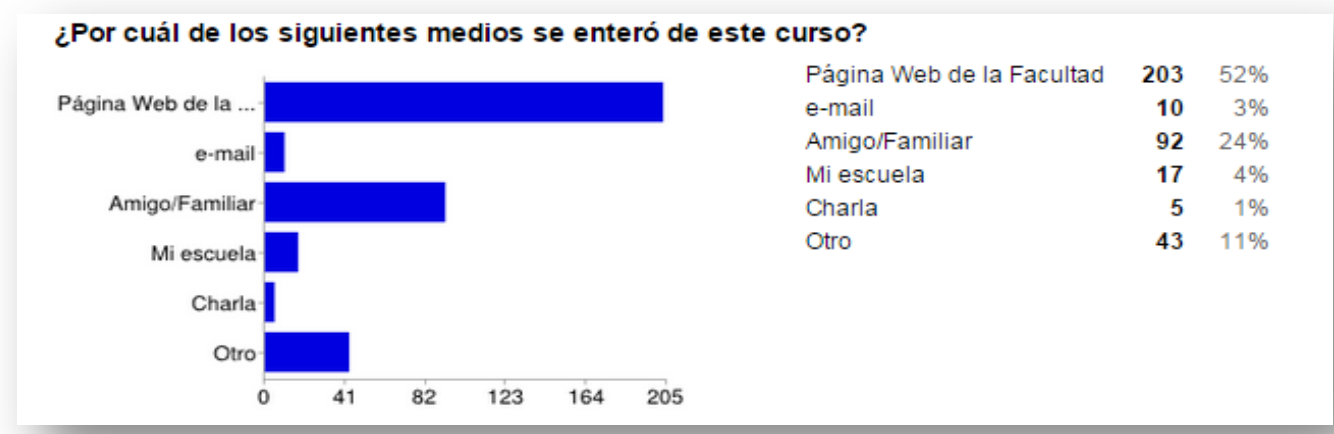

Figura 31

Difusión del curso 


\subsection{Encuestas Finales}

La información obtenida de las encuestas de los primeros años arrojaron datos muy ricos que propiciaron un campo de análisis y de estudio para futuras modificaciones del curso y a la vez ayudan a comprender si las primeras decisiones tomadas en el diseño instruccional de este curso impartido a la distancia cumple con los objetivos del curso. También observamos en las respuestas el despliegue de temas cruciales y propios de esta modalidad como la necesidad del uso de estrategias metacognitivas y de autorregulación, las tres presencias fundamentales (la presencia social, la presencia cognitiva y la presencia didáctica, Garrison, Anderson \& Archer (2005)) que favorecen un andamiaje suministrado tanto por los tutores y coordinador como por los compañeros del curso. Y, sobre todo debemos remarcar esa ausencia de contacto físico que se aprecian en la modalidad a distancia y que se permeabilizan en las encuestas.

Según las encuestas del 2008 y 2009 y de un total de 21 encuestas recibidas, tomamos los siguientes datos:

- El $100 \%$ de los alumnos realizaba por primera vez un curso en la modalidad de educación a distancia.

- El $80 \%$ no está habituado al uso de EVEA.

- El $80 \%$ dice no haber tenido problemas con las nuevas tecnologías.

- El $100 \%$ utiliza el buscador de internet Google.

- El $85 \%$ utiliza herramientas de Chat y servicios de e-mails.

- Solo dos alumnos dijeron haber usado blogs y ninguno indicó haber usado wikis.

En las diferentes cohortes han participaron personas de diferentes provincias: Misiones, Corrientes, Formosa, Córdoba, Santa Fe, Río Grande, Mendoza, Salta, Tierra del Fuego, Neuquén, Chubut, Río Negro, La Pampa, Buenos Aires y de distintas ciudades como: Mar del Plata, Hurlingham, Florencio Varela, Olavarría, Las Flores, Campana, Choele Choel, Ensenada, Chaves, Berisso, Playa Unión, Bariloche, Concordia, Wanda de Puerto Iguazú, Puerto Madryn, Gral. Madariaga, Junín, Tres Arroyos, Miramar, Azul, etc. y en su gran mayoría de la ciudad de La Plata (lugar donde se encuentra físicamente la UNLP), capital de la provincia de Buenos Aires y también de sus alrededores: Gonnet, Villa Elisa. También se inscribieron personas desde otros países: Chile, Brasil, Venezuela, Perú, Colombia, Paraguay, Ecuador y España. 
Estos son datos que consideramos muy importantes debido a que uno de los objetivos del curso es llegar a lugares distantes a nuestra facultad, FAHCE-UNLP. Los aspirantes a nuestra carrera manifestaron con expectativas el deseo de realizar el curso eDACTA debido a que su elección de carrera les provocaría un cambio de lugar de residencia para cursar las carreras dado a que estas carreras son dictadas en su modalidad tradicional: presencial. La posibilidad que el curso e-DACTA les ofrece de conocer sobre la carreras con anterioridad a realizar cambios importantes en sus vidas (mudanzas, alquileres, nuevas amistades, etc.) es de gran aceptación y agradecimiento por parte de los interesados en estudiar en la ciudad de La Plata.

Tomando los datos de las primeras encuestas resumidas en el informe el proyecto e-DACTA del año 2008 (Apéndice 5) y las fichas del año 2009 junto con las últimas encuestas que abarcan los años 2010 al 2015, resumiremos las respuestas dadas a la preguntas sobre su opinión sobre el curso e-DACTA en los siguientes párrafos:

Desde la perspectiva del alumno, la descripción del curso e-DACTA fue muy positiva ya que las repuestas reflejaron a la experiencia como "excelente", "bien organizado" "interesante", una propuesta "totalmente nueva", "súper practico" y "todo un desafío"20; un $20 \%$ reconoció haberse sentido "confundido" y hasta "perdido" en las primeras semanas pero que luego se sintió una mejora en la comprensión del uso del EVEA y hasta llegar a un punto de "acostumbramiento". El curso los ayudó a "decidir su futuro, a acercarse a la facultad, "a poner énfasis en errores de escritura"; apreciaron la dinámica de grupos y el apoyo constante de los tutores a los cuales los sintieron "presentes", "atentos", "excelentes" y que propiciaron un contexto contenedor aportando su "disponibilidad" inmediata y un "buen seguimiento". Con respecto al material usado y los temas tratados, elogiaron los temas como "originales" y "entretenidos"; a las guías de estudio las vieron como muy buenas para "ampliar vocabulario y aprender otros aspectos", "los temas eran variados y permitían dentro de las pautas una libre expresión"; solo un alumno especificó haber tenido problemas que no podía ver algunas de las guías completas (los posibles motivos pueden haber sido no haber seguido la recomendación de usar otro explorador de internet o la ausencia de algún programa de software complementario como Java o Flash, los cuales se pudieran haber solucionado si se hubiera manifestado este problema en su momento ante su tutor).

\footnotetext{
${ }^{20}$ Las palabras transcriptas textualmente de los alumnos son resaltadas entre comillas.
} 
Desde el punto de vista afectivo, los alumnos se explayaron sobre este tema utilizando frases como me sentí "distendida", "cómoda", "un poco perdida al principio", "me sentí acompañada por mis tutores y coordinadora", "me ayudó a progresar", "sentí mucha responsabilidad por los manejos del tiempo", "disfruté mucho", "me divertí con los ejercicios", "me gustó la modalidad", "me gustó conocer a mis futuros compañeros", "me sentí contenido por mi tutor", fue "interesante y emocionante a la vez ya que fue una forma de acercarme hacia lo que es la facultad".

Con respecto a los puntos negativos que encontraron en el curso, hicieron referencia a problemas con el EVEA que no funcionaba bien por momentos; esto se debió a que existieron problemas tecnológicos durante las primeras semanas de comenzado el curso, si bien los alumnos fueron informados de este problema, algunos lo comentaron en las encuestas y con respecto a los que dejaron el curso en las primeras semanas, no sabremos si abandonaron el curso por este motivo al no haber respondido a las encuestas finales. También dos alumnos hicieron referencia al tiempo del curso, para uno era largo y para otro corto; otro alumno sugirió que el curso no se superpusiera con los meses de clases de la escuela secundaria; algo muy difícil de lograr, ya que en el último año de la secundaria los alumnos tienen muchas actividades en la segunda parte del año y la primera parte todavía hay muchos alumnos que no han elegido una carrera universitaria aún. Las tareas o actividades que los alumnos del curso pueden realizar además de las del curso pueden ser varias: estudiar y asistir a las clases de las materias del último año, cursos de orientación vocacional, rendir exámenes finales y/o materias previas que adeudan algunos alumnos, viajes de finalización de la educación secundaria, etc.

En los siguientes comentarios (figuras 32 y 33 ) de las encuestas podemos observar como dos alumnos resaltan el cambio que el curso provocó en relación al uso de las tecnologías como herramienta de ocio a herramienta para el estudio.

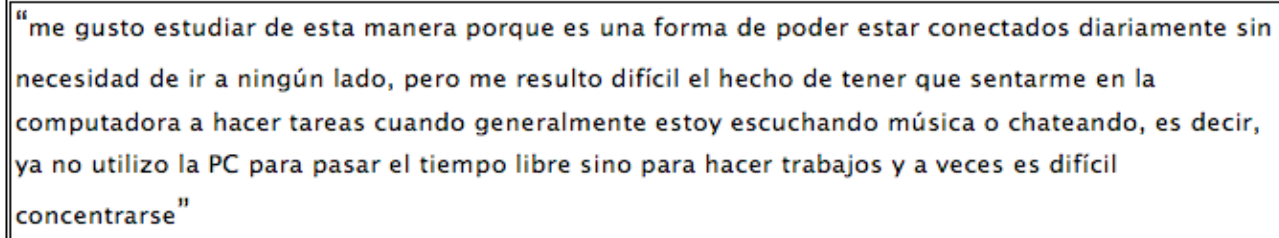


"Me abrió las puertas hacia el uso de Internet como herramienta a la hora de estudiar o difundir información. Aprendi a trabajar con una plataforma de enseñanza virtual."

Figura 33

Comentario 2 sobre uso de las TIC

Encuestas 2009

En otro comentario (figura 34) apreciamos como un alumno pondera la aparición de un andamiaje entre pares y expertos (tutores), el hecho de sentirse cómodos con otras personas que comparten los mismos intereses, destaca la necesidad de sociabilización en relación a los demás integrantes del curso y la posibilidad que el curso les brinda de tener un primer contacto con la universidad y despejar prejuicios.

\begin{tabular}{||l||l||}
\hline $\begin{array}{l}\text { Contención por } \\
\text { parte de los } \\
\text { compañeros }\end{array}$ & $\begin{array}{l}\text { "Conoci personas muy piolas, que hasta nos pasábamos los trabajos e intercambiamos } \\
\text { opiniones de ellos. Y me di cuenta que muchos están en la misma condición que yo, con } \\
\text { las mismas dudas e incertidumbres. Además que ya tengo una amiga para estudiar el año } \\
\text { que viene. }{ }^{\text {" }}\end{array}$ \\
\hline \hline $\begin{array}{l}\text { Contención por } \\
\text { parte de los } \\
\text { profesores }\end{array}$ & $\begin{array}{l}\text { "Vuelvo a decirlo: jincreible el trabajo que hicieron! La verdad no me lo esperaba por todo } \\
\text { lo que me contaban de las universidades, pero el apoyo que tuve de ustedes fue muy } \\
\text { bueno. iiGRACIAS!! " }\end{array}$ \\
\hline
\end{tabular}

Figura 34

Comentarios 3 de las Encuestas 2009

Andamiaje y presencia social

En el próximo comentario (figura 35) podemos ver cómo el alumno utiliza sus habilidades metacognitivas para poder reflexionar sobre sus capacidades y demuestra un interés por poder continuar intentando mejorar su conocimiento. También nos informa sobre el alcance del objetivo pedagógico del curso e-DACTA de "ampliar las prácticas de disponibilidades y habilidades en lengua inglesa a efectos de favorecer la articulación entre saberes adquiridos en el nivel medio y el trayecto de esos mismos saberes en la institución universitaria." 
"La experiencia me gusto, yo la carrera ya la tenía elegida, pero me ayudo a darme cuenta si tengo el nivel, creo q un poco más bajo es mi nivel, pero bueno, intentaré."

Figura 35

Comentario sobre

Habilidades metacognitivas y

nivel requerido para el ingreso a las carreras

Encuestas 2009

Las encuestas realizadas a partir del año 2010 (59 encuestas iniciales y 43 encuestas finales completadas) arrojan datos muy parecidos y solo percibimos un cambio en el perfil tecnológico del alumno y este cambio nos expresa que los alumnos en los últimos años tienen un acercamiento mayor a las nuevas tecnologías.

En las encuestas del 2008 y 2009 los alumnos expresaron que jamás habían realizado un curso a distancia ni habían utilizado un EVEA. En los últimos año podemos observar que un porcentaje bajo ha comenzado a conocer y utilizar un EVEA (figura 36). Además, agregan que han usado algún tipo de EVEA en las escuelas secundarias como apoyatura de materias. (figura 37 )

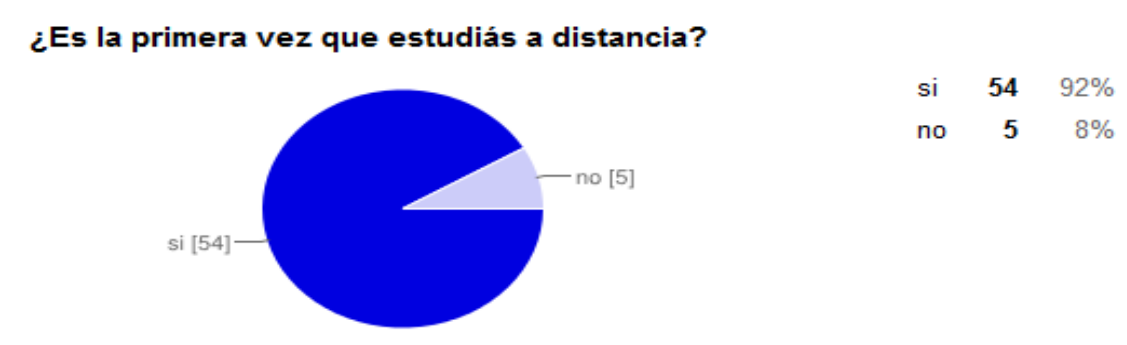

Figura 36

Estudios de EaD

Datos extraídos de las Encuestas 2010/14 


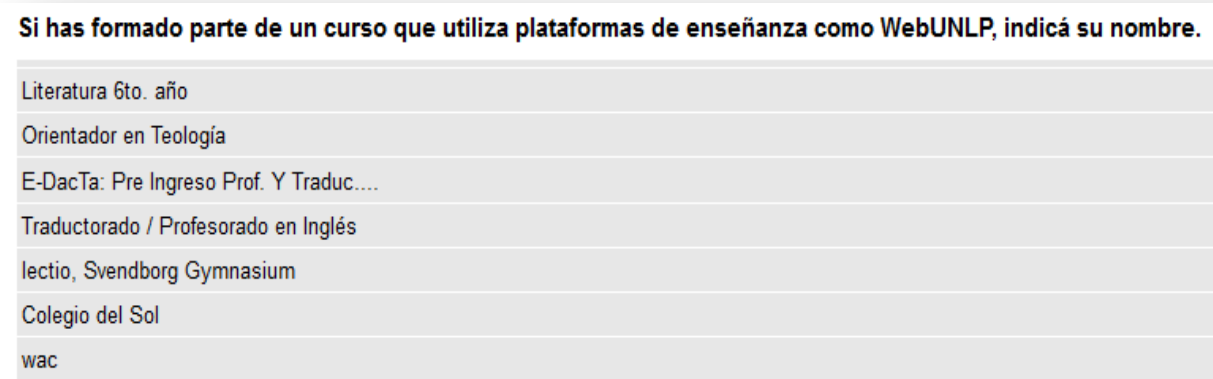

Figura 37

Estudios de EaD mediante EVEA

Datos extraídos de las Encuestas 2010/14

La figura 38 muestra como las tecnologías se van incorporando como herramienta de estudio en las prácticas educativas habituales de las escuelas secundarias; un $46 \%$ dice haber usado las tecnologías para aprender.

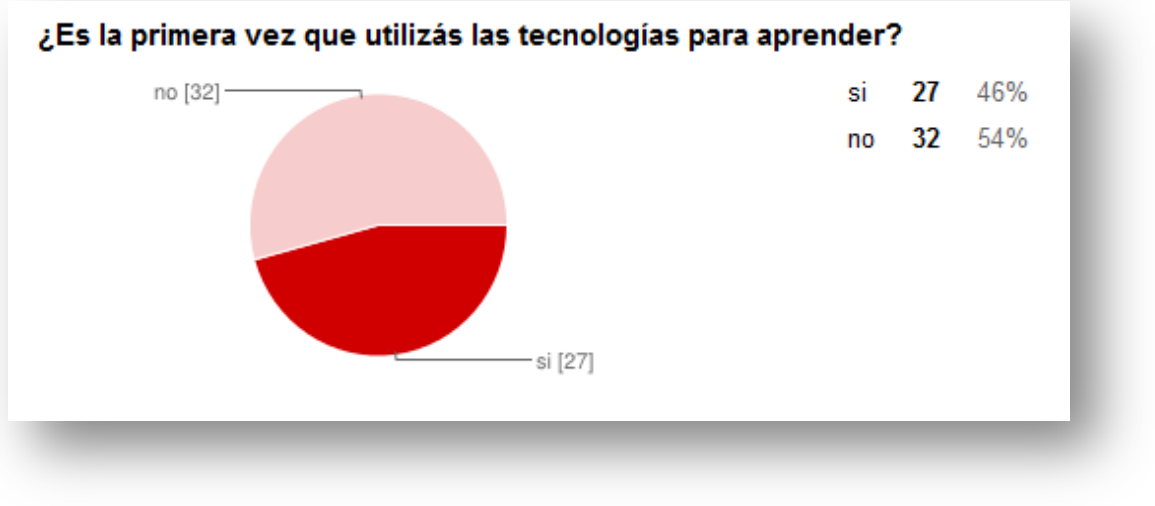

Figura 38

Uso de las tecnologías como herramienta de estudio 1

Datos extraídos de las Encuestas 2010/14

En la figura 39 solo un $7 \%$ indica no haber usado las nuevas tecnologías en sus estudios secundarios; en cambio, todos (100\%) usan las tecnologías para estudiar. Estos datos son importantes porque se vieron reflejados en el uso de la plataforma en las últimas cohortes al no presentar problemas en el uso de las mismas. Además estos datos corroboran una idea que tenemos en relación del uso de las tecnologías por parte de los alumnos de nivel secundario en general y su uso en las escuelas: "Todos los alumnos encuestados usan las nuevas tecnologías para estudiar pero no necesariamente las usan en la escuela secundaria." 
¿Cuánto uso has hecho de las nuevas tecnologías en la escuela secundaria?

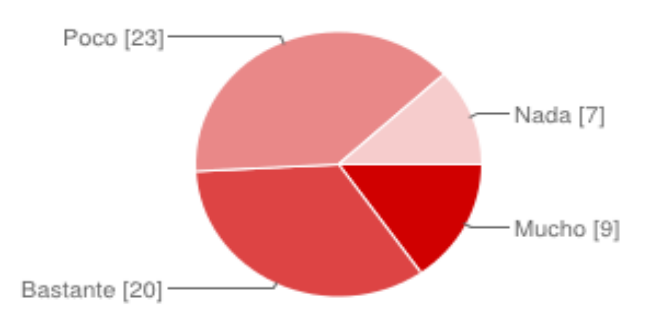

$\begin{array}{lrr}\text { Mucho } & \mathbf{9} & 15 \% \\ \text { Bastante } & \mathbf{2 0} & 34 \% \\ \text { Poco } & \mathbf{2 3} & 39 \% \\ \text { Nada } & \mathbf{7} & 12 \%\end{array}$

Bastante [20]

\section{¿Cuánto usas las nuevas tecnologías para estudiar?}

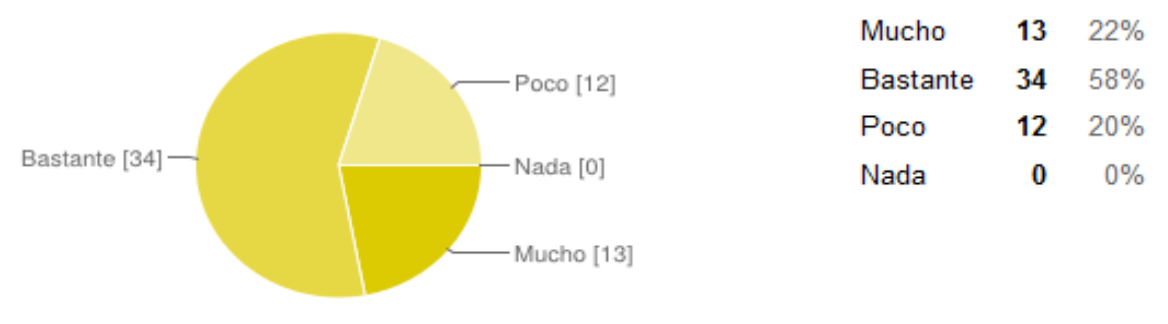

Figura 39

Uso de las tecnologías como herramienta de estudio 2

Datos extraídos de las Encuestas 2010/14

Los datos sobre el uso de redes sociales como Facebook o Twitter y otras herramientas de la Web 2.0 los solicitamos a partir del año 2010 que es el momento en que comienzan a expandir el uso de las mismas como herramientas de ocio y como instrumentos de enseñanza-aprendizaje.

En la figura 40 podemos observar como las herramientas de la Web 2.0 comienzan a expandirse en su uso como entretenimiento, especialmente en los últimos años; pero lamentablemente, también se visualiza claramente que desde las escuelas secundarias no se han impulsado la creación de espacio con sitios propios de las instituciones para propiciar entornos especiales de comunicación, información y de aprendizaje para los alumnos. 


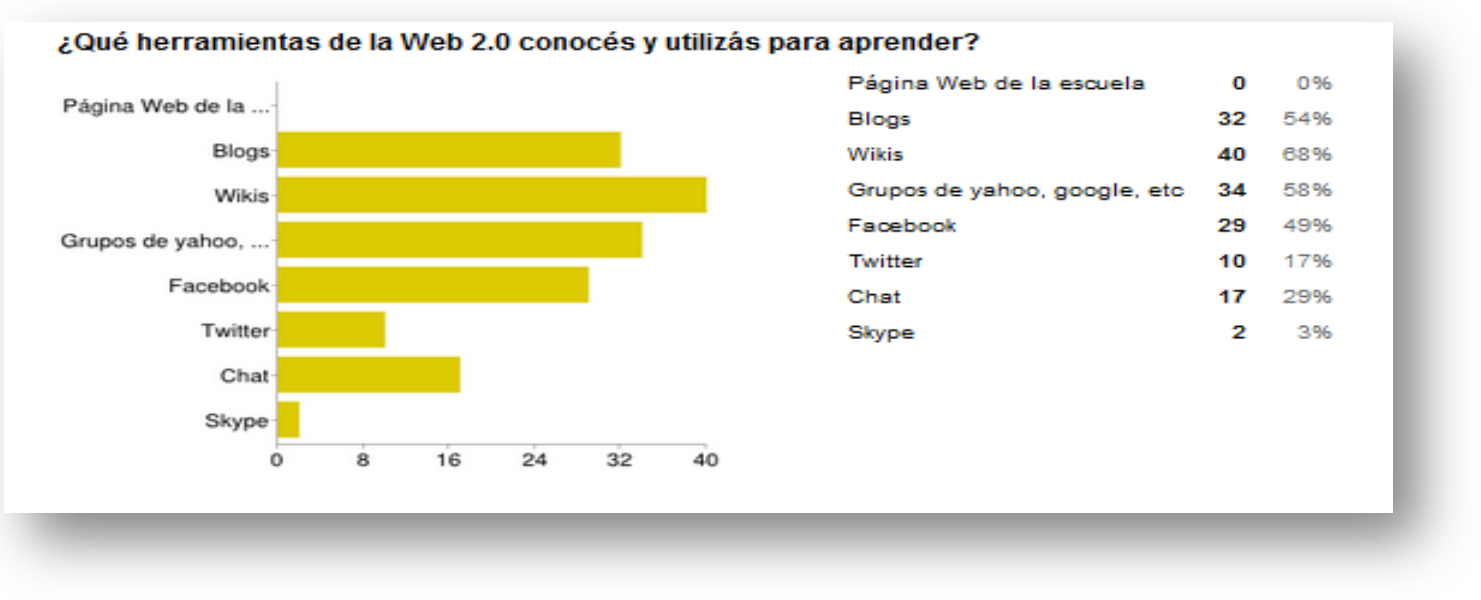

Figura 40

Herramientas Web 2.0 (1)

Datos extraídos de las Encuestas 2010/14

En la próxima figura (figura 41) observamos que los alumnos no tienen inconvenientes en el uso de las redes sociales como Facebook, sólo el 5\% manifestó haber tenido dificultades. Twitter seguidas por blogs y wikis presentan dificultades en su manejo. En encuestas hechas informalmente en clases de la cátedra Lengua Inglesa $1^{21}$ (Primera materia que cursan los alumno luego del ingreso) podemos decir que todos conocen que es un blog, aunque muchos no saben armar uno y la gran mayoría no sabe qué es una wiki; aunque reconocen el nombre de Wikipedia, no saben bien qué es una wiki, cómo está compuesta y sus usos.

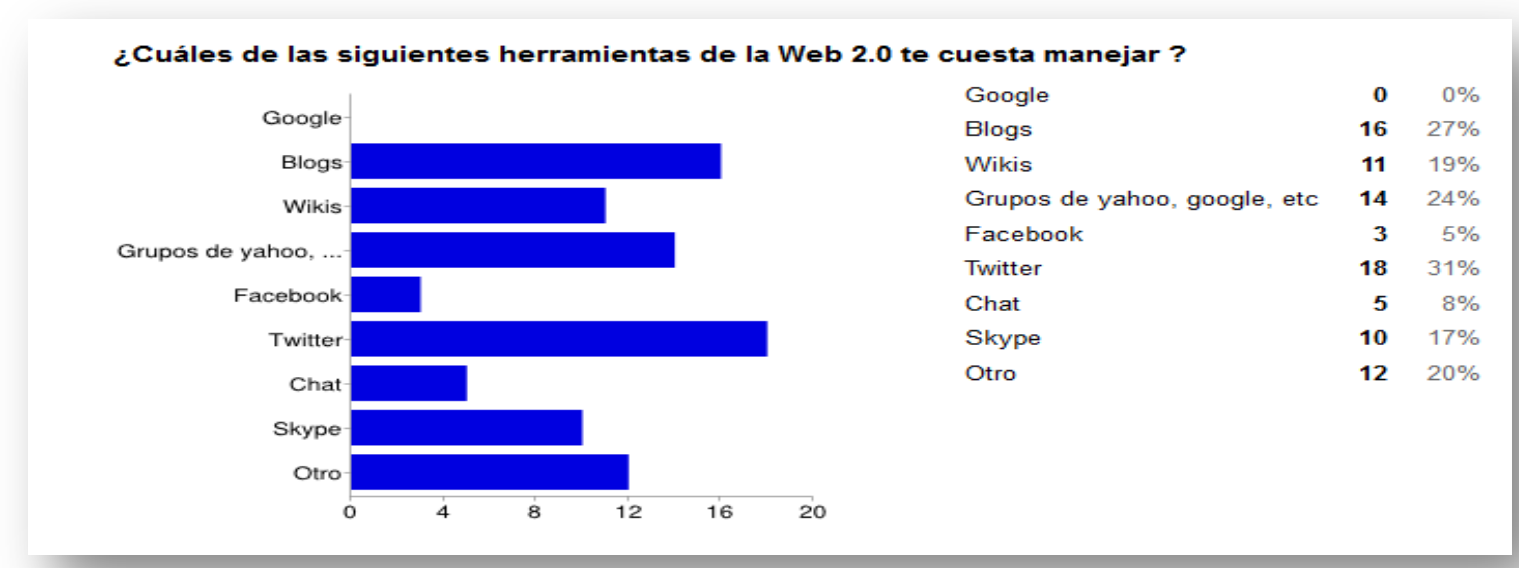

Figura 41

Herramientas Web 2.0 (2)

Datos extraídos de las Encuestas 2010/14

\footnotetext{
21 Experiencia docente extraída de la primera materia que cursan los alumnos luego del ingreso y en la que la autora de esta tesis es Ayudante Diplomada Ordinaria desde 1999.
} 
Estos datos sobre el uso de herramientas web 2.0 los consideramos importantes para poder determinar cuáles de ellos podríamos usar para complementar en el uso del EVEA.

\subsection{Facebook del curso e-DACTA}

Tomando los datos en las encuestas sobre el incremento en el uso de las redes sociales, y especialmente el dato sobre el uso social que hacen de las mismas (figura 42), se abrió en el año 2010 un espacio ${ }^{22}$ en la red social Facebook para que los alumnos del eDACTA recibieran notificaciones sobre el inicio, avance y fin del curso. Habíamos observado que los alumnos no chequeaban con frecuencia los e-mails, por lo tanto no recibían notificaciones sobre el curso.

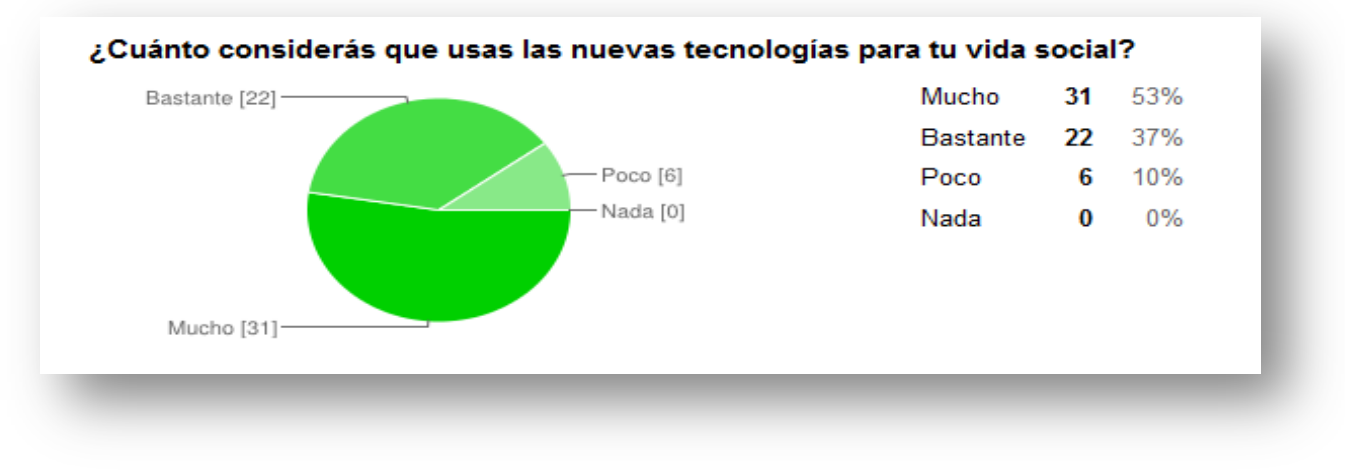

Figura 42

Uso de las redes sociales

En la figura 43 podemos observar un aporte en el muro sobre el inicio del curso en una de las primeras publicaciones en el muro de Facebook del e-DACTA:

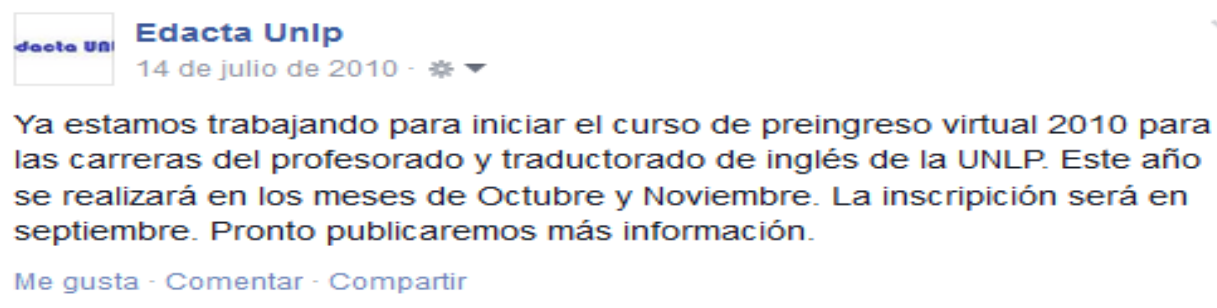

Figura 43

Ejemplo 1 de posteo en el Facebook del e-dacta

22. https://www.facebook.com/edacta.unlp 
El Facebook del curso e-DACTA, además de funcionar como medio de difusión del inicio del curso, se aprovecha como una guía desde el momento en que se inscriben al curso ya que pueden pedir amistad ni bien se publica la información sobre la inscripción del curso. (Figura 44)

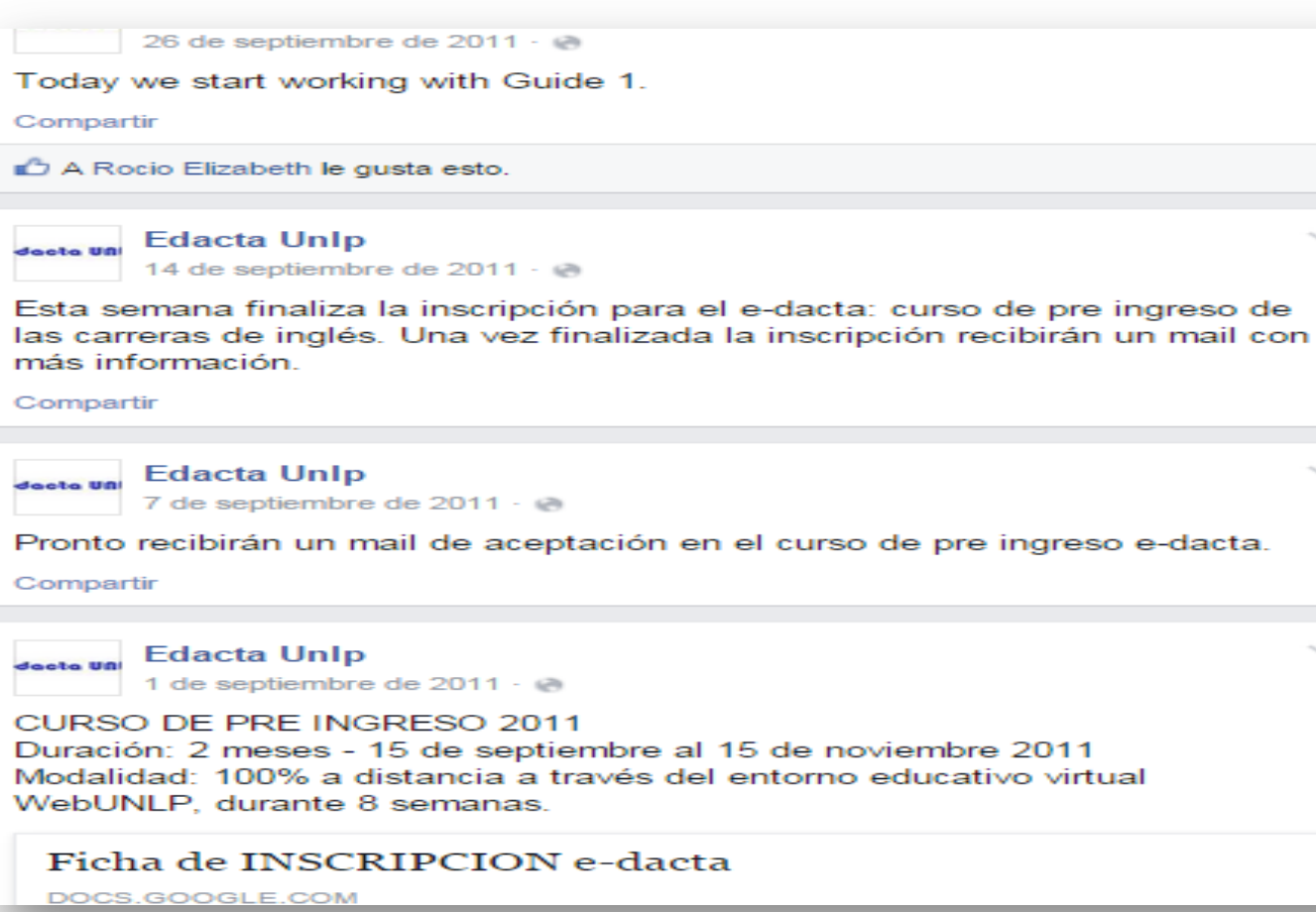

Los aportes en el Facebook ayudan como pistas metacognitivas propiciando un andamiaje durante la cursada del e-DACTA. La idea es invitar a los alumnos a estar atentos ante alguna nueva actividad y ante el inicio de una nueva semana y así notificar a los alumnos e invitarlos a trabajar en el curso desde un sitio donde se conectan con una alta frecuencia. Otros recordatorios o avisos que se publican son las fechas de entrega de trabajos o la realización de las evaluaciones y también se envían mensajes de aliento como acompañamiento hasta la finalización del mismo. (Figura 45) 


\section{Edacta UnIp}

$$
13 \text { de noviembre de } 2011 \text { - e }
$$

Our course is coming to an end. This week you still have time to participate in the forums that you haven't yet, to send you composition task, to ask questions about the faculty and the English courses (NEW FORUM) On the week of the 21st you will be able to do a written and listening self-

evaluation test. And those who wish to sit for an oral test contact us, and we will arrange a suitable time to meet on-line. Hope you are all finel!!

Figura 45

Ejemplo 3 de posteo en el Facebook del e-dacta (Traducción ${ }^{23}$ )

Aclaramos que los alumnos reciben notificaciones vía e-mail en la mensajería interna del EVEA y en casilla personal del alumno por afuera del EVEA en idioma inglés; es por este motivo que la mayoría de los aportes en el muro del Facebook del e-DACTA están escritos en español para poder seguir ayudándolos en el caso que no comprendan bien las instrucciones en la lengua meta. En el resto de las actividades se utiliza la lengua meta, inglés.

Con respecto al uso del EVEA de la UNLP, el $53 \%$ de los alumnos manifestaron que el mismo les resultó sencillo en su uso, y el $41 \%$ dice que no es tan sencillo. El $91 \%$ (figura 46 y 47) nos indica que el acceso está entre los rangos buenos y muy buenos, solo al $9 \%$ le pareció regular. Cabe aclarar que esta pregunta se realiza en las encuestas iniciales, es decir, durante las primeras semanas del curso.

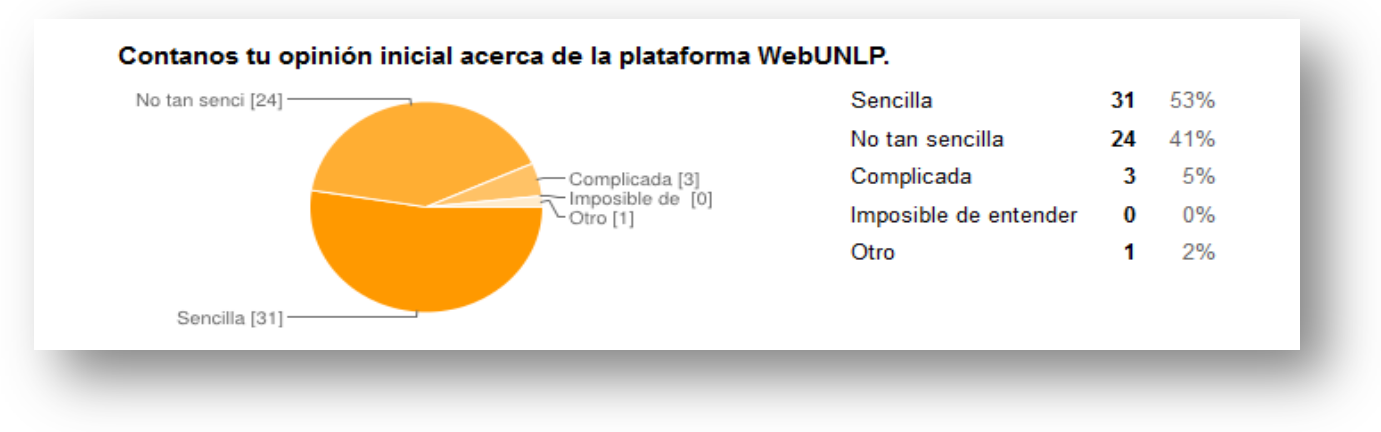

Figura 46

Opinión de los alumnos sobre el EVEA

\footnotetext{
23 Traducción: "Nuestro curso está llegando a su fin. Durante esta semana todavía tienen tiempo para participar en los foros en los que aún no han participado, para enviar la tarea composición, para hacer preguntas sobre la facultad y los cursos de Inglés (NUEVO FORO). La semana del 21 también tendrán que realizar una auto -evaluación que comprender una prueba sobre escritura y otra de escucha. Y, aquellos que deseen realizar un examen oral, pónganse en contacto y arreglaremos un horario conveniente para encontrarnos online. j!!Espero que todos se encuentren bien!!!"
} 


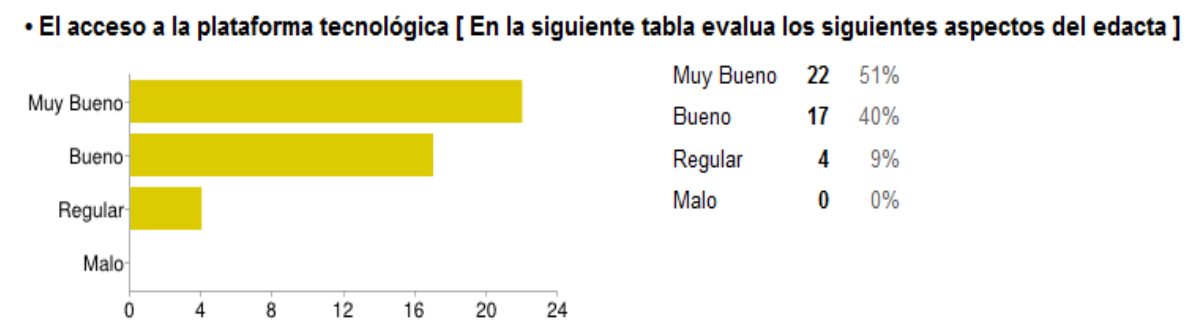

Figura 47

Acceso al EVEA

Cuando los alumnos se encuentran con un nuevo entorno y una nueva modalidad de aprendizaje les cuesta entender la navegación y el formato del curso; pero esta sensación de estar perdidos se desvanece después de las primeras semanas que es cuando comienzan a acostumbrarse al entorno, y a aprender a autorregular sus aprendizaje y a desarrollar nuevas estrategias de estudio, poniendo especial atención a las metacognitivas, ya que son esenciales en estos ámbitos de estudio. Es interesante leer la opinión de un alumno sobre este tema en la figura 48.

Al principio me costó un poco habituarme porque prefiero tener las cosas en papel antes que en la pantalla (me las arreglé imprimiendo las cosas) y también porque no conocia el entorno.

Figura 47

Comentario sobre el uso del EVEA

La encuesta inicial finalizó con las preguntas “¿Creés que es necesario usar las nuevas tecnologías en la enseñanza? ¿Por qué?” y de las repuestas de los alumnos resumimos lo siguientes conceptos:

- La enseñanza en general debería usarlas, ya que otros sectores de la vida se modernizan con ellas.

- Usarlas implicaría disminuir la brecha que hay entre los que saben usarlas y los que no.

- Son de fácil acceso a la información y rápidas para obtener datos además de ser prácticas y cómodas. 
- Llegan a más personas; a personas que están a la distancia o con algún impedimento físico.

- El uso de las mismas permiten que más gente acceda a distintos saberes desde otros lugares y no solo desde una institución educativa.

- Facilitan la enseñanza, y amplifican las posibilidades de aprender.

- Agilizan la administración de los tiempos y recursos personales.

- Nos permiten estar actualizados.

- Es una gran posibilidad para aquellos que eligieron o están por elegir estas carreras.

Este resumen realizado con las respuestas brindadas por los futuros alumnos nos demuestran cuan presentes están y que importantes son para ellos las TIC en la educación. Si bien en las encuestas manifestaron al inicio del curso una incomodidad o sentimientos de rareza al estudiar en línea, luego descubrieron que el espacio del EVA les provocó un acostumbramiento positivo al lograr comprender mejor su funcionamiento. Pero aún así, destacaron que lo mejor que sintieron que les brindó el entorno fue la posibilidad de conocer a sus futuros compañeros y de interactuar con ellos y los tutores.

\subsection{Conclusión}

Las encuestas aportaron información muy valiosa que nos ayudaron a comprender mejor el perfil del alumno aspirante de las carreras inglés aportando con evidencias claramente expuestas en las respuestas dadas a las preguntas de las encuestas. Asimismo, con las mismas nos nutrimos de los datos que nos brindaron las encuestas en relación a una información muy valiosa que ayudo e impulsó a realizar modificaciones como por ejemplo: el tiempo de ejecución del curso, los espacios de reflexión metacognitivos, los modos de difusión del curso incorporando nuevas herramientas tecnológicas y optimizando así las formas de comunicar, de brindar información y de mejorar la interacción, eje fundamental de nuestro curso. También nos ayudaron en darnos cuenta que íbamos por un camino correcto en relación a los objetivos propuestos del e-DACTA, es decir, de acompañar, guiar, y mostrar nuestras carreras de inglés en la facultad, FAHCE, y la universidad, UNLP.

Los alumnos expresaron su opinión sobre la experiencia del curso e-DACTA con diferentes adjetivos muy positivos y alentadores: maravillosa, excelente, útil, interesante, genial; aunque también manifestaron sentirse raros o confundidos al principio por no haber trabajado en línea con anterioridad. Según se expresaron en las encuestas los alumnos ven 
en su gran mayoría a esta experiencia nueva de diversas maneras. Desde el punto de vista académico resultó interesante y motivante en relación a la adquisición de herramientas para comprender mejor su nivel de inglés, y además les permitió conocer algunos aspecto del ámbito universitario desconocidos para ellos. Y desde el punto de vista lo social, les facilitó el hecho de poder hacer nuevos, y tal vez futuros, compañeros y profesores. También manifestaron, desde lo cognitivo, haber aprendido nuevo vocabulario y nuevas estructuras gramaticales.

Otro dato interesante es que el curso e-DACTA traspasó las fronteras de nuestro país llegando a países limítrofes como Chile, Paraguay $Y$ Uruguay, otros de Latinoamérica como Perú, Venezuela, Ecuador y Colombia y uno de Europa, España. En este caso podríamos decir que superó nuestras expectativas geográficas. 


\section{Capitulo 6}

\section{La Metacognición en la Distancia}

\subsection{Introducción}

En este capítulo vamos a describir las estrategias metacognitivas propiciadas por la propuesta didáctica de nuestro curso e-DACTA. Destacaremos la importancia en los roles de los tutores y la confección de los e-portfolios por parte de los alumnos. Ya no habíamos explayado sobre la importancia de crear espacios que impulsen el desarrollo de las estrategias metacognitivas y la importancia de poseer los conocimientos metacognitivos en el capítulo 1.5 (página 37) de este estudio de tesis. También podemos ver en los apéndices 14 y 15 la consigna y ejemplos de e-portfolios.

\subsection{El uso de e-portfolios en los cursos a distancia}

El portfolio es una carpeta con documentos que pueden estar compuestos por diferentes formatos (textos, gráficos, multimedia) o un espacio (en el caso del "e-portfolio", un documento digital o espacio virtual) en donde el alumno puede guardar una colección de evidencias de trabajos realizados por él, reflexiones metacognitivas de su aprendizaje, artículos de lectura relacionados con sus estudios, formación profesional, intereses personales, etc. Estos documentos pueden ser privados, públicos o compartidos con una audiencia limitada dependiendo de los usos del mismo.

Barberá et al (2006) han hecho un estudio exhaustivo sobre la implementación de eportfolios en cursos a distancia, ellos resaltan cuan importantes son para los alumnos: "Desde la perspectiva del estudiante, la elaboración de un portfolio académico le permitirá aprender a planificarse y a autogestionarse a partir de las orientaciones del docente, a ser más autónomo en el proceso de aprendizaje y a promover la toma de decisiones durante la actividad educativa; en definitiva, le permitirá y le facilitará la regulación de su propio proceso de aprendizaje." 


\section{La enseñanza de una lengua extranjera utílizando tecnología dígital}

El uso de e-portfolio (Barberá y Martin, 2011: 32) ayuda al alumno a crear un ámbito de trabajo donde su aprendizaje adquiera significado y sea efectivo y también para que el alumno sea responsable de su propio aprendizaje potenciando la reflexión y la autoevaluación del mismo. Más adelante Barberá y Martin (2011: 36) hacen referencia del portfolio como una herramienta didáctica que propicia el desarrollo del conocimiento metacognitivo.

Gracias a la propuesta estos espacios el alumno puede escribir sobre las fortalezas, las dificultades, los progresos y los éxitos de los procesos de aprendizaje; el alumno se focaliza en una profunda autorreflexión (metacognición) de su propio proceso de aprendizaje que puede provocar sentimientos de satisfacción por lo aprendido o sentimientos de insatisfacción por no haber aprendido, provocando cambios en el curso de sus estudios, los cuales se pueden manifestar en pedidos de ayuda a sus tutores o pares directa o indirectamente.

La intención en el uso de los e-portfolios es poder ayudar a incrementar la participación de los alumnos en los EVA y a que los alumnos sean más conscientes de su trabajo provocando un mayor compromiso en sus estudios.

Según Gallego et al ( 2009) el portfolio es una estrategia de aprendizaje. Existen varios tipos de e-portfolios desde el punto de vista de sus usos (Mellado, 2007, p. 86 en Gallego et al (2009)): "como recurso pedagógico, inclusión y revisión de evidencias, intervención en el aula, análisis críticos, retroalimentación, evaluación de proceso, autoevaluación, interacción, instrumento de evaluación, etc.” Y que según los objetivos pueden ser utilizados para "autoevaluar, documentar el aprendizaje a lo largo del tiempo, documentar el desarrollo profesional, curriculum, evaluación, acreditación para promoción presentación de logros, reflexión, etc." (Gallego et al, 2009)

McCombs (1988) en Rodriguez Fuentes, Gustavo (2009) resume lo hasta aquí expuesto en referencia a los factores o "sistemas" como los llama McCombs que propician la adquisición del conocimiento:

\footnotetext{
"el sistema metacognitivo, en interacción con el sistema cognitivo y el sistema afectivo, implicará tanto el conocimiento (conciencia) como el control (autorregulación) de la cognición y del afecto, la planificación estará especialmente afectada por las percepciones que el aprendiz tenga de los requisitos de la tarea y por los esquemas, conocimientos y estrategias de los que el sujeto dispone al abordar cada tarea de aprendizaje."
} 
En el curso e-DACTA se los invita a los alumnos a que realicen reflexiones metacognitivas sugiriéndoles diferentes formatos libres a seleccionar por parte de los alumnos como por ejemplo en formato de presentaciones de PPT, blogs, wikis, documentos de tipo Word, etc. Mostraremos algunos ejemplos muy creativos en sus diseños y útiles en relación a la información propiciada para mejorar las guías por ejemplo y para saber sobre sus ritmos de trabajo o para ayudar ante dudas.

Dos alumnas abrieron y diseñaron espacios en formato de blogs ${ }^{24}$ para escribir su eportfolios. El primero de ellos podemos observar que el alumno lo inició pero luego lo abandonó, y el segundo (figura 49) lo utilizó durante las semanas del curso.

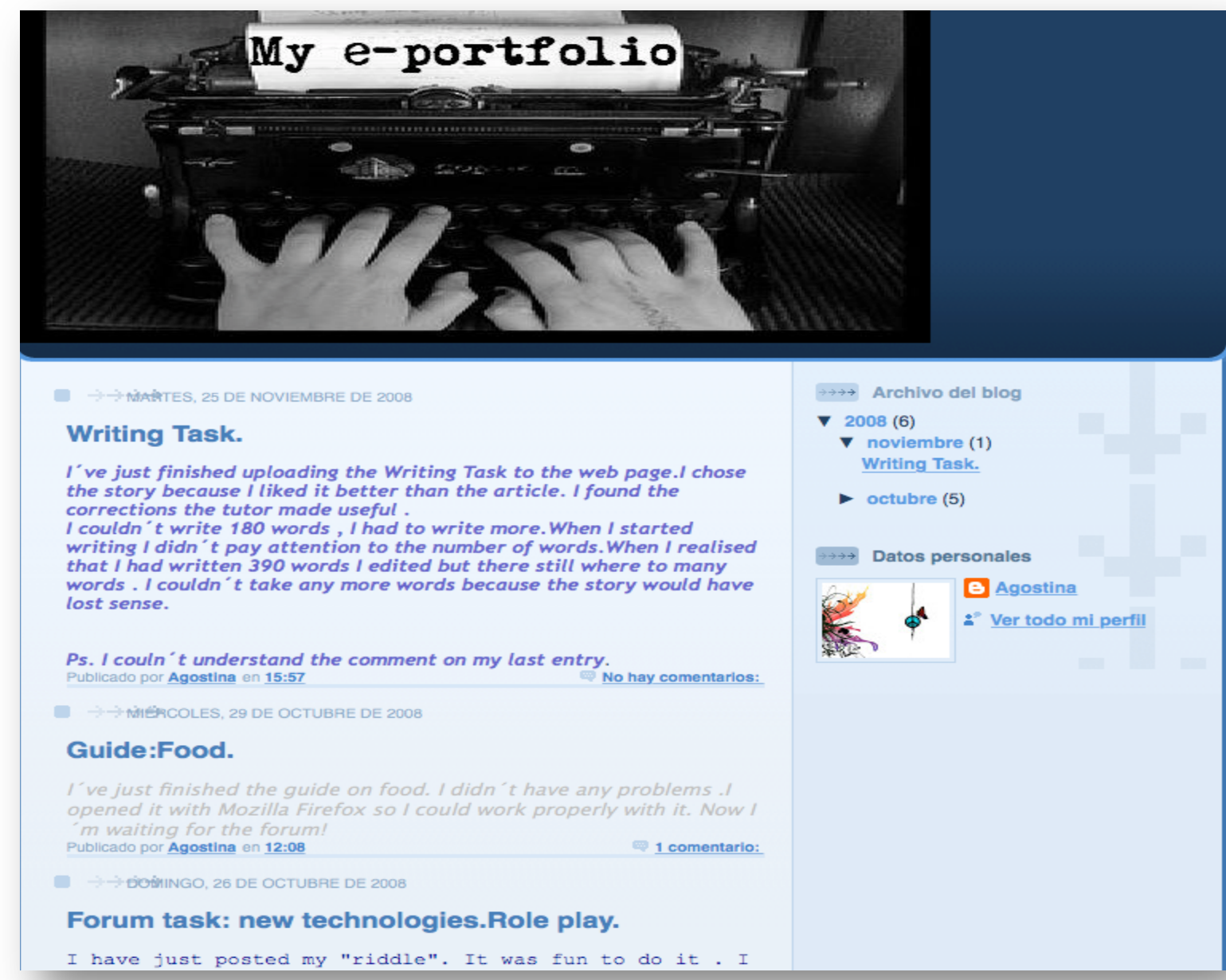

Figura 48

Ejemplo de e-portfolio con formato de Blog

\footnotetext{
${ }^{24}$ Las siguientes URL son de dos ejemplos de blogs de los alumnos: http://agorusiani.blogspot.com/ http://mylearningportfolio.blogspot.com
} 


\section{La enseñanza de una lengua extranjera utilizando tecnología dígital}

Otros alumnos prefirieron utilizar los formatos de un procesador de texto usaron el software Word de Microsoft. Un ejemplo recibido en este formato lo compartimos en el espacio en la web llamado /ssuu: http://issuu.com/lilianasimon/docs/e-portfolio_suarez

También los alumnos optaron por otros formatos para armar sus e-portfolios: el uso de presentaciones en formato de PPT de Microsoft. Un ejemplo de e-portfolio se puede visualizar en el siguiente enlace: http://issuu.com/lilianasimon/docs/my_e-portofolio_alumna_pf

Algunos e-portfolios son estéticamente más atractivos que otros debido a los formatos que los alumnos eligieron y por las imagines o fotografía o animaciones utilizadas para acompañar los textos; aún así, destacamos los aportes de los e-portfolios que contenían solamente textos, ya que también nos brindaron una información substanciosa sobre las expectativas, compromisos, ilusiones o desilusiones de los alumnos además de compartir las reflexiones metacognitivas de su propio progreso en el curso que el trabajo en el EVEA les provocó a cada uno de ellos.

Al leer los e-portfolios que compartieron los alumnos se observó un gran compromiso por parte de los alumnos; se explayaron sobre las emociones que les provocaron al interactuar con sus compañeros y con el EVEA. Muchas de estas emociones ya estaban presentes en la misma proporción que en los datos que arrojaron las encuestas finales. Volvieron a expresar la sensación de ansiedad y entusiasmo que les provoca pertenecer al curso. Manifestaron si tuvieron problemas y si se solucionaron los mismos. Comentaron sobre las actividades que realizaron cada semana resaltando las partes en que se encontraron con más dificultades o si tuvieron algún inconveniente en relación al uso del EVEA y/o en relación a sus conocimientos de inglés. Incluso algunos alumnos expresaron que notaron que deben leer y estudiar más, otros se alegraron al realizar las actividades casi sin errores. También indicaron si les gustó y si disfrutaron o no las guías desde el punto de vista de los temas tratados. Las descripciones textuales de las emociones muchas veces fueron acompañadas por emoticones que robustecieron las emociones que querian expresar; resaltaron estas emociones de felicidad, confusión, tristeza o sentimiento de culpa con caritas felices, perplejas, tristes, avergonzada, etc. por no haber cumplido con alguna tarea por diferentes motivos: viajes, enfermedades, estudios, exámenes, etc.

También manifestaron sentir orgullo ante la felicitaciones por su trabajo por parte de sus tutores. Y por ultimo, no queremos dejar de lado un aporte en los e-portfolios donde una alumna pondera a nuestro curso por el hecho de haber aprendido mucho sobre tecnología 
acotando que "hizo cosas que nunca había hecho antes": escribir e-portfolios en formato PPT, bajar y subir archivos, bajar software, participar en foros, etc.

\subsection{Conclusión}

El aporte que los alumnos nos dejaron en los e-portfolios fue tan valioso como las respuestas que nos dejaron en las encuestas analizadas en el capítulo anterior. El trabajo metacognitivo realizado por los alumnos fue excelente ya que ayudó a comprender mejor sus gustos, necesidades, emociones durante todo el curso. Al haber usado e-portfolios los alumnos lograron autorregular su aprendizaje, reflexionar sobre lo aprendido y comprender sus necesidades individuales en que cada uno de ellos debían mejorar para lograr iniciar con éxito la carrerea elegida. 


\section{Capitulo 7}

\section{Conclusiones}

\subsection{Introducción}

El presente trabajo de tesis ha tenido como objetivo principal realizar la descripción de dos propuestas pedagógicas junto con el análisis de la interacción en los foros y chats del curso e-DACTA. En el recorrido del trabajo se han realizado diferentes aportes que resumiremos a continuación junto con las conclusiones especificas del estudio de las interacciones y los futuros trabajos.

Comenzaremos con la exposición de los aportes realizados como producto del desarrollo de este trabajo de tesis. Luego, presentaremos el estado del arte en relación a la enseñanza de lenguas y las tecnologías de enseñanza, el estudio comparativo de los proyectos DACTA y e-DACTA y el estudio de las interacciones en el e-DACTA que a su vez se subdividen desde diferentes perspectivas: a) la social y emocional, b) la pedagógica y c) la tecnológica. $Y$, para finalizar, haremos una breve descripción de los trabajos futuros que se originaron a partir del proceso de esta investigación.

\subsection{Aportes de la presente tesis}

El desarrollo de este trabajo de tesis ha permitido:

- La composición de un estado del arte de los procesos de enseñanza y aprendizaje de lenguas extranjeras en general y en particular en los procesos de enseñanza y aprendizaje de una lengua extranjera, integrando tecnologías de enseñanza y aprendizaje.

- El estudio de investigaciones en relación a la presencia social relacionadas con las interacciones en la presencialidad y en la educación a distancia, los cuales permitieron concretar el estudio específico de las interacciones virtuales. Se tomaron pues, un conjunto de indicadores de presencia social analizados por Garrison y Anderson (2005) y también adaptamos indicadores de presencia en la interacciones 
virtuales otros elementos que adaptamos del análisis en al presencialidad de otros autores, Tarone (1981) en Armendariz y Ruiz (2005).

- El análisis de datos extraídos de las respuestas dadas en las encuestas y eportfolios del curso.

\subsection{Marco teórico y estado del arte}

Después de haber indagado sobre las enseñanza del inglés mediada por tecnología digital y las interacciones resultantes por el uso de los EVEA, de haber recorrido los diferentes espacios dentro de los EVEA que han cobijado a nuestro curso desde su primera cohorte en el año 2008 y de haber contemplado los elementos que se ponen en juego para propiciar las interacciones de los participantes del curso, expondremos en detalle en los siguientes párrafos sobre nuestro recorrido en función a la descripción dentro de un marco teórico y estado del arte de las propuestas pedagógicas: el libro DACTA y el curso de preingreso denominado e-DACTA.

Vigostsky y Bruner nos abrieron el camino marcando la importancia de la presencia social facilitada en las interacciones entre pares y lo maestros, ya que la misma es esencial para que el aprendiente avance en su aprendizaje a través de la ZDP (Zona de Desarrollo Próximo) junto con la presencia docente que provee la guía y el apoyo del experto y la colaboración de sus pares. Es fundamental propiciar un sólido andamiaje para que el alumno desarrolle sus estrategias de aprendizaje y logre aprender, en nuestro caso, una LE.

La presencia cognitiva se apreció con Krashen (1982) quien nos guió en lo más profundo con las teorías cognitivas en relación a los que sucede dentro del individuo. Lo aprendido se manifiesta en el viaje que en la adquisición de una lengua realiza desde la 'entrada' (INPUT) del conocimiento hasta la "salida' (OUTPUT) del conocimiento y que finaliza en el conocimiento apropiado (INTAKE) por el individuo. Los lineamientos pedagógicos seguidos por el curso coinciden con los de particularidad, practicabilidad y posibilidad que se basan en los parámetros pedagógicos de la pedagogía del postmétodo (Kumaravadivelu, 2001). Este sistema tridimensional propuesto se aplicó a través de la experiencia de los años en que el e-DACTA y se implementó basándonos en la lista de macro-estrategias de "maximizar las oportunidades de aprendizaje, facilitar una interacción 
negociada, minimizar los desajustes perceptuales, activar heurísticos intuitivos, propiciar una conciencia lingüística, contextualizar entradas lingüísticas, integrar habilidades idiomáticas, promover la autonomía del alumno, incentivar la conciencia cultural y garantizar la pertinencia social." (Kumaravadivelu, 2001)

La evolución de la tecnología en estos años nos ayudó a comprender mejor la integración de las TIC en la enseñanza de una LE. Pudimos ver en nuestro estudio como CALL fue evolucionando a través del tiempo siempre acompañado por las metodologías de enseñanza de una LE.

Las otras denominaciones con que se fue denominado el acercamiento de las tecnologías a la enseñanza de lenguas fue variando CALL, iCALL, CMC, CMCL, MALL, etc. Todas estas siglas denotan una necesidad por parte de los investigadores lingüistas y tecnológicos en estudiar y buscar evidencias sobre la integración de las TIC en la enseñanza de lenguas y que demuestren los beneficios del uso de las mismas. También muchas tecnologías ya sean programas de software, dispositivos, etc. que habían tenido mucho auge en su uso para la enseñanza de lenguas han quedado en desuso y hasta en el olvido. Cabe destacar que, en nuestro caso, los soportes de los EVEA continúan vigentes y se han expandido en el uso de las mismas tanto en curso bajo la modalidad a distancia como en aquellos bimodales que se utilizan en la mayoría de las universidades.

\subsection{Sobre el estudio comparativo de los proyectos DACTA y e-DACTA}

Tanto el libro DACTA como el curso virtual e-DACTA han ofrecido durante estos años una guía de conocimiento y de práctica para todos aquellos interesados en estudiar carreras de profesorado, traductorado y licenciaturas de inglés en la UNLP. La practicidad del libro en relación a la lectura y comprensión de textos junto con los ejercicios de práctica de la lengua inglesa han resultado ser un libro apropiado para el momento de uso que es anterior al curso de ingreso de las carreras mencionadas.

La evolución entre la primera y segunda propuesta pedagógica se realizó al tomar como base el tipo de material de estudio del libro DACTA junto con sus contenidos y lineamientos metodológicos y administración de las tutorías de acompañamiento mediante una transposición didáctica que convirtió la primera propuesta de pre-ingreso en papel en un nuevo formato: el curso virtual a distancia e-DACTA. 
El curso virtual e-DACTA hizo uso de las herramientas de foro y chat, provocando un espacio de interacción amigable propiciando el desarrollo cognitivo en los procesos de enseñanza y aprendizaje de una LE. Además el EVEA permitió otras formas de evaluaciones además de la autoevaluación que los alumnos realizan al trabajar en el entorno: el alumno es evaluado en forma grupal en las actividades del foro, es decir, se les entrega un informe general como guía de estudio remedial de errores comunes que detectamos en los aportes, e individualmente con evaluaciones sobre el uso de la lengua, redacción y evaluaciones de comprensión de lectura y de escucha. Estas actividades no se pudieron realizar con la primera propuesta pedagógica del DACTA y sus tutorías.

Pudimos también observar que los alumnos hicieron poco uso (sólo 10 consultas registradas) de las tutorías del DACTA facilitadas en los dos primeros años de su vigencia. Esta fue la razón principal ante la necesidad que notamos de tener que armar un puente de articulación más interactivo entre el nivel secundario y la universidad: el curso e-DACTA.

La propuesta virtual del e-DACTA facilitó la posibilidad de proporcionar una interactividad significativa no solo en referencia a la interactividad entre contenidos y alumnos, sino también en relación a las propuestas de interacción entre pares y docentes propiciadas por las herramientas sincrónicas y asincrónicas.

La evolución y mejora de la segunda propuesta pedagógica radica principalmente entre otras cualidades que desarrollaremos en detalle en las presentes conclusiones, en que el e-DACTA ofrece la posibilidad de ser realizado por una mayor cantidad de alumnos que se encuentran en localidades dispersas (otras ciudades, provincias y países) autorregulando los tiempos de estudio con el andamiaje provisto por los docentes del curso e incrementando las interacciones entre los docentes y alumnos.

En referencia a las características distintivas de los cursos virtuales a distancia, podemos decir que el curso e-DACTA se distingue por las siguientes características:

$\checkmark$ Gratuito: pertenece a una universidad publica.

$\checkmark$ Ecológico: no es necesario imprimir ningún material.

$\checkmark$ Ubicuo: se puede trabajar en cualquier lugar.

$\checkmark$ Democrático: el acceso al curso en relación al tiempo y lugar.

$\checkmark$ Flexible: los tiempos son pautados pero amplios y flexibles. 
$\checkmark$ Colaborativo: el diseño de tareas propician el trabajo grupal.

$\checkmark$ Reflexivo: el diseño didáctico propicia tareas metacognitivas que estimulan a los alumnos a desarrollar una actitud critica frente al material de estudio y al uso apropiado de la lengua.

$\checkmark$ Autorregulable: en relación al programa propuesto y los tiempos y esfuerzos en la dedicación de los estudios de los alumnos en la virtualidad.

Si bien el e-DACTA heredó la propuesta de enseñanza del DACTA en relación al tipo de tareas a realizar en las guías de estudio del e-DACTA y las tutorías, el resto de la propuesta fue innovadora y atractiva debido a la integración de las nuevas tecnologías y en relación a la incorporación de las actividades sincrónicas y asincrónicas como chats, foros, uso de redes sociales como Facebook para difusión y comunicación del curso y blogs como plataforma para armar los e-portfolios.

\subsection{Conclusiones especificas}

\section{Sobre el estudio de las interacciones en el e-DACTA}

Creemos que el alumno que estudia lenguas aprende interactuando, es decir, necesita de una alta exposición a la LE en diferentes contextos que propicien las habilidades del habla tanto en los formatos orales y como en los textuales. Cómo ya dijimos anteriormente, la interacción en nuestro curso virtual se produce ante la necesidad que tiene el alumno de comunicarse (p.86, cap.4) impulsado por diferentes causas: resolver una tarea, aclarar dudas, conocer a sus pares y docentes, socializar, pero sobre todo para aprender una LE.

Después de haber analizado en profundidad los contenidos de dos chats y dos foros del e-DACTA podemos llegar a las siguientes conclusiones desde diferentes perspectivas y presencias que observamos en los dos proyectos estudiados, el libro Dacta y el curso virtual e-DACTA. Ellas son:

- La presencia social y emocional

- La presencia Pedagógica

- La presencia Tecnológica 


\section{La enseñanza de una lengua extranjera utilizando tecnología dígital}

\subsubsection{Desde el punto de vista social y emocional:}

La presencia social (Garrison y Anderson, 2005) estuvo presente en las interacciones estudiadas tanto desde lo afectivo como desde la comunicación abierta y la cohesión. La participación activa en los espacios de los foros, chats y e-mails aportó datos muy concluyentes junto con las encuestas y el conocimiento metacognitivo expresado por los alumnos en los e-portfolios. La información recolectada desde estos espacios nos proveyó de un material muy rico para poder conocer mejor y dibujar un perfil del alumno aspirante a las carreras de inglés de la FAHCE, UNLP y el cual está impregnado de emociones de diferentes dimensiones: ansiedades, miedos, alegrías y sobre todo de deseos de formar parte de una nueva comunidad académica.

Desde los primeros aportes en el primer foro en que los alumnos compartieron una presentación personal observamos que se logró la conformación de una comunidad virtual en el EVEA. Al presentarse (Foro 1) ante sus compañeros y durante el primer chat también evidenciamos la necesidad de comunicarse haciendo uso de la LE que también es objeto de estudio en nuestro caso. Lograron desde el principio romper barreras al vencer temores y participar en nuevo entorno (para la mayoría completamente nuevo) usando una LE, pidiendo y brindando ayuda a aquellos que la requerían.

Los aportes realizados en los foros revelan que fueron constructivos en relación a las tareas planteadas en las consignas y desarrolladas apropiadamente en el marco del espacio de la herramienta del foro. En el foro 2 siguieron los pasos de la tarea de manera adecuada logrando cumplir con los objetivos propuestos armando un dialogo que siguió todo el tiempo el hilo en pos de la tarea.

La comunicación sincrónica y asincrónica a través de los chats y foros propiciaron la presencia social que se inicia en cada uno de los individuos y que se plasma en una comunidad virtual aportando dinamismo y sentido de pertenencia a un grupo social que se encontró en un tiempo determinado antes de ingresar a la facultad acobijados por las nuevas tecnologías cuyo entorno virtual propicia el aprendizaje mediante la interacción entre pares y docentes y promovido por la interactividad y la autoevaluación de los materiales de estudio que guían a los integrantes del curso para saber cuales son los conocimientos necesarios para estudiar inglés en la FAHCE, UNLP. El deseo de pertenecer a una nueva comunidad y de conocer más sobre las carreras elegidas impulsan a los alumnos a querer participar en las tareas propuestas propiciando una exposición a la lengua 
que favorece el aprendizaje de la LE al utilizarla en contextos auténticos mediados por el marco del chat y del foro.

A medida en que los alumnos se apropian del entorno (es decir, van conociendo el funcionamiento del EVEA y van comprendiendo el tipo de tareas a realizar en el curso) comienzan a entablar nuevas relaciones sociales que se hacen más evidentes en los chats. El diálogo que surge en los encuentros de chats funcionan como un andamiaje para los alumnos a través de interacción la cual promueve los intercambios de información, elaboración de trabajos individuales y de trabajo colaborativo. Notamos que en las salas de chats los alumnos se sienten motivados y esto se refleja en varios elementos presentes en las interacciones (el alto uso de emoticones, ciertas palabras, comentarios, abreviaciones y/o puntuación remarcada) y sobre todo, en el compromiso que muestran al realizar las tareas que requieren de una respuesta inmediata al estar simultáneamente comunicándose dentro del espacio provisto por el EVEA.

Si bien la participación en los foros impulsadas por las consignas de las tareas proponen intercambios que se relacionan con la vida personal y social de los alumnos, observamos que la tendencia en los foros en la producción de aportes fue más formal y junto con un uso del registro lingüístico y gramatical apropiado, por este motivo los indicadores de afecto son más altos en los chats que en los foros.

Por ultimo, recordamos que el objetivo primario de ambas propuestas pedagógicas es aportar una guía a los alumnos al ofrecer datos sobre la vida académica, el entorno geográfico de la facultad y al acompañar en el auto-descubrimiento del nivel de inglés requerido para poder comenzar a estudiar las carreras de inglés en la Facultad de Humanidades y Ciencias de la Educación de la Universidad Nacional de La Plata.

\subsubsection{Desde el punto de vista pedagógico:}

Las tareas en los foros del e-DACTA fueron pensadas y desarrolladas en los espacios tecnológicos provistos por el entorno amigable del EVEA y organizadas para ser realizadas después del estudio de las guías con lecturas motivadoras de textos, audios y videos auténticos y ejercicios de practica y de estudio de vocabulario, estructuras gramaticales, cohesión y cohesión entre otros áreas propias del proceso de enseñanza y aprendizaje de una LE. 
Al comparar las actuaciones de los alumnos en los chats y foros pudimos evidenciar lo aclamado por Levy $(2006,98)$ que afirma que mientras la comunicación sincrónica (chats) parece centrarse en el significado y dejar de lado las convenciones de la lengua, la comunicación asincrónica (foros) concede más tiempo a los alumnos para elaborar su respuestas y monitorear la puntuación y ortografía. Aunque Levy (2006) agrega que aún así en la comunicación asincrónicas se observaban oraciones mal formadas, errores de puntuación y ortografía.

Podemos afirmar entonces que tanto en el chat como en el foro se puede notar claramente que el medio (las herramientas electrónicas propia del chat y del foro) predispone a un comportamiento adecuado por parte del alumno en relación a los registros lingüísticos y no lingüísticos (emoticones) utilizados, dejando evidencias en la formalidad de los aportes; siendo así el chat más informal y el foro más formal. Esto se evidencia en el uso del vocabulario mas informal y del uso de estructuras más simples. En los foros pudimos observar que los alumnos no cometen casi errores gramaticales o uso inadecuado de la lengua.

En los encuentros sincrónicos también pudimos notar las características propias del chat de espontaneidad y de inmediatez que favorecen el desarrollo de las estrategias metalingüísticas del aprendizaje y que se evidencian en los momentos en que los alumnos efectúan las autocorrecciones de sus producciones escritas.

Observamos también que en el corpus de los chats analizados se evidenció la coconstrucción de conocimiento en aquellos casos en que los alumnos se auxiliaron entre pares sin la ayuda de los expertos (en nuestro caso, los tutores) en la búsqueda de una palabra o idea a desarrollar, en el orden en el dialogo, en seguir el hilo de la conversación, en el respeto de los tiempos y formas respetuosas logrando una socialización adecuada y amable en los encuentros de chat.

En relación al uso de la lengua materna, a la cual recurrimos como docentes en determinados casos (el alumno no comprende, por ejemplo, una consigna o información importante para llevar a cabo alguna tarea) notamos que en general el alumno del nivel del curso recurre a ella con más frecuencia en modalidades de enseñanza presenciales. En cambio, notamos que en el curso virtual e-DACTA el porcentaje de uso de la lengua materna por parte de los alumnos fue muy bajo: 8 veces en dos chats y nunca en los foros. La lengua materna, español, no aparece en los aportes de los foros y es limitada su 
recurrencia en los chats. Podríamos concluir con estos datos que la mayoría de los alumnos que participaron de las actividades de los foros y chats poseen recursos lingüísticos esperados para el ingreso a las carreras de inglés de la FAHCE, UNLP.

La presencia del docente en el e-DACTA fue fundamental no sólo para lograr armar la comunidad de aprendizaje sino para guiarlos, motivarlos, retroalimentarlos y hacer modificaciones cuando se consideraban necesarias en el cronograma ante algún imprevisto o necesidad de ayuda. También su rol es muy importante en la evolución de los foros iniciándolos, manteniéndolos activos y armando las conclusiones para darles un cierre.

El tutor del e-DACTA, además de los roles comunes que posee todo tutor en línea, actúa como evaluador con el fin de guiar al alumno en su autoconocimiento de la lengua. Su roles varían desde motivador, orientador, observador hasta el de cambiar de posición y tomar el rol de alumno para mostrar ejemplos de las actividades propuestas.

\subsubsection{Desde el punto de vista tecnológico:}

Gracias al desarrollo y evolución de las nuevas tecnologías pudimos poner en marcha el curso virtual. La posibilidad de poder alojar un curso en líneas en un EVEA nos permitió desarrollar el curso e-DACTA. Tanto WebUNLP (cohortes del 2008 al 2013) como AulasWeb (utilizada desde el 2014), los EVEA de la UNLP, han propiciado el uso de las herramientas tecnológicas que favorecen la interacción mediante los espacios de mensajería, foros y de chat que las mismas proveen; si bien todos los espacios del curso eDACTA fueron descriptos y estudiados, nuestros objeto de análisis de estudio fueron los espacios de chat $y$ de foros.

Para la gran mayoría de los alumnos el uso de las tecnologías de un EVEA era una novedad. Pudimos constatar, con aquellos alumnos que lograron cumplir con los objetivos mínimos del curso y que respondieron las encuestas del curso e-DACTA compartiendo sus opiniones sobre sus experiencias, que a la mayoría les resulto un poco difícil al inicio del curso en relación al aprendizaje del uso y de la adecuación del EVEA junto con la nueva forma de estudio que la modalidad a distancia implica; pero que al finalizar la primera semana, el entorno ya se había tornado amigable y motivante. Esperaban con ansias comenzar la semana con nuevas actividades demostrando un claro interés y responsabilidad por parte de los alumnos. 
Los encuentros sincrónicos propiciados por la herramienta del chat facilitaron la realización de tareas tales como conocer a los otros (saber quiénes son, dónde viven, sus gustos, sus expectativas, etc.), planificar tareas, discutir o compartir cuestiones que no requieren de mucha preparación previa. Estas tareas las realizaban a veces sin la presencia del tutor demostrando un interés por socializar y conocer más sobre las nuevas carreras en general.

Los encuentros asincrónicos mediados por la herramienta de los foros propiciaron un trabajo autorregulado por los alumnos al realizarse en diferentes momentos al no ser necesario estar conectados simultáneamente para cumplir con la tareas. Una de las razones principales por la cual un individuo decide realizar un curso virtual es por su característica distintiva de ubiquidad que poseen los cursos virtuales y la posibilidad de trabajar con tiempos más flexibles que en la presencialidad.

Otras herramientas tecnológicas utilizadas por el coordinador fueron los formularios para alojar las encuestas y las presentaciones iniciales en Google Drive. También se abrieron blogs y wikis que utilizaron los alumnos que para armar los e-portfolios. Las encuestas online realizadas con los formularios de Google nos proporcionó junto con el trabajo de e-portfolios un material rico en reflexiones y opiniones que evalúan el curso eDACTA y que nos ayudaron a tomar decisiones en relación a cambios de material o metodologías a seguir. Los e-portfolios fueron armados con diferentes herramientas tecnológicas elegidas por el alumno como por ejemplo, documentos de procesador de texto, presentaciones de PPT, blogs y wikis. Estas actividades también fueron de ayuda para que los alumnos pudieran no solo expresar sus descubrimientos metalingüísticos y metacognitivos, sino que a través de la escritura y la elaboración de los e-portfolios los alumnos pudieran incrementar su exposición y practica de la LE.

\subsection{Trabajo Futuro}

Hemos observado en el presente estudio que la presencia social a través de la interacción es fundamental en relación a que la misma posibilita un acompañamiento en todas las etapas de un curso a distancia desde los inicios del mismo, cuando los alumnos comienzan a formar parte de un nuevo grupo social hasta lograr integrarse al mismo, desde lo informativo y pedagógico y durante las instancias de seguimiento y de evaluaciones. 
Por este motivo es que nos gustaría ahondar más en nuestros futuros estudios sobre todo en las estrategias y recursos lingüísticos y no lingüísticos que propician un andamiaje más completo con la incorporación gradual de tareas basadas en el uso de otros sistemas de mediación con tecnología digital: audios, videos y video-conferencias que fomentan una mayor interacción en el desarrollo de las macro-habilidades lingüísticas orales de escucha y de habla de nuestro curso e-DACTA. Nos interesan estudiar estas tareas de producción oral con profundidad, no solo a nivel lingüístico y pedagógico sino también en relación al uso de las tecnologías en la enseñanza extrayendo el valor de las herramientas de comunicación como las herramientas de video-conferencias como Skype o Adobe Connect y otras herramientas de grabación de audios como Voxopop o Voice Thread.

Observamos que, en relación a las actividades metacognitivas de los e-portfolios, no todos los alumnos participaron de estas tareas debido a varias causas: la falta de conocimiento de algunas herramientas tecnológicas, la falta de tiempo o a que estas actividades son dejadas para el final de las semanas y luego no se completan. Si bien realizamos un cambio en relación con este tema, es decir, cambiamos los e-portfolios de las primeras cohortes por foros de reflexiones con aportes en forma grupal, notamos también que no todos dejaron sus reflexiones. Por estos motivos y debido a la importancia en relación a la recolección de datos que estos espacios nos proporcionan, no sólo para llevar a cabo mejoras en la propuesta de pre-ingreso sino para que los mismos funcionen como andamios reflexivos sobre el aprendizaje individual de cada participante del curso, nos gustaría ahondar sobre el uso de e-portfolios y así lograr armar un espacio más interactivo y atractivo para que los alumnos puedan desarrollar las tareas metacognitivas de los eportfolios.

Creemos que la capacitación y actualización permanente de los docentes optimizan las actuaciones docentes en los EVEA. Es por esta razón que consideramos, como futuros pasos, continuar con la capacitación de los tutores en pos de realizar una tarea de seguimiento mayor y mejor dentro del marco de la enseñanza abriendo y compartiendo nuevos espacios de reflexión en relación a la educación a distancia que promueven la optimización en relación a la presencia docente en los futuros cursos tanto con el uso de las herramientas ya utilizadas como foros y chats como en los otros recursos tecnológicos en el párrafo anterior mencionados. 
También tenemos posibilidades de estudiar las aportaciones del presente estudio comparándolas con las de otro curso a distancia de lengua inglesa en el marco de otro contexto cultural pero con edades y niveles de competencia similares y que se encuentren trabajando con algunas de estas herramientas.

Por ultimo, en relación a futuros trabajos, nos queda como desafío conocer y estudiar más en profundidad la participación de algunas alumnos en relación a aquellos alumnos que tienen una presencia vicaria en los cursos.

Concluimos aclarando que el presente trabajo fue realizado con el objetivo de poder compartir con colegas nuestra experiencia de trabajo en la virtualidad en tiempos en que las tecnologías ya son partes de nuestra practicas educativas tanto en las modalidades a distancia como en los cursos presenciales tradicionales. Creemos que nuestro aporte junto con las conclusiones expresadas abren un dialogo a la reflexión y futuras investigaciones sobre la integración de las tecnologías en estos tiempos de desarrollo tecnológico en relación a los procesos de enseñanza y aprendizaje de una lengua extranjera. 


\section{Referencia Bibliográfica}

Armendáriz, Ana y Ruiz Montani, Carolina (2005). El Aprendizaje de Lenguas Extranjeras y las Tecnologías de la Información. Lugar Editorial, Buenos Aires, Argentina.

Bange, P. (1992). À propos de la communication et de l'apprentissage en L2, in AILE Nº1, Paris, Encrages. (pp.53-85).

Barberà, Elena, Bautista, Guillermo, Espasa, Anna , y Guasch, Teresa (2006). Portfolio electrónico: desarrollo de competencias profesionales en la red, Revista de Universidad y Sociedad del Conocimiento, Vol. 3 - Nº 2 ISSN 1698-580X (consulta realizada Octubre 2006) www.uoc.edu/rusc

Barberà, Elena (2005). La evaluación de competencias complejas. EDUCERE. Vol. 31, pág. 497-504

Barberà, Elena y Gregori, Elena de Martín Rojo (2011). Portfolio electrónico: aprender a evaluar el aprendizaje. Editorial UOC.

Bax, Stephen (2003). CALL_past, present and future. Department of Language Studies. Canterbury Christ Church University College, Canterbury,UK. System 31, 13-28.

Bax , Stephen (2011). Normalisation Revisited: The Effective Use of Technology in Language Education. International Journal of Computer-Assisted LanguageLearning and Teaching April-June 2011, Vol. 1, No. 2 (consulta realizada julio 2016 ) https://www.academia.edu/3754724/Normalisation_Revisited_The_Effective_Use_of_Techn ology_in_Language_Education)

Bruner, J. (1988). Desarrollo cognitivo y educación. Madrid: Morata, Compilación de J. Palacios.

Bruner, J. S. (1978). The Role of Dialogue in Language Acquisition. In A. Sinclair, R., J. Jarvelle, and W. J.M. Levelt (eds.) The Child's Concept of Language. New York: SpringerVerlag. 
Chapelle, C.A. (2005). Interactionist SLA Theory in CALL Research. In J. Egbert and G. Petrie, (Eds.) Research Perspectives on CALL, (pp.53-64). Mahwah, NJ: Laurence Erlbaum Associates.

Chiappa, B; Lira, Margarita; Sara, Leonor \& Simón, Liliana (2005). El Rol del la Interacción en la Adquisicion de una Lengua Extranjera. Revista Puertas Abiertas , UNLP. Número 1, ISSN 1853-614X http://www.puertasabiertas.fahce.unlp.edu.ar/numeros/numero-1/numero-1

Coleman (2005). CALL from the margins: effective dissemination of CALL research and good practices, ReCALL 17 (1): 18-31. Cambridge University Press

Egbert \& Petrie (2005). CALL, Research Perspectives. Washington State University. Routledgge

Ellis, R. (1999). Learning a Second Language Through Interaction. Amsterdam: John Benjamins.

Egbert, J, Mikel Petrie, G (2007). CALL Research Perspectives. Routeledge. London Fainholc, Beatriz. (1999). La interactividad en la Educación a Distancia. Buenos Aires: Paidós. Cuestiones de Educación.

Ferrante, Adela. (2004). Capacitación docente de profesionales: tutorías y uso de entornos virtuales en Argentina. Informe de Investigaciones Educativas. 2004, vol.XVIII, no.1-2 [citado 30 Enero 2016], p.25-35. (Consulta realizada en marzo 2016) http://biblo.una.edu.ve/ojs/index.php/IIE/article/view/106

Friesen, Norman \& Kuskid, Alex (2013). Modes of Interaction 3rd International Handbook of Distance Education. (Consulta realizada en marzo 2016)

https://works.bepress.com/norman friesen/15/

Garrison, D. R. y Anderson, T. (2005). El e-learning en el siglo XXI. Investigación y práctica. Barcelona: Octaedro. 
Gunawardena, C. N., \& Zittle, F. J. (1997). Social presence as a predictor of satisfaction with a computer-mediated conferencing environment. American Journal of Distance Education, $11,8-26$

Jarvis \& Krashen (2014). Is CALL Obsolete? Language Adquisition and Language Learning Revisited in a Digital Age , TESL-EJ Volume 17, Number 4 (Consulta realizada en julio 2016) http://www.sdkrashen.com/content/articles/2014_is_call_obsolete_pdf.pdf

Gallego, Domingo; Cacheiro, María Luz; Martín, Ana M.,Angel, Wilmer (2009). El ePortfolio como estrategia de Enseñanza y aprendizaje. EDUTEC Revista Electrónica de Tecnología Educativa. Núm. 30 Noviembre 2009. (Consulta realizada en enero 2014) ISSN 1135J9250. http://edutec.rediris.es/revelec2/revelec30/

Garrison, D.R., \& Cleveland-Innes, M. (2005). Facilitating cognitive presence in online learning: Interaction is not enough. American Journal of Distance Education, 19(3), 133-148.

Hauck, Mirjam \& Stickler, Ursula (2006). What Does It Take to Teach Online? CALICO Journal, Vol. 23, No. 3 (Consulta realizada en marzo 2016) https://calico.org/html/article_100.pdf

Hauck, Mirjam \& Stickler, Ursula (2007). Metacognitive Knoledge, Metacognitive Strategies, and CALL. En Egbert, J, Mikel Petrie, G (2007) CALL Research Perspectives. Routeledge. London

Holland, Melissa, Sams, Michelle and Kaplan, Jonathan (2010). Intelligent Language Tutors: Theory Shaping. Routledge, UK.

Krashen, S.D. (1982). Principles and Practice in Second Language Acquisition. Oxford: Pergamon. UK.

Kukulska-Hulme, Agnes, Norris, Lucy and Donohue, Jim. (2015). Mobile Pedagogy for English Language Teaching: a guide for teachers. British Council, UK (Consulta realizada en julio 2014) http://englishagenda.britishcouncil.org/sites/ec/files/E485\%20Mobile\%20pedagogy\%20for\% 20ELT_FINAL_v2.pdf 
Kukulska-Hulme, A. (2006). Mobile language learning now and in the future. In: Svensson, Patrik ed. $\mathrm{Fr}^{\circ}$ an vision till praktik: Spr ${ }^{\circ}$ akutbildning och Informationsteknik (From vision to practice: language learning and IT). Swedish Net University ( $N$ ätuniversitetet), Sweden, pp. 295-310.

Kumaravadivelu , B. (2001). Toward a postmethod pedagogy. En TESOL Quarterly 35: 537560

Kumaravadivelu, B. (1994). The Postmethod Condition: (E)merging Strategies for Second/Foreign Language Teaching. TESOL Quarterly, 28, 27-48.

Kumaravadivelu, B. (1999a). Critical Classroom Discourse Analysis. TESOL, Quarterly 33, 453-484.

Kumaravadivelu, B. (199b). Theorising Practice, Practising Theory: The Role of Critical Classroom Observation. In H. Trappes-Lomax \& I. McGrath (Eds.), Theory in Language Teacher Education (pp. 33-45). London: Longman.

Kumaravadivelu, B., \& Bean, M. (1995). The Practicum in TESOL: A Dialogic Model. Paper presented at the 29th Annual TESOL Convention, Long Beach, CA.

Lamy , M.N.\& Hampel, Regine (2007). Online Communication in Language Learning and Teaching. Palgrave Macmillan, UK.

Levy, M. (1997). CALL: Context and conceptualisation. Oxford, UK: Oxford University Press.

Levy, M \& Stockwell, Glenn (2006). CALL Dimensions. Options and Issues in ComputerAssisted Language Learning. Lawrence Erlbaum, USA.

Litwin, E. (Compiladora) (2000). Educación a distancia. Temas para el debate en una nueva agenda educativa. Buenos Aires: Amorrortu.

McCombs, B. (1988). Motivational skills training: Combining metacognitive, cognitive and affective learning strategies. En C.E. Weinstein, E.T. Goetz y P.A. Alexander (Eds.) Learning and study strategies: Issues in assessment, instruction and evaluation. New York: Academic Press. 
Marta Mena (2004) La evolución de la educación a distancia. Entrevista publicada en Educar y realizada Veronica Castro. (Consulta realizada agosto 2016)

http://portal.educ.ar/noticias/entrevistas/marta-mena-la-evolucion-de-la.php

Moore, M. G. (2012). The Theory of Transactional Distance. En M. G. Moore (Ed.) (2012)

The Handbook of Distance Education. Third Edition. New York, Routledge. Pp.131-170.

Mike Levy \& Glenn Stockwell (2006). CALL Dimensions: Options and Issues in ComputerAssisted Language Learning.Lawrence Erlbaum Associates. New York

Panadero, Ernesto y Alonso Tapia, Jesús (2014). ¿Cómo autorregulan nuestros alumnos? Revisión del modelo cíclico de Zimmerman sobre autorregulación del aprendizaje. Anales de Psicología,Vol. 30, № 2 (mayo), 450-462.

http://dx.doi.org/10.6018/analesps.30.2.167221

Pegrum, M. (2009). From Blogs to Bombs: The Future of Digital Technologies in Education. Crawley, Australia: UWA Publishing.

Rodriguez Fuentes, Gustavo (2009). Motivación, Estrategias de Aprendizaje y Rendimiento académico en estudiantes de E.S.O. Tesis Doctoral (Consulta realizada enero 2014) http://ruc.udc.es/bitstream/2183/5669/1/RodriguezFuentes_Gustavo.TESIS_GRF_210109.p df

Ruberg, L. F., Moore, D. M. \& Taylor, c. d. (1996). Student Participation, Interaction, and Regulation in a Computer-mediated Communication Environment. En A Qualitative Study, Journal of Educational Computing Research, 14, pp. 243-268

Rubin, J. \& Thompson, I. (1994). How to Be a More Successful Language Learner. New York: Heinle \& Heinle.

Pujol Berché, Mercè (2001). Las repercusiones de la tarea en las producciones de aprendientes adultos de español. En Estudios de Lingüística, Universidad de Alicante

Shearer, Rick L. (2012). Theory to practice in Instructional Design. En M. G. Moore (Ed.) (2012) The Handbook of Distance Education. Third Edition. New York, Routledge. Pp. 500534. 
Simón, Liliana y Stamboni, Juan (1999). DACTA (Dispositivo de Apoyo Académico por Tareas Autoadministradas) Inglés, 1 (ISSN 1514-9366), Facultad de Humanidades y Ciencias de la Educación (FHCE), Universidad Nacional de La Plata, Argentina.

Socolovsky, Yamile. (2014). Fortalecimiento de la docencia y democratización de la universidad. Revista Política Universitaria, IEC-CONADU. Año1,No.1. Argentina, Pp.1-7.

Sutton, L. A. (2001). The Principle of Vicarious Interaction in Computer-mediated

Communications. International Journal of Educational Telecommunications 7(3), 223-242.

Sutton, L. A. (1999). Vicarious Interaction in Computer-mediated Communication: Comparative Impact on Student Achievement and Satisfaction. En 16th Annual Arizona Educational Research Organization Conference, Flagstaff, Arizona.

Tarone, E. (1981). Some Thoughts on the Notion of Communication Strategy, en TESOL Quaterly 15:285-295.

Tiffin, John \& Rajasingham, Lalita (1995). In Search of the Virtual Class; Education in an Information Society. New York, USA. Routledge.

Underwood J. (1984). Linguistics, computers and the language teacher: a communicative approach. Rowley, MA: Newbury House

Underwood J. (1989). On the edge: Intelligent CALL in the 1990s. En Computers and the Humanities 23: 71-84.

Vigotsky, L.S. (1988) . El desarrollo de los procesos psicológicos superiores. México: Grijalbo. Traducción de la versión inglesa, Mind in the Society: The development of higher psychological processes. Cambridge, MA: Harvard University Press

Warschauer M. (1996). Computer Assisted Language Learning: an Introduction.

In Fotos S. (ed.) Multimedia language teaching, Tokyo: Logos International: 3-20. (Consulta realizada noviembre 2015) http://www.ict4lt.org/en/warschauer.htm 
Warschauer \& Healey (1998). Computers and Language Learning: An Overview, Language Teaching Research 31 (2): 57-71.

Warschauer \& Kern (2000). Network-based Language Teaching: Concepts and Practice. Cambridge, Cambridge University Press

Warschauer M. (2000). CALL for the 21st Century, IATEFL and ESADE Conference, 2 July 2000, Barcelona, Spain.

Wood, D. J., Bruner, J. S., \& Ross, G. (1976). The Role of Tutoring in Problem Solving. Journal of Child Psychiatry and Psychology, 17(2), 89-100.

Tiffin, J. y Rajasingham, L. (1997). En busca de la clase virtual. La educación en la sociedad de la información. Barcelona, Paidós.

Zangara, Aejandra y Sanz, Cecilia (2012). Aproximaciones al concepto de interactividad educativa. En Actas de I Jornadas de Difusión y Capacitación de Aplicaciones y Usabilidad de la Televisión Digital Interactiva. (Consulta realizada enero 2015) http://sedici.unlp.edu.ar/bitstream/handle/10915/25943/Documento_completo.pdf?sequence $=1$

Zimmerman, B. J. (2000). Attaining self-regulation: A social cognitive perspective. En M. Boekaerts, P. R. Pintrich \& M. Zeidner (Eds.), Handbook of self-regulation (pp. 13-40). San Diego, California: Academic Press.

Zimmerman, B. J., \& Moylan, A. R. (2009). Self-regulation: Where metacognition and motivation intersect. En D. J. Hacker, J. Dunlosky \& A. C. Graesser (Eds.), Handbook of Metacognition in Education (pp. 299- 315). New York: Routledge 


\section{Apéndices}

\section{APÉNDICE 1}

\section{Texto Guía}

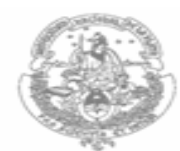

\section{Bienvenidos al curso de pre ingreso e-Dac.ta}

\section{Presentación}

\section{Bienvenidos al curso de pre ingreso e-DACTA:}

Esta modalidad de estudio les permitirá a los alumnos aspirantes al curso de ingreso introductorio a las carreras del profesorado y traductorado de inglés, participar desde distintos lugares y en diferentes horarios, brindando así la posibilidad de que cada uno pueda administrar sus tiempos de estudio, e intercambiar ideas y compartir experiencias con compañeros de diferentes puntos geográficos.

Contarán con el acompañamiento permanente de los tutores, que les ofrecerán los medios de comunicación necesarios para realizar consultas y efectuarán el seguimiento de las actividades propuestas.

Esperamos que la experiencia que adquieran en este curso les sea muy útil. Les pedimos también que nos hagan llegar sus comentarios y sugerencias, lo que nos permitirá mejorar la calidad de nuestra propuesta.

Sugerencias: edactaunlp@gmail.com

\section{Descripción}

El propósito fundamental del presente curso es recrear en un contexto nuevo los aprendizajes que los aspirantes alumnos ya han adquirido durante años de estudio de una lengua extranjera.

La metodología de trabajo tiene como objetivo revisar vocabulario, estructuras, tiempos verbales, lectura de artículos, cuentos cortos, etc. en forma creativa y productiva. Se basa en técnicas de trabajo individuales y en grupos, como actividades básicas de enseñanza y de aprendizaje.

Nuestro propósito es brindar a los alumnos los recursos necesarios para la aplicación de esta metodología, con el fin de que puedan conocer el nivel requerido y reconocer las actividades que se realizarán en caso de decidirse por estas carreras universitarias, favoreciendo asi la transformación y construcción del conocimiento.

\section{Destinatarios}

Aspirantes al curso de ingreso da las carreras del profesorado y traductorado de inglés que estén cursando o ya hayan cursado el último año de la secundaria del sistema educativo argentino con conocimientos básicos de manejo de Windows y procesador de textos.

\section{Objetivos}

- Fortalecer las estrategias de articulación diseñadas para las carreras de Inglés del Departamento de Lenguas y Literaturas Modernas

- Investigar y analizar diferentes ejemplos propuestos por el material diseñado específicamente para este curso.

- Desarrollar una competencia comunicativa intermedia en lengua inglesa

- Estimular el aprendizaje autónomo y la motivación por aprender 
Temario (ver cronograma)

Antes de comenzar, se recomienda leer atentamente y además, imprimir y tener a mano el cronograma de actividades.

\section{Metodología de Trabajo}

La propuesta de capacitación incluye actividades que se realizarán a través de la Plataforma de e-learning WebUnlp coordinadas por un equipo de tutores que estarán en contacto con los cursantes intercambiando con ellos materiales, información, consultas y otros aspectos relevantes que hacen al desarrollo del curso.

Entre las actividades propuestas:

- Descarga de los materiales: cada semana el cursante podrá bajar a su computadora los materiales para leerlos sin necesidad de estar conectado.

- Interacción en línea: se utilizarán herramientas de comunicación, provistas por la plataforma de e- learning, tales como: correo electrónico, foros de debate y chats sincronizados, mediante las cuales los cursantes podrán realizar consultas y/o intercambiar ideas relacionadas con la temática planteada.

- Realización de actividades: se trabajará de manera autónoma con las guías de trabajo, las cuales presentan diferentes actividades de ejercitación y de reflexión de temas propuestos con la posibilidad de autoevaluación. (Pronto recibirán la modalidad de trabajo con las guías de estudio).

- Seguimiento del cursante: el seguimiento de los tutores será constante, para acompañar y sostener el éxito del proceso.

El curso tendrá dos tipos de evaluación:

- de proceso o seguimiento: acceso a los materiales y participación en los foros de debate;

- evaluaciones on line y realización de trabajos prácticos obligatorios.

\section{Requisitos técnicos}

Disponer de:

- Una PC con procesador Intel Pentium de $166 \mathrm{MHz}$, equivalente o superior y $32 \mathrm{MB}$ RAM, con sistema operativo; o Apple Macintosh con procesador PowerPC de $200 \mathrm{MHz}$ o superior y $32 \mathrm{MB}$ RAM, con sistema operativo Mac OS 8.6 o superior.

- Conexión a internet y una dirección de correo electrónico.

E Navegador web: Windows Explorer y Firefox Mozilla

Para poder trabajar sin inconvenientes recomendamos a instalación de:

- Firefox Moxila para poder trabajar con las guías.

- Real Player para trabajar con las actividades de escucha (listening activities)

- Adobe Reader (lectura de documentos)

\section{Cronograma}

\begin{tabular}{|l|l|}
\hline Semana 1 & $\begin{array}{l}\text { Plataforma de e-learning: paseo por la Plataforma virtual de WebUnlp. } \\
\text { Familiarización con las herramientas } \\
\text { Encuesta Inicial } \\
\text { Foro Inicial: Presentaciones. } \\
\text { Guía I + Foro }\end{array}$ \\
\hline Semana 2 & Guía 2 + Foro \\
\hline Semana 3 & Guía 3 + Foro \\
\hline Semana 4 & Guía 4 + Tarea \\
\hline Semana 5 & Guía 5+ Foro \\
\hline Semana 6 & Autoevaluaciones \\
\hline Semana 7 & Actividades de foro \\
\hline Semana 8 & \\
\hline
\end{tabular}

NOTA: El presente cronograma será ampliado en detalles durante el curso.

¿Cómo empezar? 
A partir de la lectura de la presentación en power point que ya han recibido vía e-mail antes de ingresar a este curso (si no la han recibido solicitarla vía e- mail a destinatario de correo lesimon (Prof Liliana Simón-Coordinadora del curso e-dac.ta) reconocerán y adquirirán habilidades para el uso de las herramientas y servicios que la Plataforma ofrece.

La forma de acceso al material de trabajo semanal es la misma para todos las semanas. Haciendo clic en Contenidos, se despliega una lista en la que encontrarán el título de cada semana ya habilitado para la descarga de los materiales, con una breve descripción de su contenido.

A medida que vayan leyendo y reconociendo todas las posibilidades de esta herramienta de e-learning los invitamos a presentarse a través del Foro de presentación en la Semana 2.

Nuestras sugerencias:

r Visite cada una de las secciones de la Plataforma para aprovechar al máximo sus aplicaciones;

$\checkmark \quad$ Tenga siempre a mano el cronograma de trabajo para una mejor organización y poder cumplir con los tiempos establecidos;

$\checkmark$ Complete los datos personales que considere necesario compartir con sus compañeros;

r Importante: Tilde las opciones para recibir mensajes en tu casilla de correo personal (ver filmina 6 del ppt "Presentación Webunlp para alumnos e-dac.ta" y agregue una foto (real y personal). Recuerden que pronto se estarán conociendo personalmente.

$6 \quad$ Manual de Ayuda: puede descargar en formato pdf el manual de ayuda de la plataforma ( ver a filmina 4 del ppt "Presentación Webunlp para alumnos e-dac.ta")

$\checkmark \quad$ no comience la participación en el foro sin haber trabajado antes con la guía de la semana;

$\checkmark \quad$ visite periódicamente la herramienta Bulletin Board para encontrar novedades del curso;

r participe en el foro leyendo atentamente las consignas.

$\checkmark$ comuníquese por e-mail con su tutor y coordinador ante cualquier inconveniente.

\section{Recuerden}

A diferencia de un curso presencial, la interacción en instancias virtuales de aprendizaje no se da cara a cara. Pero eso no impide compartir experiencias e intercambiar ideas, y lograr así una comunidad virtual de enseñanza y de aprendizaje. Por eso es fundamental estar en contacto permanente con los tutores del curso.

Por último, les recordamos que el objetivo fundamental de este curso es desarrollar e integrar las habilidades lingüísticas adquiridas $y$, asi poder guiarlos en la lectura, escritura y escucha con el soporte de material auténtico elaborado especialmente para este nivel.

Esperamos que puedan recrear y disfrutar en un contexto virtual pensado y diseñado exclusivamente para ustedes: aspirantes alumnos a las carreras de inglés que ofrece el departamento de Lenguas Modernas.

Espero encontrarlos en nuestro espacio Atentamente, 


\section{APÉNDICE 2}

Cronograma: e-DACTA Schedule

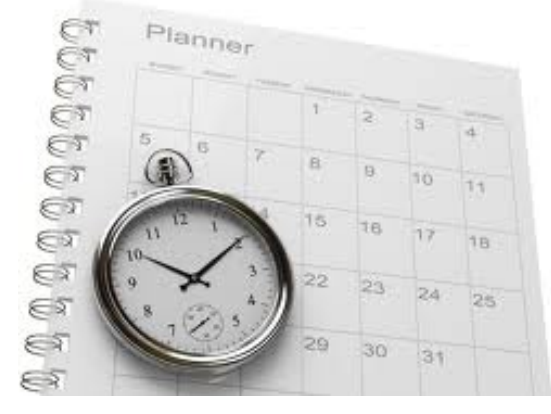

\section{September \& October}

\begin{tabular}{|l|l|}
\hline Week & Tasks \\
\hline 16th September & Welcome Forum \& Getting to know the WebUNLP platform \\
\hline 23rd September & Guide 1 Work \& Forum Task \\
\hline 30th September & Guide 2 Work \& Forum Task \\
\hline 7th October & Guide 3 Work \& Forum Task \\
\hline 14th October & Guide 4 Work \& Forum Task \\
\hline 21st October & Revision \\
\hline 28th October & Self- evaluation tests \\
\hline 4th November & Goodbye Forum \\
\hline
\end{tabular}




\section{APÉNDICE 3}

\section{Afiche de difusión}

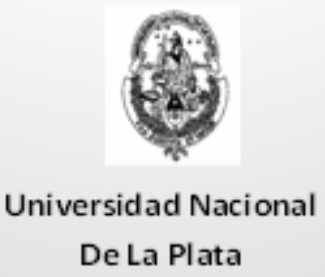

Facultad de Humanidades y Ciencias de la Educación

Depatamento de Lenguas Moder nas

\section{Curso de Pre-ingreso 2009}

Curso de preparación para el Curso Introductorio

a las carreras de Inglés 2010

Modalidad a distancia

Cupos limitados

Fecha de inscripción: 15 al 30 de agosto

Consultas e inscripción:

edacta@gmail.com 


\section{APÉNDICE 4}

Ficha de Inscripción 2010/2015

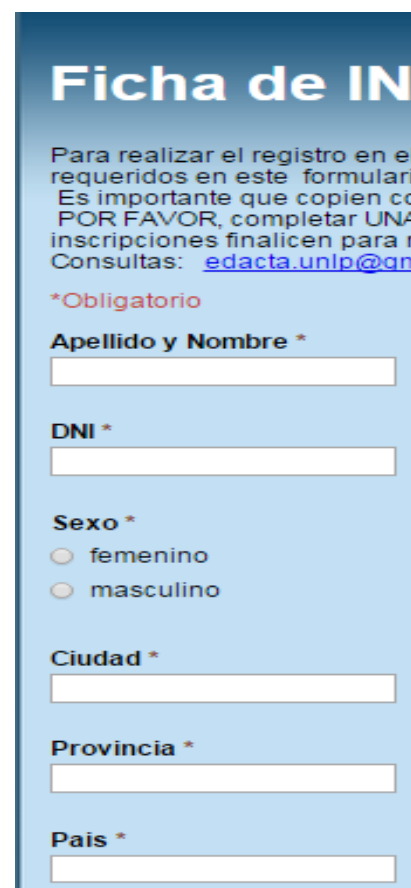

Nombre de la Escuela Secundaria *

Actualmente está cursando el último año de la escuela secundaria?

si

no

Otro:

Nombre y nivel del último libro utilizado para aprender inglés *

Porqué le interesa hacer este curso?*

Mejorar mi inglés

Conocer más sobre la carrera

Conocer más sobre el ámbito universitario

Otro:

Su conexión a internet es: *

Cable modem

WiFi

Otro:

Desde DONDE se conecta a Internet habitualmente ?*

$\square$ casa

escuela

cyber cafe

casa de amigos

trabajo

Otro: 


\section{APÉNDICE 5}

\section{Resumen de Encuesta Inicial y Final}

ENCUESTA INICIAL

\begin{tabular}{|c|c|c|c|c|c|c|c|c|c|c|}
\hline $\begin{array}{l}\frac{0}{0} \\
\frac{}{\overline{0}} \\
\frac{0}{4}\end{array}$ & 䠞 & 足 & $\frac{\pi}{0}$ & $\begin{array}{l}\text { 유 } \\
\frac{\pi}{0} \\
\frac{0}{\pi} \\
0 \\
\end{array}$ & $\begin{array}{l}\frac{\pi}{0} \\
\frac{0}{0} \\
0 \\
w\end{array}$ & $\stackrel{0}{\stackrel{0}{0}}: \frac{0}{x}$ & 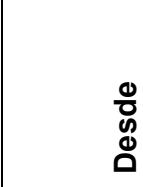 & $\begin{array}{l}\text { 은 } \\
\text { 끈 } \\
\text { 오 }\end{array}$ & 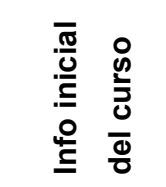 & 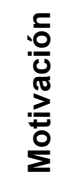 \\
\hline$A b$ & 17 & $F$ & Bs AS & Junín & Normal superior & $\begin{array}{l}\text { Banda } \\
\text { Ancha }\end{array}$ & Hogar & 12 a 16 & $\begin{array}{l}\text { Pág Web } \\
\text { FHCE }\end{array}$ & 23 \\
\hline $\mathrm{Ba}$ & 18 & $F$ & Bs AS & Junin & Esc. Media $n^{\circ} 9$ & $\begin{array}{l}\text { Banda } \\
\text { Ancha }\end{array}$ & Hogar & 12 a 20 & $\begin{array}{l}\text { Pág Web } \\
\text { FHCE }\end{array}$ & 13 \\
\hline $\mathrm{BI}$ & 17 & $F$ & Bs AS & Mar del Plata & $\begin{array}{l}\text { Inst San Nicolás } \\
\text { de los Arroyos }\end{array}$ & $\begin{array}{l}\text { Banda } \\
\text { Ancha }\end{array}$ & Hogar & 12 a 16 & $\begin{array}{l}\text { Pág Web } \\
\text { FHCE }\end{array}$ & 13 \\
\hline $\mathrm{Ca}$ & 20 & $F$ & Bs AS & Campana & $\begin{array}{l}\text { ColegioPadre } \\
\text { Adi Francia }\end{array}$ & $\begin{array}{l}\text { Banda } \\
\text { Ancha }\end{array}$ & $\begin{array}{l}\text { Hogar } \\
\text { Cyber }\end{array}$ & 16 a 20 & $\begin{array}{l}\text { Pág Web } \\
\text { FHCE }\end{array}$ & 2 \\
\hline Si & 18 & $F$ & Bs AS & $\begin{array}{l}\text { Gral } \\
\text { Madariaga }\end{array}$ & $\mathrm{EEMN}^{\circ} 2$ & $\begin{array}{l}\text { Banda } \\
\text { Ancha }\end{array}$ & Hogar & 17 a 20 & Charla & 13 \\
\hline $\mathrm{Di}$ & 17 & $M$ & Bs AS & Gonnet & Esquiu & $\begin{array}{l}\text { Banda } \\
\text { Ancha }\end{array}$ & Hogar & 12 a 20 & No dice & 13 \\
\hline $\mathrm{Er}$ & 17 & $F$ & Bs AS & Hurlingham & $\begin{array}{l}\text { Inst. Sgrado C } \\
\text { de Jesús }\end{array}$ & $\begin{array}{l}\text { Banda } \\
\text { Ancha }\end{array}$ & Hogar & 12 a 20 & $\begin{array}{l}\text { Pág Web } \\
\text { FHCE }\end{array}$ & 13 \\
\hline $\mathrm{Fa}$ & 17 & $F$ & $\begin{array}{l}\text { Entre } \\
\text { Ríos }\end{array}$ & Villa Elisa & $\begin{array}{l}\text { Inst Comercial } \\
\text { Almafuerte }\end{array}$ & $\begin{array}{l}\text { Banda } \\
\text { Ancha }\end{array}$ & Hogar & 8 a 12 & $\begin{array}{l}\text { Pág Web } \\
\text { FHCE }\end{array}$ & 3 \\
\hline $\mathrm{Fe}$ & 28 & $F$ & Bs AS & La Plata & Auxiliadora & $\begin{array}{l}\text { Cable } \\
\text { Modem }\end{array}$ & Hogar & 16 a 20 & $\begin{array}{l}\text { Pág Web } \\
\text { FHCE }\end{array}$ & 12 \\
\hline Go & 22 & $F$ & Bs AS & F. Varela & No dice & $\begin{array}{l}\text { Banda } \\
\text { Ancha }\end{array}$ & $\begin{array}{l}\text { Hogar } \\
\text { Trabajo }\end{array}$ & 8 a 20 & $\begin{array}{l}\text { Pág Web } \\
\text { FHCE }\end{array}$ & $\begin{array}{ll}1 & 2 \\
3 & \end{array}$ \\
\hline $\mathrm{Gu}$ & 18 & $F$ & $\begin{array}{l}\text { Chubu } \\
t\end{array}$ & $\begin{array}{l}\text { Playa Unión, } \\
\text { Chubut }\end{array}$ & $\begin{array}{l}\text { English Institute } \\
\text { Rawson }\end{array}$ & $\begin{array}{l}\text { Banda } \\
\text { Ancha }\end{array}$ & $\begin{array}{l}\text { Hogar } \\
\text { Escuela } \\
\text { amigos }\end{array}$ & $\begin{array}{l}8 \text { a } 12 \text { y } \\
16 \text { a } 20\end{array}$ & $\begin{array}{l}\text { Amigo/Fa } \\
\text { milia }\end{array}$ & $\begin{array}{ll}1 & 2 \\
3 & \end{array}$ \\
\hline Lo & 17 & $M$ & $\begin{array}{l}\text { Rio } \\
\text { Negro }\end{array}$ & Bariloche & $\begin{array}{l}\text { Inst Dante } \\
\text { Alighieri }\end{array}$ & $\begin{array}{l}\text { Banda } \\
\text { Ancha }\end{array}$ & $\begin{array}{l}\text { Hogar, } \\
\text { amigos }\end{array}$ & 16 a 20 & $\begin{array}{l}\text { Amigo/Fa } \\
\text { milia }\end{array}$ & 13 \\
\hline Ma & 21 & $F$ & Bs AS & La Plata & $\begin{array}{l}\text { UNLP Fac } \\
\text { Psicología }\end{array}$ & $\begin{array}{l}\text { Banda } \\
\text { Ancha }\end{array}$ & Hogar & 12 a 20 & $\begin{array}{l}\text { Amigo/Fa } \\
\text { milia }\end{array}$ & 1 \\
\hline Mi & 17 & $F$ & $\begin{array}{l}\text { Entre } \\
\text { Ríos }\end{array}$ & Concordia & $\begin{array}{l}\text { Ins San José } \\
\text { Adoratrices }\end{array}$ & $\begin{array}{l}\text { Banda } \\
\text { Ancha }\end{array}$ & Hogar & 16 a 20 & $\begin{array}{l}\text { Pág Web } \\
\text { FHCE }\end{array}$ & $\begin{array}{ll}1 & 2 \\
3 & \end{array}$ \\
\hline Ok & 17 & $F$ & $\begin{array}{l}\text { Corrie } \\
\text { ntes }\end{array}$ & Corrientes & $\begin{array}{l}\text { Saint Patrick } \\
\text { college }\end{array}$ & $\begin{array}{l}\text { Banda } \\
\text { Ancha }\end{array}$ & Cyber & 16 a 20 & $\begin{array}{l}\text { Pág Web } \\
\text { FHCE }\end{array}$ & 3 \\
\hline
\end{tabular}


La enseñanza de una lengua extranjera utilizando tecnología dígital

\begin{tabular}{|c|c|c|c|c|c|c|c|c|c|c|}
\hline $\mathrm{Pa}$ & 17 & $\mathrm{~F}$ & $\begin{array}{l}\text { Rio } \\
\text { Negro }\end{array}$ & Choele Choel & $\begin{array}{l}\text { Ins Sagrado C } \\
\text { de Jesús }\end{array}$ & $\begin{array}{l}\text { Cable } \\
\text { Modem }\end{array}$ & Hogar & 17 a 20 & No dice & 13 \\
\hline Po & 18 & $F$ & $\begin{array}{l}\text { Mision } \\
\text { es }\end{array}$ & $\begin{array}{l}\text { Wanda(dpto } \\
\text { Iguazú) }\end{array}$ & $\begin{array}{l}\text { Inst Ntra Sra del } \\
\text { Iguazú }\end{array}$ & Dial Up & Hogar & 12 a 20 & $\begin{array}{l}\text { Pág Web } \\
\text { FHCE }\end{array}$ & 1 \\
\hline $\operatorname{Re}$ & 20 & $F$ & Bs AS & Olavarría & $\begin{array}{l}\text { Inst ens Inglés St } \\
\text { George }\end{array}$ & $\begin{array}{l}\text { Banda } \\
\text { Ancha }\end{array}$ & Hogar & 12 a 16 & $\begin{array}{l}\text { Pág Web } \\
\text { FHCE }\end{array}$ & 2 \\
\hline $\mathrm{Ri}$ & 17 & $\mathrm{~F}$ & Bs AS & Las Flores & Inst San Miguel & $\begin{array}{l}\text { Banda } \\
\text { Ancha }\end{array}$ & Hogar & no dice & $\begin{array}{l}\text { Pág Web } \\
\text { FHCE }\end{array}$ & $\begin{array}{l}\text { no } \\
\text { dice }\end{array}$ \\
\hline Rom & 17 & $F$ & Bs AS & Berisso & $\begin{array}{l}\text { IEM San Franc } \\
\text { de Asís }\end{array}$ & $\begin{array}{l}\text { Banda } \\
\text { Ancha }\end{array}$ & Hogar & 12 a 20 & $\begin{array}{l}\text { Pág Web } \\
\text { FHCE }\end{array}$ & 3 \\
\hline Roq & 17 & $M$ & Chubut & Pto Madryn & FAPE & $\begin{array}{l}\text { Banda } \\
\text { Ancha }\end{array}$ & Hogar & 16 a 20 & $\begin{array}{l}\text { Pág Web } \\
\text { Unlp }\end{array}$ & 13 \\
\hline $\mathrm{Ru}$ & 17 & $F$ & Bs AS & La Plata & $\begin{array}{l}\text { Colegio del } \\
\text { Centenario }\end{array}$ & $\begin{array}{l}\text { Cable } \\
\text { Modem }\end{array}$ & Hogar & 16 a 20 & $\begin{array}{l}\text { Amigo/Fa } \\
\text { milia }\end{array}$ & 1 \\
\hline $\begin{array}{l}\text { Suar } \\
\text { ez }\end{array}$ & 19 & $F$ & $\begin{array}{l}\mathrm{T} \\
\text { Fuego }\end{array}$ & Rio Grande & $\begin{array}{l}\text { CEP Inst de } \\
\text { inglés }\end{array}$ & $\begin{array}{l}\text { Banda } \\
\text { Ancha }\end{array}$ & Hogar & 12 a 16 & $\begin{array}{l}\text { Pág Web } \\
\text { FHCE }\end{array}$ & 1 \\
\hline To & 17 & $\mathrm{~F}$ & Bs AS & Junín & $\mathrm{EMN}^{\circ} 7$ & $\begin{array}{l}\text { Banda } \\
\text { Ancha }\end{array}$ & Hogar & 12 a 16 & $\begin{array}{l}\text { Pág Web } \\
\text { FHCE }\end{array}$ & 1 \\
\hline Vi & 17 & $F$ & Bs AS & Tres Arroyos & $\begin{array}{l}\text { Col Jesús } \\
\text { Adolescente }\end{array}$ & $\begin{array}{l}\text { Banda } \\
\text { Ancha }\end{array}$ & Hogar & 16 a 20 & $\begin{array}{l}\text { Pág Web } \\
\text { FHCE }\end{array}$ & 1 \\
\hline
\end{tabular}

Motivación: 1 . Conocer más acerca de la carrera $\quad$ 2. Complementar las clases presenciales

3. Lograr un acercamiento al ámbito universitario

ENCUESTA FINAL

\begin{tabular}{|c|c|c|c|c|c|c|c|c|c|c|c|}
\hline Encuesta Final & A1 & A2 & A3 & A4 & A5 & A6 & A7 & A8 & A9 & A10 & A11 \\
\hline \multicolumn{12}{|l|}{ Opinión sobre la modalidad } \\
\hline ¿Es la primera vez que estudias a distancia? & si & si & si & si & si & si & si & si & si & si & si \\
\hline Estás habituado al uso de estos entornos & no & no & no & no & no & no & no & si & si & no & si \\
\hline $\begin{array}{l}\text { Es la primera vez que estudías bajo esta } \\
\text { modalidad }\end{array}$ & si & si & si & si & si & si & si & si & si & si & si \\
\hline Me cuesta mucho la tecnología & si & no & no & no & no & si & no & no & no & no & \\
\hline Me cuesta comunicarme en otro idioma & no & no & no & no & no & si & no & si & no & si & no \\
\hline Prefiero la modalidad presencial & si & si & si & si & si & si & si & no & si & si & si \\
\hline $\begin{array}{l}\text { Prefiero la modalidad mixta: presencial y } \\
\text { virtual }\end{array}$ & si & si & si & si & si & no & si & si & no & si & si \\
\hline
\end{tabular}




\begin{tabular}{|l|l|l|l|l|l|l|l|l|l|l|l|l|l|}
\hline Encuesta Final & A1 & A2 & A3 & A4 & A5 & A6 & A7 & A8 & A9 & A10 & A11 \\
\hline \multicolumn{2}{|l|}{ Herramientas de la Web 2 usas con frecuencia: } \\
\hline Buscadores cómo Google & $x$ & $x$ & $x$ & $x$ & $x$ & $x$ & $x$ & $x$ & $x$ & $x$ & $x$ \\
\hline Chat & $x$ & $x$ & & & $x$ & $x$ & $x$ & $x$ & $x$ & $x$ & \\
\hline e-mails & & $x$ & $x$ & $x$ & $x$ & $x$ & & $x$ & $x$ & $x$ & $x$ \\
\hline Blogs & & $x$ & & & & & & & & & & \\
\hline Wikis & & $x$ & $x$ & & & & & & & & \\
\hline Grupos
\end{tabular}

\section{2.- Acerca de este curso}

\section{a.- ¿Por qué razón te inscribiste en este curso?}

- A1: Para crear una vía más de comunicación con la facultad, para aprender, probar mi nivel de inglés, tener una idea para el ingreso, y porque todo lo que pueda hacer para perfeccionarme que esté a mi alcance, lo hago.

- A2: Para evaluar mis conocimientos de inglés, aprender nuevos aspectos del lenguaje y acercarme a la modalidad de trabajo de la Facultad

- A3: Me costó mucho decidirme por una carrera, cuando por fin me decidí por esta, quise ver el nivel con el cual me encontraría en la facultad, si estaba preparada o no, y para aprender más y reforzar conocimientos.

- A4: Deseaba conocer el nivel de inglés que se exige en la universidad.

- A5: Porque quería familiarizarme con las actividades que podríamos llegar a hacer el año que viene en la carrera y para ver si mi nivel de inglés es suficiente.

- A6: Me inscribí porque siempre me interesó el idioma, y traductorado en inglés era una de las carreras que me gustaría seguir. Además quería interiorizarme y así poder decidirme.

- A7:

- A8: Me inscribí en el curso porque quería saber más acerca de la carrera. Y saber si estoy al nivel de entrar a la facultad.

- $\quad$ A9: Para ir adecuándome a la facultad, y fijarme el nivel que necesito para comenzar el curso.

- A10: Para introducirme en la carrera de ingles y ver como era el nivel.

- A11: Porque me agrada el idioma y representa un gran complemento para mi carrera como comunicadora social. Además me permitirá una salida laboral más amplia 


\section{b.- ¿Qué te pareció la experiencia cuando la iniciaste?}

- A1: Cuando inicie me costó bastante porque no entendía la plataforma, pero una vez que comencé a agarrarle la mano, me resulto fácil y súper practico.

- A2: Me pareció excelente. Me sentí muy cómoda y me gustó mucho la modalidad de trabajo y aprendizaje

- A3: Media confusa al principio porque tuve problemas para recibir las indicaciones, pero después todo fue mejorando. Uno, al no estar acostumbrado a este tipo de cosas se siente un poco perdido y solo, pero después vas mejorando.

- A4: Interesante y emocionante a la vez ya que fue una forma de acercarme hacia lo que es la facultad.

- A5: Fue algo nuevo para mí. Me ayudó a decidir si esto es en realidad lo que quiero hacer en el futuro.

- A6: Fue algo totalmente nuevo, ya que no estoy acostumbrada a manejarme en el idioma habitualmente. La experiencia fue muy buena y me ayudó bastante a progresar.

- $\quad$ A7:...

- A8: Cuando recién empecé sentí mucha responsabilidad. También vi que la mayoría de mis compañeros tenían un nivel más de inglés que yo o que tenían un vocabulario más extenso que el mío.

- A9: Estaba muy entusiasmada, luego se complicó un poco por el tiempo que lleva, pero pude adecuarme. Me gustó, aunque prefiero el modo presencial.

- A10: Buena, me pareció bien eso de dividirnos por grupos con diferentes profesores porque por lo menos mi tutor me siguió mucho durante el curso y se interesó hacia el final cuando deje de participar.

- A11: Representa todo un desafío, sobre todo porque me ayuda a poner énfasis en mis errores de escritura. Permitiéndome un vocabulario mas abarcativo del idioma.

c.- Expresa claramente hasta qué semana del curso seguiste todas las actividades del cronograma y enumera las razones por las que, dado el caso, dejaste de presentar las actividades y seguir el curso en los tiempos establecidos.

- A1: El único trabajo que no pude presentar fue el de My e-portfolio porque estaba en Bariloche, me gustaría saber si es que tengo tiempo para presentarlo. $Y$ pienso terminar el curso, es decir seguirlo hasta la última semana, disfrute mucho haciéndolo.

- A2: Seguí todas las actividades del cronograma hasta la 8va semana, salvo el blog. Encontré la actividad de describir la experiencia de cada semana bastante difícil ya que la modalidad de trabajo y la experiencia que iba adquiriendo era muy complicada de redactar sin repetirme a mí misma una y otra vez en cada post. Pensé en usar ese espacio para ampliar mis posts del Foro de la plataforma (es muy difícil expresar en 80 palabras todo lo que uno quisiera decir sobre ciertos temas) pero esa no era la finalidad del blog. Pido mil disculpas y quizás lo actualice en un futuro. Creo que puede llegar a ser útil (al menos para mí) a pesar de estar fuera del cronograma

- A3: Realice todas las actividades, creo que sólo una vez me atrase con la entrega, las razones pueden ser:1)curso de 15 a 21:35 hs en el colegio, 2)en las mañanas voy a ingles y a gimnasia, 3) y los fines de semana generalmente trabajo

- A4: Hasta la cuarta semana. El colegio, exámenes internacionales, etc, me llevaban demasiado tiempo por lo que tuve que dejar de lado las actividades de este.

- A5: Creo que presenté todas las actividades y trabajé todas las semanas. 
- A6: Seguí las actividades hasta la última semana de noviembre.

- $\mathrm{A} 7: \ldots . .$.

- A8: .....

- A9: Presenté todas las actividades que me fueron asignadas, algunas tardé en entregarlas porque no tenía tiempo, pero cumplí.

- A10: Hice del cronograma hasta la actividad de Modern Technologies, (esta la hice pero no puse la actividad del foro). Deje de a poco desde el viaje a Bariloche (en octubre) y después fui mirando lo que se iba haciendo pero no participé. $Y$ ya en noviembre con las pruebas y la fiesta de egresados entre cada vez menos. Además después de me entere que no se puede anotar en dos carreras diferentes en la Universidad de La Plata (pensaba anotarme en periodismo e inglés) asique eso también contribuyo a que pierda el interés. Igualmente el curso me pareció muy bueno aunque la plataforma no me anduvo muy bien pero fue una buena experiencia igualmente.

- A11: No recuerdo exactamente la fecha, pero considero que en lo posible he cumplido con todas las actividades del programa.

\section{d.- ¿En qué podemos mejorar para futuras implementaciones y explica por qué?}

- A1: materiales /ejercicios: Los únicos ejercicios que me costaron son aquellos en que no se muestra el verbo para conjugar.

- A2: El acceso a la plataforma tecnológica: Este aspecto es el único a mejorar a mi criterio, ya que las fallas tecnológicas dificultan el trabajo.

- A3: El acceso a la plataforma tecnológica: Al principio costaba entrar, pero luego ya no. Tal vez podrían poner como una explicación de cada sector de la plataforma, ya que solíamos perdernos jaja

- A4: .....

- A5: Materiales / ejercicios: Por ahí me parecieron un poco repetitivos, aunque supongo q no hay muchas otras actividades aparte de Reading, use of English y listening

- A6: Distancia con los docentes (necesitaría ver a mis tutores para aprender mejor) Creo que sería importante ver a los tutores para aprender mejor y sacarse bien las dudas, igualmente la organización fue buena y no tuve demasiadas dudas.

- A7: ........

- A8: - Desempeño de los tutores: Estaría bueno que hubiera un Chat o algo similar, para que a los impacientes como yo les lleguen las respuestas mas rápido.

- A9: - Materiales / ejercicios: Algunos textos son aburridos, le dan más importancia a las fechas y los nombres que al contenido en sí.

Cronograma (muchas actividades, pocas actividades, curso muy extenso o corto):Curso corto, hubiese preferido que dure un mes más.

Distancia con los docentes (necesitaría ver a mis tutores para aprender mejor) Me resultaría más fácil aprender ciertas cosas si vería personalmente a mi tutor

- A10: Materiales / ejercicios: Me parece que se debe cambiar el foro ese de corner language porque al tener todas las respuestas ahí es como que ya te induce al momento de responder que poner y eso. No es que te vas a copiar pero entras y ves todo lo mismo que no te dan muchas ganas de postear para poner lo mismo. Cronograma : El cronograma me parece bueno pero por ahí la fecha en que se hace es medio complicada, tal vez si se iniciara antes y terminara para noviembre facilitaría a que todos los 
alumnos intenten terminar el curso y les quede el tiempo correspondiente para las actividades de fin de año del colegio. Desempeño de los tutores : El tutor que me toco (Jimena) me comportó muy bien conmigo, me fue preguntando por qué no participaba y me iba informando lo que faltaba. Aunque no concrete las últimas actividades el hecho de recibir e-mails y eso de la tutora me sirvió como estimulo por ejemplo para responder esto. EL acceso a la plataforma por lo menos en mi computadora no es bueno. No sé si es problema de mi conexión o qué pero cada unos pocos minutos las pagina de la plataforma se va y hay que entrar de nuevo.

- A11:Distancia con los docentes (necesitaría ver a mis tutores para aprender mejor) De esta manera podríamos establecer una comunicación más directa y personal. Lo cual ayudaría a un desempeño más fluido en el aprendizaje.

\section{Aspectos Positivos:}

A1: La comunicación constante entre profesores y alumnos. Facilidad para realizar y entregar trabajos. E acercamiento a la facultad y la información sobre las carreras

A2: Las Guías de trabajo eran claras y entretenidas. El desempeño de los tutores fue excelente, así como su contención y su buena disposición. El Language Corner fue una herramienta muy útil para aprender y repasar aspectos muy importantes del Lenguaje.

A3: Medir el nivel en que te encontrás; obtener más conocimientos; conocer a tus futuros compañeros

A4: Ejercicios interesantes, divertidos; los tutores son atentos.

A5: La facilidad con la que podíamos manejarnos; que teníamos nuestros propios tiempos; que las profesoras se mostraron siempre dispuestas a ayudar

A6: Colaboración de los docentes en todo momento. Actividades muy organizadas, y entregadas en tiempo y forma. Muy buenas actividades, para ampliar vocabulario y afianzar otros aspectos.

A7: ---

A8: Los profesores estuvieron siempre presentes. Las guías eran completas y entretenidas.

A9: Aprendés vocabulario, y manejás tus tiempo vos, hacés los ejercicios cuando podés.

Conocés a tus compañeros antes de empezar el curso presencial. Te vas amoldando al ámbito de la universidad

A10: La división en grupos y la asignación de tutores. Las actividades tenían temas variados y permitían dentro de las pautas una libre expresión de los alumnos. El seguimiento de los tutores y la disponibilidad de los mismos para solucionar los distintos problemas o dudas.

A11: Modalidad de estudio virtual. Temáticas originales y Actividades entretenidas. Consideración por parte del equipo docente en situaciones del aprendizaje del alumno que pueden resultar difíciles.

\section{Aspectos Negativos:}

A1: Tuve unos inconvenientes con la guía de technology que no pude resolver, (me llego incompleta)

Problemas de plataforma que surgieron en un principio. Perdón pero estas son mis únicas críticas. Lo demás excelente!

A2: Problemas técnicos de la plataforma. No veo ningún otro aspecto negativo.

A3: no tener a tu tutor al lado para que te ayude y sentirte mas "respaldado"; problemas con la plataforma y malentendidos; falta de seguridad al hacer algunas actividades

A4: Coincide con los meses de clase en el colegio; había ocasiones en la que la plataforma fallaba.

A5: A veces no tenía ganas de hacer las guías porque eran el mismo tipo de actividades. En ciertos momentos no podíamos navegar correctamente por la plataforma- Nada más.

A6: Algunos problemas con la plataforma, ya que varias veces se trababa. Las actividades en los foros, a veces 
no estaban muy claras.

A7:......

A8: La plataforma funciona mal a veces. Que se cierre la sesión después de un rato.

A9: Es difícil aprender teniendo a tu profesor a distancia. Obtenés las respuestas a tus ejercicios tarde

A10: El mal funcionamiento de la plataforma. La fecha del curso (empezás con todas las ganas pero después te das cuenta de que tenés que hacer otra miles de cosas por ahi mas urgentes. En las guías, las actividades auditivas no me funcionaban.

A11: Algunos problemas de técnicos de la página virtual

\section{En general esta experiencia de aprendizaje me resultó:}

A1: a) MUY BUENA : Porque logro satisfacer con todas mis necesidades. b) Volverías a realizar un curso en esta modalidad? Sí, porque me resulto re practico y pude organizarme según mis tiempos.

c) ¿Recomendarías este curso a otras personas? $\mathrm{Si}$, es una buena manera para empezar a vincularte con la facu.

A2: a) MUY BUENA: Como dije antes, las Guías y el Language Corner me resultaron muy útiles, así como los posts de nuestros tutores acerca de aspectos del Lenguaje y errores comunes que aparecían en nuestros propios posts, dándome la posibilidad de aprender de mis propios errores. b) Volverías a realizar un curso en esta modalidad? Sí, me permite trabajar manejando mis tiempos. c) ¿Recomendarías este curso a otras personas? $\mathrm{Si}$, es un buen acercamiento al entorno universitario y permite al alumno saber sus puntos fuertes y débiles con respecto al Lenguaje y al tipo de actividades planteadas.

A3: BUENA a) Me contacte con mis futuros compañeros, aprendí algunas cosas, y me di cuenta lo que me falta reforzar. b) Volverías a realizar un curso en esta modalidad? Sí, porque se ajusta a tus horarios. C) c) ¿Recomendarías este curso a otras personas? Sí, porque siempre es bueno poder hacer estos cursos, los cuales te ayudan.

A4: Regular. No pude completar todo el cronograma. b) Volverías a realizar un curso en esta modalidad? Sí, tengo una mayor comprensión acerca de cómo se trabaja en este tipo de curso. c) ¿Recomendarías este curso a otras personas? Sí, adquirís experiencia y nuevos conocimientos.

A5: Buena. Cumplió con lo que imaginé. b) Volverías a realizar un curso en esta modalidad? Sí, porque me resulta práctico. c) ¿Recomendarías este curso a otras personas? Sí, por la misma razón anterior.

A6: Muy buena. Porque pude aprender a manejarme de manera más fluida en el idioma. b) Volverías a realizar un curso en esta modalidad? Sí, ya que te permite trabajar de manera más libre, organizando los tiempos c) ¿Recomendarías este curso a otras personas? Sí, porque es una buena manera de aprender, sin necesidad de ocupar mucho tiempo, es bueno como actividad secundaria.

A7: $\ldots . .$.

A8: MUY BUENA. Pude aprender mucho más de lo que sabía gracias a el curso y a los profesores. b) Volverías a realizar un curso en esta modalidad? Sí, porque es una buena experiencia y te ayuda bastante. c)¿Recomendarías este curso a otras personas? Sí.

A9: MUY BUENA. Pude conocer gente que va a estudiar lo mismo que yo, aprendí cosas nuevas, sé cómo se manejan en la facultad. b) Volverías a realizar un curso en esta modalidad? No, prefiero el modo presencial, aprendo mejor los temas dados. c) ¿Recomendarías este curso a otras personas? Sí, porque me gustó, por ahí a otras personas no les cuesta aprender por internet.

A10: BUENA, b) Volverías a realizar un curso en esta modalidad? Si) ¿Recomendarías este curso a otras personas? Sí. 
A11: MUY BUENA Porque me ayudó nuevamente a poner en práctica el idioma. b) Volverías a realizar un curso en esta modalidad? Si, porque es una modalidad innovadora de aprender. c) ¿Recomendarías este curso a otras personas? Sí, porque facilita manejar el tiempo dedicado al estudio y lo hace más ameno.

¿Qué te provocó este curso con respecto a tu elección de carrera universitaria?

A1: Ansiedad: Me entusiasmo mucho no veo las horas de que llegue febrero!!

Tranquilidad: Pude aclarar todas mis dudas!

Contención por parte de los profesores: La comunicación fue fundamental para llevar a cabo todas aquellas tareas y trabajos!

A2: Confianza: Gracias al curso supe qué tengo que mejorar, lo cual me da la posibilidad de hacerlo y sentirme más segura a la hora de entrar al Curso de Ingreso

A3: Desconfianza: Porque creo, tal vez no estar lo suficientemente preparada para la carrera de traductorado, y realmente no quiero decepcionar a mis padres. (Este alumno desaprobó el ingreso 2009)

A4: Más ansiedad: No tengo dudas de que me gusta mi carrera así que quiero empezar las clases en la universidad la antes posible. Desconfianza: Temo que me juzguen por mi desempeño en este curso.

A5: ...... Encuesta incompleta

A6: Más ansiedad, más tranquilidad y más confianza

A7: ---

A8: Más tranquilidad: porque sé que puedo mejorar para llegar al nivel que se necesita para ingresar a la carrera.

A9: Más ansiedad: Conocí a mis futuros compañeros, fui evaluada y me fue bien, tengo ganas de empezar ya que me dio una buena impresión de lo que es la carrera. Más tranquilidad: Pensé que me iba a encontrar con temas que no había visto nunca y que iban a ser más difíciles. Contención por parte de los compañeros: Hablé con ellos y todos sienten lo mismo q yo, es un lugar nuevo, al cual nos tenemos que acostumbrar.

Contención por parte de los profesores: Nos trataron muy bien, nos ayudaron cuando precisábamos algo y parecen ser amables.

A10: Más tranquilidad: Teniendo en cuenta los primeros momentos del curso, cuando empecé me generó más tranquilidad porque ví que el nivel era accesible. La carrera de ingles en la UNLP me la habían catalogado como muy difícil por lo que temía que el nivel sea extremadamente elevado.

A11: Más tranquilidad: Porque me permitió poner a prueba mis conocimientos.

\section{¿Cómo te sentiste estudiando de esta manera? ¿Te costó estudiar de esta manera? ¿Por qué? ¿Resultó difícil manejar tus tiempos?}

A1: Debo reconocer que siempre prefiero las clases presenciales, pero aunque no les conozco la cara a los profesores (espero hacerlo) lograron cumplir y aclarar todas mis dudas, creo que fue lo más importante. En cuanto al estudio siempre imprimí las guías y trabajos porque trabajar en la compu me cansa mucho la vista. $Y$ fue súper práctico en cuanto al tiempo.

A2: Lamentablemente me costó manejar mis tiempos debido a un problema familiar, pero el cronograma del curso es muy bueno y no me costó para nada manejar mis tiempos mientras me fue posible (salvo en el caso del blog, explicado en una de las preguntas previas)

A3: No me costó, porque al mismo tiempo, si tenía muchas dudas lo consultaba con mi profesora de inglés, fuera de la plataforma. 
A veces me complicaba con el tiempo, pero más que nada porque durante el día hago demasiadas cosas! Pero casi nunca no tuve problemas.

A4: Manejar mis tiempos fue lo más difícil. Además, como no tengo una computadora en casa me tenía que trasladar a otros lugares para realizar las actividades y así mi tiempo se reducía

A5: ......

A6: No no me pareció difícil estudiar de esta manera y por suerte pude organizarme bien los tiempos, aunque prefiero que sea presencial, ya que es más fácil para sacarse las dudas.

A7: ......

A8: Me sentí bien estudiando de esta manera y no me costó tanto hacerlo así. Por ahí me hacía falta la presencia del profesor para las dudas que tenía en el momento. Dudas chicas por ejemplo como se usa tal palabra o como se escribe tal expresión.

Pude manejarme con los tiempos porque en mi caso yo termine la escuela el año pasado y como mi trabajo no ocupaba mucho tiempo, tenía tiempo para hacer mis trabajos.

A9: No me resultó difícil manejar mis tiempos ya que yo disponía de ellos, pero sí me costó retener lo dado en los ejercicios, tuve que pasar todo a un cuaderno, pero esa es mi manera de estudiar.

A10: Es una nueva experiencia y es buena para estos casos en que es un curso o algo relativamente corto. Esta modalidad de estudio exige una doble responsabilidad por el simple hecho de que es uno quien elige los tiempos y eso te puede jugar a favor o en contra. Pero es una experiencia recomendable aunque no lo elegiría para estudiar una carrera de varios años.

A11: Me sentí más distendida y cómoda. Por el contrario me resultó un poco más fácil, pudiendo a la vez manejar mis tiempos. 


\section{APÉNDICE 6}

Formulario de la encuesta Inicial on-line (2010/2015)

\section{Encuesta Inicial del curso de pre-ingreso e- dacta}

Completar la siguiente encuesta UNA sola vez; si no se completó correctamente te llegará un mail pidiendo que vuelvas a completarla.

*Obligatorio

Apellido *

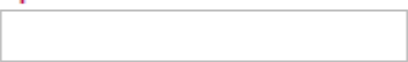

Nombre *

$+2$

Ciudad, Provincia, País *

¿Es la primera vez que estudias a distancia? *

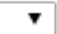

Has formado parte de un curso que utiliza plataformas de enseñanza como WebUNLP? * $\mathbf{v}$

Si has formado parte de un curso que utiliza plataformas de enseñanza como WebUNLP, indica su nombre.

Qué herramientasde la Web 2.0 conoces y utilizas para aprender? *

$\square$ Página Web de la escuela

Blogs

Wikis

Grupos de yahoo, google, etc

Facebook

Twitter

Chat

Skype

Qué herramientasde la Web 2.0 conoces y utilizas para tu vida social? *

$\square$ Página Web de la escuela

Blogs

Wikis

Grupos de yahoo, google, etc

Facebook

Twitter

Chat: msm, yahoo, etc 
Qué herramientas de la Web 2.0 manejas con facilidad? *

$\square$ Google

$\square$ Blogs

$\square$ Wikis

$\square$ Grupos de yahoo, google, etc

$\square$ Facebook

$\square$ Twitter

$\square$ Chat

$\square$ skype

$\square$ Otro:

Qué herramientas de la Web 2.0 te cuesta manejar ? *

$\square$ Google

$\square$ Blogs

$\square$ Wikis

Grupos de yahoo, google, etc

$\square$ Facebook

$\square$ Twitter

$\square$ Chat

$\square$ Skype

$\square$ otro:

Contanos tu opinion inicial acerca de la plataforma WebUNLP? *

Sencilla

No tan sencilla

Complicada

Imposible de entender

Otro:

Cuanto uso han hecho de las nuevas tecnologias en la escuela secundaria? *
Mucho
Bastante
Poco
Nada

Cuanto usas las nuevas tecnologias para estudiar? *
Mucho
Bastante
Poco
Nada

Cuanto usas las nuevas tecnologias para tu vida social? *
Mucho
Bastante
Poco
- Nada 
Cuanto usas las nuevas tecnologias para tu vida social? *

Mucho

Bastante

Poco

Nada

Pensas que es necesario usar las nuevas tecnologias en la enseñanza?Porque? *

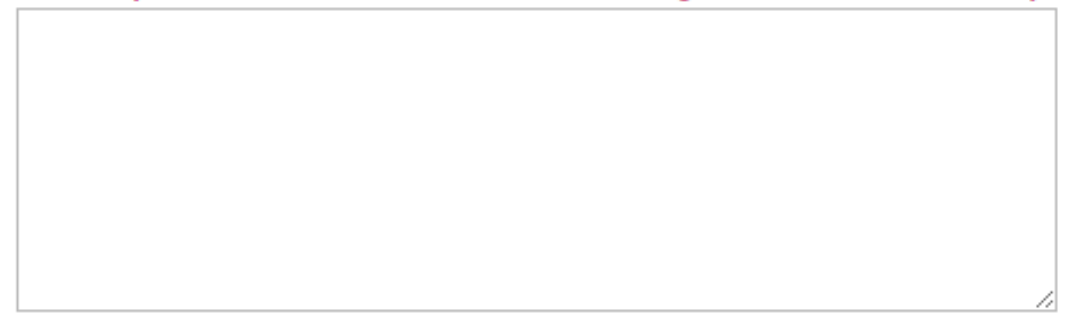

Enviar

Nunca envies contraseñas a través de Formularios de Google

Con la tec nología de

\$ Google Forms
Este contenido no ha sido creado ni aprobado por Google. Informar sobre abusos - Condiciones del servicio - Otros términos 


\section{APÉNDICE 7}

\section{Formulario de la Encuesta final on-line (2010/2015)}
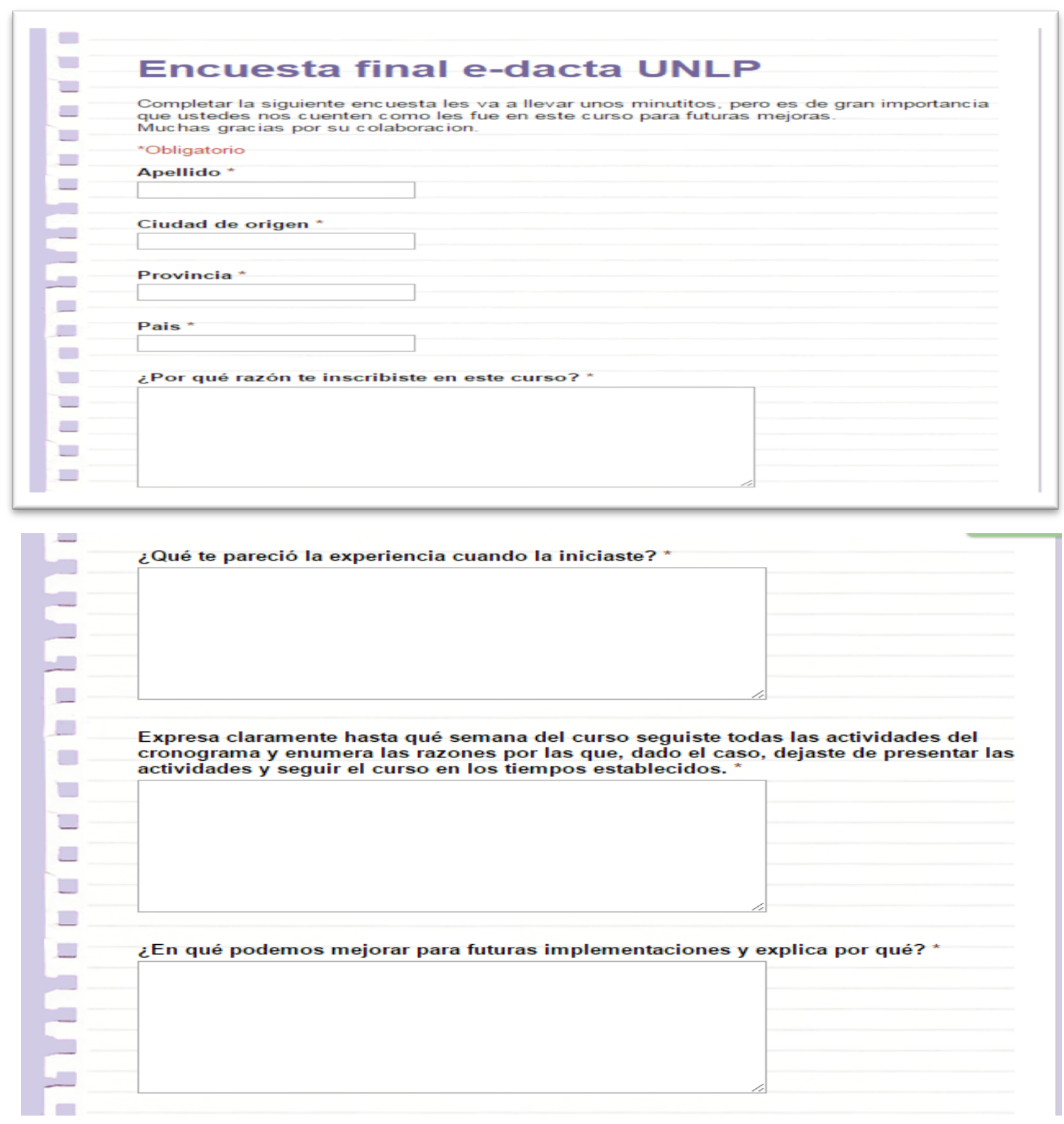
¿Qué te pareció la experiencia cuando la iniciaste? *

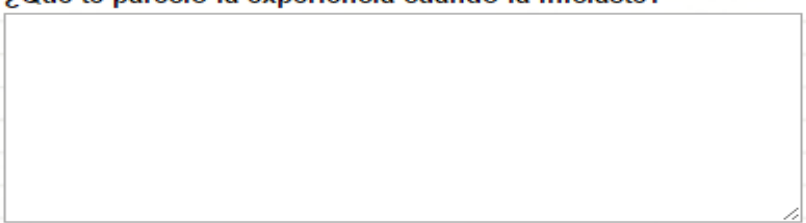

Expresa claramente hasta qué semana del curso seguiste todas las actividades del cronograma y enumera las razones por las que, dado el caso, dejaste de presentar las actividades y seguir el curso en los tiempos establecidos. *

¿En qué podemos mejorar para futuras implementaciones y explica por qué? *

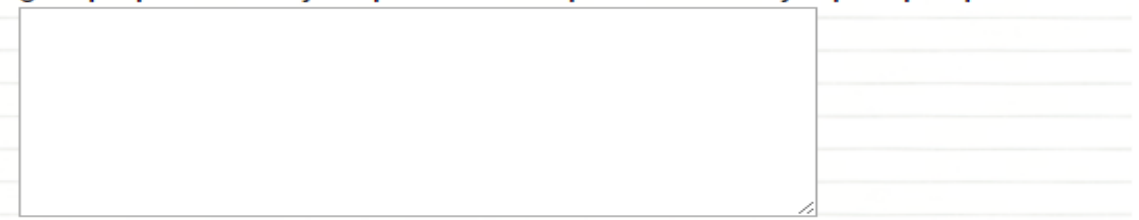

¿Qué te pareció la experiencia cuando la iniciaste? *

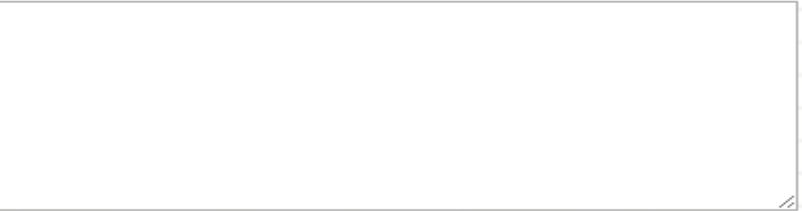

Expresa claramente hasta qué semana del curso seguiste todas las actividades del cronograma y enumera las razones por las que, dado el caso, dejaste de presentar las actividades y seguir el curso en los tiempos establecidos.

¿En qué podemos mejorar para futuras implementaciones y explica por qué? * 
En la siguiente tabla evalua los siguientes aspectos del edacta *

$\begin{array}{lll}\text { Muy Bueno } & \text { Bueno } & \text { Regular }\end{array}$

- Materiales /
ejercicios (son
muy difíciles, son
muy fáciles, no
se entienden,
etc.)
- Cronograma
(muchas
actividades,
pocas
actividades,
curso muy
extenso o
corto)etc.
- Desempeño de
los tutores (no me
contestan mis
mails, me llaman
y tratan de
conectarse todo
el tiempo y no me
dejan trabajar,
etc.)
- El acceso a la
plataforma
tecnológica
- Distancia con
los docentes
(necesitaria ver a
mis tutores para
aprender mejor)
- Grupo de
estudio "virtual"
(necesitaría ver a
mis compañeros
para aprender
mejor)

Describe los aspectos POSITIVOS del curso. Podes ampliar lo elegido en la pregunta anterior: *

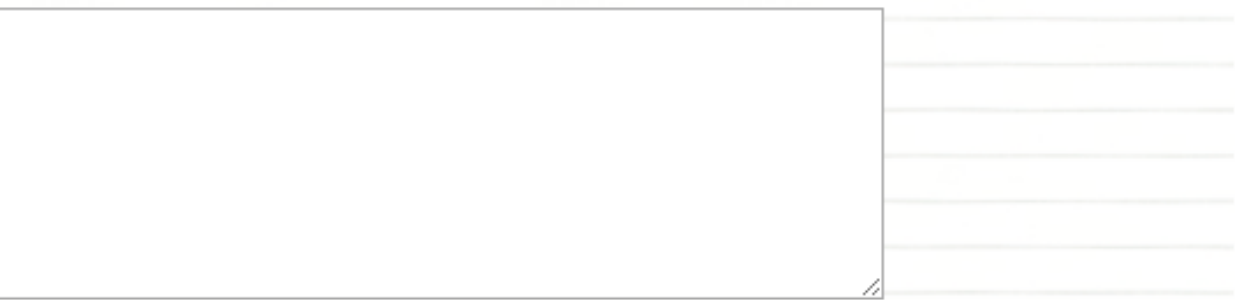

Describe los aspectos NEGATIVOS del curso.Podes ampliar lo elegido en la pregunta anterior: * 
¿Volverías a realizar un curso en esta modalidad virtual? Explicar . *

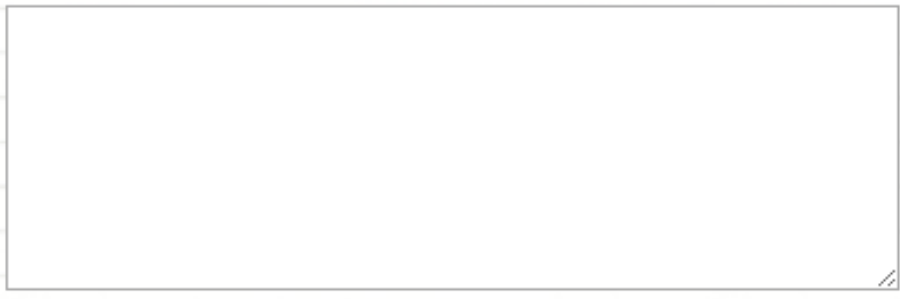

Qué te provocó este curso con respecto a tu elección de carrera universitaria? Podés responder mas de un item. *
$\square$ Ansiedad
Dudas
Tranquilidad
Confianza
Desconfianza
Soledad
Contención por parte de los compañeros
Contención por parte de los profesores

\section{¿Recomendarías este curso a otras personas? *}
si
no

Cuando inicié el curso de edacta... *

ya estaba decidido en seguir esta carrera

el curso me hizo reflexionar y no iniciaré mis estudios el próximo año

Otro:

Al finalizar el curso, me doy cuenta que mi nivel de inglés es... *
Excelente
Muy bueno
Bueno
Regular
Necesito estudiar uno o dos años más antes de comenzar
Otro:

En general esta experiencia de aprendizaje te resultó *

$\begin{array}{ccccc}\text { Excelente } & \text { Muy buena } & \text { Buena } & \text { Regular } & \text { Mala } \\ 0 & \ddots & 0 & \end{array}$

\section{Enviar}

Nunca envíes contraseñas a través de Formularios de Google. 


\section{APÉNDICE 8}

\section{Informe enviado a los tutores}

\section{E-mail enviado por la coordinadora a sus tutores:}

...Cómo verán en el cronograma que adjunto, se nos fue Mayo y parte de junio, así que trabajaremos más intensamente Junio, Julio y Agosto para que comience en Septiembre como ya está previsto. Necesito que se anoten en el curso de capacitación de la Escuela de Lenguas, así se van familiarizando con la plataforma y van aprendiendo su manejo, igual vamos a tener reuniones para ir aprendiendo su funcionamiento y cómo llevar adelante las tutorías.Ya les adelanté en un email sobre la primera etapa de elaboración de materiales. Necesito que vayan buscando textos, imágenes, videos, audio (formato mp3) para armar el material. Vamos a armar 6 guías con 6 temas diferentes.

Mercedes había empezado a trabajar con el tema "Smoking". Revisalo, Mercedes, porque hay algunas actividades que no se pueden realizar con este programa.

El programa que voy a utilizar permite cierto tipo de actividades:

A partir de textos, imágenes, videos o audios permite hacer actividades de

- multiple choice

- true and false

- $\quad$ fill in the blanks

Necesito que el material esté digitalizado, en un documento de Word, y los ejercicios con sus respuesta claras y también pueden agregar comendatarios a cada respuesta. TODOS los ejercicios deben estar contextualizados, seguir el hilo del tema principal.

Hoy les pregunté a mis alumnos de Lengua 1 por los temas que más les interesan. Aquí va una lista que nos puede ayudar:

- Fashion

- Music (Icons: The Beatles, ABBA, Madonna, Roling Stones)'80s

- Discoveries

- Plastic Surgery

- Interesting places to visit or go on vacation

- Art

- Social issues: health, politics, economy

- Marriages: how it has changed nowadays/Young couples vs. Old couples

- $\quad$ Sports (different cultures and sports)

- Movies (actors, actresses and movies that made history)

- People who made a difference

- Biographies of famous and important people

- Teenager matters

- Phobias

- Addictions

- Adolescence

- $\quad$ Friendship between woman and men. Does it exist?

- Problems between the government and the country

- Insecurity

- Topics related to our future careers

- Tattoos and piercing

- Environmental issues

- Youth and activities 


\section{APÉNDICE 9}

Forum Etiquette

\section{e-DACTA Forum Etiquette}

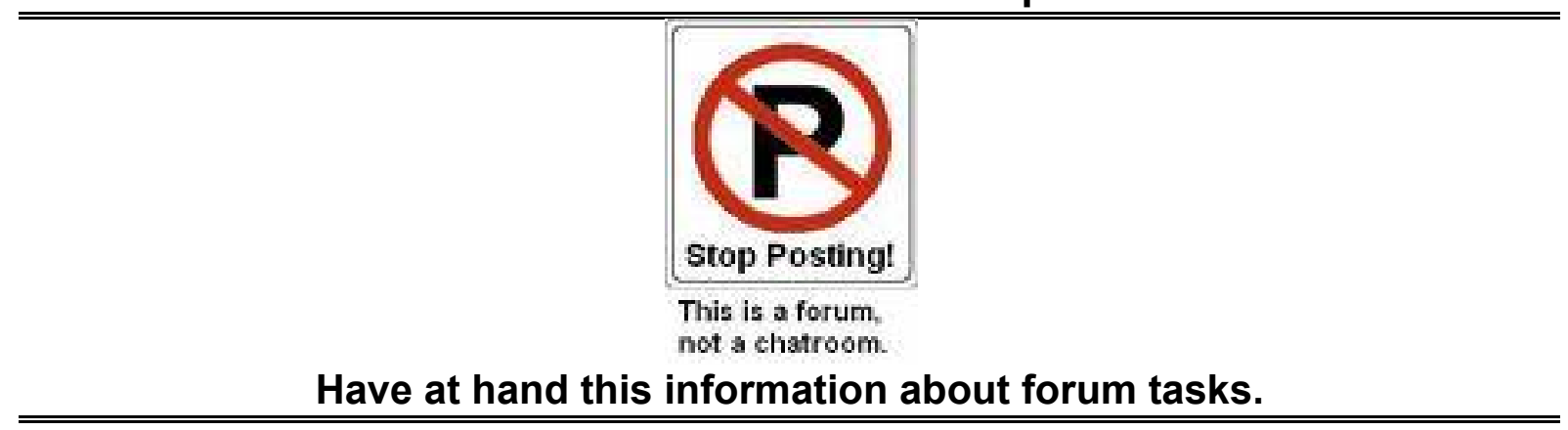

$\checkmark$ Be respectful. No personal attacks.

$\checkmark$ Be accurate. Respect the conventions of written language: style, grammar, punctuation. Remember that this is an academic context.

$\checkmark$ Be honest. Remember this is an opportunity to get to know your classmates.

$\checkmark$ Be relevant. Make sure you answer the initial question.

$\checkmark$ Be concise. Do not write more that 80 words.

$\checkmark$ Do not forget that you have to participate in the forum discussions. In this forum you will participate only once, so take your time before posting you comment.

DON'T SUBMIT a piece of writing which you have not checked first. Read through your work as if you are the reader, not the writer, to ensure the following:

- It makes sense and hangs together

- It has no grammar, punctuation or spelling slips

- You have not repeated ideas or over-used certain words. You have not used unclear or clumsy expressions. 


\section{APÉNDICE 10}

\section{Muestra de una guía}

\section{e-dac.ta Series}

(Dispositivo de apoyo académico por tareas autoadministradas electrónico)

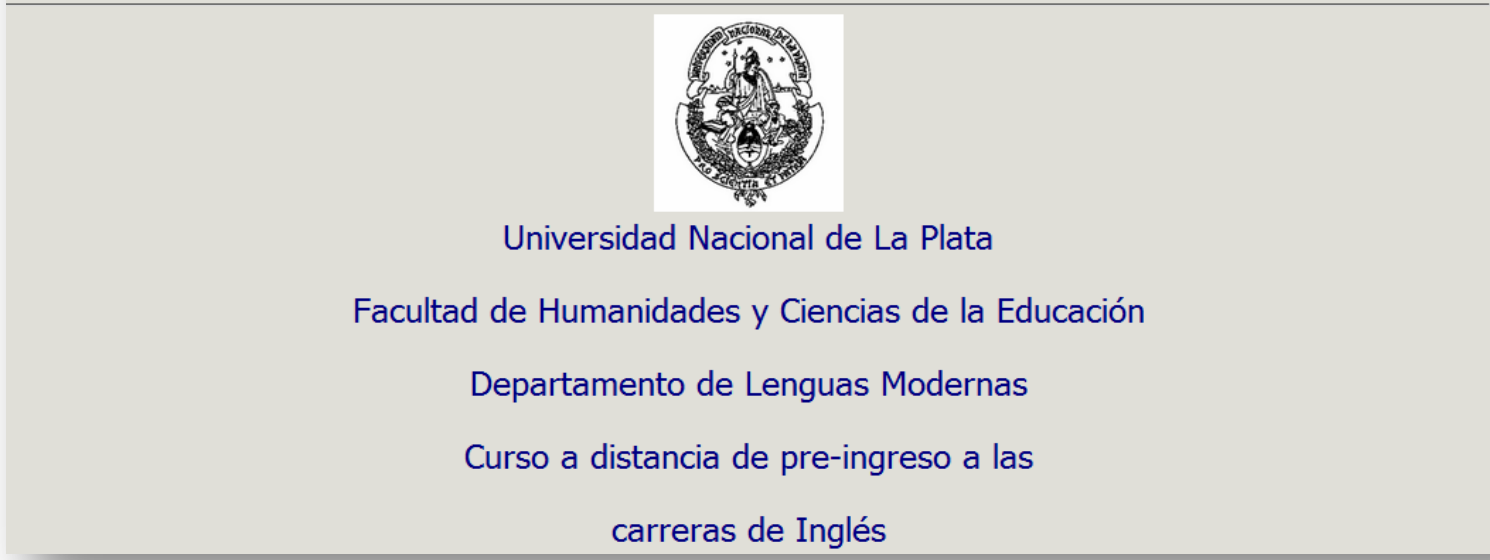

carreras de Inglés

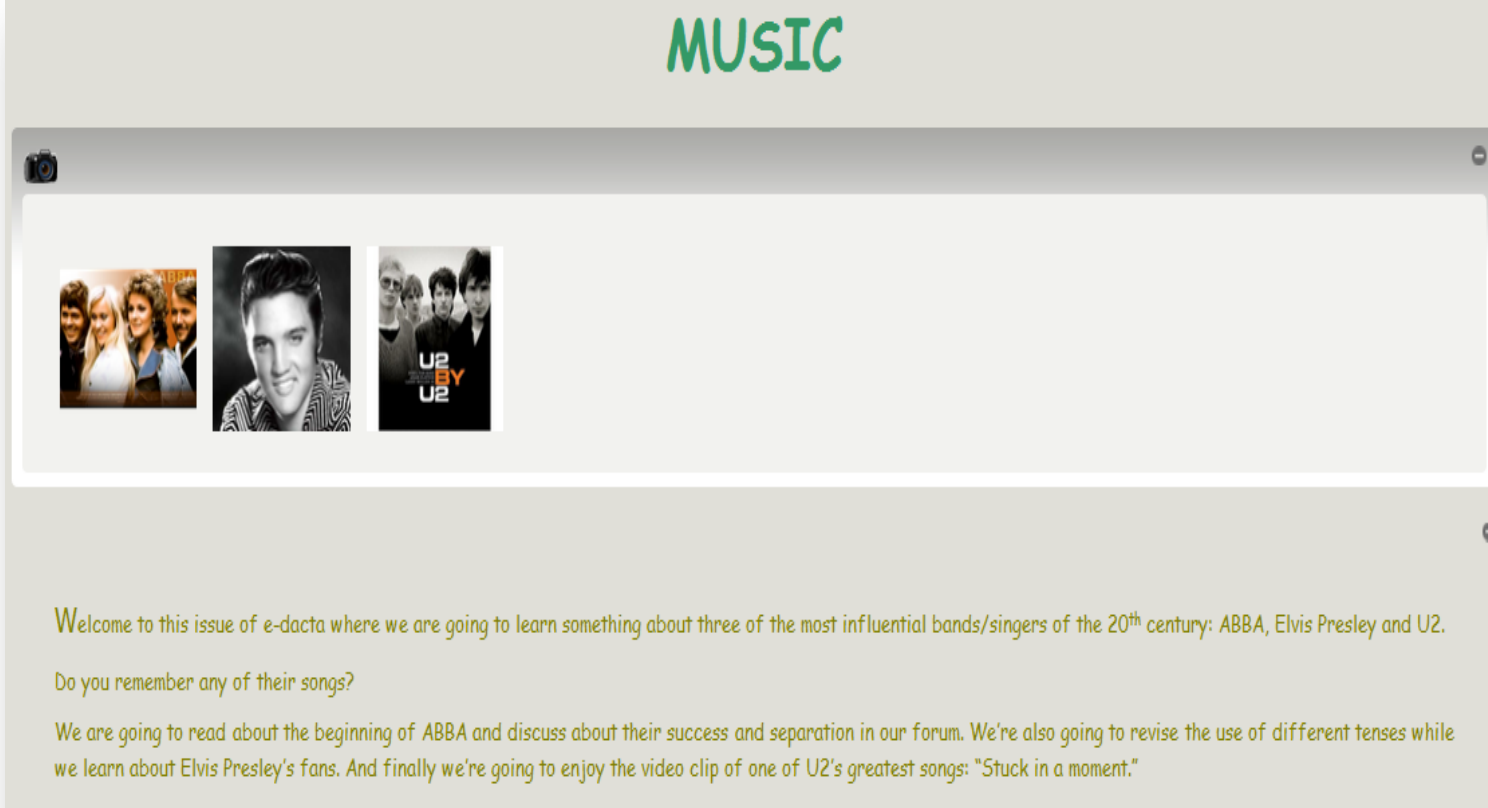

Hope you'll have a good time working. 


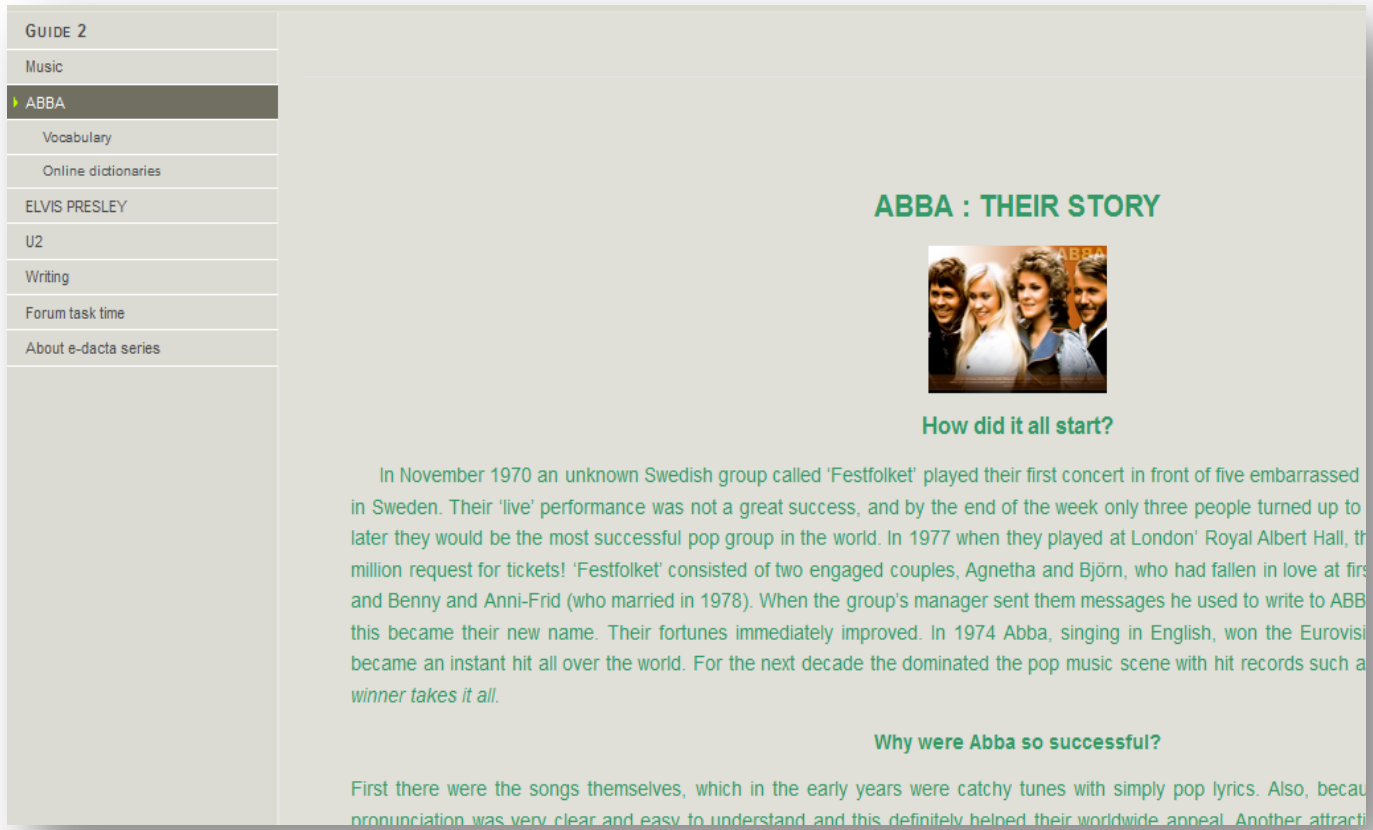

nronunciation was verv_clear and_easy to understand_and this definitelv helned their worldwide anneal_Annther attracti

\begin{tabular}{|c|c|c|c|c|}
\hline GUIDE 2 & \multirow{2}{*}{\multicolumn{4}{|c|}{ Exercise 1}} \\
\hline Music & & & & \\
\hline ABBA & & & & \\
\hline Vocabuary & \multicolumn{4}{|c|}{ gi. Gap Filling } \\
\hline Pretasks & \multirow{4}{*}{\multicolumn{4}{|c|}{$\begin{array}{l}\text { Use a dictionary to check their meanings and use them to complete the following sentences. Be careful and use } \\
\text { the correct form of the expression. }\end{array}$}} \\
\hline IExercise 1 & & & & \\
\hline Exercise 2 & & & & \\
\hline Onine dictionaries & & & & \\
\hline \multicolumn{5}{|l|}{ ELIISPRESLEY } \\
\hline U2 & \multicolumn{4}{|c|}{ a. Even though they never had a big quarrel, they just } \\
\hline Writing & & b. Jack has it all well planned, he & \multicolumn{2}{|c|}{ next Saturday at his giiffriend's favourite restaurant. } \\
\hline Forum taskime & & c. They both knew it was & and they started & immediately. \\
\hline \multirow[t]{4}{*}{ About -dacta series } & \multirow{2}{*}{\multicolumn{4}{|c|}{$\begin{array}{l}\text { d. Tom and Mary looked like the perfect couple, but they } \\
\text { affair with his best friend. }\end{array}$}} \\
\hline & & & & \\
\hline & & e. My sister and her boyfriend & \multirow{2}{*}{\multicolumn{2}{|c|}{ for almost five years, so they decided to get }} \\
\hline & Getscore & ShowClear Answers & & \\
\hline
\end{tabular}



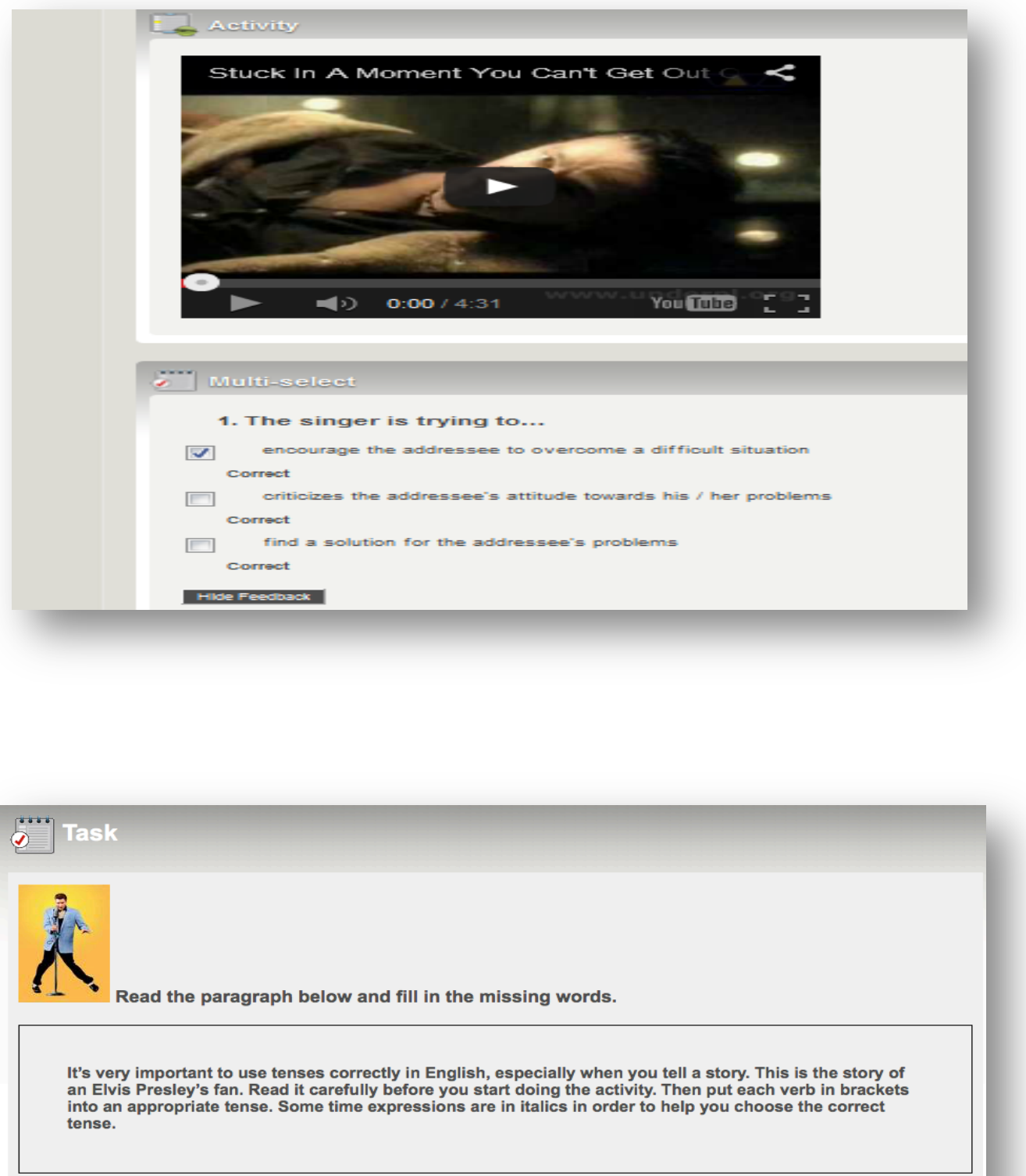

Ask hundreds of people what they (1)

(do) on a certain day in August next year, or the year after, and

there (2) $\quad$ (be) only one reply. Provided of course that the people you (3) $\quad$ (ask) (4) $\quad$ (belong) to the Elvis Presley Fan Club. Although the King of Rock and Roll (5) (die) nearly two decades ago, his fans (6) (meet) every year since then outside his home in Memphis, Tennessee, to show respect for the singer they (7) (love) so much. Fans like Jean Thomas, from Catford in South London. Jean (8) (visit) Gracelands, the house where Elvis (9) (suffer) his fatal heart attack, twice in the past five years. 'The first time

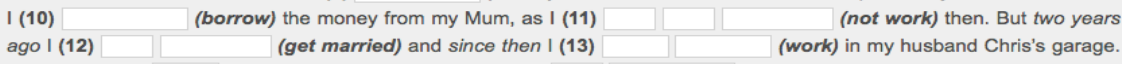
\begin{tabular}{l|l|l} 
Chris and I (14) (go) together last year, and we (15) & (think) of spending two or three months in
\end{tabular} the USA next year. I (16) - always (want)to visit some of the places where Elvis (17) (perform). Like Las Vegas for example (18) (own) every single one of his records, good and bad. 


\section{APÉNDICE 11}

NOTA: Los apellidos de los alumnos han sido removidos, solo conservamos la/s letra/s inicia/es del apellido.

\section{Chat 1}

23:48:11(F> hi!

23:50:12 ¿G> Let's add each other in Facebook, I think this chat is a Mess! LOL

24/09/00:00:38 * $\mathrm{P}$ se une a e-dacTa: Pre ingreso prof. y traduc. Ingl

24/09/00:02:23 〈P〉 hii

24/09/00:03:13 〈F〉 you are right!!!

24/09/00:03:30 〈F〉 My face is maru furgat

24/09/00:03:54 «G〉 OK, Now I'll search you! =)

24/09/00:04:01 〈F〉 ok

24/09/00:05:04 $\langle\mathrm{G}\rangle \mid$ | have just send you the invitation

24/09/00:05:27 (G) Pascual, What about you? do you have face?

24/09/00:07:59 $\langle\mathrm{P}\rangle$ yes, florencia pascual

24/09/00:08:52 «G OK

24/09/00:09:41 〈G〉 I have found lot of Florencia Pascual, who are you?

24/09/00:10:42 $\langle P\rangle$ i dont know how to tell you so you recognize me.. give me your facebook and i'll add you

24/09/00:11:04 «G〉 Ok that would be better

24/09/00:11:08 (G) Milagros Garozzo

24/09/00:11:47 $\langle G\rangle$ My photo is in black and white

24/09/00:12:55 $\langle P\rangle$ done, check

$24 / 09 / 00: 13: 08\langle G\rangle=)$

24/09/00:13:22 〈G) mm, not yet

24/09/00:15:30 $\langle P\rangle$ are you sure, cause it appears like i have already ask you to be my friend and it wont let me do it again.. god, i hate facebook

24/09/00:24:27 * $S$ se une a e-dacTa: Pre ingreso prof. y traduc. Ingl

24/09/02:46:03 * G se une a e-dacTa: Pre ingreso prof. y traduc. Ingl

24/09/02:46:44 «G〉 All done! we are friends now! =) Chat other day! =)

24/09/11:50:49 * B se une a e-dacTa: Pre ingreso prof. y traduc. Ingl

24/09/11:54:47 ¿B〉 oh, we'd better add one another to facebook, it will be easier to know all the students here lol, my facebook is Dani Bifaretti, feel free to add

24/09/12:03:03 * GO se une a e-dacTa: Pre ingreso prof. y traduc. Ingl

24/09/12:40:32 * F se une a e-dacTa: Pre ingreso prof. y traduc. Ingl

24/09/12:40:50 $\langle\mathrm{F}\rangle$ hi

24/09/12:40:59 $\langle\mathrm{F}\rangle$ anybody around?

24/09/12:57:50 * Bor se une a e-dacTa: Pre ingreso prof. y traduc. Ingl

24/09/12:59:04 «Bor» hi guys!!! I'm magdalena! I'm agree, let's add one another to facebookj

24/09/12:59:24 «Bor) it'll be great to get to know each other

24/09/13:02:21 〈F〉 MAGDALENA BOR?

24/09/13:02:44 〈F〉 THEN I CREATED A GROUP ALSO, SHOULD i MAKE IT PUBLIC?

24/09/13:04:14 〈F〉 UHI can't find you

24/09/13:17:46 * Bor

24/09/13:18:26 (Bor) sorry! i'm here again, haha my name is magdalena boran!

24/09/13:18:55 (Bor) what is the group about?

24/09/13:20:25 * Bor

24/09/13:20:32 * Bor

24/09/13:20:49 * Bor

24/09/13:20:52 * Bor

24/09/13:22:59 $\langle F\rangle$ edacta

24/09/13:23:23 $\langle F\rangle$ that's the name of the group

24/09/13:23:54 (Bor) okey! make it public if you think that's a good idea

24/09/13:24:08 $\langle F\rangle$ so we can chat and get to know each other so next year we do not feel so lonely

24/09/13:24:30 〈F〉 are u from la plata? 
24/09/13:24:41 $\langle\mathrm{F}\rangle$ or you are moving next year?

24/09/13:24:58 «Bor that's great! yes, I am from la plata, and you?

24/09/13:26:37 〈F〉 i'm from necochea

24/09/13:26:48 $\langle F\rangle$ but i'm moving next year

24/09/13:27:01 $\langle F\rangle$ with my boyfriend and my kids

24/09/13:28:54 (Bor) that's awesome! what are you planning on studying?? to be a teacher or a translator?

24/09/13:29:31 〈F> Licenciatura in fact (i don't know the english for it!)

24/09/13:30:34 (Bor) haha don't worry!

24/09/13:31:01 〈F〉 do you know it? because if you look it up

24/09/13:31:12 $\langle F\rangle$ it just says degree

24/09/13:31:26 $\langle F\rangle$ but there is no specific word

24/09/13:31:41 〈F〉 or at laest i haven't found it

24/09/13:33:15 (Bor) i think it's degree! you are right!

24/09/13:34:03 $\langle F\rangle$ so it would be

24/09/13:34:18 $\langle F\rangle$ i want to have a degree in linguistics

24/09/13:35:02 «Bor) i'd like to be a translator

24/09/13:35:58 〈F〉 good

24/09/13:36:10 $\langle\mathrm{F}\rangle$ do you know the orientations

24/09/13:36:16 〈F〉 there are?

24/09/13:36:27 〈F〉 or you will decide later?

24/09/13:39:27 (Bor) waht do you mean by orientations?

24/09/13:41:09 〈GO〉 hi evryone

24/09/13:41:21 〈GO〉

24/09/13:41:23 〈F〉 hi

24/09/13:41:53 $\langle\mathrm{F}\rangle$ if it is literature or technical

24/09/13:42:02 《GO) I must say that my English is basic

24/09/13:42:39 〈F〉 well, tell us how old are u gonzalez

24/09/13:42:48 $\langle F\rangle$ and what's your name?

24/09/13:42:54 〈Bor) there is no orientation, you learn them all

24/09/13:43:06 ¿GO〉 24 years

24/09/13:43:11 «Bor that's fine! we are doing this to learn more.

24/09/13:43:13 «GO) franco gonzalez

24/09/13:43:29 〈F〉 ah I thought you could choose!!!

24/09/13:43:32 〈F〉 sorry

24/09/13:44:03 * So se une a e-dacTa: Pre ingreso prof. y traduc. Ingl

24/09/13:44:05 «Bor> it's okey!!

24/09/13:44:06 〈F〉 Franco

24/09/13:44:18 〈GO〉 tell me

24/09/13:44:23 $\langle F\rangle \mid$ think $i$ added you in facebook

24/09/13:44:36 «GO) franCo joaquin gonzalez

24/09/13:44:37 $\langle\mathrm{F}\rangle$ i hope it's you

24/09/13:44:50 $\langle F\rangle$ if not $i$ added someone with your name

24/09/13:44:53 〈F〉 jejeje

24/09/13:44:59 * Pa se une a e-dacTa: Pre ingreso prof. y traduc. Ingl

24/09/13:45:10 〈F〉 magda i couldn't find you

24/09/13:45:35 «So > hi!

24/09/13:45:51 《GO) furgat giv me your facebook

24/09/13:46:50 $\langle F\rangle$ Maru furgat

24/09/13:47:00 $\langle\mathrm{F}\rangle$ hi soto quiroga!

24/09/13:47:01 (Bor) you find me on facebook as magui boran

24/09/13:47:06 $\langle F\rangle$ how are $u$ ?

24/09/13:47:17 〈F〉 oki doki9

24/09/13:47:42 (GO) find me as franCo gonzalez

24/09/13:47:45 (SO) really good idea being facebook friends, i just can't undesrtand this chat

24/09/13:47:55 〈P〉 hii

24/09/13:48:10〈F〉 hiiiii

24/09/13:48:17 〈F〉 how are $u$ ?

24/09/13:48:22 «SO > i'm paula, by the way 
24/09/13:48:30 〈F〉 Paula

24/09/13:48:33 〈F〉 ok

24/09/13:48:35 〈Pa〉 fine, just woken up

24/09/13:48:43 «SO > kind of sleepy

24/09/13:48:49 〈F> Magui i swear god i cant find you!!!

24/09/13:49:02 «GO) furgat i send the request

24/09/13:49:04 «F〉 pau! u went out last night!

24/09/13:49:28 〈SO〉 no lol, last nigth i was more like a granny

24/09/13:49:51 〈Pa〉 lol

24/09/13:49:52 « $\mathrm{SO}$ > i watched a movie with my sis and went to bed an 1 am

24/09/13:50:04 〈F〉 lol

24/09/13:50:08 «SO > how about you?

24/09/13:50:17 $\langle\mathrm{F}\rangle \mid$ | think I am the granny here!

24/09/13:50:27 (F) i'm the eldest so far

24/09/13:50:37 〈 $\mathrm{Pa}$ i did the exact same thing, and $i$ also ate ice cream

24/09/13:50:54 «SO if you're not 30, then youre still young!

24/09/13:51:07 〈F〉 i'm 26

24/09/13:51:10 «SO〉 o0000000oh ice crem, want some now!

24/09/13:51:19 〈F〉 wait

24/09/13:51:26 (Bor) hahahah let me add you

24/09/13:51:33 (SO) great, just young enough to be cool lol

24/09/13:51:36 〈F〉 i am the pregnant here so "antojos" only for me

24/09/13:51:48 〈F〉 ok

24/09/13:51:53 $\langle\mathrm{Pa}$ ) congratulations, boy or girl?

24/09/13:51:59 〈F〉 add me Maru F...

24/09/13:52:32 «SO > Oh! now i remember your mail or whatever whe had to write, you have a son callec aaron !

24/09/13:52:32 «Bor〉 i can't find either

24/09/13:52:47 〈Bor〉 you*

24/09/13:53:11 $(F)$ yesssssssss

24/09/13:53:26 «SO〉 me? I'm Paula Soto-Quiroga. I'm the only one with that name

24/09/13:53:42 〈F〉 don't tell me that your dog is called the same way! I have a friend who has a dog called AARON!

24/09/13:53:46 «Bor〉 okey, i'll add you

24/09/13:53:54 «Bor> too

24/09/13:54:23 〈F〉 my baby

24/09/13:54:26 «Bor) i forgot $\mathrm{i}$ had already addedd you paula

24/09/13:54:27 〈F〉 a boy

24/09/13:54:48 $\langle F\rangle$ i'll be sorrounded by men

24/09/13:54:50 〈 $\mathrm{F}\rangle$ hehehe

24/09/13:55:07 (Bor) hahaha that's so nice! congrats maru!!

24/09/13:55:15 〈 $\mathrm{F}\rangle$ but i'm having problems finding a name for my second child

24/09/13:55:25 (Furgat) thanks!

24/09/13:55:57 (Bor> i still can't find you, what's you profile picture?=

24/09/13:56:02 «Bor〉?

24/09/13:56:21 〈Bor) done!

24/09/13:56:25 (Bor) finally!

24/09/13:56:31 $\langle\mathrm{F}\rangle$ uh a difficult one! is a "picasa" with many small ones

24/09/13:56:42 (SO) i add you both!

24/09/13:56:44 (Bor) yes!

24/09/13:57:08 〈F〉 great

24/09/13:57:09 〈Pa〉 add me Florencia Pascual

24/09/13:57:26 〈F〉 i'll see and find you in her profile

24/09/13:57:40 «SO > i was about to ask your full name lol

24/09/13:58:10 〈F〉 good good

24/09/13:58:13 〈Pa i'm a mind reader Iol

24/09/13:58:22 〈F〉 franco I had added someone else

24/09/13:58:30 «Bor) done florencia!

13:58:50 〈 $\mathrm{Pa}$ 〉 paula we have a lot of friends in common 
13:59:35 〈SO〉 yes! where do you study?

14:00:08 〈Pa〉 esquiu, city bell

14:01:39 «SO > oh you know mara leyes

$14: 02: 04{ }^{*}$ Bor

14:02:06 $\langle\mathrm{Pa}\rangle$ yes

14:02:57 (SO) she's a friend's best friend

14:04:20 〈F〉 ok

14:04:34 〈F〉 guys see $u$ around I hope

14:04:39 〈Pa〉 camila fulco marcos briguez julieta ferella belen trivi facundo insausti and santi diaz went to school with me

14:04:59 〈F〉 i'm having luch

14:05:01 〈Pa〉 bye, see you

14:05:08 〈SO〉 camila it's friends with mara and my friend

14:05:08 〈F〉 see you!

$14: 05: 13$ 〈SO enjoy it !

14:05:43 «SO > marcos facundo and santi now go to my school

14:06:05 « $\mathrm{SO}$ > i now julieta from dance classes and belen from english clases

$14: 06: 15$ «SO > la plata is really small

14:11:45 * Pa se une a e-dacTa: Pre ingreso prof. y traduc. Ingl

14:12:08 $\langle\mathrm{PA}\rangle$ i was going to put the same but my computer suddenly shutted down

$14: 14: 27$ (SO ) sometimes when $i$ turn off the volume happens the same

14:16:51 〈 $\mathrm{Pa}\rangle \mathrm{i}$ touched the buton that says "power" in the keyboard, i didn't mean to.. i don't even know why somebody will put that buton in the keyboard, no sense

$14: 18: 23$ 〈SO did and thought that way many times

14:21:03 (PA) see you soon, bye

14:21:39 〈SO> have to go, see you!

14:44:44 * B se une a e-dacTa: Pre ingreso prof. y traduc. Ingl

$14: 57: 47 * \mathrm{~S}$ se une a e-dacTa: Pre ingreso prof. y traduc. Ingl

15:09:21 $\langle\mathrm{B}\rangle$ emm

15:09:37 $\langle\mathrm{B}\rangle$ anybody there?

15:30:16 * Pa se une a e-dacTa: Pre ingreso prof. y traduc. Ingl

15:34:37 * $\mathrm{G}$ se une a e-dacTa: Pre ingreso prof. y traduc. Ingl

15:42:15 〈G〉 Hi people, Anybody there?

15:43:25 * D se une a e-dacTa: Pre ingreso prof. y traduc. Ingl

15:43:39 «D) hi!!

16:08:20 * P se une a e-dacTa: Pre ingreso prof. y traduc. Ingl

16:44:57 (D) i know belen, she goes to schoolwith me ! we ae finishing school is our last year

17:19:05 * B se une a e-dacTa: Pre ingreso prof. y traduc. Ingl

17:55:23 * P se une a e-dacTa: Pre ingreso prof. y traduc. Ingl

17:55:44 〈B〉 mm

17:59:32 * $\mathrm{M}$ se une a e-dacTa: Pre ingreso prof. y traduc. Ingl

19:48:39 * Pa se une a e-dacTa: Pre ingreso prof. y traduc. Ingl

19:52:08 * SO se une a e-dacTa: Pre ingreso prof. y traduc. Ingl

21:46:45* $\mathrm{G}$ se une a e-dacTa: Pre ingreso prof. y traduc. Ingl

22:08:45* $S$ se une a e-dacTa: Pre ingreso prof. y traduc. Ingl

22:09:13 〈S B hello

$22: 10: 01\langle S B\rangle$ is anybody there to answer me!

22:13:18 $\langle\mathrm{P}\rangle$ hi

22:15:28 $\langle\mathrm{S} B$ 〉 hello

22:15:40 〈S B > finally somebody

22:15:52 ( $S B$ ) where are you from?

22:16:17 〈Pa〉 la plata, and you?

22:16:52 «S B i from cutral co

$22: 17: 00$ ( $S B\rangle$ is in neuquen

$22: 17: 20$ 〈S B〉 how old are you?

$22: 17: 34$ (S) 17 and you?

22:18:15 $(S$ ) tell me your full name so i add you on facebook, we have a group there

$22: 18: 27$ 〈S B〉 17

22:19:06 〈 $S B\rangle$ my face is Ro $S \ldots \ldots$. 
22:21:35 〈Pa〉 what does your profile picture look like? there are too many ro sandoval

22:22:41 $(S \mathrm{~B}$ ) im wearing a red hat and im with a friend

22:23:03 $\langle S B\rangle$ he is drees like a zoombie

22:23:07 〈S B〉 jajajajajja

22:23:49 〈Pa〉 done, check

22:24:00 $\langle\mathrm{Pa}$ 〉 hahaha

22:24:12 〈S B〉 do you find me?

22:25:12 $\langle\mathrm{Pa}$ 〉 yes, $i$ have already sent you the friendship request

22:25:41 $\langle\mathrm{S} B\rangle$ how is your full name

22:26:00 $\langle P\rangle$ florencia pascual

$22: 26: 36$ 〈 $\mathrm{B}\rangle$, how is your picture

22:27:58 $\langle\mathrm{P}\rangle$ ) one side of my face

22:28:00 $\langle P\rangle$

22:29:11 〈S B〉 done i add you all ready

$22: 31: 43\langle S B\rangle$

22:33:11 ( $P$ 〉 yes! you should have received a notification from the group edacta.. did you get it?

22:37:40 〈S B〉 what?

\section{Chat 2}

19:20:32 «Simon: tutor» Hi

19:20:39 «Simon) How are you?

19:20:44 «Simon〉 I was here at $6 \mathrm{pm}$

19:20:48 〈L) WHATS UP

19:20:48 〈B〉 oh hi teacher!

19:20:56 〈B〉 you are late! hahaha

19:21:08 〈 $S B$ 〉 jajaja justin is an idiot

19:21:11 〈S B> hi teacher!

19:21:13 〈Simon〉 but I coudn't find anyone.

19:21:21 〈L〉 did you watch it?

19:21:27 (L) jaja

19:21:35 «Simon〉 The the webpage was blocked!!!!

19:21:35 «S Baru〉 jaja yes

19:21:39 (B) liliana, i have a question, may i?

19:21:53 «Simon〉 sorry!!!!You know, technologies!!!!

19:22:02 〈B〉 hahahah!!!

19:22:16 (Simon) yes

19:22:48 (B) Lil! do you know if we are going to use the DACTA book and the american short stories next year?

19:22:49 «Simon) I have designed this course in 2008

19:23:33 «Simon) And this year I notice that this group is very enthusiastic

19:24:15 〈Simon〉 I will open soon a forum about the faculty and course of studies issues

19:24:17 〈B〉 yes like little kids! we really want to go to the university hah

19:24:49 〈S B〉 im afraid for the test jaja

19:25:10 〈L〉 dont worry

19:25:15 * $\mathrm{L}$ se ha desconectadode e-dacTa: Pre ingreso prof. y traduc. Ingl

19:25:24 «Simon〉 I am also a teacher at ENGLISH LAnguage 1

19:25:27 ¿Sanchez Baru> but i dont speak english very well

19:25:31 * L se une a e-dacTa: Pre ingreso prof. y traduc. Ingl

19:25:32 〈 $B$ 〉 and there will be an optional test in november at university to know more or less how we are prepared?

19:26:06 〈B〉 ahh so we are going to meet you next year hahah!

19:26:15 «Simon` yes, you have the optional test, the DACTA and e dacta

19:26:45 «Simon) probably. There are 5 "comisiones" in E LAnguage 1

19:27:03 〈S B > what is comisiones?

19:27:11 〈B〉 LOL, well. i hope hahah

19:27:11 〈Simon〉 I used to be the coordinator of the entrance courses 
19:27:17 〈B〉 "grados", "cursos

19:27:26 〈Simon〉 but then I had twins and....

19:27:30 〈S B > ahh thanks

19:27:40 〈S B〉 ahh congratulations!!!!

19:27:48 〈B〉 wow nice!!

19:28:08 «Simon〉 comisiones are the group in which the "cátedras" are divides to attend the prácticos 19:28:35 «Simon) sorry, divided

19:28:58 〈B〉 and can we choose the comision? because of the time, i mean, i wouldn't like to go to universitry at night hahah

19:29:13 〈Simon〉 at night???

19:29:21 «Simon` or in the evening?

19:29:28 〈B〉 hahahha

19:29:29 〈B〉 yes!

19:29:43 (B) sorry! im still learning!

19:29:51 〈Simon` there are groups in the morning and in the afternoon

19:30:02 «Simon» it's OK

19:30:14 〈B〉 ah better for me! haha

19:30:31 〈L〉 do u have the test of the last year?

19:30:31 〈Simon` up to $6 \mathrm{pm}$

19:31:06 «Simon` The first year you have English Language 1, Phonetics 1 and Grammar 1 in English!!!!

19:31:16 «Simon〉 Everything in English!!!!

19:31:25 «S B〉 ahh!!

19:31:55 «Bifaretti but i bet we wont pass and we will have only the spanish subjects!!

19:31:56 «Simon> Where are U from?

19:31:58 $\langle$ B oh joke

19:32:02 $\langle B\rangle=P$

19:32:13 (B) Berisso here!

19:32:13 〈Simon〉 yes

19:32:17 ( $\mathrm{S} B$ 〉 we are going to be yanquis! jaja

19:32:27 (L) jajaja gringos

19:32:30 «Sanchez Baru〉 la plata

19:32:32 (Simon` why?

19:32:33 〈B〉 shut up! hahahahah

$19: 32: 35$ 〈 $\mathrm{B}$ 〉 and you?

19:32:52 〈B) teachers prefeer british enlgish, don't they?

19:33:06 (Simon) I live in La Plata. When I was a student I lived in City Bell

19:33:26 «Simon` MAybe, but I learned English in the USA

19:33:58 〈B〉 wow! have you been to usa?

19:34:01 〈S B〉 did you travel?

19:34:14 (Simon) And when I had to take the course on Phonetics I had to learn the English pronunciation

19:34:41 〈Simon〉 Nevertheless, both are accepted now.

19:34:54 〈B〉 yes and it's very hard to get used to the acent

19:35:09 «Simon> I live with my family for two years in Washington DC because of my father's job

19:35:29 〈B〉 and that's why you decided to be an english teacher?

19:35:47 (S B) guau so you learn english in usa?

19:36:02 «Simon) I was 10 when I decided to be a teacher

19:36:09 $\langle S B\rangle$ i think tat is the best way to learn english

19:36:18 〈S B〉 really? 10?

19:36:31 〈B〉 WOW.... very little to decide!

19:37:43 «Simon` yes, it's goog to travel or live in a foreign country

19:38:03 «Simon` Are you going to be teachers or translators?

19:38:24 $\langle S B\rangle$ i dont know

19:38:25 〈B〉 translator ${ }^{\wedge} \wedge$

19:38:37 (L) i prefer our country

19:38:46 (L) and im gonna be a translator

19:38:52 «Simon» why?

19:39:07 〈L〉 why what? 
19:39:24 «Simon` why oue country? to learn a language?

19:39:37 (L) not to learn

19:39:39 * L se ha desconectado de e-dacTa: Pre ingreso prof. y traduc. Ingl

19:39:51 * L se une a e-dacTa: Pre ingreso prof. y traduc. Ingl

19:40:20 〈L) to live

19:40:56 (B) liliana what we can do being translators? do you recieve a text and you can translate it in your house and then bring it?

19:41:50 〈Simon〉 Of course, it's good to live for a short period abroad. But nothing like Argentina. I totally agree.

19:42:08 «S B> like freelance??

19:42:35 〈B〉 smt like that

19:42:48 〈B〉 or work for a bussiness

19:42:49 «Simon` Yes sth like that.

$19: 43: 14\langle S B\rangle$ but is it very difficult to get a job?

19:43:22 (Simon) yes, but usually U have more job opportunities in BS AS

19:44:10 «Simon〉 Well, I have to go and cook if not my kids will eat me!!!!The will be 11 on Sunday and the little one is 6

19:44:14 $\langle\mathrm{B}$ 〉 yes besides, in BS AS there is another career, interpretariado

19:44:38 〈B〉 oh well!

19:44:40 (B) hahahha

$19: 44: 45$ 〈S B i have to go too

19:44:47 〈Simon) CU soon

19:44:47 (L) see ya

$19: 44: 51\langle B\rangle$ it ok tracher lil!

19:44:53 «Simon〉 Bye bye

19:44:57 〈B〉 cya people!

19:45:12 〈S B〉 nice to meet you teacher!!

19:45:18 〈S B〉 bye dani see you

19:45:19 〈B〉 it's* oghhh

19:45:30 〈B〉 bye sanchez hahha

19:45:39 〈S B〉 jaja

19:45:47 (L) chau newton 


\section{APÉNDICE 12}

\section{Corpus de los foros}

\section{Foro 1}

List of contributions of the Forum Welcome to the course!!!

Instruction

First read carefully the forum etiquette handout.

After having read the forum etiquette handout, you will be ready to start posting in this forum.

Instructions: write a paragraph including: your name, age, city, school, interests, free time, expectations of your future course of studies, etc. Number of words: $50 / 80$ words.

TIPs: write your post using a word document; it will help you with the revision and the number of words. Then copy and paste your comment in the forum.

Remember to edit you work before posting anything.

Good luck- :)

Quantity of Contributions 41

Date and hour of sending September 18, $2013-14: 57: 05$

Sent by Simon, Liliana

Title Forum instructions

\section{Sent text}

First read carefully the forum etiquette handout.

After having read the forum etiquette handout, you will be ready to start posting in this forum.

Instructions: write a paragraph including: your name, age, city, school, interests, free time,

expectations of your future course of studies, etc. Number of words: $50 / 80$ words.

TIPs: write your post using a word document; it will help you with the revision and the number of words. Then copy and paste your comment in the forum.

Remember to edit you work before posting anything.

Good luck- :)

Date and hour of sending September 18, 2013 - 19:49:54

Sent by $\mathrm{Ag}$

Title RE: Forum instructions

Sent text

Hello Liliana!, My name is Mariano, I'm 19 years old, I live in Berazategui from Buenos Aires, my school is Tristan Achaval Rodriguez from Ducilo, I like to cook, play videogames, listen music, make more cool friends, in my free time I use my computer specially for play games, watch the TV and I don't know... spend time with my family and I don't really know what kind of courses I will make in the future, Bye!

Date and hour of sending September 18, 2013 - 20:16:47

Sent by $\mathrm{Ba}$

Title RE: Forum instructions

\section{Sent text}

My name is Julieta B, I-m 21 years old and I-m from Mar del Plata. I studied at the San Agustín school and then I studied psychology at the Universidad Nacional de Mar del Plata for three years, but I realized that it was not the most suitable carrer for me. So I-m waiting anxiously to start this new career since I-ve always loved the English language and its study. I-m also excited about moving to a different city and meeting new people. 
Date and hour of sending September 18, 2013 - 21:02:59

Sent by $\mathrm{Al}$

Title RE: Forum instructions

\section{Sent text}

Hello everyone! My full name is Lucas A, I'm 17 years old and I-m from La Plata. My current school is 'Instituto Bivongesi'. I really love singing, it's my passion and I'm really good at. Other interests include drawing, English, and writing reviews about TV shows. In my free time, I enjoy singing a lot and writing my own songs. I hope this course becomes 'easier' as time goes by and that I'll make new friends over the time.

Date and hour of sending September 18, $2013-21: 47: 43$

Sent by Sg

Title RE: Forum instructions

\section{Sent text}

Hi everybody ! My name is Maité and I live in Wilde. I went to Loreto in Sarandí. Reading is my passion and that is mainly what I do on my free time. I also love music, my favourite bands are Foo fighters and The doors. I am looking forward to use this course to find new friends and to prepare my self for this new course of studies.

Date and hour of sending September 18, 2013 - 22:32:01

\section{Sent by Bo}

Title Hi!

\section{Sent text}

Hi Everyone! My name is Gabriela. I'm a PhD student at Universidad Nac. de La Plata, Fac. Cs Exactas. I work in Photochemistry fields. Surely, I'm older than most of you but I'm very enthusiastic about this course. I like traveling and meeting new people everywhere. I'm pregnant. Emma (our baby) is coming for Christmas!.

Enjoy!!

Gaby

Date and hour of sending September 18, 2013 - 22:50:54

\section{Sent by $\mathrm{Ca}$}

Title Hello!

\section{Sent text}

Hi everyone! My name is Florencia, I-m twenty-one years old and I'm from La Plata. I went to San Vicente de Paul high school and then I started to study architecture, but a few months ago I decided to drop out. It just wasn-t my thing. I love reading and dancing and that-s mostly what I do on my free time. I-m very excited about starting a new career next year and I hope to make some new friends!

Date and hour of sending September 19, 2013 - 06:57:01

Sent by An

Title RE: Forum instructions

\section{Sent text}

Hi everyone! My name is Soledad, and I'm seventeen years old. I'm from Tandil. I'm studing in "Instituto Martín Rodríguez" secundary. I like travel and know new things. In my free time sometimes I read a novel or I meet with my friends or boyfriend. I'm so excited to start the carreer, and I hope this will be the correct road!

Date and hour of sending September 19, 2013 - 15:00:00

Sent by Es

Title RE: Forum instructions

\section{Sent text}

Hi Liliana!

Good day, my name is Eugenia, I'm 21 years old. I live in La Plata from Buenos Aires. My school was Institute Hijas de La Cruz from here. I like cook diferent foods, listen to music,watch tv and paint. In my free time I use my computer, watch the TV, study English in a institute.

In the future, I will be a English teacher. I love teach.

Bye, see you later. 
Date and hour of sending September 19, 2013 - 18:33:17

Sent by Sc

Title Hello!

Sent text

Hi everyone! My name is Micaela S and I-m 18 years old. I-m from Puerto Madryn but for a year I-ve been living in La Plata. I used to study in -Hermana María Sara Carbajal- school, then started Medicine but it just wasn-t my thing. Instead, I-ve always loved English so I-m pretty sure that I-II enjoy this career. I love listening to music and spend some quality time with my friends, and hope to get to know you all soon!

Date and hour of sending September 19, $2013-20: 07: 24$

\section{Sent by Co}

Title Hello!

\section{Sent text}

Hey! I-m Martin C. I-m 19 years old and I-m from La Plata. I-m in the last year of high school in -Ex Comercial San Martin Media 31 school. University is something that I really want to do. I love English and I hope this career to be the right career to me. Well, I love listening to music, writing music, and play the piano. That-s all about me. See you soon!

listening to music, writing music, and play the piano. That-s all about me. See you soon

Date and hour of sending September 19, 2013 - 23:21:03

Sent by Sz

Title RE: Forum instructions

\section{Sent text}

Hello everyone! I'm Victoria Sz and I'm 18. I live in La Plata and I'm on my last year at Bachillerato de Bellas Artes. I'm keen on films and books, I really enjoy going to the cinema, hanging out with friends and travelling. I'm looking forward to take part in the university life, meeting new people and improving my English as well. I can't wait!

See you,

Vicky.

Date and hour of sending September 20, 2013 - 13:54:18

Sent by Valeria , Zabala

Title RE: Forum instructions

\section{Sent text}

Hello guys, My name is Valeria Z, I-m 18 years old and I live in Olavarria. I love speaking english and meet new people, I've never gone to an English institute, but I went on exchange to Denmark for one year and I learnt it. I go to the conservatory of music and I play piano, guitar and I sing a little bit, I like to read and I love internacional music. In my future I want to do the English Translator career at UNLP

Date and hour of sending September 20, 2013 - 19:50:07

Sent by $\mathrm{V}$ (tutor)

Title Welcome everyone!

\section{Sent text}

Hello! I'm so glad to learn about all of you, as you know I'm your tutor. I'm a teacher and a translator, I love my career. I like translating but teaching is my passion. I really enjoy working in a classroom and here, in this virtual meeting place.

Let me tell you a bit more about me... I love reading novels and watching TV, I also like surfing the internet. But I don't have enough free time. I've got two kids and I spend most of my free time playing board games and telling stories.

Once again, welcome to the course!

Date and hour of sending September 21, 2013 - 02:54:32

Sent by Po

Title Hello classmates and teacher!!

Sent text

Hi Everyone! My name is Gisela, I'm twenty one years old, and I'm from Carhué, but I'm live in La Plata. I study Music at FBA (UNLP). In my free time I like sing, listen to music, read books, 
watch movies, dance and more things. I want to learn English and I'm so happy for do it. I wait met new people and enjoy the lessons together. ¡Happy student’s day! Bye!

Date and hour of sending September 21, 2013 - 16:41:39

Sent by $\mathrm{Ca}$

Title RE: Forum instructions

Sent text

Hi everyone! My name is Emilio C, I-m 18 and I live in Comodoro Rivadavia, Chubut. I go to a technical school called ENET 1 and this is my last year there so I-m pretty excited and a little sad too! I really like travelling and meeting new places. In my free time I usually watch TV and go out with friends. In the future I would like to be an english translator. I love english! I'm looking forward to meet you all!

Date and hour of sending September 21, 2013 - 19:36:24

Sent by $\mathrm{Da}$

Title RE: Forum instructions

Sent text

Hello everyone!

My name-s Ana Julia D .I-m nineteen years old and I-m from La Plata. I finished my studies last year at Normal 2 de La Plata highschool and this year I studied Antropology at UNLP. I like playing volleyball and I love rollerblading. In my free time I like listening to music, meet my friends and watch TV. I can-t wait to start this new career and meet you all soon!

Date and hour of sending September 22, 2013 - 00:07:04

Sent by $\mathrm{Ga}$

Title Greetings

Sent text

Hello, my name is Fabian G, I'm from Bahia Blanca, even so I work and live in Buenos Aires.

In my free time I like to read, visit new places, and on Mondays I attend an English course in the UBA English Laboratory.

I've always wanted to make a career in English Language, but l've never been given the chance before. I'm really excited for this new course and hope to learn even more.

Date and hour of sending September 22, 2013 - 01:24:03

Sent by Sp

Title Hello!

Sent text

Hello everybody! My name is Yamila and according to what I saw I'm the oldest here...

I like traveling, surfing the Internet, photography, going to the cinema, etc. I am very anxious to start with this course and I hope to learn much more.

"See" you!

Date and hour of sending September 23, 2013 - 14:55:51

Sent by OI

Title Hello everyone!!

Sent text

Hi everyone, my name is Julieta $\mathrm{O}, \mathrm{I}$ am 17 years old and I am in my last year of school. I live in Tandil, which is a beautiful city with a lot of touristic places. I go to Ernesto Sabato School. My hobbies are basically, as most of teenagers, spending time with my friends and family. In the future I would really like to be able to travel, I am thrilled about this online course, so I hope it help me to improve my English.

Date and hour of sending September 23, 2013 - 20:51:54

Sent by $\mathrm{Ga}$

Title Hello everybody!!

Sent text

Hello! my name is Melina. Im from Las Flores, and Im 17 years old. Im going to Normal School, and in the future I want study english in La Plata. I like go out with friends, and meet new people. I love dance and sing, and my hobbie is play the guitar. Goodbye, and see you later!! 
Date and hour of sending September 23, 2013 - 21:55:54

Sent by Lo

Title My new group

Sent text

Hello,

I would like to introduce myself. My name is Estela $L$ and I am 44 years old. I am from Temperley in Lomas de Zamora.?xml:namespace prefix = "o" ns = "urn:schemas-microsoft-com:office:office" /

In my free time, I like reading things in English, surfing the Internet and listening to music. I also enjoy walking in the open air and having mate.

One of my long-term goals is to graduate as Sworn Translator. In the meantime, I want to learn new things and use English in a new context.

Let-s get ready to learn!

Estela

Date and hour of sending September 23, $2013-22: 19: 58$

Sent by $\mathrm{Al}$

Title $\mathrm{Hi}$ !

\section{Sent text}

Hello! My name is Noelia A, i'm eighteen years old and I live in La Plata. In my free time i like listening to music, chat with friends and going to the gym!, and now that I have more free time than before (I quit university this year, to start the carreer I've always loved, I want to be an English translator!) I like to practice English and read english books. I graduated from Colegio Obispo Anunciado Serafini last year. I'm really excited about starting this new stage in my life!

See you soon!

Date and hour of sending September 23, $2013-23: 41: 46$

Sent by $\mathrm{V}$

Title Hi everyone!

\section{Sent text}

Hello! my name's Luciana, I'm seventeen years old and I live in Azul, Buenos Aires. I go to San

Cayetano's school since kínder. I love spending time there and the teachers are very kind so it's not a heavy routine.

Besides English, which is my personal love, I enjoy dancing, cooking and going out with my friends.

That are things that I also like doing in my free time add to taking naps, and walk in the park.

In my future, I would like to improve my english studying translation, taking courses to overcome myself, and maybe learn other languajes too. I hope I find this experience exciting specially to convince myself that this is what I want to do for the rest of my life.

Date and hour of sending September 24, 2013 - 05:28:08

Sent by $R$

Title Hi everybody!

Sent text

My name is Priscila and I've just turned 30.

Although I studied many things, like music, English, yoga; I never got a degree in anything, mainly because I've been travelling and living in different countries for the last seven years. Now I feel like coming back home and settling down with my 3 year-old girl and my partner. I hope I can do it this time!

Looking forward to meeting you all.

Date and hour of sending September 24, 2013 - 20:42:30

Sent by $\mathrm{Pa}$

Title Hello everyone!

Sent text

Hi! My name is Sofía, I-m eighteen and I live in La Plata. I-m still finishing high school at San Miguel Garicoïts School, and very eager to do so. I spend my free time mostly browsing on Internet; but I usually draw, read, cook and/or listen to music too. I love languages, and I want to study Lingüistics 
too; with this career I hope to learn more about the English language and to aid on international communications. See you soon!

Date and hour of sending September 24, $2013-20: 50: 55$

\section{Sent by $R$}

Title Hello!

\section{Sent text}

Hello everyone! I'm Camila. I'm 18 years old and I'm from La Plata but I live in Berisso. I'm on my last year of high school at Instituto Justo Santa Maria de Oro. I love watching movies, listening to music, going to the gym, travelling and hanging with my friends. I hope this course will be useful for everybody and I'm really excited for it. Cant wait to see you soon!

Date and hour of sending September 25, 2013 - 13:57:22

Sent by Se

Title RE: Forum instructions

Sent text

My name is Luciana, I-m 18 years old, I live in La Plata and I-m studying to sit for the First Certificate exam in December. I like listening to music, watching anime series and to spend time with my friends. I hope to learn more with this course and to meet new people.

See you! :-)

Date and hour of sending September 25, 2013 - 15:14:00

Sent by $\mathrm{lb}$

Title $\mathrm{Hi}$ !

Sent text

Hi everyone! My name is Camila, I'm 18 years old and I live in Necochea, Buenos Aires. I go to a Danish School and this is my last year there. I like travelling, listening to music, reading and going out with friends. In future I want to study english translator, learn another languages and also meet new people. See you !!

Date and hour of sending September 25, 2013 - 16:06:24

Sent by $\mathrm{Br}$

Title Hello everyone!

Sent text

Hello everyone! My name is Jesica, I'm 23 years old and I live in La Plata. I graduated in Normal 3 school a years ago. In my free time I like listening to music, being on the computer and studying English. So I hope to learn more about English in this course of studies and of course meet new people.

See you!

Date and hour of sending September 25, 2013 - 20:53:49

Sent by $\mathrm{V}$

Title Hi everyone!

\section{Sent text}

Hello! my name's Luciana, I'm seventeen years old and I live in Azul, Buenos Aires. I go to San Cayetano's school and I love spending time there. Besides English, I enjoy dancing, cooking and going out with my friends. I also spend my free time walking in the park. In my future, I would like to improve my english studying translation and maybe learning another languaje. I hope I find this experience exciting! kisses

Date and hour of sending September 26, 2013 - 21:48:24

Sent by $\mathrm{Ci}$

Title RE: Hi!

Sent text

Hi everyone! I-m Fiorella and I-m from La Plata. I-m 17 years old and I'm in my last year of secondary school which is called Colegio del Sol. Apart from English, what I enjoy the most is dancing and hangin out with friends. I-m really excited about this course! I think it will make us understand better 
what we need to know about this career and everything that concerns to it. Bye!

Fio

Date and hour of sending September 26, $2013-21: 53: 41$

Sent by $\mathrm{Ca}$

Title Hi!

\section{Sent text}

Hi! I'm María Pilar, I'm 17 years old and I'm from La Plata. I go to Centenario's school, and I'm in my last year. Apart from school and my english lessons, I take singing lessons, and now I'm starting to learn piano. I am also a member of the UNLP's choir, and that's one of the activities that I enjoy the most. I think that this course will help us to know more about english, to know more about each other, and to have a better start at university. It's really nice to meet you!

Pilar

Date and hour of sending September 27, $2013-22: 48: 20$

Sent by $\mathrm{Fi}$

Title $\mathrm{Hi}$ !

Sent text

Hi everyone! My name is Abril, I'm 17 years old and I'm from Rio Negro. I'm on my last year of high school at C.E.M $n^{\circ} 29$. I'm also studying to sit for the First Certificated Exam in November. I enjoy spending time with friends and playing sports and I love travelling to different places. I hope to learn more about English and to have a great time. Wish you luck! Abril :)

Date and hour of sending September 28, 2013 - 15:19:44

Sent by Sa

Title RE: Forum instructions

Sent text

Hello everyone! I'm Florencia and I'm from Neuquen. I'm 19 years old. Apart from English, what I enjoy is dancing, travelling and spending time with my boyfriend. I'm excited about this course! I think It will make us understand better what we need to know about the next year. Bye!

Date and hour of sending September 28, 2013 - 18:50:05

Sent by $\mathrm{Ca}$

Title HI

Sent text

Hello everybody!.My name is mariana, i'm 34 years old, i'm from villa maria,cba; went to ISBR. my goal is to get to be a english translator, hopeing this could be for once of all, like to travell, enjoy my family and dogs, passing time with my friends, my collegues from work and love to read a lot. see you soon! and good luck everyone!.

Date and hour of sending October 1, 2013 - 14:53:36

Sent by To

Title Hello!!!!

Sent text

Hello everyone, my name is Ariana, I'm 29 years old, I-m from Tres Arroyos, I was living in Mar del

Plata for almost 12 years, and I-m a Publicist. But actually I-m working in Tres Arroyos in a company of logistic in the administration apartment. I'm older than most of you but I'm want learn like all of you. Actually my new hobby is swim, I love it!

Date and hour of sending October 6, 2013 - 01:08:03

Sent by Fa

Title Hello

Sent text

Hello, my name is Lucía, I am 18 years old and I live in La Plata. I am doing my last year at Bellas Artes secondary school, I really like music and visual art in general but what I love is the history of art. $\mathrm{I}$ am also interested in fashion design and I am doing a course of dresmaking. In my free time I enjoy reading and watching movies. I am doing this english course because I am interested in go on 
studying this career and I want to know the contents and the level of difficulty that I will have to deal with in a future.

Goodbye everyone,

Lucía

Date and hour of sending October 17, 2013 - 12:16:04

Sent by Ru

Title Hi ! I am..

\section{Sent text}

Hi! My name is Sofia R, I am seventeen years old and I live I Villa la Angostura that is a small town in Neuquen. I am on my last year in the high school CPEM 17, I-m really interested in my next year because I-m going to start studying in the Universidad de La Plata the career of English translation. In my free time I use sing, stay with friends and also I like going out with my friends on weekends. I except to get into the career and finish it in the time that is expected.

Nice to meet you, Sofi

\section{Foro 2}

\section{List of contributions of the Forum New Technologies - Quantity of Contributions 26}

\section{Instructions}

You-re going to choose an item of technology and you-re going to describe its size, its use, its typical users, its cost, origin, material its made of, etc. But DO NOT reveal the item: your partners will guess what it is!!! Here-s an example.....

This is an electrically operated machine that you cannot carry everywhere because its quite big (though it comes in different sizes). Its usually white. Its used by all the members of the family, hopefully, at noon or at night. How does it work? You need introduce different sorts of utensiles and after an hour or so you take them out perceiving a noticeable change in them. I wish I had one of this.

Date and hour of sending October 7, 2013 - 10:50:53

\section{Sent by Simon, Liliana}

Title Forum instructions

\section{Sent text}

We recommend you to start with this forum after you have finished studying the Guide on Technology. Instructions: You're going to choose an item of technology and you're going to describe its size, its use, its typical users, its cost, origin, material its made of, etc. But DO NOT reveal the item: your partners will guess what it is!!!

Here-s an example.....

This is an electrically operated machine that you cannot carry everywhere because its quite big (though it comes in different sizes). Its usually white. Its used by all the members of the family, hopefully, at noon or at night. How does it work? You need introduce different sorts of utensiles and after an hour or so you take them out perceiving a noticeable change in them. I wish I had one of this.

Date and hour of sending October 7, $2013-11: 57: 53$

Sent by Julieta

Title guess...

\section{Sent text}

It is an electrical operating machine which I guess that most of you have in your house, although (according to my experience) I doubt that you use it on a daily basis. In regards to colours, the most usual is white, but it can also be grey and now I have seen that it comes with a lot of nice designs in red, yellow, blue and black. I can only say that if you stop using it and you don-t like to dip your hands, you won-t have anything to wear. 
Date and hour of sending October 7, 2013 - 14:04:39

Sent by tutor

Title New forum : ask and answer

Sent text

Thanks for starting the forum! Remember that this time you are also supposed to answer your classmates' questions and then wait for confirmation.

Date and hour of sending October 7, $2013-22: 44: 48$

Sent by Noelia

Title New Technologies

Sent text

Let's guess!

This is a really useful tool, and it has been invented a long time ago! Previous things like this used to be really big and heavy, like a brick. But luckily nowadays they are a lot smaller and very practical, and also have music player, camera, and even GPS!! But believe it or not, their main function always was the personal communication

Date and hour of sending October 9, 2013 - 20:36:44

Sent by Yamila

Title Can I already guess??

Sent text

Date and hour of sending October 9, $2013-21: 16: 08$

Sent by Lucas

Title New Techonologies

Sent text

Well, if I have to describe one thing that is a part of technology, here it goes:

It's something people use almost every single day, some people, every day, actually. It has multiples functions, and it allows you to talk with your friends, or check your emails if you want to, and even listen to music. It has existed since the late 80 s and has developed a lot since. It is used a lot in music industry, at work, and at some schools. It's easy, come on! See you :)

Date and hour of sending October 14, 2013 - 22:22:02

Sent by tutor

Title RE: Can I already guess??

Sent text

Of course you can, Yamila!

Date and hour of sending October 16, 2013 - 12:08:04

Sent by Micaela

Title Let's guess!

Sent text

This machine is electrically operated, so it replies when you plug its wire on. It isn't very big, but it's hard to carry it, because it's quite heavy. It usually comes in three colours: white, black or grey (most of them are white). It can be used by every member of the family because it's easy to manipulate (by a circular handle or digital buttons mainly) You use it with food only, to defrost it or heat it. I think the majority of you have one of this at home, because it's easy, fast and sometimes it helps you get rid of cooking!

P.S: Shoud we guess one of the items or all of them? Just in case, I think Julieta's answer is a washing machine.

See you!

Date and hour of sending October 16, 2013 - 18:05:01

Sent by Camila

Title New technologies

Sent text

Well, i think Micaela's answer is a microwave.

Here's another one: Its something you need if you want to listen to music especially if you go to parties because it amplifies the music if you want it loud. You can see two of them commonly next to 
a computer.

Good luck!

Date and hour of sending October 17, 2013 - 10:48:22

Sent by tutor

Title keep working!

\section{Sent text}

Good descriptions! And good guesses! Please after a classmates answers a question, the one who wrote the description should confirm/reject each guess.

By the way, no one wrote the name of the device described in the instructions,

Keep participating, please!

Date and hour of sending October 17, 2013 - 19:35:08

Sent by Micaela

Title Great!

Sent text

Very good Camila, the correct answer is microwave!

Mercedes, I believe the device described in the instructions is a dishwasher, is that correct?

Bye!

Date and hour of sending October 17, 2013 - 21:13:24

Sent by tutor

Title RE: Great!

Sent text

You're right, Micaela!

Micaela escribió:

Very good Camila, the correct answer is microwave!

Mercedes, I believe the device described in the instructions is a dishwasher, is that correct?

Bye!

Date and hour of sending October 17, 2013 - 21:18:12

Sent by Valeria

Title RE: New technologies

Sent text

are you talking about Speakers???

Camila escribió:

Well, i think Micaela's answer is a microwave.

Here's another one: Its something you need if you want to listen to music especially if you go to parties because it amplifies the music if you want it loud. You can see two of them commonly next to a computer.

Good luck!

Date and hour of sending October 20, 2013 - 12:32:11

Sent by Camila

Title New technologies

Sent text

This is something that we use all the time. It's used wash things that we use everyday. It has different sizes, colours and prices. On the outside, most are plastic or sheet.

Date and hour of sending October 21, $2013-01: 11: 15$

Sent by Sofía

Title l'll try and guess!

\section{Sent text}

I think this is a little more difficult; sorry!

It's a tool very valuated by professional artists, animators and people who draw for a living. It needs to be plugged in a PC or another similar device. It has two parts: an object you grab and use to draw, and a rectangular surface on which you sketch. It comes in different sizes, and it isn-t more expensive 
than a personal laptop. Nowadays, in our country it is used to register signatures in personal documents, etc.

I think Noelia's one is a cellular phone.

Date and hour of sending October 21, 2013 - 18:06:09

Sent by Emilio

Title New technologies

Sent text

It's a device specially designed to archive any kind of document or information you need to move from a computer to another one, or to plug it in a music reproductor. It's really common to have one of these. It comes in different colours, sizes and shapes. Some of them come in form of animals or famous people like Bob Marley.

I think Sofia's answer is a graphic tablet, hope I'm right!

Date and hour of sending October 21, $2013-21: 09: 12$

Sent by Luciana

Title New technologies

Sent text

I think Emilio-s answer is a pendrive.

This is a popular electrical gadget; it comes in different colours and sizes. You can carry it on your hand or in your pocket. It has many features that allow you to do many things, like listening to music and playing games; you can even archive information in it.

Date and hour of sending October 21, 2013 - 22:05:46

Sent by Florencia

Title new technologies

\section{Sent text}

This is an electronic device that you can carry around with you very easily. It is used to entertain ourselves. You can listen to music, watch videos and even communicate with other using it. It is bigger than a cellphone but smaller than a computer and you can control it using your fingers. It comes in different colours but it always has a rectangular shape. It can be used by anyone who enjoys new technologies.

Date and hour of sending October 22, 2013 - 17:28:47

Sent by Lucas

Title RE: new technologies

Sent text

Let me guess! I think it's a tablet computer, isn't it?

Florencia escribió:

This is an electronic device that you can carry around with you very easily. It is used to entertain ourselves. You can listen to music, watch videos and even communicate with other using it. It is bigger than a cellphone but smaller than a computer and you can control it using your fingers. It comes in different colours but it always has a rectangular shape. It can be used by anyone who enjoys new technologies.

Date and hour of sending October 22, $2013-21: 23: 14$

Sent by Camila

Title RE: RE: New technologies

Sent text

Thats the right answer!

Valeria ,escribió:

are you talking about Speakers???

Camila escribió:

Well, i think Micaela's answer is a microwave.

Here's another one: Its something you need if you want to listen to music especially if you go to parties because it amplifies the music if you want it loud. You can see two of them commonly next to 
a computer.

Good luck!

Date and hour of sending October 23, 2013 - 19:35:14

\section{Sent by Sofía}

Title RE: New technologies

\section{Sent text}

Yes, you are!

Emilio escribió:

It's a device specially designed to archive any kind of document or information you need to move from a computer to another one, or to plug it in a music reproductor. It's really common to have one of these. It comes in different colours, sizes and shapes. Some of them come in form of animals or famous people like Bob Marley.

I think Sofia's answer is a graphic tablet, hope I'm right!

Date and hour of sending October 28, 2013 - 22:58:51

Sent by Emilio

Title RE: New technologies

Sent text

You're right!

Luciana escribió:

I think Emilio-s answer is a pendrive.

This is a popular electrical gadget; it comes in different colours and sizes. You can carry it on your hand or in your pocket. It has many features that allow you to do many things, like listening to music and playing games; you can even archive information in it.

Date and hour of sending November 1, 2013 - 16:02:08

Sent by Camila

Title New technologies

Sent text

This object has a lot of variety of sizes. The material of this object it-s mostly compounded of plastic and glass. It-s a rectangle. Most of the users can transport it wherever they want. The rectangle it-s also compounded by another geometry pieces in the inside, all of the squares, that are in the inside, have a particular function, actually all of them sink when you press with your finger and automatically return to their place when you take your finger from that place. Each square has two or more colors. The color forms letters and numbers on the square. This object can be used for all the family. It-s also compounded by a screen when you can visualized every function of the technology system. You can use it when you plug the object to a source of electricity.

Date and hour of sending November 2, 2013 - 16:14:22

Sent by Luciana

Title New Technologies

\section{Sent text}

This object comes in different sizes, colours, brands and models. Some of them have economic prices and others are a bit expensive. They are made of plastic. We usually use it for comunicate with other people by talking or sending messages. Also we can play games with it, takes photos, and sometimes its works as an alarm clock! In the last time we'd become extremely addicted to them and it also has cut the interaction with the person that it's sitting next to us.

It's so easy! What is it?

Date and hour of sending November 3, $2013-21: 28: 35$

Sent by Lucas

Title RE: New Technologies

Sent text

$\mathrm{Hi}$... Tell me, is it a mobile phone? 
Luciana escribió:

This object comes in different sizes, colours, brands and models. Some of them have economic prices and others are a bit expensive. They are made of plastic. We usually use it for comunicate with other people by talking or sending messages. Also we can play games with it, takes photos, and sometimes its works as an alarm clock! In the last time we'd become extremely addicted to them and it also has cut the interaction with the person that it's sitting next to us.

It's so easy! What is it?

Date and hour of sending November 3, 2013 - 22:40:40

Sent by Luciana

Title RE: RE: New Technologies

Sent text

you're totally right! congrats! $\mathrm{n}$

Lucas Daniel escribió:

Hi... Tell me, is it a mobile phone?

\section{Luciana escribió:}

This object comes in different sizes, colours, brands and models. Some of them have economic prices and others are a bit expensive. They are made of plastic. We usually use it for comunicate with other people by talking or sending messages. Also we can play games with it, takes photos, and sometimes its works as an alarm clock! In the last time we'd become extremely addicted to them and it also has cut the interaction with the person that it's sitting next to us.

It's so easy! What is it? 


\section{APÉNDICE 13}

\section{Ejemplo de un foro sobre retroalimentación}

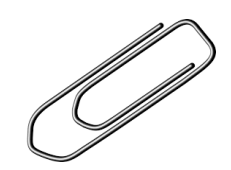

Retroalimentación provista por los tutores sobre el uso de la lengua meta en los aportes de los alumnos

\section{Feedback on Forum "My life in 2011"}

First of all, we'd like to tell you that all your contributions to this forum were very good. Thanks for your posts.

We'd like to make some comments about the language used. Read them carefully and contact us if you don't understand a topic.

\section{Use of capital letters}

Remember to use capital letters. We've noticed that some of you forget to capitalize the first person pronoun "l". Take in to account that we also use capital letters for

- The names of days, months and public holidays (e.g. Easter)

- the names of people and places

- people's titles (e.g. Mr)

- nouns and adjectives referring to nationalities and regions, languages, regions, ethnic groups and religions (e.g. Catalan, Jewish, German)

- the first word and often other nouns, verbs, adverbs and adjectives in names of films, books, plays, pictures, magazines (e.g Gone with the Wind or Gone with the wind)

(Source: Swan, M (1995) Practical English Usage. Oxford, OUP)

\section{Use of subject and verbs}

In English you cannot omit the subject or the main verbs of sentences. Only in informal spoken English we can leave out unstressed personal pronouns or verbs at the beginning of the sentence if the meaning is clear without them. Eg. Must dash $\rightarrow$ I must dash; Careful what you say $\rightarrow$ Be careful

\section{Difference between specially and especially}

"especially" means "above all"

"specially" means "in a particular way, for a particular purpose"

Use of infinitive after "to"

We always use a verb in the infinitive after "to" 